\title{
Rehabilitation following lumbar disc surgery : a biopsychosocial perspective
}

Citation for published version (APA):

Ostelo, R. W. J. G. (2002). Rehabilitation following lumbar disc surgery : a biopsychosocial perspective. [Doctoral Thesis, Maastricht University]. Datawyse / Universitaire Pers Maastricht. https://doi.org/10.26481/dis.20020619ro

Document status and date:

Published: 01/01/2002

DOI:

10.26481/dis.20020619ro

Document Version:

Publisher's PDF, also known as Version of record

\section{Please check the document version of this publication:}

- A submitted manuscript is the version of the article upon submission and before peer-review. There can be important differences between the submitted version and the official published version of record.

People interested in the research are advised to contact the author for the final version of the publication, or visit the DOI to the publisher's website.

- The final author version and the galley proof are versions of the publication after peer review.

- The final published version features the final layout of the paper including the volume, issue and page numbers.

Link to publication

\footnotetext{
General rights rights.

- You may freely distribute the URL identifying the publication in the public portal. please follow below link for the End User Agreement:

www.umlib.nl/taverne-license

Take down policy

If you believe that this document breaches copyright please contact us at:

repository@maastrichtuniversity.nl

providing details and we will investigate your claim.
}

Copyright and moral rights for the publications made accessible in the public portal are retained by the authors and/or other copyright owners and it is a condition of accessing publications that users recognise and abide by the legal requirements associated with these

- Users may download and print one copy of any publication from the public portal for the purpose of private study or research.

- You may not further distribute the material or use it for any profit-making activity or commercial gain

If the publication is distributed under the terms of Article $25 \mathrm{fa}$ of the Dutch Copyright Act, indicated by the "Taverne" license above, 
Rehabilitation Following Lumbar Disc Surgery A biopsychosocial perspective 
ISBN: $90-5278-344-6$

Lay out: Cobie Martens, UM Epidemiologie, Maastricht

Cover photo: Diver (by Nick Clements)

Cover design: Linda Rieken

Printing: Datawyse | Universitaire Pers

2002 by: R. Ostelo

All rights neserved. No part of this thesis may be reproduced or transmitted in any form or by any means, electronic or mechanical, including photocopying, recording or any information storage or retrieval system, without permission in writing from the author, or, when appropriate, from the publishers of the publications. 


\section{Rehabilitation Following Lumbar Disc Surgery}

A biopsychosocial perspective

\section{PROEFSCHRIFT}

ter verkrijging van de graad van doctor aan de Universiteit Maastricht

op gezag van de Rector Magnificus,

Prof. dr. A.C. Nieuwenhuijzen Kruseman volgens het besluit van het College van Decanen, in het openbaar te verdedigen

op woensdag 19 juni 2002 om 14.00 uur

$$
\text { door }
$$

Raymond W.J.G. Ostelo

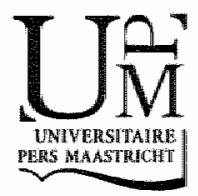




\title{
Promotores
}

Prof. dr. ir. P. A van den Brandt

Prof. dr. ir. H,C.W. de Vet (Vrije Universiteit Medisch Centrum Amsterdam)

\author{
Co-promotores \\ Dr. M.W. Berfelo \\ Dr. J.W. S. Vlaèyen
}

\section{Beoordellingscommissie}

Prof dr. Si. van der Linden (voorzitter)

Prof, dr. E.A.M. Beuls

Prof. dr. L.M. Bouter (Vrije Universiteit Medisch Centrum Amsterdam)

Prof. dr. M.A. van den Hout

Prof. dr. M. Von Korff (University of Washington)

The study presented in this thesis was conducted at the Department of Epidemiology and was embedded in the Research institute for Extramural and Transmural healthcare (EXTRA), Maastricht University, The Netherlands. EXTRA participates in the Netherlands School of Primary Cane Research (CaRe), which was acknowledged in 1995 by the Royal Netherlands Academy of Arts and Sciences (KNAW). The study was funded by grants of the "Profeleringsfonds" of the University Hospital Maastricht (azM) and the Foundation "Annafonds" Leiden the Netherlands.

Financial support for the printing of this thesis has been kindly provided by the Department of Epidemiology of Maastricht University, The Academy for Physiotherapy and Contracting BV of Hogeschool Zuyd, The Dutch Cochrane Center, Regionaal Genootschap Fysiotherapie Midden en Zuid Limburg, and The Royal Society for Physiotherapy (KNGF) 


\section{CONTENT}

1 Introduction

2. Rehabilitation after first time lumbar disc-surgery:

A systematic review within the framework of the Cochrane Collaboration

3 Behavioral treatment for chronic low back pain:

A systematic review within the framework of the

Cochrane Back Review Group

4 Behavioral-graded activity compared with usual care after first-time lumbar disc surgery: Considerations of the design of a randomized clinical trial

5. Effectiveness of behavioral-graded activity after first-time lumbar disc surgery

6 Behavioral-graded activity after first-time lumbar disc surgery: One-year results of a randomized controlled trial

7 Economic evaluation of behavioural graded activity following lumbar disc surgery

8 Health care provider's attitudes and beliefs regarding chronic low back pain

9 Epilogue

Summary

Samenvatting

Dankwoord

About the author

List of pubications 



\section{Introduction}


About two-thirds of all adults suffer from low back pain at some time. Low back pain is second to upper respiratory problems as a symptom-related reason for visiting a physician. 12 Deyo ${ }^{3}$ provides a broad scheme for the differential diagmosis of low back pain with an estimated prevalence in primary care: $97 \%$ of low back pain is mechanical low back or leg pain. About $1 \%$ falls under the heading nonmechanical spinal condition' and $2 \%$ is labeled as visceral disease. The term "mechanical" here is used to designate an anatomical or functional abnormality without an underlying malignant, neoplastic, or inflammatory disease. Within the mechanical low back and/or leg pain, Deyo ${ }^{3}$ estimates that $4 \%$ of the patients suffer from a herniated lumbar disc.

The natural history of a herniated umbar disc seems to be favarable *-6 Sequential MRI studies reveal that the hemiated portion of the disc tends to regress with time, with partial or complete resolution in two thirds of the cases within six months. 7, it is only in about $10 \%$ of the patients that surgery is considered within six weeks because of the pain level. If patients are diagnosed with a herniated disc, usually a period of 4 to 6 weeks' conservative treatment is implemented. The recommended treatment is "watchful waiting" and bedrest is not advised. In the event of symptoms persisting after 4 to 6 weeks, consistent with clinical findings and findings on CT or MRI, surgery is contemplated. Gibson 10 found that the standard discectomy and the microdiscectomy produce similar positive results on pain relief. However, whether these positive results hold over ten years is unclear. 10.14 Following lumbar disc surgery, between $22 \%$ and $45 \%$ of the patients experience residual sciatica, and between $30 \%$ and $70 \%$ have residual low back pain. 114 other studies report success rates ranging from $60 \%$ to $90 \%, 45-21$ meaning that despite surgery, $10 \%$ to $40 \%$ of the patients suffer from persisting symptoms, mainly consisting of pain, motor deficits, or a decreased functional status. The range in these numbers is due to different inclusion criteria for lumbar disc surgery and various definitions of successful outcome. Furthermore, it is often not clear from these studies what kind of post-surgery care, if any, was provided.

Ever since Hanssen 22 published his study in 1964 on the need for and the effectiveness of postoperative rehabilitation, this topic has been a recurrent issue in the international literature. There is a surprisingly wide variation in content of the rehabilitation programs. ${ }^{4922-25}$ These differences in treatment options and the lack of evidence-based practice were the main reason for the Royal Dutch Socicty for Physiotherapy (KNGF) to generate a consensus guideline26 in 1998 for rehabilitation following lumbar disc surgery. The aim of this guideline was to standardize treatment after lumbar disc surgery. The treatment goals immediately after surgery are: prowiding information with regard to post-surgery treatment and prognosis, pain reduction, and increasing mobility and strength. Pain should be used as a guideline to determine the intensity of the exercises and the advice about activities in daily living. After 4 to 6 weeks patients should be given further assistance to regain strength, mobility and stability of the spine and to restore normal function in daily activities and/or work. In this phase of the rehabilitation it is recommended that treatment should be provided within a clearly defined and timemstructured approach. 26 


\section{Rehabilitation following first-time lumbar disc surgery}

Despite many plausible theories with respect to the effectiveness of active, as well as passive, interventions following lumbar disc surgery, sound evidence is lacking. The choice of on specific method of rehabilitation is mainly based on personal expenence of care providers, or on studies of poor methodological quallity. ${ }^{25.26}$ It has been suggested that passive treatment modalities should have no place in rehabilitation after first time lumbar disc surgery and that active treatment is of jaramount importance 26,27 An active rehabilitation program would enhance the patients" independence from thealth care services in the long run. Therefore, the first objective of this thesis is to identify and summarize available evidence of all actiwe treatment options that are used in rehabilitation programs as described in the international literature. Chapter 2 describes this systematic review, which was performed to evaluate the effectiveness of active rehabilitation programs following lumbar disc surgery.

\section{Cognitive-behavioral treatment}

Recently, the focus of attention within rehabilitation following lumbar disc surgery has shifted towards a more biopsychosocial perspective. Manniche 27 has suggested that high intensity programs contront patients with their fears and insecurities and that they should learn that symptoms related to training are not necessarily dangerous. Moreover, the consensus guideline ${ }^{26}$ states that, whenever necessary, cognitive-behavioral treatments should be considered, especially in cases of excessive pain and avoidance behavior, for example due to fear of movement and of further injury.

Cognitive-behavioral theory is based on the bilopsychosocial model, and following the Internationall Association for the Study of Pain (IASP) definition of pain 28 , considers pain to be an emotional experience that can be modulated by cognitive and contextual factors. Based on this model three cognitive-behavioral treatment modalities have been proposed: operant, cognitive, and respondent.29,30 Each of these treatment modalities focuses on the modification of one of the three response systems that characterize emotional experiences: behavior, cognitions, and physiological reactivity.

Operant treatments are based on the operant conditioning principles of Skinner 1 and have been introduced to the area of pain by Fordyce, ${ }^{32}$ They include positive reinforcement of healthy behavior and consequent withdrawal of attention towards pain behavior and time-contingent instead of pain-contingent pain management. 32 The operant treatment principles can be applied by all health care disciplines involved with the patient. An operant treatment program always starts with a number of baseline trials in which the patient exercises to the limit of tolerance. The patient and the therapist then set a quota of exercises to be performed at each session. Initial quotas are lower than baseline levels, but are systematically increased towards a preset goal. 
Cognitive treatment is designed to identify and modify patients maladaptive cognitions regarding their pain and disability. Cognitions the meaning of pain, expectations regarding control over pain) can be modified directly by cognitive techniques including Socratic dialogue, and behavioral experiments challenging mistaken beliefs about pain and its consequences, or indirecty by teaching patients cognitive coping skills, such as attention diversion and relaxation, 3

Respondent treatment is designed to modify the physiological response system directly - for example, by reduction of muscular tension. A respondent treatment provides patients with a model of the association between tension and pain, and teaches the patients to replace muscular tension by a tension-incompatible reaction. Relaxation, electromyographic biofeedback, progressive relaxation, and applied relaxation, are frequently used for this purpose.20,30

Cognitive-behavioral techniques are often applied together as part of a comprehensive treatment approach and may include education of the patient about a multidimensional view of pain; identification of pain-eliciting and painaggravating thoughts, feelings and behavior; identification and modification of maladaptive cognition; use of coping strategies, hypnosis, (applied) relaxation, and electromyographic biofeedback. $29,34,35$

So far, cognitive-behavioral treatment has been described and evaluated within the field of chronic low back pain and not for rehabilitation following lumbar disc surgery. However, a systematic evaluation of all available evidence within the field of chronic low back pain is lacking. Therefore, the second objective of this thesis is to identify and summarize all randomized controlled trials on cognitive-behavioral treatment for chronic low back pain. Chapter 3 describes this systematic review.

\section{The randomized controlled trial}

As mentioned above, not all patients operated for a herniated lumbar disc recover satisfactorily. In general, two different models can be distinguished to explain the unsatisfactory results. The biomechanical model of disease mainly focuses on somatic issues. Clinical recognition and diagnosis of the underlying pathological condition provide the basis for the rational physical treatment of the illness. For example, if muscle weakness and decreased range of motion are considered to be the cause of residual low back pain, treatment then consists of muscle strengthening and exercises in order to regain adequate mobility of the spine. In many proposed rehabilitation programs these kinds of physical treatment options are the core of the program, in addition to providing the patient with information concerning prognosis and treatment and advice about activities in daily living.

The biopsychosocial model emphasizes the role of psychological and social factors in the development and maintenance of symptoms. For example, fear of movement/re-injury might lead to avoidance of activities, which, in due course, could result in a decreased functional status ${ }^{36}$. Also, following lumbar disc surgery, psychosocial aspects, such as fear of movement, may be important to the patient. 
Directing interventions to psychosocial aspects might, therefore, be promising in terms of patient outcome. As far as we know, there is no randomized controlled trial published yet evaluating cognitive-behavioral programs following lumbar disc surgery. Within the cognitive-behavioral field, operant therapy is the most relevant therapy to be applied by physiotherapists and it aims to increase health behaviors using graded activity and positive reinforcement, to decrease pain behavior and increase tolerance llevels. 30,32 Therefore, the third objective of this thesis is to investigate whether a behavioral graded activity program, which is an operant treatment, is more (cost)-effective than usual care as offered by physiotherapists for patients with residual symptoms 6 weeks after first-time lumbar disc surgery. The current randomized controlled trial is carried out in a primary care setting in which the majority of these patients are usually treated.

Chapter 4 describes the design of the randomized controlled trial with patient recruitment and measurements from November 1997 until December 1999. Information about the design is valuable because it allows a critical assessment of the methods and a-priori choices independent of the outcome of the study.

Chapter 5 presents the results of the outcome measurements ( 3 months after randomization to evaluate the short-term effects, and in Chapter 6 the long-term results at the 6 - and 12 -month follow-up are presented. Chapter 7 describes the results of the economic evaluation.

\section{Attitudes and beliefs of physiotherapists}

The primary focus within research on chronic low back pain has, so far, been on patients. Within the group of patients with chronic low back pain, individuals report a wide variety in the level of disability. Furthermore, how patients deal with their complaints is often not related to the level of self-reported pain or tissue damage. Artitudes and beliefs about the relationship between pain and function appear partially to explain this variation. ${ }^{3 .}$ Therefore, attitudes and beliefs might be an important patient characteristic. However, these attitudes and beliefs may possibly be modulated by attitudes and beliefs of health care providers. Patients' attitudes and bellefs might be reinforced if they find that they share similar attitudes and beliefs with health care providers. In order to assess these mechanisms, it is necessary also to focus research on attitudes and beliefs of health care providers. The fourth aim of this thesis is therefore to survey the attitudes and beliefs of Dutch physiotherapists.

Chapter 8 describes the results of this national survey of physiotherapists' attitudes and beliefs concerning chronic low back pain. Furthermore, we made an initial imptus to develop the Pain Attitudes and Beliefs Scale for Physiotherapists. (PABS_PT) which measures different treatment orientations of the physiotherapist.

Chapter 9 critically reviews the methodology and results of the systematic reviews, as well as the randomized controlled trial. Furthermore, the implications of the results for further research and clinical practice are discussed. This thesis concludeds with a summary in both English and Dutch. 


\section{REEERENCES}

1. Hart LG, Deyo RA, Cherkin DC. Physician office visits for low back pain. Frequency, clinical evaluation, and treatment patterns from a U.S. natonal survey. Spine 1995;20(1):11-9.

2. Andersson GB. Epidemiological features of chronic low-back pain. Lancet $1999 ; 354(9178): 581-5$.

3. Deyo RA, Weinstein JN. Low back pain. New England Journal of Medicine $2001 ; 344(5): 363-70$.

4. Vroomen PC, Troost J. Het lumbosacrale radiculaire syndroom: ook zonder MRI. diagnostiek en behandeling grote kans op herstel. Nederlands Tijdschrift vowr Geneeskunde 2000;144(49):2333-6.

5. Postacchini $F$. Lumbar disc herniation: a new equilibrium is needed between nonoperatiwe and operative treatment. Spine 2001;26(6):601.

6. Ito T, Takano Y, Yuasa $\mathbb{N}$. Types of lumbar hemiated disc and clinical course. Spine $2001 ; 26(6): 648-51$.

7. Bozzao A, Gallucci M, Masciocchi C, Aprile I, Barile A, Passariello R. Lumbar disk hermiation: MR imeging assessment of natural history in patients treated without surgery. Radiology 1992;185(1):135-41.

8. Delauche Cavallier MC, Buclet C, Laredo JD, et al. Lumbar disc herniation. Computed tomography scan changes after conservative treatment of nerve root compression. Spine $1992 ; 17(8): 927 \times 33$.

9. Vroomen PC, de Krom MC, Wilmink JT, Kester AD, Knottnerus JA. Lack of effectiveness of bed rest for sciatica. New England Journal of Medicine 1999;340(6):418-23.

10. Gibson AJN, Grant IC, Waddell $G$. The Cochrane review of surgery for lumbar disc prolabs and degenerative lumbar spondylosis. Spine 1999;24(17):1820-32.

11. Weber H. Lumbar disc herniation. A controlled, prospective study with ten years of observation. Spine 1983;8(2):131-40.

12. Yorimitsu $\mathrm{E}$, Chiba $\mathrm{K}$, Toyama $Y$, Hirabayashi $\mathrm{K}$. Long-term outcomes of standard discectomy for lumbar disc herniation. Spine 2001,26(6):652-7.

13. Dvorak J, Valach L, Fuhrimann P, Heim E. The outcome of surgery for lumbar disc herniation. II. A 4-17 years' follow-Lup with emphasis on psychosocial aspects. Spine $1988 ; 13(12): 1423-7$.

14. Spangfort EV. The lumbar disc herniation. A computer-aided analysis of 2,504 operations. Acta Orthop Scand Suppl 1.972;95:1421-95.

15. Korres DS, Loupassis G, Stamos K. Results of lumbar discectomy: a study using 15 different evaluation methods. European Spine Journal 1992;1:20-4.

16. Barrios C. Ahmed M, Arrotegui JI, Bjornsson A. Clinical factors predicting outcome after surgery for herniated lumbar disc: an epidemiological multivariate analysis. J Spinal Disord 1990,3(3):205-9.

17. Pappas CTE, Harrington T. Sorntag VKH. Outcome analysis in 654 surgically treated lumbar disc herniations. Neurosurgery 1992;30(6):862-6.

18. Smulders WLM, Loon van G. Nabehandeling na Iurnbale discectomie of chemonucleolyse. Een 'out-patient' enquête. Fysiopraxis 1993;2(9):4-6.

19. Hume $M$, Alaranta $H$. Factors predicting the result of surgery for lumbar intervertebral disc herniation. Spine 1987;12(9):933-8.

20. Manniche C, Asmussen KH, Vinterberg H, Rose Hansen EB, Kramhoft J, Jordan A. Back pain, sciatica and disability following first-time conventional haemilaminectomy for lumbar disc herniation. Use of "Low Back Pain Rating Scale" as a postal questionnaire. Dan Med Bull 1994;4111):103-6.

21. Manniche $\mathrm{C}$, Asmussen $\mathrm{KH}$, Vinterberg $\mathrm{H}$, Rose Hansen EB, Kramhoft J, Jordan A. Analysis of preoperative prognostic factors in first-time surgery for lumbar disc herniation, including Finmeson's and modified Spengler's score systems. Dan Med Bull $1994 ; 41[1]: 110-5$.

22. Hansen JW. Postoperative management in lumbar disc protrusions. Acta Orto Scan $1964 ; 71$ (suppli:1-47.

23. Zylbergold RS, Piper MC. Lumbar disc disease: comparative analysis of physical therapy treatments. Archives of Physical Medicine and Rehabilitation 1981;62(4):176-9. 
24. Noordzij CM, Dolder wan R. Fysiotherapeutsche begeleicing van geopereerde HNP. patienten. Nedrlands Tijdschrift voor Fysiotherapie 1991;1017/8):160-2.

25. Hibma $d$, Groothof JW, Post D. Postsurgery care for patients after lumbar disc surgery [Dutch] De nazorg van geopereerde herniapatienten. Medisch Contact 1997;52:561-3.

26. Bemmel van R, Boer den J, Hendriks HJM, al. Consensus Guidelines: Rehabilitation after lumbar disc surgery (Dutch) KNGF-ontwerprichthin; Postoperatief Lumbosacraal Radiculair Syndroom. Amersfoort: Royal Dutch Society for Physiotherapy (KNGF), 1998.

27. Manniche $C$, skall HF, Braendholt $L$, et al. Clinical trial of postoperative dynamic back exercises after first lumbur discectomy. Spine 1993; 18(1):92-7.

28. International Association for the Study of Pain SoT. Classification of chronic pain syndromes and definitions of pain terms. Pain 1986;supplement 3:s1-\$225.

29. Turk DCFH. Etiological theories and treatments for chronic back pain. II. Psychological models and interventions. Pain 1984 19(3): 209-33.

30. Vlaeyen JW, Haazen IW, Schuerman JA, Kole Snijders AM, van Eek H. Behavioural rehabilitation of chronic low back pain: comparison of an operant treatment, an operantcognitive treatment and an operant-respondent treatment. Br J Clin Psychol 1995;34(Pt 1):95-118.

31. Skinner BF. Science and human behaviour. New York: McMillan, 1953.

32. Fordyoe WE. Behavioral rnethods for chronic pain and illiess. St. Louis: Mosby, 1976.

33. Turner JA, Jensen MP. Eflicacy of cognitive therapy for chronic low back pain. Pain 1,$993 ; 52(2): 169-77$.

34. Kole Snijders AM, Vlaeyen JW, Goossens ME, et al. Chronic low-back pain: what does cognitive coping skills training add to operant behavioral treatment? Results of a randomized clinical trial. J Consult Clinical Psychol 1999;67(6):931-44.

35. Kudy $\mathrm{TE}$, Turk $\mathrm{DC}$. Cognitive-behavioral treatment of the patient with chronic pain. In: White AH, J.P. S, eds. Spine care; diagnosis and conservative treatment. St. Louis: Mosby-Year book, 1995.

36. Vlaeyen JW, Linton Sil. Fear-avoidance and its consequences in chronic musculoskeletal pain: a state of the art. Pain 2000;85(3):317-32.

37. Rainville J, Begnal D, Phalen L. Health care providers" attitudes and beliefs about functional impairments and chronic back pain. Clinicall Journal of Pain 1995;1 1(4):287. 95. 


\section{Rehabilitation after first-time lumbar disc surgery: A systematic review within the framework of the Cochrane Collaboration}

Raymond WJG Ostelose, Henrica CW de Vet", Gordon Waddelle, Maria R Kerckhoffsate, Pieter Leffers ${ }^{a}$, Maurits W van Tuldert.

\footnotetext{
Affiliations of authors

a Department of Epidemiology, Maastricht University.

- EMGO Institute, Vrije Universiteit Medical Center Amsterdam.

- Nuffield Hospital, Glasgow, Scotland

Department of Physiotherapy University Hospital Maastricht.

- Hogeschool Zuyd, Department of Physiotherapy, Heerlen.
}

The Cachrane Library, Issue 2, 2002. Oxford: Update Software. Also (revised version): Spine (in press) 


\section{ABstract}

Background: Although several rehabilitation programs, physical finess programs or protocols regarding in struction for patients to return to work after lumbar disc surgery have been suggested, lithe is known about the efficacy and effectiveness of these treatments and there are still persistent fears of causing re-injury, re-herniation, or instability.

Objectives. The objective of this systematic review was to evaluate the effectiveness of active treatments that are used in the rehabilitation after first-time lumbar disc sur" gery.

Search strategy: We searched the Medline, Embase and Psyclit databases up to April 2000 and the Cochrane Controlled Trials Register 2001 , Issue 3.

Selection criteria: Both randomized and non randomized controlled trials on any type of active rehabilitation program after first-time disc surgery were included.

Data collection \& anclysis: Two independent reviewers performed the inclusion of studies and two other reviewers independently performed the methodological quality assessment. A rating system that consists of four levels of scientific evidence summarizes the results.

Main results: Thirteen studies were included, six of which were of high quality. There is no strong evidence for the effectiveness for any treatment starting immediately postsurgery, mainly because of lack of (good quality) studies. For treatments that start 4 to 6 weeks post-surgery there is strong evidence (level 1) that intensive exercise programs are more effective on functional status and faster return to work (short-term follow-up) as compared to mild exercise programs and there is strong evidence (level 1) that on long term follow up there is no difference between intensive exercise programs and mill exercise programs with regard to overall improvement. For all other primary outcome measures for the comparison between intensive and mild exercise programs there is conflicting evidence (level 3 ) with regard to long-term follow-up. Furthermore, there is no strong evidence for the effectiveness of supervised training as compared to home exercises. There is also no strong evidence for the effectiveness of multidisciplinary rehabilitation as compared to usual care. There is limited evidence (level 3) that treatments in working populations that aim at return to work are more effective than usual care with regard to work resumption. Also, there is limited evidence (level 3) that lowtech and high-tech exercises, started more than 12 months post-surgery are more effective in improving low back functional status as compared to physical agents, joint manipulations or no treatment at all. Finally, there is no strong evidence for the effectiveness of any specific intervention when added to an exercise program, regardless of whether exercise programs start immediately post-surgery or later. None of the investigated treatments seem harmful with regard to re-herniation or re operation.

Reviewers conclusions: There is no evidence that patients need to have their activities restricted after first-time lumbar disc surgery. There is strong evidence for intensive exercise programs (at least if started about 4-6 weeks post-operativel on short-term for functional status and faster return to work and there is no evidence they increase the re-operation rate. It is unclear what the exact content of post-surgery rehabilitation should be. Moreover, there are no studies that investigated whether active rehabilitation programs should start immediately post-surgery or possibly 4 to 6 weeks later.

Key indexing terms: low back pain, post-surgery, systematic review, rehabilitation, exercises 


\section{BACKGROUND}

The lumbosacrall radicular syndrome (LRS) is based on a lumbar disc prolapse. LRS is characterized by irradiating pain over an area of the buttocks or legs served by one or more spinal nerve roots of the lumbar vertebrae or sacrum, combined with phenomena associated with nerve root tension or neurological deficit. It is estimated that there are between 60,000 and 75,000 new cases of LRS in the Netherlands each year. The direct and indirect costs because of LRS are estimated at 1.6 billion US\$ per annum. ${ }^{2}$ In the Netherlands, with a population of about 16 million people, 10,000 to 11,000 operations are performed each year because of the lumbar disc prolapse 1 . An international comparison showed that the rate of back surgery in the United States was at least $40 \%$ higher than in any other country and was more than five times those in England and Scotland. ${ }^{4}$

The success rate of lumbar disc surgery varies from $60 \%$ to $90 \% n^{5-11}$ There are differ ences between studies with regard to inclusion criteria, criteria for surgery and operationalization of success, which may account for the wide range in success rate. These figures show that in $10 \%$ to $40 \%$ the results of surgical operation are unsatisfactory and patients still have symptoms. These persisting symptoms mainly consist of pain, motor deficits and a decreased functional status. In $2 \%$ to $19 \%$ of patients who undergo a first-time disc-surgery, a recurrent herniated lumbar disc occurs, of which $74 \%$ occur within 6 months after their first operation, 12,13 If, despite the operation, patients still suffer from persisting symptoms further treatment is often recommended (e.g. physiotherapy, rehabilitation programs).

There is a persistent controversy about the necessity and duration of restriction of activities after lumbar disc surgery. Although several active rehabilitation programs, physical fitness programs or protocols regarding instruction for patients to return to work after lumbar disc surgery have been suggested, there are still persistent fears of causing re-injury, re-herniation, or instability. $14-16$ Unfortunately, little is known about the effectiveness of these treatments. In this review, we systematically evaluated the ef fectiveness of active treatments that are used in the rehabilitation after first-time lumbar disc surgery using the methods of the Cochrane Collaboration.

\section{METHODS}

\section{Objectives}

The objective of this systematic review was to determine if active rehabilitation after lumbar disc surgery is more effective than no treatment, and which type of actiwe rehabilitation is most effective.

First, we clustered treatments according to the start of treatment:

1. Active rehabilitation that start immediately post-surgery

2. Active rehabilitation that start 4-6 weeks post-surgery

3. Active rehabilitation that start more than 12 months post-surgery 
For every cluster the following comparisons were investigated:

A. Active rehabilitation versus no treatment, placebo or waiting list control

$B$. Active rehabihtation wersus other kind of active rehabilitation

C. Specific intervention in addition to active rehabilitation versus active rehabilitation alone

\section{Criteria for considering studies for this rewiew}

Types of studies. Both randomized controlled trials (RCTs) and non-randomized controlled trals (CCTs) were included.

Types of participants. Subjects who had first-time lumbar disc surgery because of a lumbar disc prolapse, between 18 and 65 years of age, were included. All types of surgical techniques for lumbar disc herniation (for example, standard discectomy, microdiscectomy, laser discectomy and chemonucleolsis) were included.

Types of interventions. Trials with one or more types of active rehabilitation programs aiming at functional restoration (improvement in functional status and return to work) were included. Examples of treatments that were considered are (supervised) exercise therapy, functional restoration programs or rehabilitation-oriented approaches in insurance medicine. Excluded were treatments solely aiming at pain relief (e.g. medication) or improvement of physical outcomes such as strength or flexibility.

Types of outcome meastures. Trials were included if they used at least one of the four primary outcome measures that we considered to be important, that is pain (e.g. VAS), a global measure of improvement loverall improvement, proportion of patients recovered, subjective improvement of symptoms), back pain specific functional status (e.g. Roland Disability Questionnaire, Oswestry Scale), and return to worlk (return to work status, days off work). Outcomes of physical examination (e.g. range of motiom, spinal flexibility, degrees of straight legraisung or muscle strength), behavioral outcomes (e.g. anxiety, depression, pain behavior) and generic functional status (SF-36, Nottingham Health Profile, Sickness Impact Profile) were considered as secondary outcomes. Other outcomes such as medication use and side effects were also considered.

\section{Search strategy for identification of studies}

All relevant trials meeting our inclusion criteria were identified by:

A a computer aided search of the Medline (from 1966 to April 2000), Embase (from 1988 to April 2000 ) and Psyclit (from 1984 to April 2000) databases using the search strategy recommended by the Editorial Board of the Cochrane Back Review Group, "Specific search terms for low back pain, lumbar disc surgery and post surgery treatment were added. No language restriction was used. The complete search strategy is available on request from the first author.

$B$ Screening of the Cochrane library, 2001 , Issue 3 .

C Screening of references given in relevant reviews and identified trials.

D Screening of personal bibliographies and communication with experts in the field.

\section{Methods of the review}

Study selection. Two reviewers (HCW de Vet and MW van Tulder) independently selected the studies to be included in this systematic review by applying selection criteria to the studies that were retrieved by the literature search. Consensus was used to re- 
solve disagreements concerning selection and inclusion of studies and thrd reviewer (P Leffers) was consulted if disagreements persisted.

Methodological quahty assessment. The criteria recommended in the method guidelines for systematic reviews in the Cochrane Back Review Group were used. "Two reviewers (MR Kerckhoffs and RWJG Ostelo) independently assessed the methodological quality of included studies. We decided not to blind studies for authors, institution or journal because the reviewers who performed the quality assessment were familiar with the literature. A consensus method was used to resolve disagreements and a third reviewer (P Leffers) was consulted if disagreements persisted. If the article did not contain enough information regarding the methodological criteria (i.e. if one or more criteria were scored "unclear"), the reviewers contacted the authors for additional information. The quality assessment form was mailed to all authors and they were also asked whether they agreed with the quality assessment.

Data extraction. Two neviewers (MR Kerckhoffs and RWJG Ostelo) independently extracted data from the studies using a standardized form. Data extraction was pretested using two RCTs on back pain without surgery. Domains that were assessed for data extraction were characteristics of patients and interventions, and results on primary and secondary outcome measures.

Data analysis. Because studies were clinically heterogeneous with regard to study population, types of treatment and reference treatments, and outcomes and measurement instruments, no meta-analysis was performed. Therefore, results are summarized using a rating system for levels of evidence in which the quality and outcome of individual studies is taken into account.

The rating system consists of four levels of scientific evidence and has been used in previous systematic reviews in the field of back pain $1 \mathrm{~s}$ :

1 Strong evidence - provided by generally consistent findings in multiple high quality RCTs.

2a Moderate evidence - provided by generally consistent findings in multiple low quality RCTs.

$2 b$ Moderate evidence - provided by generally consistent findings in multiple CCTs.

3 Limited or conflicting evidence - only one RCT or CCT (either high or low quality) or inconsistent findings in multiple RCT's or CCTS.

4 No evidence - no RCTs or CCTs.

High quality studies were defined as RCTs that fulfilled fiwe or more of the internal validity criteria.

\section{Description of studies}

Two RCTs compared treatment programs that started immediately post-surgery: Straight leg raising ${ }^{19}$ and an intensive exercise program. 20 Seven studies investigated treatments that started four to six weeks post-surgery: one RCT multidisciplinalry rehabilitation, ${ }^{21}$ one CCT aerobic exercises, 22 two RCT's intensive exercise programs compared to mild exercise programs, ${ }^{2,24}$ one $\mathrm{RCl}$ compared intensive exercise programs to no treatment, ${ }^{25}$ one RCT compared a supervised group training with an individual training at home ${ }^{26}$ and one $\mathrm{RCT}$ assessed therapeutic horseback riding as additional therapy to a rehabilitation program. ${ }^{27}$ All these studies recruited patients in a general 
health care setting. In a working population one CCT assessed a functional restoration program28 and 1 RCT assessed a rehabilitation-oriented approach in insurance medicine. Finally, two studies assessed treatment regimes that started more than 12 months post-surgery: one RCT assessed the effectiveness of adding hyperextension to an intensive exercise program and one RCT compared high-tech exercises; low-tech exercises, joint manipulations, physical agents and a control group. ${ }^{31}$ Table 2 presents the study characteristics.

\section{Methodological quality of included studies}

The criteria list as recommended by the Cochrane Back Review Group was used in this systematic review. ${ }^{\prime 3}$ Only items reflecting the internal validity of RCTs were used for quality assessment. If blinding of patients was not feasible, we redefined item 4 of the criteria list. In that case item 4 was scored positive if the credibility of applied treatments was evaluated and treatments were equally credible and acceptable to patients. We also redefined the criterion 2 , about dropouts and withdrawals by dividing this into two criteria, one concerning dropouts during the intervention period and one concerning withd rawals during follow-up. Each criterion was scored as "positive" "negative" or "unclear". A total score was computed by adding up positive scores into a sum score and high quality was defined as fulfilling at least 5 of the validity criteria.

Internal validity criteria:

la method of randonization

1 b concealment of treatment allocation

2a drop-out rate during the intervention period

$2 \mathrm{~b}$ withdrawals during follow-up

3 co-interventions avoided or equal

4 blinding of patients.

5 blinding of outcome assessment

6 blinding of care providers

7 intention-to-treat analysis

8 compliance

9 similanity of baseline characteristics

10 adequate length of follow-up

\section{RESULTS}

\section{Study selection}

The search yielded 427 studies in Medline, 414 in Embase and 135 in the Cochrane library. The first selection was based on keywords, title and abstract, resulting in the inclusion of 15 studies. After reading of the full text papers, two studies were excluded because one study evaluated intraoperative epidural corticosteriods ${ }^{32}$ and one evaluated the use of parenteral Ketorolac during wound closure. ${ }^{33}$ Both interventions did not match our definition of active rehabilitation as described in the protocol. This process resulted in 13 studies; 11 RCTs and 2 CCTs. 


\section{Methodological quality}

The two reviewers disagreed about $47(30 \%)$ of the total of 156 quality criteria $\ 13$ studlies times 12 criterial. Most of them were due to erroneous reading. The two reviewers reached consensus on 39 items: 17 were scored "negative", 11 "positive" and 11 "unclear. For the 8 criteria on which disagreement persisted a third reviewer (P Leffers) was consulted, resulting in 2 "negative" criteria, 1 "positive" criterion and 5 "uncleerr" criteria. After this process 51 criteria (32\%) still were "unclear". Eight authors las Manniche is author of two studies this represents nine studies/ responded to our request and provided additional information on their studies. As a result, we changed 11 "unclear" scores and one "negative" score into "positive", indicating that the criterion was met. Furthermore two "unclear" scores were changed into "negative". Six RCTs were considered to be of high quality: $\operatorname{Dolan}^{25}(7)$, Donceel29 (7), Manniche ${ }^{30}(7)$, Danielsen ${ }^{23}$ (6), Kjellby-Wendt ${ }^{20}(6)$, and Manniche ${ }^{24}(6)$. Table 1 shows the final results of the quality assessment.

No studies met the criteria regarding blinding of patients or blinding of care provider"s. Only one study ${ }^{20}$ met the criteria regarding the blinding of outcome assessment. Five $\operatorname{RCTs}^{23-26,30}$ had an adequate concealment of treatment allocation. Nine studies $20,21,23$. 26,28-30 had an adequate length of follow-up (six months or more).

\section{Effectiveness of rehabilitation programs}

1. Comparisons among rehabilitation programs that start immediately after surgery. 1 A Treatment versus no treatment, placebo or waiting list control No trials were identified.

\section{$1 B$ Treatment versus ather kind of treatment.}

One low quality RCT' compared an intensive seven days auto-assisted straight leg raise (SLR) regime for eight times a day with a two-hour interval with a mild straight leg raise regime that performed this same exercise only once a day for seven days. There were no significant differences between both groups on pain, disability (Oswestry or SLR after one week and six weeks. The study did not present data with regard to re-operation rates. There is limited evidence (level 3) that an intensive straight leg raise regime is not more effective compared with a mild straight leg raise regime. A high quality RCT ${ }^{20}$ compared an intensive exercise program that consisted of increasing daily activities, home training (mobilization, trunk strengthening) and later mainly intensive muscle strengthening exercises and cardiovascular exercises with a control group that received no increasing daily activities, exercises only once a day and no promotion of cardiovascular exercises. 
Tablo 1. Gtalty assesment of the included sudies on the effectiveness of active rehabilitation following lumber disc argery.

\begin{tabular}{|c|c|c|c|c|c|c|c|c|c|c|c|c|c|}
\hline Storty & 18 & 10 & $2 a$ & $2 b$ & 3 & 4 & 5 & 6 & 7 & $g$ & 9 & 10 & Sopre \\
\hline Alarante $190 \%$ & 7 & $?$ & + & + & $?$ & - & - & 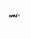 & - & $?$ & $?$ & + & 3 \\
\hline Brerurest 18904 & - & - & $\dot{4}$ & + & $?$ & $-n$ & 3 & - & $\div$ & + & $?$ & - & 絭 \\
\hline Buhe 1 gud & 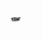 & $=$ & $?$ & $?$ & - & - & $?$ & - & $m$ & $?$ & $?$ & + & $\frac{1}{1}$ \\
\hline Datelenen 2000 & + & $b$ & + & t & $?$ & - & - & - & $f$ & $?$ & - & + & 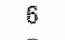 \\
\hline Dolan $20 \mathrm{yog}^{2}$ & + & + & + & + & $?$ & - & $n$ & $w$ & - & + & * & + & 7 \\
\hline Doncest $\$ 9990$ & t. & - & \# & 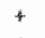 & $?$ & $m$ & $y$ & - & + & $\frac{1}{5}$ & $\frac{2}{7}$ & + & 7 \\
\hline Johengson 1904 & + & + & - & $?$ & $\gamma$ & - & 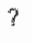 & - & 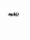 & $?$ & $?$ & + & 3 \\
\hline Kitteringham 1906 & - & - &. & $?$ & $?$ & - & - & - & - & - & - & - & 0 \\
\hline Kolby Hondl 19902 & 4 & + & - & $*$ & $?$ & - & + & $\infty$ & - & $?$ & แ & + & 6 \\
\hline Manniche $1993 a^{24}$ & + & + & - & + & $?$ & - & - & - & $?$ & + & + & $\frac{2}{3}$ & 6 \\
\hline Mannerye 1993b & + & $\#$ & - & - & + & - & - & - & $*$ & + & $\div$ & + & 7 \\
\hline Rothatmit $1997^{2}$ & - & - & + & - & $*$ & - & - & - & - & * & t. & - & $\frac{4}{4}$ \\
\hline Throm 1994 & 7 & $?$ & $?$ & $?$ & - & - & - & - & 8 & 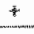 & 4 & - & 2 \\
\hline
\end{tabular}

The results show that there are no statistically significant differences on any of the primary outcome measures, but some differences on secondary outcomes. There was one re-operation $(3.4 \%)$ in the intervention group and two re-operations $(6.5 \%)$ in the reference group. "There is limited evidence (level 3) that an intensive exercise program and a less active program are equally effective on long term for global perceived effect, pain and return to work.

$1 \mathrm{C}$ Specific interwention in addition to a treatment program versus treatment alone No trials were identified.

\section{Comparisons among rehabilitation programs that stant $4-6$ weeks post surgery}

2 A Treatment versus no treatment, placebo or wating list control

One high quality RCT 25 compared an exercise program (improving strength and endurance of trunk muscles and mobility of spine and hips, one hour sessions, twice a week for four weeks) versus no treatment. For both primary outcome measures (pain, functional status) and secondary outcome (range of motion, psychological outcome measures) no between groups comparisons were presented.

\section{$2 B$ Theatment versus other kind of treatment}

Two high-quality RCTs 2324 compared intensive exercise programs with mild exercise programs. Both studies reported no statistically significant differences between groups on overall improvement after 12 months follow-up. Both studies showed a statistically significant difference on functional status in advantage of the intensive exercise program on short-term and one study ${ }^{23}$ reported this also on long-term follow-up. In both studies return to work and daily activities was statistically significantly better in the intensive exercise ptograms on short-term but not on long-term. The RCT by Danielsen ${ }^{23}$ revealed a statistically significant better short-term pain relief in advantage of the intensive program but not on long-term. Danielsen 23 found one-year re-operation rates that were negligible.

There is strong evidence (level 1) that intensive exercise programs are more effective on functional status and faster return to work (short-term follow-up) and there is strong 
evidence that on long term follow up there is no difference between both interventions with regard to overall improvement. For all other primary outcome measures there is conflicting evidence (level 3) with regard to long term follow-up.

One low-quality $\mathrm{RCT}^{21}$ compared a multidisciplinary rehabilitation program that consisted of sessions with a physical therapist, psychiatrist, occupational therapist, psychologist, social worker and an intensive back school with usual care. At 1-year followup, there were no statistically significant differences between groups on global perceived effect, sick leave or re-operation rate (3.7\% in both groups). There is limited evidence (level 3) that multidisciplinary rehabilitation and usual care are equally effective.

One low-quality RCT20 compared a supervised exercise program to home exercises. Both interventions had the same exercises and intensity. Re-operation rate was negligible in both groups. There is limited evidence (level 3) that supervised exercises and home exercises are equally effective on global perceived effect, disability, pain and mobility.

Two studies specifically included patients in a work setting. One bigh-quality RCT compared a multidisciplinary rehabilitation-oriented approach in insurance medicine with usual care. There is limited evidence (level 3) that a rehabilitation-oriented approach in insurance medicine is more effective on return to work at long-term followup. One low-quality CCT28 assessed a functional restoration program versus usual care. This study does not present between-groups comparisons.

$2 \mathrm{C}$ Specific intervention in addition to a treatment program versus treatment alone One low quality RCT27 added horseback riding (thrice a week for 20 minutes per session) to an intensive 4 weeks rehabilitation program. There were no statistically significant differences for overall improvement on short-term. (No long-term follow-up in this study.) There was a statistically significant faster return to work in the intervention group. There were no statistical significant differences on pain and physical measures. There is limited evidence (level 3 ) that adding therapeutic horseback riding to a rehabilitation program is effective for return to work but not for overall improvenent.

One low-quality $\mathrm{CCT}^{22}$ added aerobic exercises to a treatment program. All outcome measures were performed at three month.s. There is limited evidence (level. 3) that adding aerobic exercises to a treatment program is not more effective on functional status, pain and depression than exercises alone.

3. Comparisons among rehabilitation programs that start more than 12 months post surgery

3 A Treatment versus no treatment, placebo or waiting list control

No studies were identified. 


\section{B Treatment wersus other kinds of treatment}

One llow-quality RCT 31 compared physical agents with joint manipulations, high-tech exercises, low-tech exercises and no treatment. There is limited evidence (level 3 ) that low-tech and high-tech exercise are more effective in improving low back functional status as compared to physical agents, joint manipulations or no treatment.

\section{$3 C$ Specific intervention in addition to a treatment program versus treatment alone} One high-quality RCT 30 added hyperextension to an intensiwe exercise program. On short-term there was a statistically significant improvement on functional status that was equalized at long-term follow-up. There were no re-operations. There is moderate evidence (level 3) that adding hyperextension to an intensive exercise program is not more effective than intensive exercise alone on overall improvement or functional status.

Table 2. Study obaracteristics.

\begin{tabular}{|c|c|c|c|}
\hline ALthor & Participants & interventions & Outcones \\
\hline $\begin{array}{l}\text { Alaranta } \\
198623\end{array}$ & $\begin{array}{l}212 \text { patients after } \\
\text { first fime disc } \\
\text { suigery because } \\
\text { of lumbar } \\
\text { prolaps: opera- } \\
\text { iion that was } \\
\text { usually carred } \\
\text { out through an } \\
\text { interlaminat } \\
\text { trepanation and } \\
\text { besides sequester } \\
\text { all loose nucleus } \\
\text { pulposus was } \\
\text { removed }\end{array}$ & 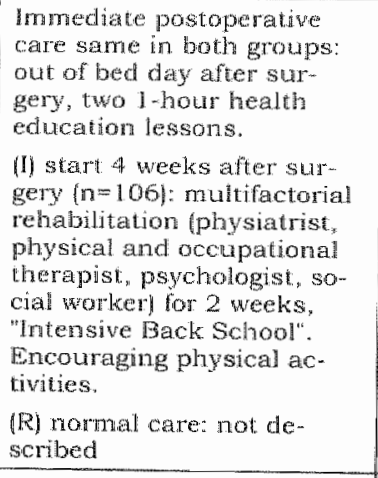 & 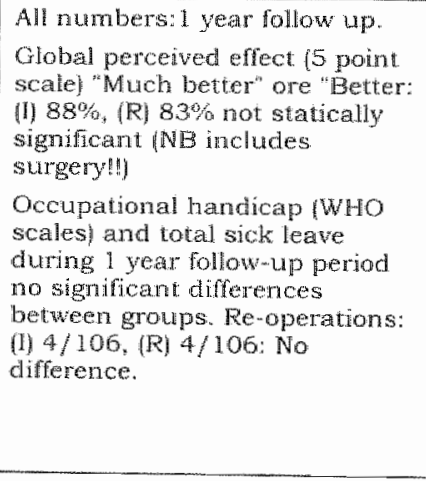 \\
\hline $\begin{array}{l}\text { Brempan } \\
199422\end{array}$ & 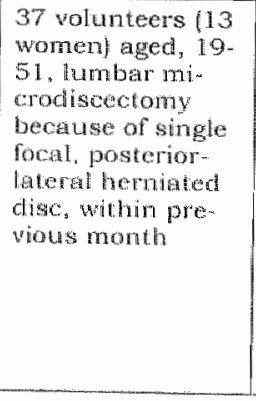 & 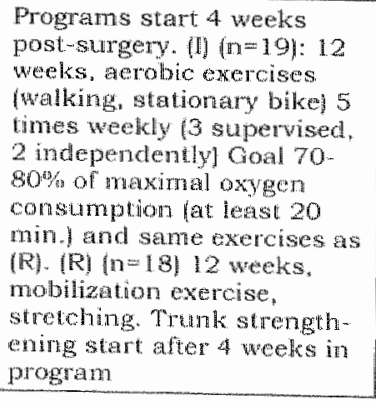 & 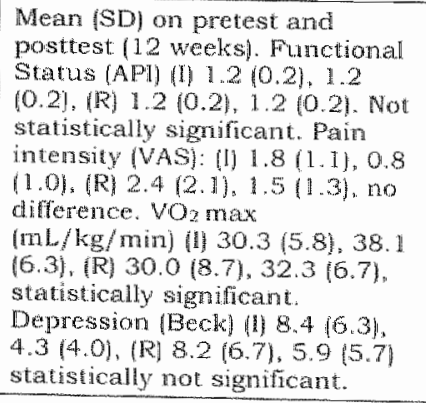 \\
\hline
\end{tabular}




\begin{tabular}{|c|c|c|c|}
\hline Awthor & Participants & Mterventions & Obiroomes \\
\hline $\begin{array}{l}\text { Burke } \\
199420\end{array}$ & $\begin{array}{l}\text { 85 patients afier } \\
\text { post-iminectomy } \\
\text { ftime since sur- } \\
\text { gery not stated), } \\
\text { unable to perorm } \\
\text { required physical } \\
\text { job demands, off } \\
\text { primary job for } \\
\text { mot less than } 6 \\
\text { weeks, no signif- } \\
\text { cant psycho- } \\
\text { pathology, unre- } \\
\text { lated medical } \\
\text { problems stabi- } \\
\text { lized }\end{array}$ & 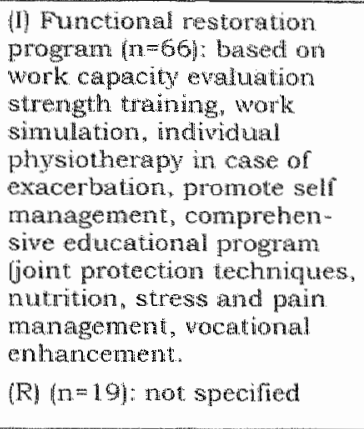 & 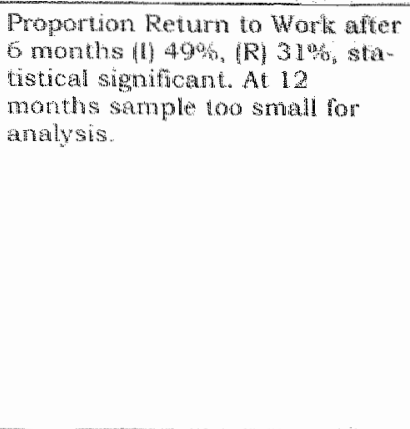 \\
\hline $\begin{array}{l}\text { Damichsen } \\
20 \text { ono } 23\end{array}$ & 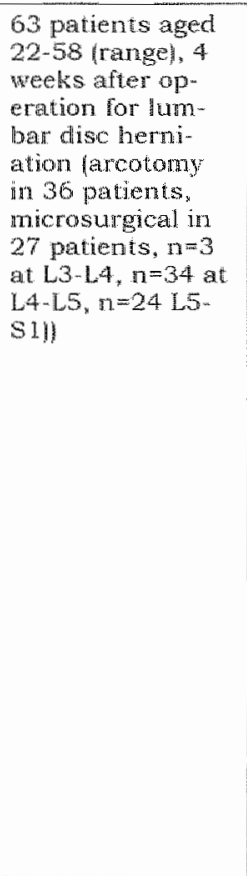 & 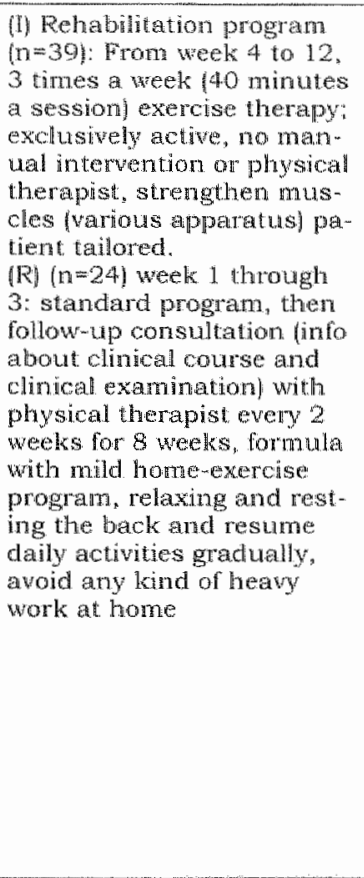 & 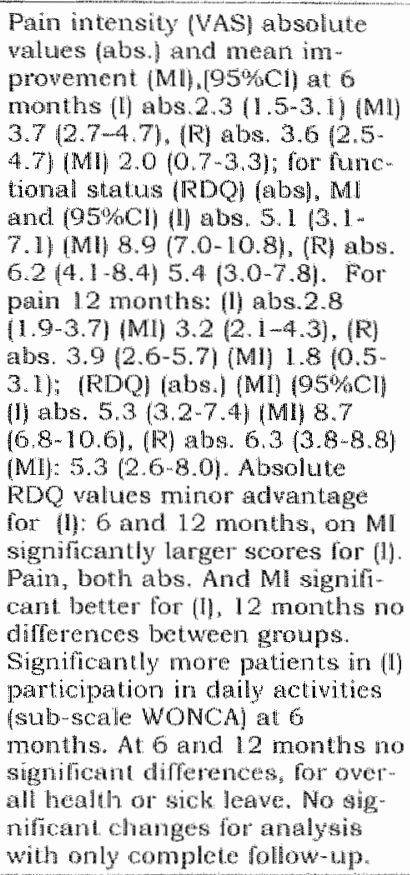 \\
\hline
\end{tabular}




\begin{tabular}{|c|c|c|c|}
\hline Author & Participants & Interventions & Outcomes \\
\hline $\begin{array}{l}\text { Dolan } \\
200025\end{array}$ & 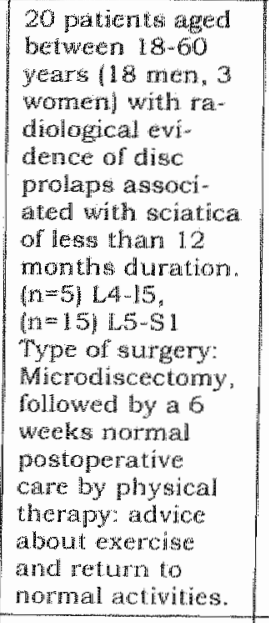 & 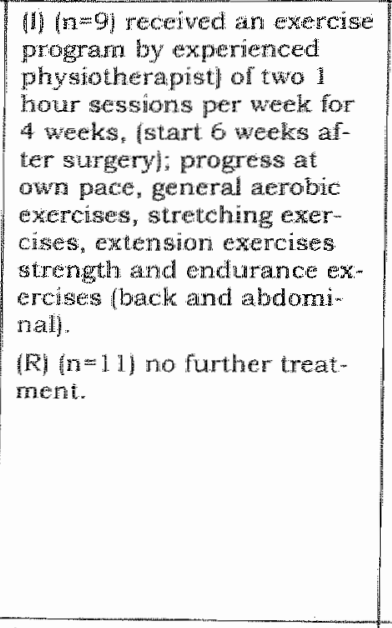 & 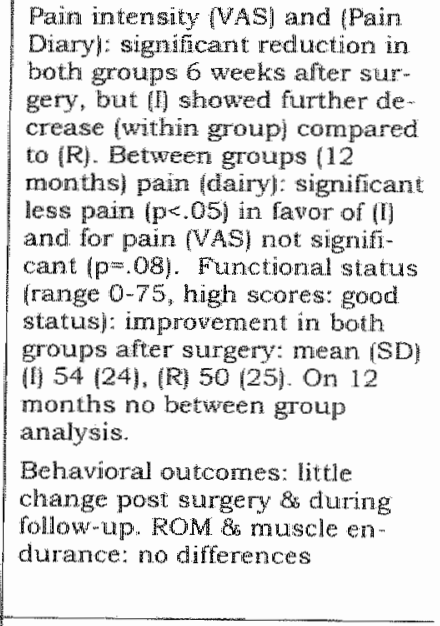 \\
\hline $\begin{array}{l}\text { Donceres } \\
19992 \%\end{array}$ & 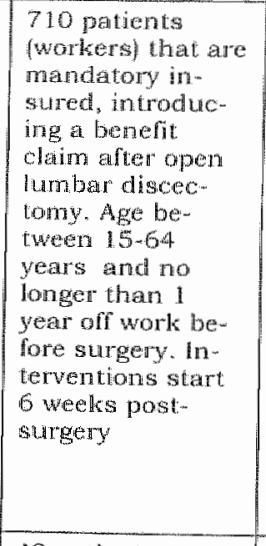 & 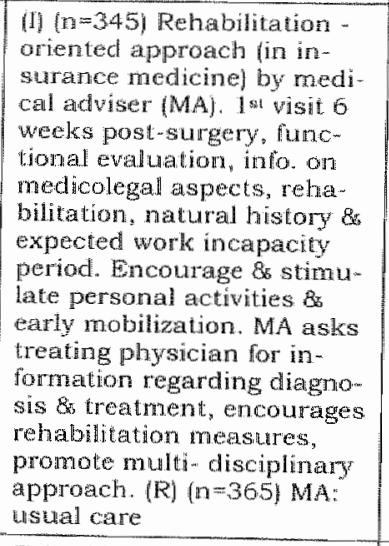 & $\begin{array}{l}\text { On return to work at foltow-up } \\
\text { (52 weeks): (I) } 89,9 \% \text { (R) } 81,9 \% \text {. } \\
\text { Staticically significant }\end{array}$ \\
\hline $\begin{array}{l}\text { Johannsen } \\
\text { log4 }\end{array}$ & 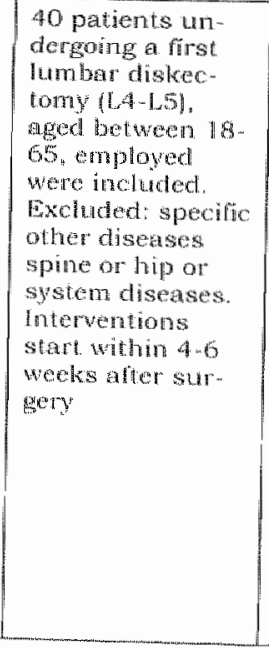 & 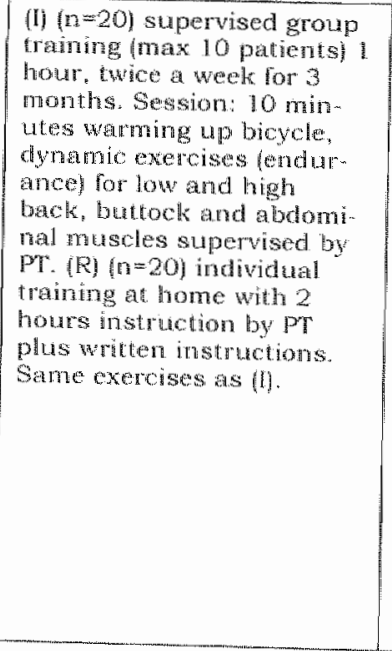 & 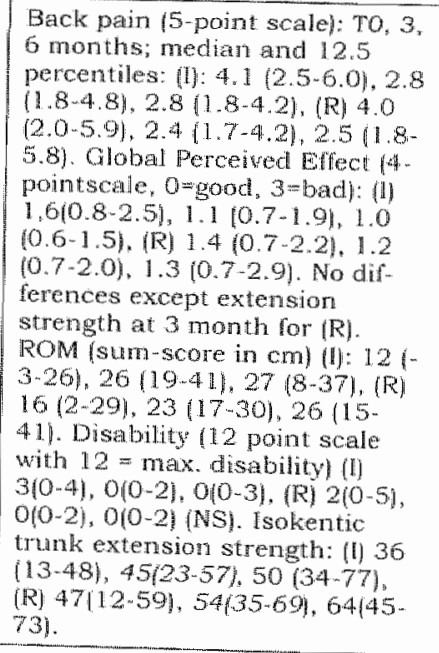 \\
\hline
\end{tabular}




\begin{tabular}{|c|c|c|c|}
\hline Author & Particupants & Intenpentions & ortcomes \\
\hline $\begin{array}{l}\text { Kiteringham } \\
1996: 9\end{array}$ & 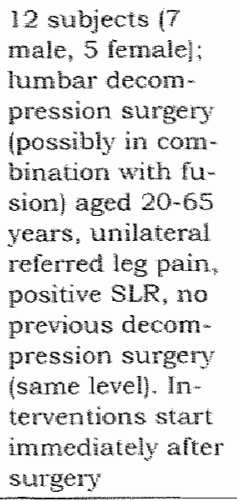 & 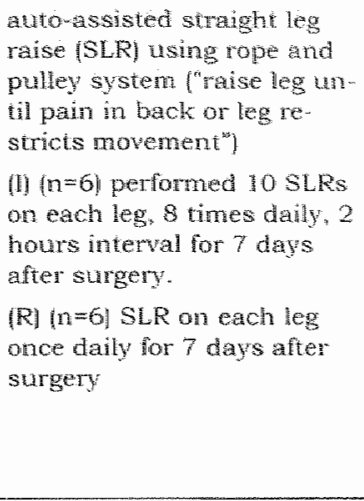 & 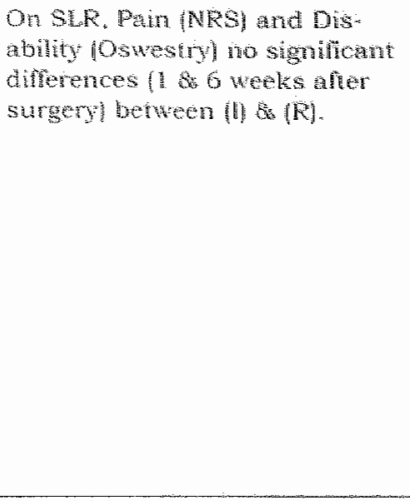 \\
\hline $\begin{array}{l}\text { Kjellby:- } \\
\text { Wendi } 1998 \\
20\end{array}$ & $\begin{array}{l}60 \text { patients laged } \\
16 \text {-70 years), ni- } \\
\text { crodiscectomy } \\
\text { after not } \\
\text { responding to } \\
\text { conservative } \\
\text { treatment. } \\
\text { Patients with re- } \\
\text { operation other } \\
\text { surgery as micro- } \\
\text { discectomy } \\
\text { without micro- } \\
\text { scope (e.g } \\
\text { laminectomy). th- } \\
\text { tementions start } \\
\text { immediately after } \\
\text { surgery }\end{array}$ & 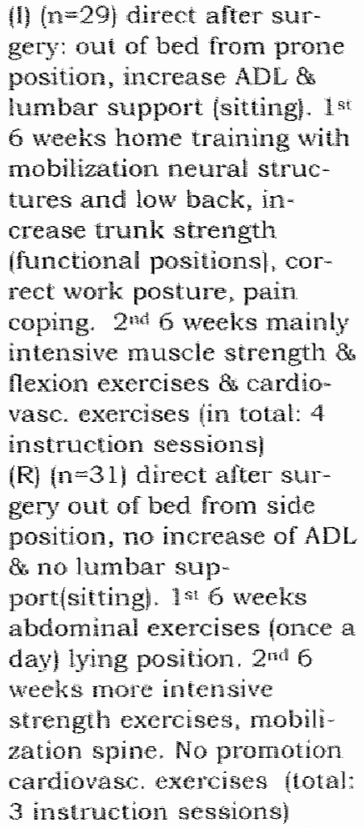 & 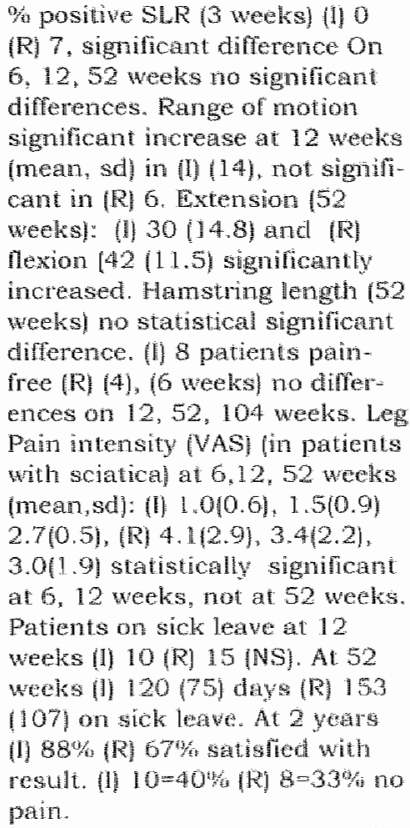 \\
\hline
\end{tabular}




\begin{tabular}{|c|c|c|c|}
\hline Axuritior & Participants & Werenthons & Othomes \\
\hline 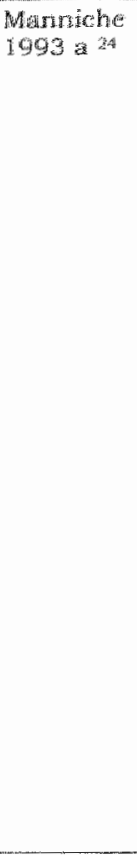 & 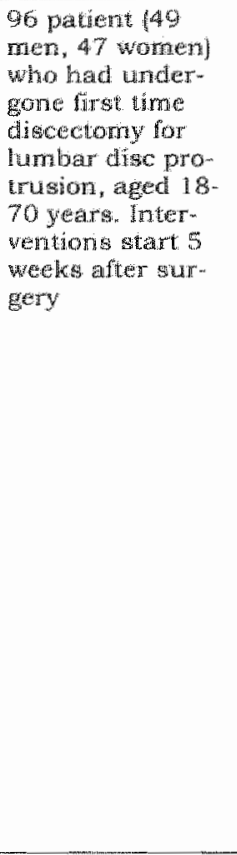 & 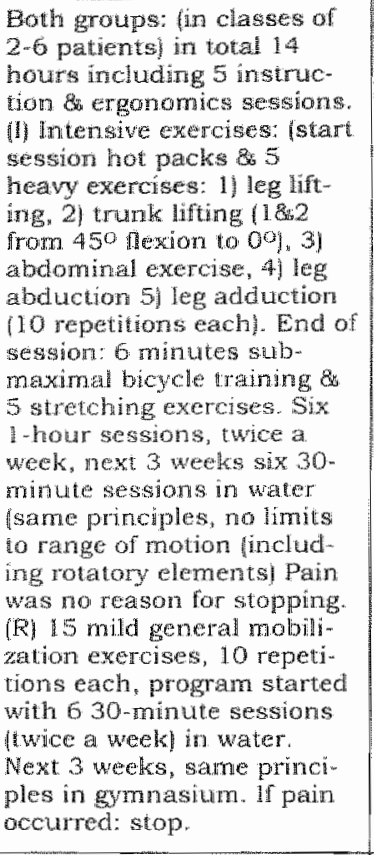 & 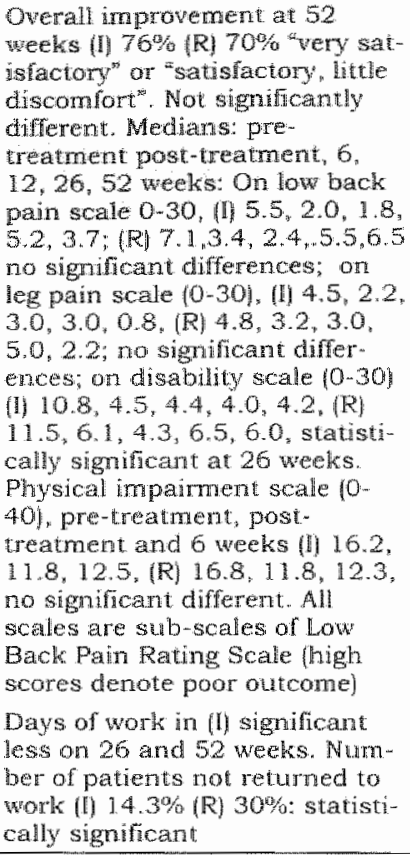 \\
\hline $\begin{array}{l}\text { Mannidhe } \\
1993 \mathrm{~b} 50\end{array}$ & 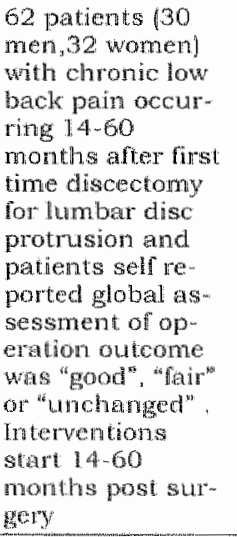 & 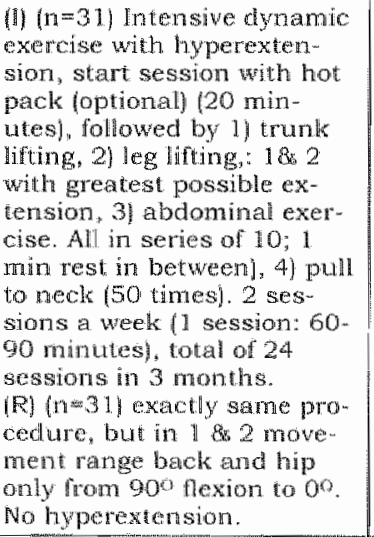 & 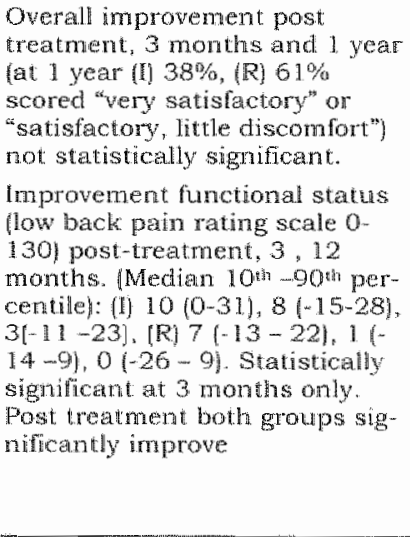 \\
\hline $\begin{array}{l}\text { Rotheupt } \\
199727\end{array}$ & 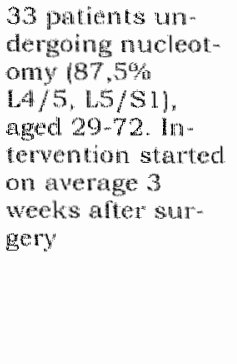 & 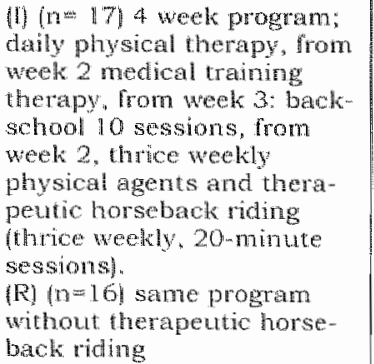 & 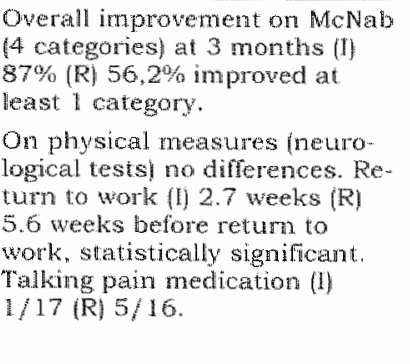 \\
\hline
\end{tabular}




\begin{tabular}{|c|c|c|c|}
\hline Author & Panticipants & merantions & Ortoomes \\
\hline $\begin{array}{l}\text { Timmin } \\
199435\end{array}$ & 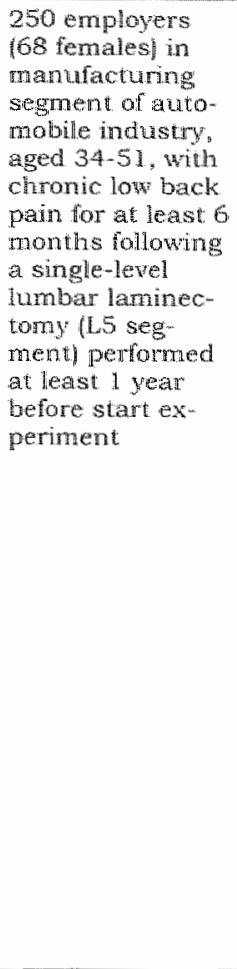 & 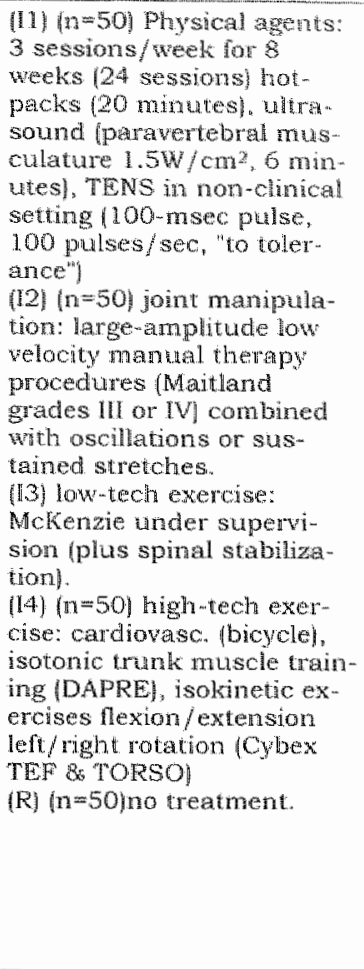 & 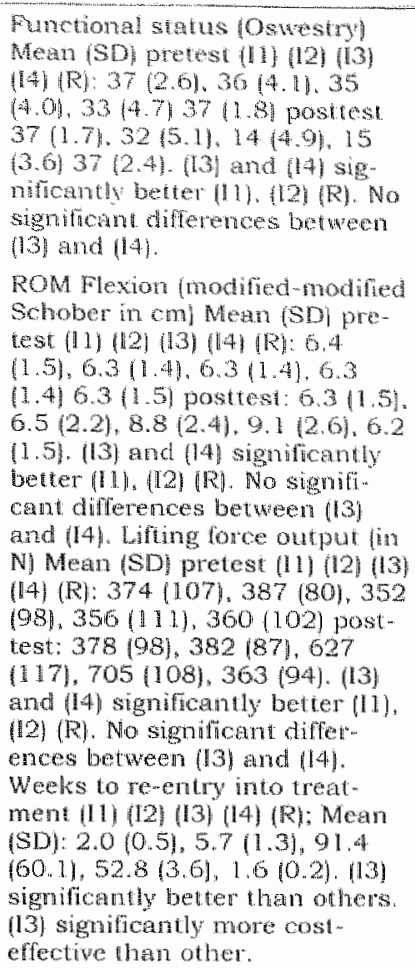 \\
\hline
\end{tabular}

\section{Discussion}

In this systematic review 13 studies were included. The studies were very heterogeneous with regard to timing, ranging from two days post-surgery up to more than 12 months post-surgery. Also the duration and intensity of the interventions differed widely, from a one-week post-surgery simple straight leg raise regime to a three-month rehabilitation program. Therefore, we onsidered statistical pooling of the results not appropriate.

The qualitative analysis showed that there is no strong evidence for any treatment that start immediately after surgery. For treatments that start four to six weeks postsurgery there is strong evidence (level 1) that intensive exercise programs are more effective on functional status and faster return to work (short-term follow-up) and there is strong evidence (level 1) that on long term follow up there is no difference between both interventions with regard to overall improvement. For all other primary outcome measures there is conflicting evidence (level 3) with regard to long-term follow-up. Furthermore, we found no strong evidence for supervised training or for multidisciplinary rehabilitation. There is limited evidence that treatments in working populations that aim at return to work are more effective than usual care with regard to return to work. Also, there is limited evidence that low-tech and high-tech exercises, started more than 
12 months post-surgery are more effective in improving low back functional status as compared to physical agents, joint manipulations or no treatment. Finally, there is no strong evidence for any specific intervention when added to an exercise program.

Three studies investigated the effects of more intensive exercise regimes that started 4 6 weks after surgery. $23,24,26$ The re-operation rates in these studies were negligible. Similar findings were reported in a study that assessed an exercise program that started immediately post-surgery. 20 Because of these negligible rates we conclude that it is not harmful to return to activity after lumbar disc surgery and, consequently that it is not necessary for patients to stay passive after a lumbar disc surgery. This is in line with Carragee who concluded that lifting of postoperative restrictions after limited discectomy allowed shortened sick leave without increased complications. ${ }^{6}$ One high quality RCT ${ }^{2}$ found that a rehabilitation-oriented approach by medical advisers of sacial security (based among others on the study by Carragee increased the probability of a return to work for patients after lumbar disc surgery in a work setting. Although this is only one (high quality) RCT these results look promising. However, approaches like this are highly dependent on the social security system. Further research is needed to assess whether such interventions can be applied in other systems and whether they are (costw) effective.

In this systematic review all surgical techniques were a-priori included. Patients included in the studies all had received standard discectomy or microdiscectomy. A recent systematic Cochrane review showed that that there were no significant differences in effectiveness between these two approaches. Therefore it is unlikely that different surgical techniques have biased the results of this systematic review.

In general the methodological quality was not satisfactory. However, some of the intermal validity criteria are very difficult to achieve for studies in this field. It is almost impossible to blind patients, for example. Therefore we redefined this item and assessed whether authors of individual studies evaluated the credibility or whether treatments were acceptable to patients. Unfortunately, none of the included studies addressed credibility or acceptability. This is an important issue for future research. Also the crim terion with regard to blinding of care providers was not fulfilled in any study. Obviously, this is also a criterion that is difficult to achieve but still might introduce bias. Therefore it is important to conduct a blinded outcome assessment. However, most publications were not clear with regard to how outcome assessment was performed and only one study 20 had a positive score on this quality criteria. Most studies had a positive score with regard to the adequate length of follow-up. This might reflect that some journals state very clear in their instructions for authors that sufficient follow-up should be included in the study. In general, scoring the internal validity from the pubLication remains difficult. Especially if information is not included in the publication, it is uncertain whether the authors did not fulfill that specific item. Hopefully the CONSORT statement hat was recently published in some major medical journals will help to improve the quality of the publication of future research. ${ }^{35}$

But even if the quality assessment leads to the conclusion that a study is of high quallity (high internal validity) it is still difficult to determine what the external validity is. In 
our rewiew the RCT by Dolan 25 has a high quality score, but the number of included patients per group is 9 respectively 1 1. This nakes the extrapolation of the nesults of this trial hazardous.

In this systematic review we used the levels of evidence that have been used in previ. ous systematic reviews in the field of back pain. 18 Based on these levels we conclude that for treatments that start foun to six weelks post-surgery there is strong evidence (level 1) that intensive exercise programs are more effective on functional status and faster return to work (short-term follow-up) and there is strong evidence (level 1) that on long term follow up there is no difference between both interventions with regard to overall improvement. However, it should be clearly stated that although the evidence is strong, this conclusion is based on only two (high-quality) studies. If a-priori, we had used another definition of strong evidence (e.g. three or more studies) the conclusion would have been that there was only moderate evidence. Therefore, the conclusions cannot be interpreted as absolutely convincing because the definitions of these levels are rather arbitrary.

An important topic for future research is the identification of relevant subgroups. The goal of lumbar disc surgery is to relieve the leg pain of patients. Kjellby-Wendt ${ }^{20}$ pre sented a positive outcome for a subgroup with residual leg pain in favor of early active training. But numbers were too small and no firm conclusion could be drawn. This raises the question whether patients with residual leg pain should be treated different as compared to patients without residual leg pain.

Although we conclude that it is not harmful to return to activity after lumbar disc surgery and therefore it is not necessary for patients to stay passive after a lumbar disc surgery it is still unclear what exact components should be included in rehabilitation programs. Intensive programs seem to be more effective but they are also more expen. sive. Therefore cost effectiveness analysis should be performed in order to assess whether intensive rehabilitation programs, if started early after surgery, lead to a reduction in costs in terms of less healthcare utilization or earlier return to work. But, the evidence for intensive rehabilitation programs is certainly not overwhelming and the focus of these programs is still on biomechanical outcome measures such as range of motion or strength. This is remarkable because in most studies patients can be considered as chronic because they had symptoms for at least several months before surgery. Therefore psychosocial factors (e.g. fear avoidance, kinisiophobia, catastrophizing) might be very important. It has been suggested that high-intensity programs confront patients with their fears and insecurities and they learn that symptoms related to training are not necessarily dangerous. ${ }^{30}$ However, in most studies the finterventions are not specifically designed to address this kind of outcome measures, and consequently they are not taken into account. We suggest that in future research behavioral components should be added to (intensive) exercises programs in order to assess the effectiveness of biopsychosocial oriented approaches in the rehabilitation after firsttime disc surgery. Future research should also focus on the implementation of rehabilitation programs in daily practice. Should all patients be treated post surgery or is a minimal intervention with the message "return to an active life style" sufficient and do 
only patients that stil have symptoms 4-6 weeks post-surgery need to participate in rehabilitation programs? The cost effectiveness of this approach needs to be investigated In conclusion, more research is needed on the (cost-) effectiveness of rehabilitation after first-time disc surgery.

\section{REVIEWER' CONCLUSIOMS}

\section{Implications for practice}

There is no evidence that patients need to have their activities restricted after first-time lumbar disc surgery. There is strong evidence that intensive exercise programs, starting 4-6 weeks post-surgery, are more effective on functional status and faster return to work (short-term follow-up) and there is strong evidence that on long-term follow-up there is no difference between both interventions with regard to overall improvement. There is no evidence they increase the re-operation rate.

\section{Implications for research}

Future research should focus on what the exact content of treatment programs should be and how they should be implemented in daily practice. Should all patients be treated post surgery or is a minimal intervention with the message "return to an active life style" sufficient, and do only patients that still have symptoms 4-6 weeks post surgery need to participate in rehabilitation programs? Furthermore, future research should focus on identification of relevant subgroups with an emphasis on psychosocial factors.

\section{SYNopsis}

After first-time lumbar disc surgery intensive exercise programs seem to be more effective than mild exercise programs and there is no evidence they increase re-operation rates. Therefore it is not necessary for patients to stay passive after surgery. It is unclear what the exact content of active post-surgery rehabilitation should be. Moreover, there are no studies that investigated whether active rehabilitation programs should start immediately post-surgery or possibly 4 to 6 weeks later.

\section{ACKNOWLEDGEMENTS}

We would like to thank Claus Manniche for his critical appraisal of an earlier draft of this systematic review.

\section{POTENTIAL CONHLICT OF INTEREST}

Gordon Waddell is editor of the Cochrane Back Review Group. His involvement does not seem to be a source of conflict of interest in the Back Review Group as any editor who is a reviewer is excluded from editorial decisions on the review in which they are participating. 


\section{REFERENCES}

1. Health Council of the Netherlands. Management of the lumbosacral radicular syndrome (sciatica). The Hague: Health Council of the Netherlands, 1999

2. van Tulder MW, Koes BW, Bouter LM. A cost-of-illness study of back pain in The Notherlands. Pain 1995;62(2):233-40.

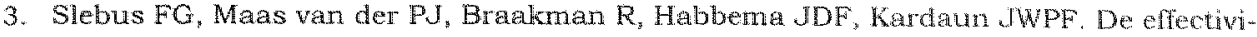
teit van beeldvormende diagnostiek en chirurgie bij de lumbale hernia nuclei pulposi. Rotterdam: Rapport aan het Ministerie van WVC, 1989.

4. Cherkin DC, Deyo RA, Loeser JD, Bush $T$, Waddell $G$. An international comparison of back surgery rates. Spine 1994;19(11):1201-6.

5. Korres. DS, Loupassis G, Stamos K. Results of lumbar discectomy: a study using 15 different evaluation methods. European Spine Journal 1992;1:20-4.

6. Barrios C, Ahmed M, Arrotegui JI, Bjornsson A. Clinical factors predicting outcome after. surgery for herniated lumbar disc: an epidemiological multivariate anallysis. J Spinal Disord $1990 ; 3(3): 205 \cdots 9$.

7. Pappas CTE, Harrington T, Sonntag VKH. Outcone analysis in 654 surgically treated lumbar disc herniations. Neurosurgery $1992 ; 30(6): 862-6$.

8. Smulders WLM, Loon van G. Nabehandeling na lumbale discectomie of chemonucleolyse. Een "out-patient" enquête. Fysiopraxis 1993;2(9):4-6.

9. Hurme M, Alaranta H. Factors predicting the result of surgery for lumbar intervertebral disc herniation. Spine 1987;12/9/933-8

10. Manniche $\mathrm{C}$, Asmussen $\mathrm{KH}$, Vinterberg $\mathbb{C}$, Rose Hansen $\mathrm{EB}$, Kramhoft $\rrbracket_{\text {, }}$ Jordan A. Back pain, sciatica and disability following first-time conventional haemileminectomy for lumbar disc hemiation. Use of "Low Back Pain Rating Scale" as a postal questionnaire. Dan Med Bull 1994;4111):103-6.

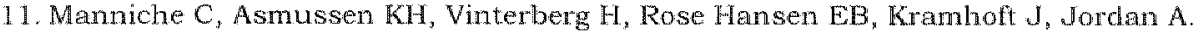
Analysis of preoperative prognostic factors in first-time surgery for lumbar disc herniation, including Finneson's and modified Spengler's score systems. Dan Med Bull $1994 ; 41[1]: 110-5$.

12. Cassisi JE, Robinson ME, OConner P, MacMillan M. Trunk strength and lumbar paraspinal muscle activity during isometric exercise in chronic low back pain. Spine $1993 ; 18(2): 245-51$.

13. Roy SH, DeLuca DL, Casavant DA. Lumbar muscle fatigue and chronic lowrer back pain. Spine 1989;14:9):992-1001.

14. Manniche C. Assessment and exercise in low back pain. With special reference to the management of pain and disability following first time lumbar disc surgery. Dan Med Bull 1995:42(4j:301-13.

15. Manniche C. Clinical benefit of intensive dynamic exercises for low back pain. Scand I Med Sci Sports $1996 ; 6(2): 82-7$

16. Carragee EJ, Helms E, O'Sullivan GS. Are postoperative activity restrictions necessary after posterior lumbar discectomy? A prospective study of outcomes in 50 consecutive cases. Spine 1996:21(16):1893-7.

17. Tulder van MW, Assendelft WJJ, Koes BW, Bouter LM. Method guidlines for systematio reviews in the Cochrane Collaboration. Back review group for spinal disorders. Spine $1997 ; 22(20): 2323-30$.

18. Tulder van MW, Koes BW, Bouter LM. Conservative treatment of acute and chronic nonspecific low back pain. Spine 1997;22(18):2128-56

19. Kitteringham $\mathrm{C}$. The effect of straight leg raise extrcises after lumbar decompression surgery - A pilot study. Physiotherapy 1996,82(2):115-23.

20. Kjellby Wendt $G$. Styf J. Early active training after lumbar discectomy. A prospective, randomized, and controlled study. Spine 1998;23(21):2345-51.

21. Alaranta H, Hurme M, Einola S, Kallio V, Knuts LR, Torma $T$. Rehabilitation after surgery for lumbar disc herniation: results of a randomized clinical trial. Int If of Rehab Res $1986 ; 9(3): 247-57$.

22. Brennan GP, Shultz BB, Hood RS, Zahmiser JC, Johnson SC, Gerber AH. The effects of aerobic exercise after Jumbar microdiscectomy. Spine 1994;19[7]:735-9. 
23. Danielsen JM, Johnsen R, Kibsgaard SK, Hellevik E. Early aggressive exercise for postoperative rehabilitation after discectomy. Spine 2000,25(8):1201-6.

24. Manniche $C_{f}$ Skall HF, Braendholt $L_{\text {, }}$ et al Clinical trial of postoperative dynamic back exercises after first lumbar discectomy. Spine 1993; 18[1]:92-7.

25. Dolan P, Greenfield $K$, Nelson. RJ. Nelson 1 W. Can exercise therapy improve the outcome of microdiscectomy? Spine $2000,25,1523-32$

26. Johannsen $\mathbb{P}$, Remvig $\mathbb{L}$, Kryger $\mathbb{P}$, et al. Supervised endurance exercise training compared to home training after first lumbar diskectony: a clinical trial. Clinical and Experimental Rheumatrogy 1994, 12(6):609 14.

27. Rothaupt D, Laser T, Ziegler H, Liebig K. Die Orthopädische Hippotherapie in der postoperativen Rehabilitation won lumbalen Bandscheibenpatienten. Eine prospektive, ramdomisierte Therapiestudie. Sportwerl. Sportschad 1997;1 1:63-9.

28. Burke SA, Harms Constas CK, Aden PS. Return to work/work retention autcomes of a functional restoration program. A multimcenter, prospective study with a comparison group. Spine 1994;19(17):1880-5.

29. Donceel $P$, Du Bois $M$, Lahaye $D$. Retum to work after surgery for lumbar disc hermiation. A rehabilitation-oriented approach in insurance medicine. Spine 1999;24(9):8726.

30. Manniche $C$, Asmussen $K$, Lauritsen $B$, et al. Intensive dynamic back exercises with or without hyperextension in chronic back pain after surgery for lumbar disc protrusion. A clinical trial. Spine 1993; 18151:560-7.

31. Timm KE. A randomized-control study of active and passive treatments for chronic lown back pain following LS laminectomy. JOSPT 1994;2016):276-86.

32. Lavyne MH, Bisky MH. Epidural steroids, postoperative morbidity, and recovery in patients undergoing microsurgical lumbar discectomy. J Neurosurgery 1992;77(1):90-5.

33. Lu Roux PD, Samudralia S. Postoperative pain after lumbar disc surgery: a comparison between parenteral ketorolac and narcotics. Acta neurochirurgica 1999;14 1(3):261-7.

34. Gibson AuN, Grant IC, Waddell $G$. The Cochrane review of surgery for lumbar disc prolaps and degenerative lumbar spondylosis. Spine 1999;24(17):1820-32.

35. Moher D, Schulz KF, Altman DG, Lepage L. "The CONSORT statement: revised recommendations for improving the quality of reports of parallel group randomised trials. Lan$\operatorname{cet} 2001 ; 357(9263): 1191-4$. 


\section{Behavioral treatment for chronic low back pain: A systematic review within the framework of the Cochrane Back Review Group}

Maurits W. van Tuldera, Raymond W.J.G. Ostelo , Johan W.S. Vlaeyen", Steven J. Linton ", Stephen J. Morley", and Willem. J.J. Assendelft
Afriliations of authors
a EMGO Institute, Wrije Universiteit Medical Center, Amsterdam.
- Department of Epidemiology, Maastricht University.
- Department of Clinical \& Experimental Psychology, Maastricht University.
"Department of Occupational Medicine, Orebro Medical Center Hospital, Örebro, Sweden
- Academic Unit of Psychiatry \& Behavioral Science, University of Leeds, Leeds, UK 'Department of General Practice \& Dutch Cochrane Center, Academic Medical Center, Amsterdam. 


\section{ABstract}

Study design: A systematic review of randomized controlled trials.

Summary of Background Data: The treatment of chronic low back pain is not primarily focused on removing an underlying organic disease, but at the reduction of disability through the modification of environmental contingencies and cognitive processes. Behavioral interventions are commonly used in the treatment of chronic (disabling) low back pain.

Objectives: To determine whether behavioral therapy is more effective than reference treatments for chronic nonspecific low back pain and which type of behavioral treatment is most effective.

Methods: The authors searched the Medline and Psyclit databases and the Cochrane Controlled Trials Register up to April 1999, and Embase up to September 1999. Also screened were references of identified randomized trials and relevant systematic reviews. Methodologic quality assessment and data extraction were performed independently by two reviewers. The magnitude of effect was assessed by computing a pooled effect size for each domain (i.e., behavioral outcomes, overall improvement, back pain-specific and generic functional status, return to work, and pain intensity) using the random effects model.

Results: Only five studies (25\%) were high quality. There is strong evidence (level 1) that behavioral treatment has a moderate positive effect on pain intensity (pooled effect size $0.62 ; 95 \%$ confidence interval (CI) $0.25,0.98$ ), and small positive effects on generic functional status (pooled effect size $0.35 ; 95 \%$ Cr: $-0.04,0.74$ ) and behavioral outcomes (pooled effect size $0.40 ; 95 \% \mathrm{Cl}: 0.10,0.70$ ) of patients with chronic low back pain when compared to waiting-list controls or no treatment. There is moderate evidence (level 2) that an addition of behavioral component to a usual treatment program for chronic low back pain has no positive short-term effect on generic functional status (pooled effect size $0.31 ; 95 \% \mathrm{Cl}$ : $0.01,0.64$ ), pain intensity (pooled effect size $0.03 ; 95 \% \mathrm{Cl}:-0.30,0.36$ ) and behavioral outcomes (pooled effect size $0.19 ; 95 \%$ CI $-0.08,0.45$ ).

Conclusions: Behavioral treatment seems to be an effective treatment for patients with chronic low back pain, but it is still unknown what type of patients benefit most from what type of behavioral treatment.

Key indexing terms: Behavioral treatment, Cochrane collaboration, Effectiveness, Systematic review. 


\section{BACKGROUND}

Low back pain is a major health and economic problem among populations in western industrialized countries. Chronic low back pain, in particular, is a major cause of medical expenses, absenteeism and disablement.51 A large variety of therapeutic interventions is available for the treatment of chronic low back pain. 35,52 Behavioral interventions are commonly used in the treatment of chronic (disabling) low back pain. The main assumption of a behavioral approach is that pain and pain disability are not only influenced by somatic disease, if found, but also by psychological and social factors. Chronic low back pain is not only a physical problem, but may also depend on the patient's attitudes and beliefs, psychological distress, and illness behavior. ${ }^{54}$ Consequently, the treatment of chronic low back pain is not primarily focused on removing an underlying organic disease, but at the reduction of disability through the modification of environmental contingencies and. cognitive processes. In general, three behavioral treatment approaches can be distinguished: operant, cognitive, and respondent. 38,5 Each of these focuses on the modification of one of the three response systems that characterize emotional experiences: behavior, cognitions, and physiologic reactivity.

Operant treatments are based on the operant conditioning principles of Skinner and have been applied to pain by Fordyce. They include positive reinforcement of healthy behavior and consequent withdrawal of attention toward pain behavior, time-contingent instead of pain-contingent pain management, and spouse involvement.12 The operant treatment principles can be applied by all health care disciplines involved with the patient. The program always starts with a number of baseline trials in which the patient exercises to the limit of tolerance. The therapist. then sets a quota of exercises to be performed at each session. Initial quotas are lower than baseline levels, but are increased systematically toward a preset goal. Each successfully performed increment is positively reinforced by all treatment staff. 12

Cognitive treatment is designed to identify and modify patients' cognitions regarding their pain and disability. Cognitions (the meaning of pain, expectations regarding control over pain) can be modified directly by cognitive restructuring techniques (such as imagery and attention diversion), or indirectly by the modification of maladaptive thoughts, feelings and beliefs. ${ }^{46}$

Respondent treatment is designed to modify the physiologic response system. directly - for example, by reduction of muscular tension. Respondent treatment includes providing the patient with a model of the association between tension and pain and teaching the patient to replace muscular tension by a tension incompatible reaction, for example relaxation, electromyographic biofecdback, progressive relaxation, and applied relaxation, are frequently used. $3 x, 5$,

Behavioral techniques are often applied together as part of a comprehensive treatment approach. This so-called cognitive-behavioral treatment is based on a 
multidimensional model of pain including physical, affective, cognitive and behavioral components. Cognitive-behavioral treatment may include education of the patient about a multidimensional view of pain; identification of pain-eliciting and pain-aggravating thoughts, feelings and behavior; identification and modification of maladaptive cognition; use of copirig strategies, hypnosis, (applied) relaxation, and electromyographic biofeedback,

A large variety of behavioral treatment methods are used for chronic low back pain, because there is no general consensus about the definition of operant and cognitive methods. Furthermore, behavioral treatment often consists of a combination of these methods or is applied in combination with other therapies (such as medication or exercises). Previous reviews have summarized the literature concerning behavioral therapy for chronic pain, $3,9,24,4,3$ and chronic back pain. $39,41,52$ In this review, the effectiveness of behavioral therapy for chronic low back pain is evaluated systematically, by using the methods of the Cochrane Collaboration with the most recent literature included.

The objective of this systematic review was to determine whether behavioral therapy is more effective than reference treatments for chronic nonspecific low back pain and to determine which type of behavioral treatment is most effective. Comparisons that were investigated are:

1. Comparison among different types of behavioral treatment

2. Behavioral treatment versus placebo, no treatment, or waiting-list controls

3. Behavioral treatment versus other kinds of treatment

4. Behavioral treatment in addition to another treatment (e.g. physiotherapy) versus the other treatment alone.

\section{METHODS}

\section{Criterla for considering studies for this review}

Types of studies. Only randomized controlled trials (RCTs) were included.

Types of participants. Subjects with nonspecific low back pain, between 18 and 65 years of age, were included. Chronic low back pain was defined as symptoms persisting for 12 weeks or more. RCTs that included subjects with specific low back pain caused by pathological entities such as infection, neoplasm, metastasis, osteoporosis, rheumatoid arthritis, or fractures were excluded.

Types of interventions. The RCTs in which one or more types of behavioral treatments, were used - that is, treatments based on behavioral therapy principles, - were included. Examples of good descriptions of these treatments are given by Fordyce ${ }^{12}$ and Roberts ${ }^{32}$ for operant treatments, Turk et al ${ }^{40}$ for cognitive treatments, and Andrasik ${ }^{2}$ and Belar and Kibrik ${ }^{6}$ for respondent treatments.

Types of outcome measures. Included were RCTs in which at least one of the outcome measures that the reviewers considered to be important was used: overall improvement (either selfureported or observed), back pain-specific functional status (e.g. Roland-Morris Questionnaire, Oswestry Questionnaire), generic functional 
status (e.g. Sickness Impact Profile), return to work fexpressed as the number of days of sick leave or the proportion of patients returned to work, and pain intensity (e.g. self-reported pain intensity expressed on a visual analogue scale [VAS] or numerical rating scale [NRS]/. In the behavioral domain, any type of behaviotal outcome was considered relevant (e.g. pain behavior, cognitive errors and perceived or observed levels of tension, anxiety, depression).

\section{Search strategy for identification of studies}

All relevant RCTs meeting our inclusion criteria were identified by:

A) A computer-aided search of the Medline database for the period 1966 through April 1999, the Embase database for the period 1988 through September 1998 , and the Psyclit database for the period 1974 trough April 1999, using the search strategy recommended by the Editorial Board of the Cochrane Back Revicw Group th The highly sensitive search strategy of the UK Cochrane Centre (October 1996), based on the first two stages of the Medline search strategy recommended by the Cochrane Handbook (Appendix $V$ of Section $V$ ) and published by Dickersin et allo was nun in conjunction with a specific search for low back pain and behavioral treatment. The RCI's inclucled were those published in English, Dutch, German, or Swedish.

B) Screening references given in relevant identified publications and reviews.

C) Screening The Cochrane library, 1998, issue 4.

D) Citation tracking of the RCTs identified by the prior step, using Science Citation Index.

\section{Methods of the review}

Study selection. Two reviewers (RWJG Ostelo and MW van Tulder) independenty selected the trials to be included in the systematic review. Consensus was used to resolve disagreements concerning inclusion of RCTs and a third reviewer (JWS Vlaeyen) was consulted if disagreements persisted.

Methodologic quality assessment. The methodologic quallity of the RCTs was inclependently assessed by two rewewers (RWJG Ostelo and MW van Tulder). The criteria list recommended in the method guidelines for systematic reviews in the Cochrane Back Review Group was used in this review ${ }^{2}$ Only the items reflecting the internal validity of the RCTs were used to assess the methodologic quality of the RCTs llable 1),

Because it is difficult to blind patients to behavioral treatment, the criterion regarding the blinding of patients was redefined. If blinding was not feasible, item 4 of the criterion list was scored positive if the credibility of the treatments was evaluated and treatments were equally credible and acceptable to patients." The criterion about drop-outs and withdrawals was also redefined by dividing it into two criteria: one for drop-outs during the intervention period, and the other for withdrawals during follow-up. Each criterion was scored as "positive", "negative" or 
Tatste 1. Methodologic criteria.

Intenal wabitity crteria:
(a) method of randonization
ib) conceament of treament allocation
2a) drop-out rate during the intervention period
2b) whth trawals during follow up
3) co-interventoris avoided or equel
4 ) binding of patients
$5)$ binding of outcome assessument
6) blinding of care providers
7) intertion-10-treat analysis
b) compliance
9) similapily of baseline characteristics
10) addervabe ingth of follown

$\begin{array}{lll}+ & - & ? \\ + & - & ? \\ + & - & ? \\ + & - & ? \\ + & - & ? \\ + & - & ? \\ + & - & ? \\ + & - & ? \\ + & - & ? \\ + & - & ? \\ + & - & ? \\ + & - & ?\end{array}$

"unclear". A total score was computed by counting the number of positive scores, and high quality was defined as fulfilling six $(50 \%)$ or more of the validity criteria.

The articles were not blinded for authors, institution, and journal, because the reviewers who performed the quality assessment were familiar with the literature. Consensus was used to resolve disagreements, and a third reviewer (JWS Vlaeyen) was consulted if disagreements persisted. If the article did not contain information on the methodologic criteria (i.e. if one or more criteria were scored "unclear") the authors were contacted for additional information.

Data extraction. Two reviewers (RWJG Ostelo and MW van Tulder) independently extracted the data considering the following domains: behavioral outcomes, overall improvement, back pain-specific functional status, generic functional status, return to work, and pain intensity.

Data-analysis. Within every study, effect sizes were computed for each outcome variable so that a positive effect size indicated a positive effect " For example, a positive effect size could indicate a decrease in pain intensity or an increase in functional status. If a study reported multiple outcome variables within a domain, a mean effect size for that domain was computed. Separate meta-analyses were performed for post-treatment and long-term results 6 months or more after randomization) for the various domains fi.e. behavioral outcomes, overall improvement, back-pain specific and generic functional status, return to work, and pain intensity) for every comparison (e.g. cognitive versus operant treatment or behavioral treatment versus other treaments). The magnitude of effect was assessed by computing a pooled effect size for each domain using the random effects model. If a study compared more than one type of behavioral treatment (e.g. cognitive as well as operant treatment) with no treatment, waiting list controls, or placebo, a mean effect size for these behavioral treatments was computed and used in the statistical pooling. An effect size between 0.2 and 0.5 was considered a small effect size, between 0.5 and 0.8 a medium effect size, and of 0.8 or more a large effect size. 
A rating system was used to summarize the strength of the scientific evidence consisting of four levels:

1. Strong evidence: provided by generally consistent findings in multiple thighquality RCTs.

2. Moderate evidence: provided by generally consistent findings in one high-quality RCT and one or more low-quality RCTs or by generally consistent findings in multiple low-quality RCTs.

3. Limited or conflicting evidence: only one RCT (either high-or low-quality) or inconsistent findings in multiple RCTs.

4. No evidence: no RCI's.

High-quality studies were defined as RCTs that fulfilled six or more of the validity criteria. Generally consistent findings were defined as $75 \%$ or more of the studies having statistically significant findings in the same direction.

\section{RESULTS}

\section{Study selection}

Our search collected in 37 references from Medline, 68 from Embase, and 178 from Psyclit. However, 19 publications were included in both Medline and Embase, 11 in both Medline and Psyclit, 12 in both Embase and Psyclit, and seven in Medline, Embase and Psyclit. Two hundred forty-four publications were identified in these three electronic databases. The first selection was based on titles, keywords, and abstracts, and resulted in both reviewers including 16 studies, rejecting 211 , being uncertain about inclusion of 23, and disagreeing about 26 studies. Copies of the full papers of the 49 publications, about which the reviewers were not sure or disagreed, were subsequently assessed. A thitd reviewer was consulted for one study because disagreement about its inclusion or exclusion persisted . 26 This study was excluded, because the functional restoration treatment was not considered a true behavioral treatment. The final selection was based on the full papers and resulted in inclusion of three additional trials. Another two additional trials were identified through reference checking, resulting in a total of 21 studies that were selected for this review.

One of the studies identified through reference checking was excluded, because electromoygraphic biofeedback treatment. was given in addition to a standard pain and rehabilitation program and was designed to increase the strength of trunk extensors instead of to induce relaxation. ${ }^{3}$ The results of this process yielded 20 studies for inclusion in this review. Three of these studies were reported in two publications, 21,22 three publications, $13,16,53$ and four publications, 1720 respectively. 


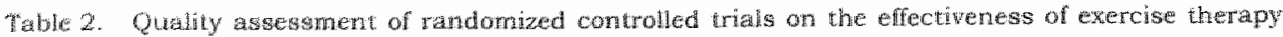
for low back pesin.

\begin{tabular}{|c|c|c|c|c|c|c|c|c|c|c|c|c|c|}
\hline Referenco & $1 a$ & 10 & $2 a$ & $2 \mathrm{~b}$ & 3 & 4 & 5 & 6 & 7 & 8 & 8 & 10 & Tolat \\
\hline Almaier $92^{3}$ & $=$ & - & + & 4 & 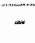 & - & - & - & - & + & + & - & 4 \\
\hline Baster "gi" & + & - & - & - & 4 & - & - & - & - & + & + & - & 4 \\
\hline Bru $94^{7}$ & $?$ & $?$ & $?$ & $?$ & $?$ & $\ldots$ & - & - & - & $?$ & $?$ & - & 0 \\
\hline Busth "85: & $?$ & $?$ & 4 & $?$ & $?$ & * & * & - & $\infty$ & $?$ & + & - & 4 \\
\hline Donaidson 'G4" & $?$ & $?$ & $?$ & - & $?$ & - & - & - & $?$ & + & - & + & 2 \\
\hline Kole-Snifders $96^{16}$ & + & + & + & - & + & + & + & - & 4 & - & + & + & 9 \\
\hline Lindstróm $92^{17 \cdot 20}$ & + & + & * & + & + & - & * & - & $\frac{4}{3}$ & $\div$ & 4 & + & 10 \\
\hline Linnton "892: & * & + & $*$ & + & - & - & + & - & 4 & + & + & - & 8 \\
\hline MicCaulen 832 & - & - & + & - & * & - & - & - & - & * & + & - & 4 \\
\hline Newton-John 9528 & - & - & + & - & + & - & - & - & - & + & 4 & - & 4 \\
\hline Nicholas 91 to & $?$ & $?$ & + & - & + & $?$ & - & - & - & + & - & $*$ & 4 \\
\hline Nicholas 920 & $?$ & $?$ & * & + & * & $?$ & - & - & - & $?$ & - & - & 3 \\
\hline Nouwen 1833 & - & - & + & + & + & - & - & - & * & 4 & + & - & 6 \\
\hline Rose 97 t & - & - & - & - & - & - & - & - & - & - & + & - & 1 \\
\hline Strong 982 & - & - & - & - & + & + & - & + & - & - & 4 & - & 4 \\
\hline Stuckey $186^{3}$ & $?$ & $?$ & - & - & $?$ & + & - & - & - & $?$ & - & - & 1 \\
\hline Turner $82^{4 ?}$ & - & - & - & - & $m$ & + & - & - & - & - & + & + & 3 \\
\hline Turner $888^{44}$ & - & - & $*$ & + & - & + & * & - & $=$ & - & + & + & 6 \\
\hline Turner 9045 & + & - & - & - & - & - & + & - & - & - & + & * & 4 \\
\hline Thurner 9340 & - & - & - & + & - & + & + & - & - & - & + & * & 5 \\
\hline
\end{tabular}

\section{Methodologic quality}

Table 2 shows the final results of the quality assessment. After consensus, 70 (29\%) of the 240 quality assessments (20 studies, 12 criteria) were scored "unclear:". Ten authors responded to a request and provided additional information on 13 studies (Turner was first author of 4 included RCTs). As a result, 20 "unclear" scores were changed into positive, indicating that the criterion was met, and 20 "unclear" scores were changed into negative. The additional information from the authors also resulted in the changing of nine negative scores into positive. In general, the methodologic quality of the RCTs included in this review was low. Only five studies $(25 \%)$ had 6 or more positive scores, which was our preset threshold for high quality. 4, $32,2,4,4$ Only the criteria regarding drop-out rate during intervention period (item 2a) and similarity of baseline characteristics (item 9 ) were met by $50 \%$ of the RCTs or more. In none of the studies was the care provider blinded.

\section{Study characteristics}

Study characteristics are presented in Table 3. Eight studies were identified that compared various types of behavioral treatment.7,16,25,28,29,44,46,47 Eleven studies compared some type of behavioral treatment with no treatment, waiting list controls or placebo. $7,3,6,22,23,31,3 \%, 44,4 \%$ Two studies compared behavioral treatment with some other kind of treatment. ${ }^{8,415}$ Six studies compared behavioral treatment in addition to another treatment with that treatment alone $4,29,30,36,45$ One study evaluated group versus individual treatment and the effects of duration of treatment. 33

There were 14 RCTs that specifically mentioned the qualification of therapists and 6 RCTs that did not mention the therapists qualifications, 1.7, 11,38,28,3? An example of sufficient description of qualifications of therapists was 'psychologist who had had 5 
years of experience with chronic pain patients since completing his clinical qualifications". ${ }^{29}$ An example of insufficient description was "a physical therapist". "s Five studies did not report the results in a way that allowed their inclusion in the statistical pooling, $\pi, 8,16,22,25$

\section{Effectiveness of behavioral treatment}

1. Comparison among different types of behawioral treatment.

1.1 Cognitive versus operant. Only one low quality study was identified that compared cognitive to operant treatment. ${ }^{29}$ All groups in this study also received a physiotherapy back education and exercise program. The operant treatment group reported a significantly greater improvement on generic functional status, but not on pain or any outcome measure within the behavioral domain. There is limited evidence (level 3) that cognitive and operant treatments are equally effective.

1.2 Cognitive versus respondent. Three low-quality studies compared cognitive to respondent treatment consisting of progressive muscle relaxation training. ${ }^{7} 46,47$ One study could not be included in the meta-analysis, because data were not adequately presented. With the random effects model, the pooled effect size after treatment for pain intensity was $0.28195 \%$ Confidence inteval (Cl) $-0.38,0.95, Q=0.89$, df 1$]$, for generic functional status $-0.35[95 \% \mathrm{Cl}$ : $0.87,0.22, Q=0.27$, df 1$]$, and for outcomes in the behavioral domain - 0.05 $[95 \% \mathrm{CI}:-0.93,0.82, \mathrm{Q}=2.25$, df 1$]$. Only one study reported long term outcomes, and the differences between groups were not statistically significant. ${ }^{46}$ There is moderate evidence (level 2) that respondent treatment is no more effective in improving pain intensity, generic functional status, or behavioral outcomes.

1.3 Operant versus respondent. There is no evidence, because none of the identified studies compared operant to respondent treatment.

1.4 Cognitive-behavioral versus cognitive. Only one low-quality study included a comparison between a cognitive-behavioral and a cognitive treatment group. 4. The cognitive behavioral treatment consisted of cognitive therapy and progressive muscle relaxation and imagery. There were neither posttreatment nor long-term statistically significant differences between the groups on any of the outcome measures (global improvement, functional status, and pain). There is limited evidence (level 3) that cognitive-behavioral and cognitive treatment are equally effective. 
Table s. Study charackeraters.

\begin{tabular}{|c|c|c|c|}
\hline study & Partaciparts & Interventions & Oubames \\
\hline Altraider 92 & 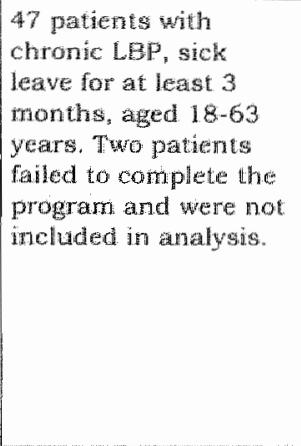 & 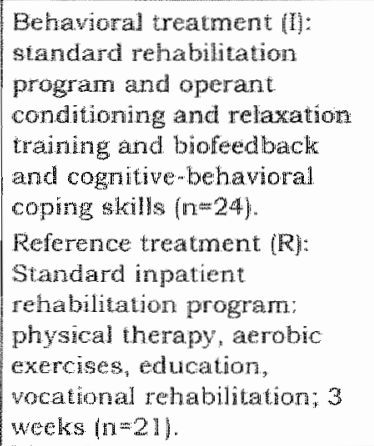 & $\begin{array}{l}\text { Mean scones on Mall } \\
\text { Pain Questionmaire } \\
\text { pretreatment, post- } \\
\text { treatumt and ather } 6 \\
\text { months (T) } 24.24,23.76 \\
\text { and } 22.66 \text { vs (R) } 20.33 \text {, } \\
18.05 \text { and } 18.19 \text {. No } \\
\text { signifrcan differences on } \\
\text { any outcome measures. }\end{array}$ \\
\hline Basion $97^{4}$ & $\begin{array}{l}94 \text { patients with } \\
\text { whronic LBP wom } \\
\text { dhee pan treatnent } \\
\text { centers. Fighteer } \\
\text { patients dropped out } \\
\text { and were not included } \\
\text { in analysis. }\end{array}$ & 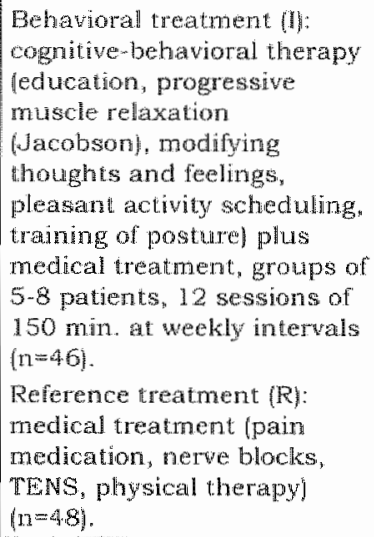 & 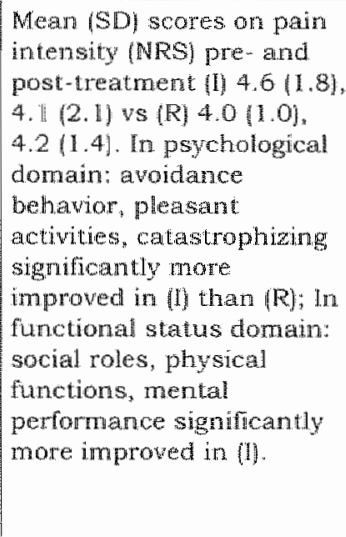 \\
\hline $\mathrm{Bru} 94^{\circ}$ & 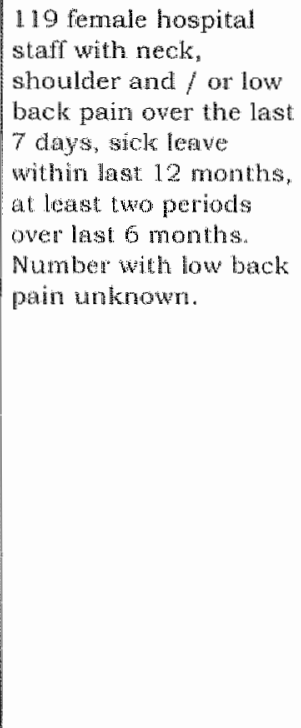 & 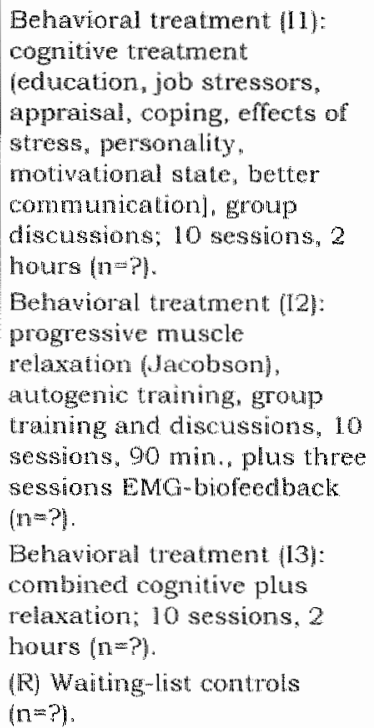 & $\begin{array}{l}\text { Intensily of LBP and } \\
\text { duration of LBP post- } \\
\text { treatmert significantly } \\
\text { more improved in (12) than } \\
\text { (11), (I3) and (R). Data in } \\
\text { graphs. }\end{array}$ \\
\hline
\end{tabular}




\begin{tabular}{|c|c|c|c|}
\hline Study & Participants & Thiernentions & Ontcompes \\
\hline Busin $85^{\circ}$ & $\begin{array}{l}72 \text { patients writh } \\
\text { chronic } L B P, \text { aged } 20 \text { - } \\
65 \text { year's, wolunteers } \\
\text { recruted through } \\
\text { media monncements. }\end{array}$ & 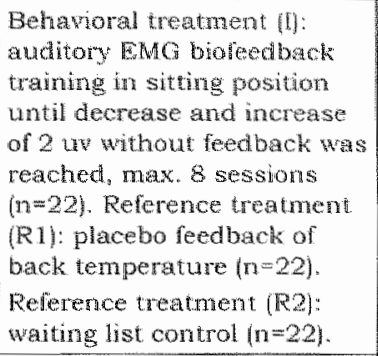 & 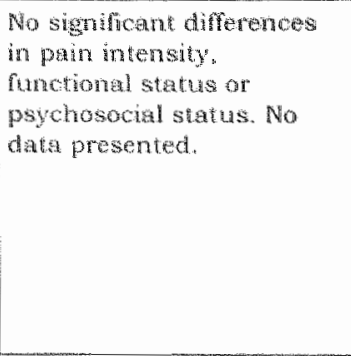 \\
\hline $\begin{array}{l}\text { Donald son } \\
9411\end{array}$ & 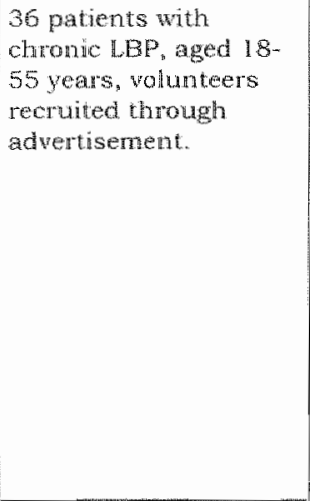 & 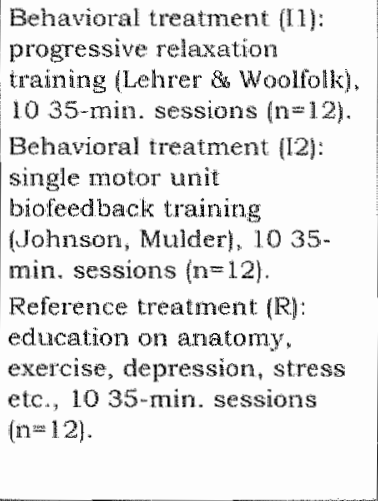 & 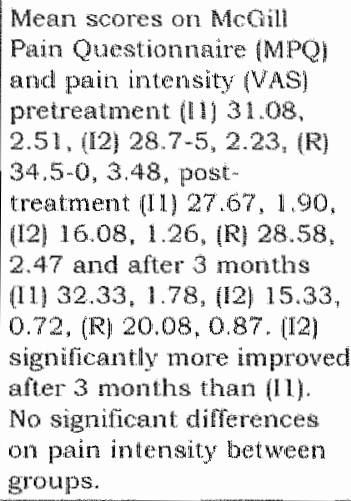 \\
\hline $\begin{array}{l}\text { Kole-Snijders } \\
9616\end{array}$ & $\begin{array}{l}148 \text { patients with } \\
\text { chronic LBP, aged } 18 \text {. } \\
65 \text { years, observable } \\
\text { pain behavior, partne } \\
\text { willing to participate, } \\
\text { referred by general } \\
\text { practitionets, hospitals } \\
\text { and rehabilitation } \\
\text { center. }\end{array}$ & 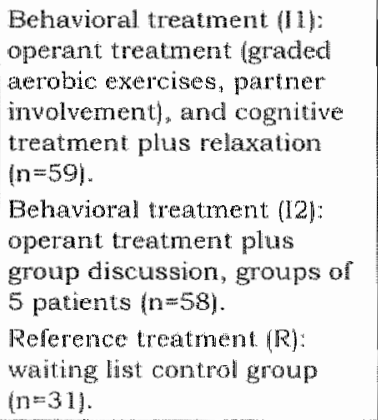 & 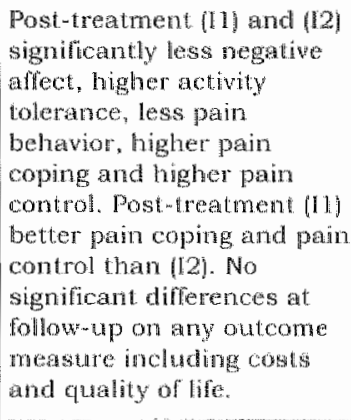 \\
\hline $\begin{array}{l}\text { Lindstmon } \\
921720\end{array}$ & $\begin{array}{l}103 \text { patients with } \\
\text { subecute LBP, blue- } \\
\text { collar workets sick- } \\
\text { listed lor at least } 6 \\
\text { weeks. }\end{array}$ & 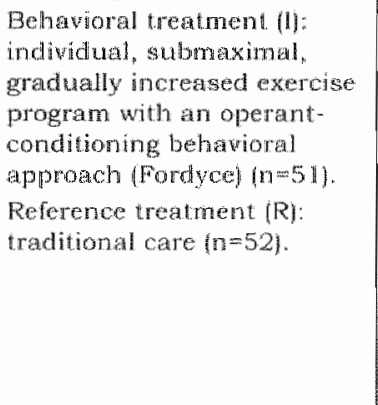 & 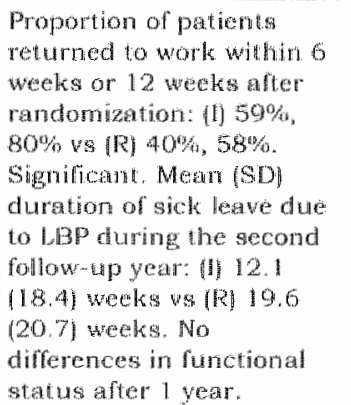 \\
\hline
\end{tabular}




\begin{tabular}{|c|c|c|c|}
\hline suduty & Partiapants & Interwentions & Onicomes \\
\hline Winton 8922 & 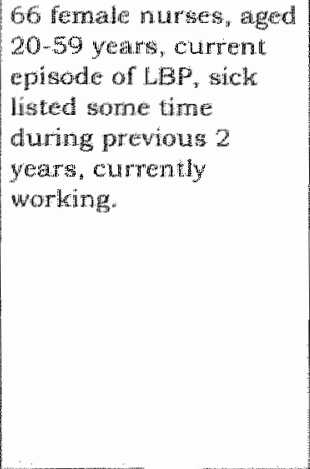 & 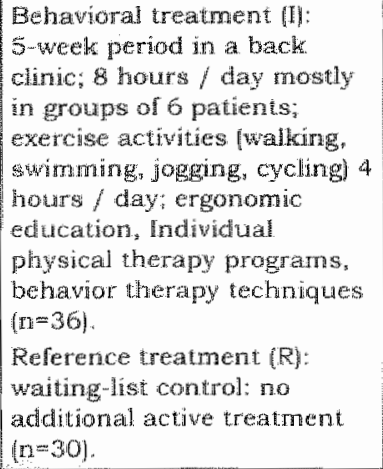 & 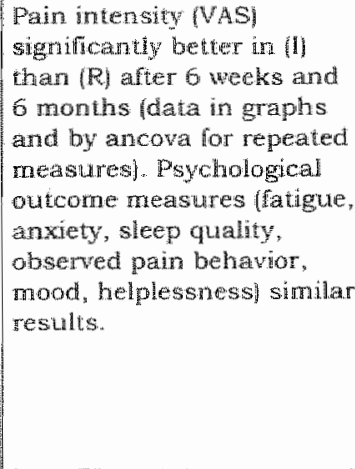 \\
\hline McCannley $33^{25}$ & 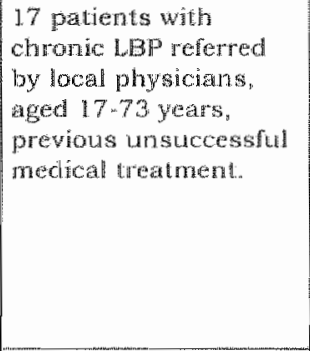 & 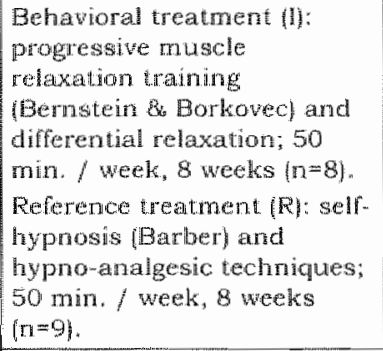 & 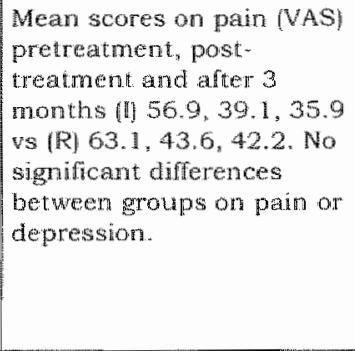 \\
\hline $\begin{array}{l}\text { Newtorl-John } \\
\text { 9) } 5 \text {-24 }\end{array}$ & $\begin{array}{l}44 \text { patients with } \\
\text { chronic LBP, aged } 18 \text { - } \\
65 \text { ycars, nefered by } \\
\text { medical practiononets } \\
\text { or self-refertad } \\
\text { through media } \\
\text { publicity. }\end{array}$ & 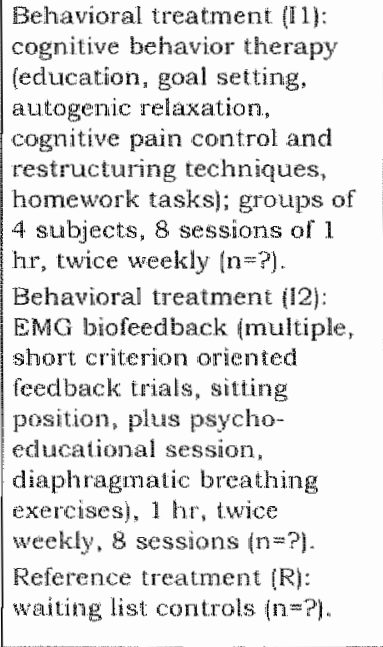 & 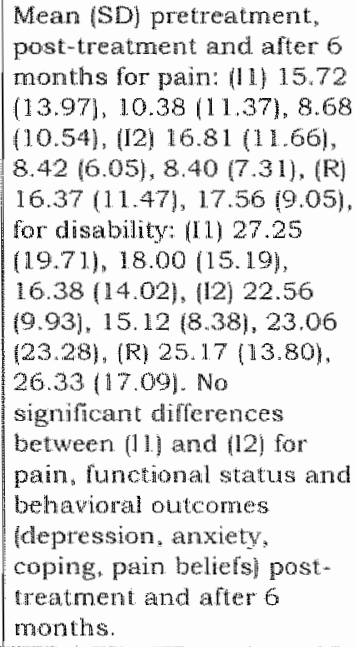 \\
\hline
\end{tabular}




\begin{tabular}{|c|c|c|c|}
\hline Strdat & Panticipants & Mreraterions & Ontoonses \\
\hline Wicholas 9129 & $\begin{array}{l}58 \text { patients with } \\
\text { chromic LBP, aged } 21- \\
63 \text { years, selected from } \\
\text { patients refened from } \\
\text { a pain clinic, and by } \\
\text { specialists and gencral } \\
\text { medical practioners. } \\
\text { Data avalable on } 48 \\
\text { patiens post- } \\
\text { treatment and } 39 \text { at } \\
\text { follow-up. }\end{array}$ & 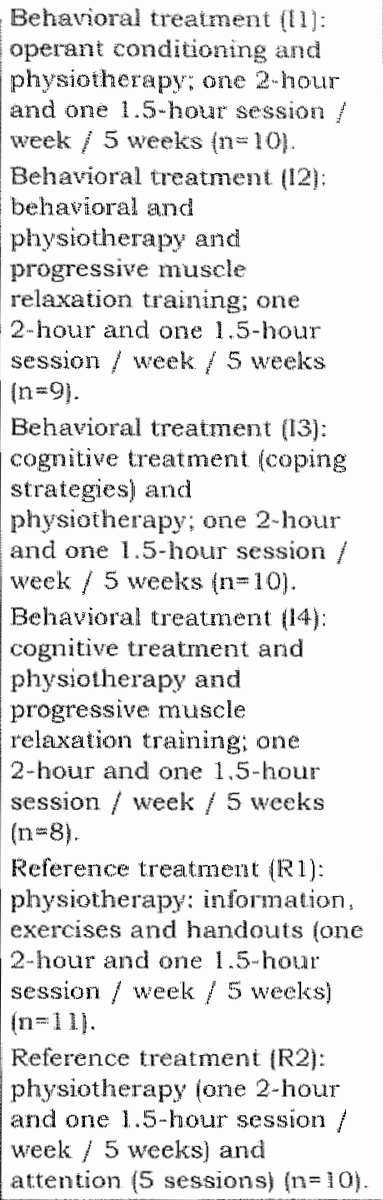 & 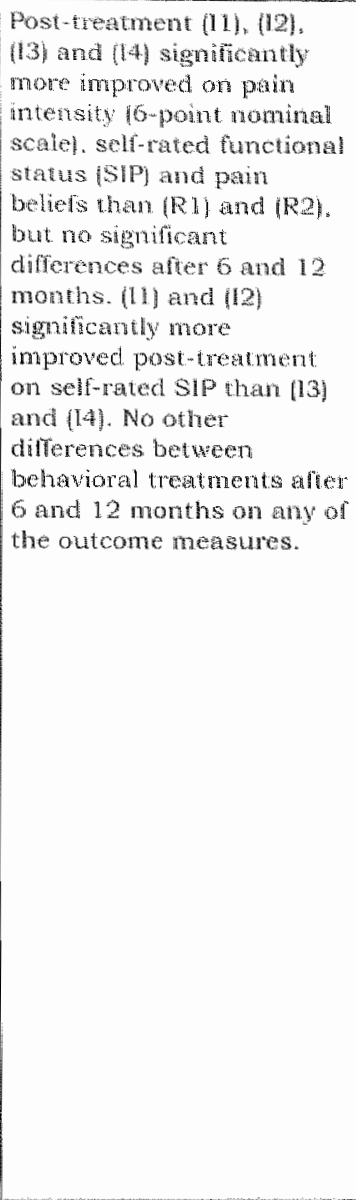 \\
\hline Micholas "9230 & $\begin{array}{l}20 \text { pathents with } \\
\text { chronio LBP, anged } 20 \text { - } \\
60 \text { years, selected from } \\
\text { patients teferted from } \\
\text { a pain alinic, and by } \\
\text { specialists and general } \\
\text { nedical practitioners. } \\
2 \text { patients dropped out } \\
\text { from each group and } \\
\text { were not included in } \\
\text { analysis. }\end{array}$ & 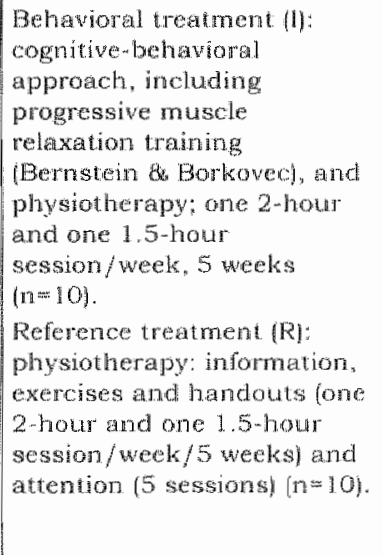 & 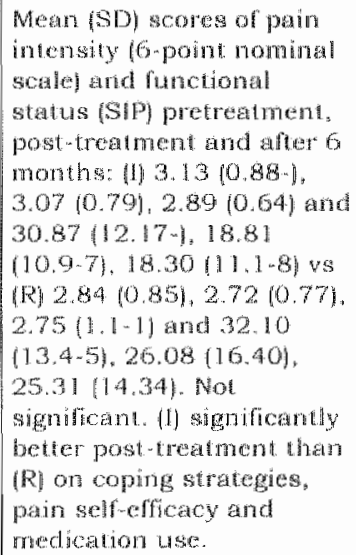 \\
\hline
\end{tabular}




\begin{tabular}{|c|c|c|c|}
\hline study & Pariogipans & Interuentions: & Outcomess \\
\hline Wouwen 83 & 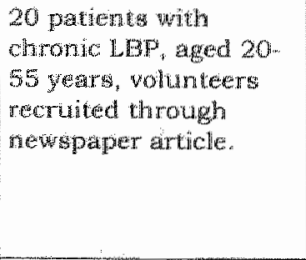 & 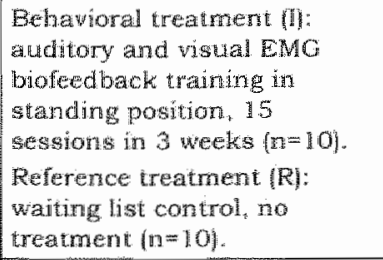 & 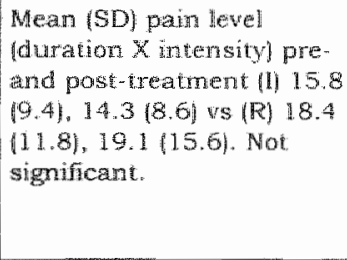 \\
\hline Koge 973 & 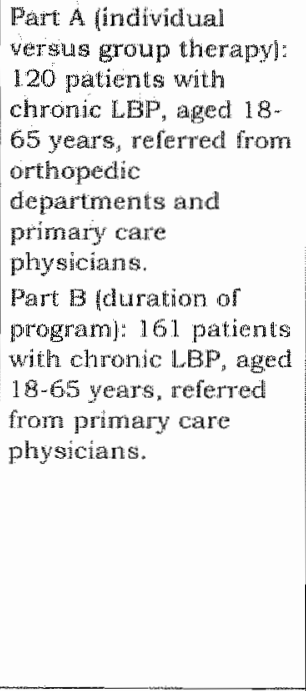 & 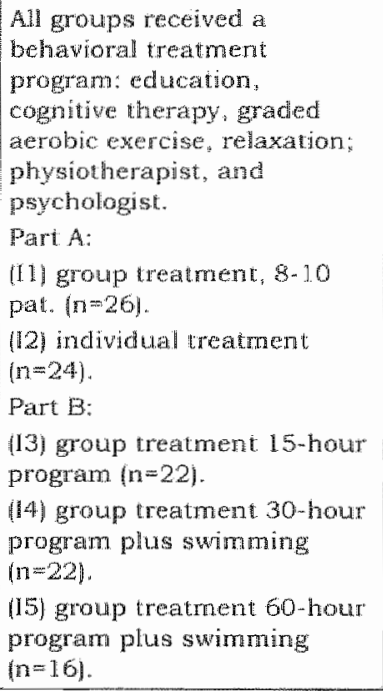 & 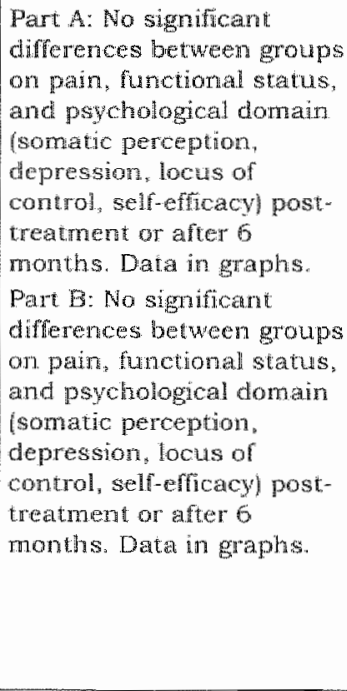 \\
\hline Strong $98^{36}$ & $\begin{array}{l}30 \text { consectitive } \\
\text { patients with chronic } \\
\text { LEP admitted to a pain } \\
\text { clinic. } 12 \text { patients } \\
\text { dropped out and were } \\
\text { not inlcuded in } \\
\text { andylysis. }\end{array}$ & 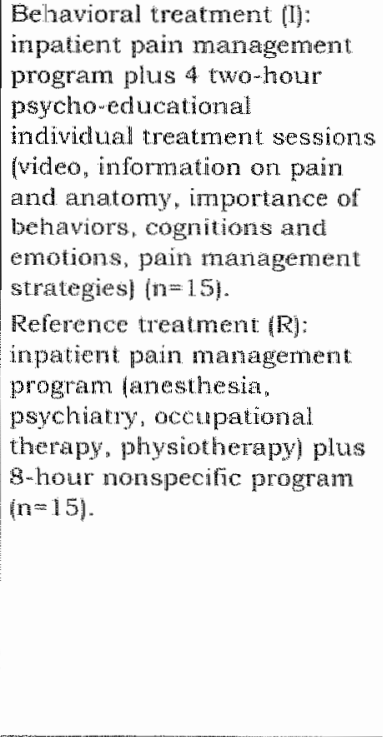 & 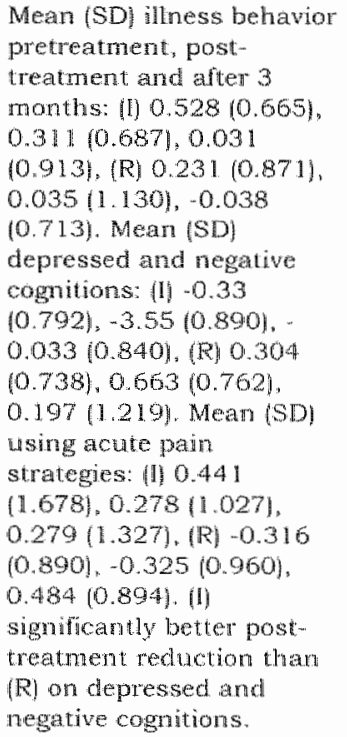 \\
\hline
\end{tabular}




\begin{tabular}{|c|c|c|c|}
\hline Shosdy & Participants & Interventions & Outoomes \\
\hline Stuckey 863 & 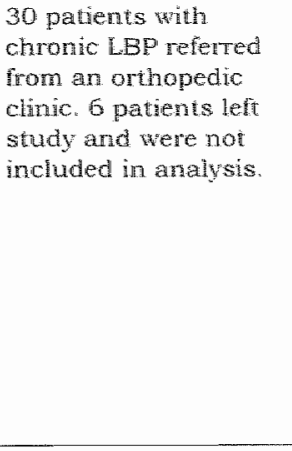 & 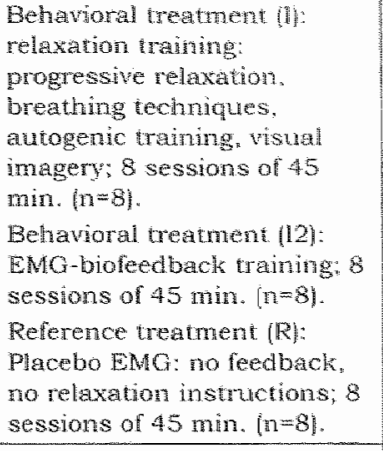 & 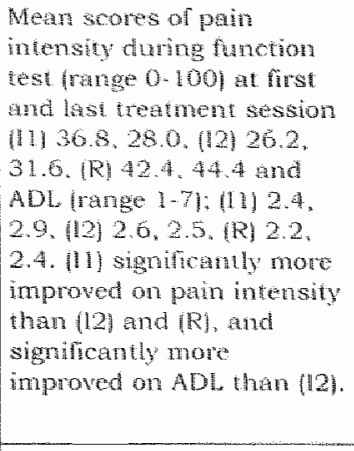 \\
\hline Tumer 8247 & 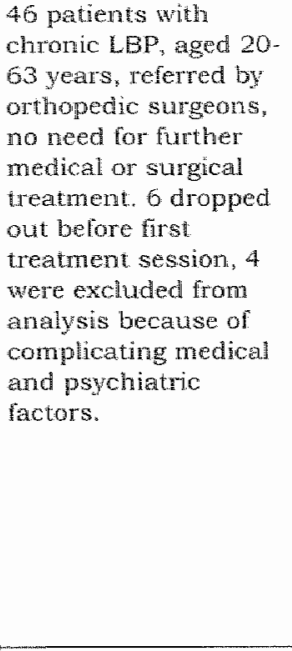 & 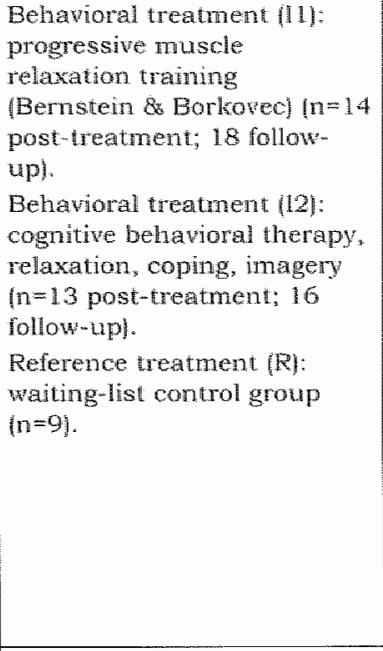 & 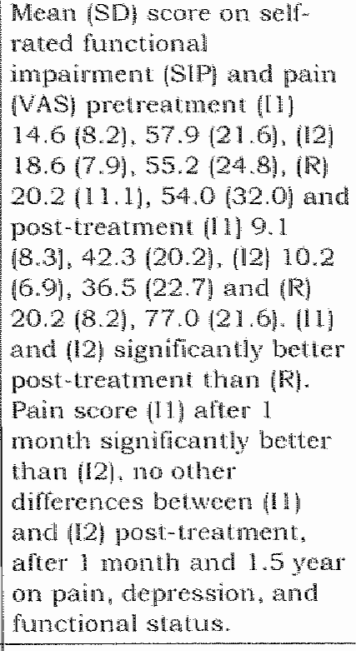 \\
\hline Turner $88^{4 a}$ & 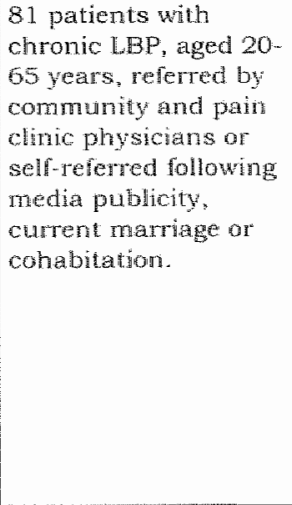 & 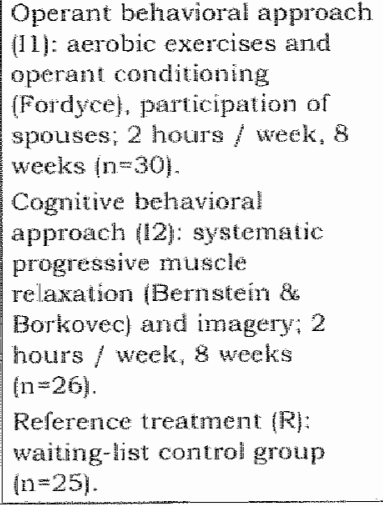 & 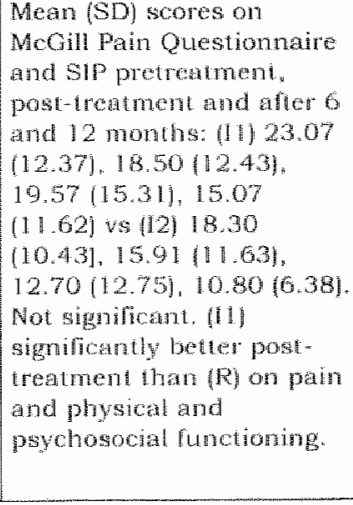 \\
\hline
\end{tabular}




\begin{tabular}{|c|c|c|c|}
\hline Sfucty & Participants & Interveratons & Outcomes \\
\hline Tumer $90^{\text {stos }}$ & 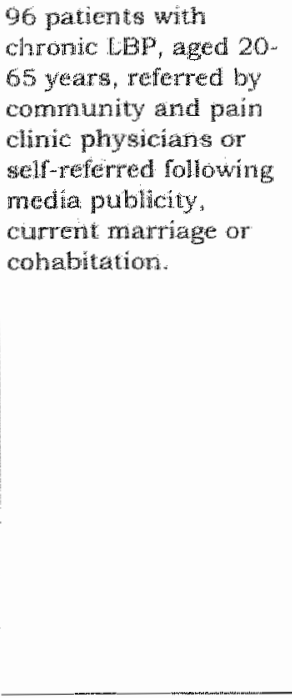 & 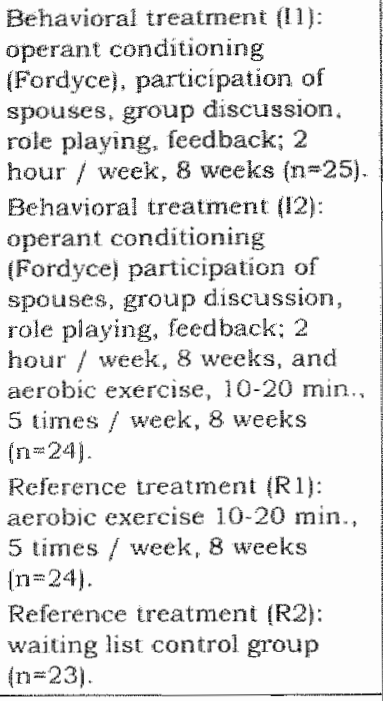 & 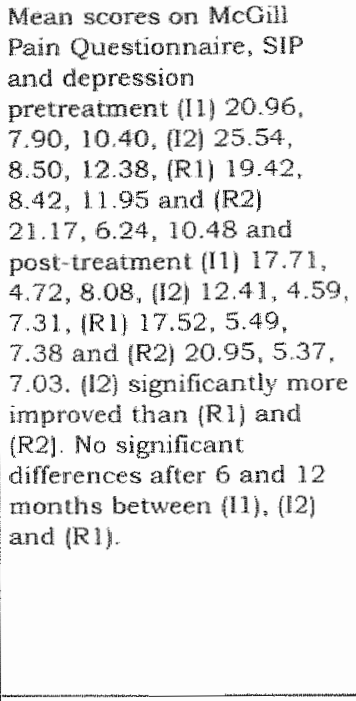 \\
\hline Tumer $93^{4 \%}$ & $\begin{array}{l}102 \text { patients with } \\
\text { chronic LBP, aged } 20 \text { - } \\
65 \text { years, refened by } \\
\text { community and pain } \\
\text { chinic physicians or } \\
\text { self-irefred following } \\
\text { media publicity. }\end{array}$ & 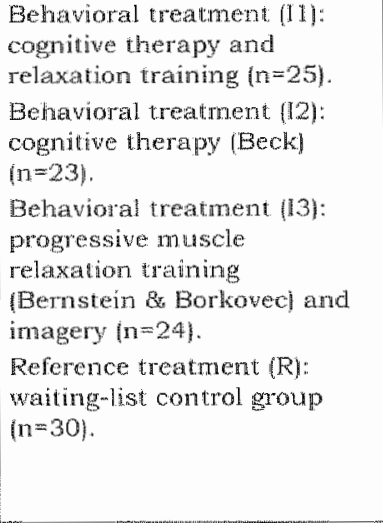 & 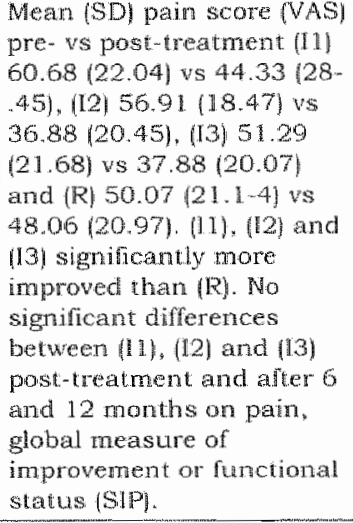 \\
\hline
\end{tabular}

1.5 Cognitive-behavioral versus operant. Two high-quality studies were identified 16,44 One study compared cognitive behavioral treatment to operant treatment and found statistically significant better posttreatment results on pain behawior, and physical and psychosocial functioning with operant. treatment, but no differences between the groups after 6 and 12 months follow-up. The other study reported better pain coping and pain control posttreatment with cognitive-behavioral treatment, but no other post-treatment or long-term differences. 19 There is conflicting evidence (level 3) that cognitivebehavioral is more or less effective than operant treatment. 
1.6 Cognitive-behavioral versus respondent. Tho low-quality studies were identified.7.28 Cognitive bebavioral therapy was compared to electronyographic biofedback in one study. ${ }^{28}$ No significant differences were found between the groups on pain or any of the outcome measures in the behavioral domain at either postreatment or at 6-month follow-up. The other study compared cognitive plus relaxation treatment to relaxation alone. 7 In this study the intensity and duration of pain were significantly more reduced in the relaxation alone group. There is conflicting evidence (level 3 ) on the comparison of effectiveness between cognitive-behavional and respondent treatment.

2. Behavioral treatment versus. no treatment, waiting ist controls, or placebo.

Elleven studies, among which four were high quality, 16,22,31.44 were identified that compared some type of behavioral treatment leither cognitive, operant, respondent or cognitive-behavioral therapy] with no treatment or waiting list controls. Seven reported data that could be used in statistical pooling, $28,31,47,44-$ 47 The pooled effect size after treatment for pain intensity was $0.62195 \% \mathrm{Cl}$ $0.25,0.98, Q=6.28$, df 61 , the pooled effect size for generic functional status was $0.35[95 \% \mathrm{Cl}:-0.04,0.74, \mathrm{Q}=5.39$, df 4], and the pooled effect size for outcomes in the behavioral domain was $0.40[95 \% \mathrm{Cl}: 0.10,0.70, \mathrm{Q}=2.98$, df 51. Three of the four studies that were not included in the statistical pooling showed similar findings.7,16:22 There is strong evidence (level 1) that behavioral treatment has a moderate positive effect on pain intensity and small positive effects on generic functionall status and behavioral outcomes of chronic low back pain patients.

A subgroup analysis of the four studies performed by Turner-47 resulted in a pooled effect size after treatment for pain intensity of 0.55 [95\% CI: 0.1. $1,0.99$ ], while the other three studies $28,31.37$ had a pooled effect size of $0.74[95 \% \mathrm{CI}$ : $0.23,1.25]$. The pooled effect size after treatment for behavional outcones was $0.32[95 \% \mathrm{Cl}:-0.02,0.66]$ for the four studies of Turner versus $0.61195 \% \mathrm{CI}$ : $0.00,1.22]$ for two other studies.28.37

3. Behavioral treatment versus other kinds of treatment.

Two studies compared behavioral treatment with some other kind of treatment, i.e., exercise 45 and usual care. ${ }^{4}$ The high-quality study reported a graded activity program to result in earlier return to work and reduced longterm sick leave in industrial blue-collar workers on sick list for 8 weeks because of sub-acute low back pain. ${ }^{18}$ The low quality study reported no significant differences between behavioral treatment and exercise with regard to pain intensity, generic functional status, and behavioral outcomes, either after treatment, or at 6 - and 12-month follow-up. 45 There is limited evidence (level 3 that a graded activity program in an industrial setting is more effective than usual care, and that behavioral treatment and exercise are equally effective. 
4. Behavioral treatment in addition to another treatment versus the other treatment alone.

Six low quality studies were identified, $1,4,29,30,36,45$. The treatments to which the behavioral therapy had been added were physiotherapy and backeducation, 29,30 a multidisciplinary treatment program, an inpatient pain management program, 36 various forms of medical treatment le.g. pain medication, nerve blocks, or physical therapy) ", and exercise therapy. ${ }^{45}$

The pooled effect size after treatment for pain intensity was $0.03195 \% \mathrm{CI}:-$ $0.30,0.36, Q=4.95$, df 4 , the poolled effect size for generic functional status was $0.31[95 \% \mathrm{Cl}:-0.01,0.64, \mathrm{Q}=0.43, \mathrm{df} 3 \mathrm{l}$, and the pooled effect size for outcomes in the behavioral domain was $0.19195 \% \mathrm{CI}-0.08,0.45, \mathrm{Q}=1.08$, df 5]. Long-term results showed a pooled effect size for pain intensity of -0.24 $195 \% \mathrm{CL}:-0.64 ; 0.16, Q=0.94$, df $3 \rrbracket$, a pooled effect size for generic functional status of $0.26[95 \% \mathrm{Cl}:-0.06,0.57, \mathrm{Q}=0.88$, df 4$]$, and a pooled effect size for outcomes in the behavioral domain of $0.32[95 \% \mathrm{Cl}:-0.06,0.71, \mathrm{Q}=6.10$, df 4]. In the only study reporting on return to work as an outcome ${ }^{1}$, investigators found that $48 \%$ in the behavioral treatment group had returned to work after 6 months compared to $67 \%$ in the control group. However, this difference was mot statistically significant.

There is moderate evidence (level 2) that an additional behavioral component to a usual treatment program for chronic low back pain has no short-term effect on pain intensity, generic functional status and behavioral outcomes. There is also moderate evidence (level 2) that there is no long-term effect on generic functional status and behavioral outcomes.

\section{DISCUSSION}

Results from the 20 studies included in this systematic review showed that there is strong evidence that behavioral treatment of patients with chronic low back pain has a positive effect on pain intensity, generic functional status, and behavioral outcomes when compared with waiting-list controls or no treatment, although the effects are only moderate or small. There is moderate evidence that a behavioral component added to a treatment program for chronic low back pain has no positive effect and conflicting evidence on the effectiveness of behavioral treatment compared with other conservative treatments. There is no strong evidence in favor of any type of behavioral treatment: cognitive, operant or respondent treatment or combinations of these treatments (cognitive-behavioral treatment). These results are more or less in line with a recently published systematic review ${ }^{27}$ of $\mathrm{RCTs}$ of behavioral treatment for chronic pain, excluding headache, that showed that behavioral treatments are more effective than waiting list controls. However, in contrast to the authors of the other review the current authors found no differences. when comparing behavioral treatment to alternative active treatments.

Most studies included in this review evaluated a "package" approach to cognitivebehavioral treatment, and little is known about the actual or comparative vallue of different methods withim cognitive-behavioral treatment. It is still unclear which 
type of behavioral treatment is the most effective, which components of behavioral treatment are necessary, and which are superfuous. This seems especially relevant now that the biopsychosocial model has been widely accepted and multimodal or multidimensional treatment programs that may include cognitive-behavioral treatment programs) are becoming more and more populat in the treatment of patients with chronic (back) pain. More research is needed on possible underlying mechanisms to define subgroups of patients who may benefit most from behavioral treatments. Promising predictors of outcome of behavioral treatment have been suggested, such as treatment credibility, 16 stages of change, 15 and patient profiles, such as the Multidimensional Pain Inventory ${ }^{39}$

Kole-Snijders et $2 .{ }^{16}$ reported that treatment credibility was an important predictor of self-reported pain coping and control, and observed activity tolerance and pain behavior at follow-up. Five stages of change have been suggested (precontemplation, contemplation, preparation, action, and maintenancel that could explain patients' motivation for treatment. ${ }^{15}$ A treatment is effective only if the patient is motivated and ready to change. Treatment credibility may be a prerequisite for willingness to participate and readiness to change. Turk et al ${ }^{39}$ suggested that customizing treatment based on psychosocial meeds of patients provides better outcomes with behavioral treatment. Patients with fibromyalgia were classified into three groups based on their response to the Multidimensional Pain Inventory. Patients with poor coping and high levels of pain had good outcomes when treated with a multidisciplinary outpatient treatment program, whereas patients with interpersonal difficulties had poor outcomes. Future studies should evaluate if these subgroups may indeed predict successful outcomes of behavioral treatment for chronic low back pain.

Recently, so called "yellow flags" have been suggested to identify psychosocial risk factors regarding attitudes and beliefs about back pain, behavior, compensation issues, diagnosis and treatment, emotions, family and work.14 Assessment of psychosocial risk factors that are likely to increase the risk for development of chronic pain and disability could become part of the management of patients with low back pain. Early identification of these risk factors, for example by use of a screening questionnaire for psychosocial risk factors, ${ }^{23}$ may lead to more effective management by identifying which patients are likely to benefit from behavioral treatment. Future research should determine if implementation of psychosocial risk assessment is feasible in daily clinical practice and if it indeed leads to more effective management.

\section{Methodologic quality}

The methodologic quality of the studies was generally poor. Many methodologic criteria regarding the internal validity of the studies were not fulfilled. Randomization, blinding of patients and outcome assessments, cointerventions and compliance were not properly conducted in many studies, and in not one study were care providers blinded. Obviously, this last criterion is difficult, and most of the time impossible to achieve in studies on behavioral treatment. Bias is likely to accur when care providers are not blinded because, by definition, they have a 
conflict of interest. In most trials included in this review, the authors of the studies actually evaluated a program developed by themselves. Bias would be less likely if evaluation of behavioral treatment programs is conducted by an independent third party.

Blinding of patients is also difficult in many RCTs of behavioral treatment, and this criterion was therefore defined as being "positive" if treatment credibility was evaluated and treatments were equally credible and acceptable to patients. Other attempts to deal with these unavoidable methodologic problems in trials of behavioral therapy include assessing adherence of therapists to protocols, ensuring that therapists deliver both treatments in trials, and assessing credibility and expectations of therapists. It has been suggested that it is also important to have information about the experience and qualifications of the psychologists who deliwered the behavioral treatment. In mosit of the studies included in this review, the qualifications of the care providers were not explicitly described. Therefore, it was not possible to perform the preplanned subgroup analysis of studies with qualified versus unqualified psychologists. It is recommended that in future trials. the qualifications and experience of therapists be described explicitly.

It is still questionable whether the criteria list that is used to assess the methodologic quality of studies included in a systematic review actually evaluates the quality of the study or the quality of the publication. After consensus, the two reviewers considered the publications 'unclear' about whether the criterion was met or not, in approximately $30 \%$ of our quality assessment scores. Additional information was requested from the authors, and the question remains if this was worth the effort. Seven authors did not respond to the request, but additional information was provicled for 13 studies included in the review. The current authors tried to identify current addresses of the authors through recent publications in Medline and Embase or through the Internet. Authors from older studies may not have been able to respond because, for example, they may have changed workplaces or they may have retired. The interpretations of the authors comments resulted in $50 \%$ of the unclear scores becoming positive and $50 \%$ becoming negative. An adcitional advantage of contacting the authors is that they get the opportumity to disagree with any of the quality assessment scores and to provide information to change that score. The authors convinced us that 10 negative scores should be positive. Contacting the authors resulted in 4 studies becoming high quality studies and in the strength of evidence for behavioral treatment becoming strong. It is recommend that other reviewers attempt to contact authors, because it is not always cleat from publications of trials whether a criterion was met, and because it seems that not all relevant information is included in the final publications of trials. In the near future, it is hoped that the quality of publications improves inasmuch as guidelines for reporting of RCTs have been published and have been adopted by an increasing number of medical journals. 5

\section{Data analysis}

In data analysis, both a quantitative and a qualitative approach was used. The quantitative approach was used to estimate the magnitude of the effect. Statistical pooling of effect sizes was performed despite heterogeneity regarding patient 
populations, interventions, and outcome measures. If a study reported multiple outcome variables within a domain, a mean affect size for that domain was computed. This frequently occurred for the behavioral domain, because most studies have a number of outcome measures within this domain, eg. anxiety, depression, and coping. The weighted mean effect size, which is the outcome of statistical pooling, provides a global idea about the effectiveness of behavioral treatment but ignores the fact that for some behavioral outcomes there may be a positive effect and for other outcomes negative effects. Interpretation of this mean effect size is difficult, and translation into clinical practice not easy.

The qualitative approach was used to estimate the strength of the evidence. A grading system for levels of evidence was used for this purpose. The strength of evidence was combined with the magnitude of effect in our final conclusions and recommendations. Others have suggested that the magnitude of effect be included as a characteristic of levels of evidence 48 . These authors considered strong evidence in favor of a treatment to be present when there were consistent positive results from at least three high quality studies; positive results were defined as statistically significant and clinically important results in favor of the treatment at issue for at least one outcome measure. Results were clinically important if the pooled estimate of effect was larger than 0.5. Although levels of evidence are still in development. and remain arbitrary, the current authors believe that in systematic reviews they provide a transparent and reproducible means to summarize the results if statistical pooling is not performed, for whatever reason.

\section{CONCLUSIONS}

\section{Implications for practice}

Behavioral treatment seems to be an effective treatment for patients with chronic low back pain. Clinicians should be more aware that psychosocial risk factors play an important role in the development of chronic back pain and disability, so that early identification of these risk factors may become part of the management of patients with low back pain.

\section{Implications for research.}

Future RCTs are needed to find out what type of patient berefits most from behavioral treatment and what type of behavioral treatment is most effective for what type of patient. In future studies, behavioral treatment should be compared to other active treatments for chronic back pain, and a cost-effectiveness analysis should be included. 


\section{KEV AND ACKNOWLEDGEMENT}

- A systematic review of randomized controlled trails was performed

- The effectiveness of behavioral treatment for chronic low back pain was evaluated

- Behavioral treatment has a small positive effect on behavioral outcomes and a moderate positive effect on pain intensity

The authors thank Rob Scholten, PhD, for statistical advice.

\section{REFERENCE}

1. Almaier EM, Lehmann TR, Russell DW, Weinstein JN, and Kao CF. The effectiveness of psychological interwentions for the rehabilitation of low back pain: a randomized controlled trial evaluation. Pan 1992;49:329-35.

2. Andrasik F. Relaxation and biofecdback for chronic headaches. In: AD Holzman and DC Turk. Pain management: a handbook of psychological treatment approaches. New York, Pergamon Press Inc., 1986:213-39.

3. Asfour SS, Khalil TM, Waly SM, Goldberg ML, Rosomoff RS, and Rosomoff HL. Biofeedback in back muscle strengthening. Spine 1990;15:510-3.

4. Basler HD, Jakle C, and Kroner-Herwig B. Incorporation of cognitive-behavioral treatment into the medical care of chronic low back patients: a controlled randomized study in German pain treatment centers. Patient Education \& Counseling 1997;31:11324.

5. Begg C, Cho M, Eastwood S et a.. JAMA 1996:276:637-9.

6. Belar CD and Kibrick SA. Biofeedback in the treatment of chronic back pain. In: AD Holzman and DC Turk. Pain management: a handbook of psychological treatment approaches. New York, Pergamon Press Inc, 1986:131-50.

7. Bru E, Mykletun R, Berge W, and Svebak S. Effects of different psychological interventions on neck, shoulder and low back pain in female hospital staff. Psychology and Health 1994;9:37 1-82.

8. Bush C, Ditto B, and Feuerstein M. A controlled evaluation of paraspinal emg biofeedback in the treatment of chronic low back pain. Health Psychology 1985;4:30721.

9 Cohen MJ, Nalibol BD, and MCArthur DL. Implications of medical and biopsychosocial models for understanding and treating chronic pain. Crit Rev Phys Rehab Med $1989 ; 3: 135-60$

10. Dickersin $K_{\text {, Scherer }} \mathbb{R}_{\text {, and }}$ Lefebvre $C$ Identifying relevant studies for systematic reviews. Br Med J 1994;309:1286-91.

11. Donaldson S, Romney D, Donaldson M, and Skubick D. Randomized study of the application of single motor unit biofeedback training to chronic low back pain. J Occup Rehabil 1994:4:23-37.

12. Fonctyce WE. Behavioral methods for chronic pain and illness. St. Louis: Mosby, 1976.

13. Goossens MEJB, Rutten-van Mölken MPMH, Kole-Snijders AMJ, Vlaeyen JWS, van. Breukelen $\mathrm{G}$, and Leidl. R. Health economic assessment of behavioural rehabilitation in chronic low back pain: a randomised clinical trial. Heath Economics 1998;7/39-51.

14. Kendall NAS, Linton SJ, Main CJ. Guide to assessing psychosocial yellow flags in acute low back pain: risk factors for long-term disability and work loss. Wellington, New Zealand: Accident Rehabilitation and Compensation Insurance Corporation of New Zealand and the National Health Committee, 1997.

15. Kerns RD, Rosenberg R, Jamison RN, Caudill MA, and Haythornthwaite J. Readiness to adopt a self-management approach to chronic pain: the pain stages of change questionnaire (psocq). Pain 1997;72:227-34. 
16. Kole-Snijders AMU, Maeyen JWS, Goossens MEJB, Rutten-wan Molken MP. Meuts PH, van Breukelen $G$, wan Eek H. Clrotic low back pan: what does cognith coping shils traning add to operant behavional treatment? Resuls of a randomized clinical trial J Consulit Clin Psychol 1999;67:931-44.

17. Lindstrom ?. A succesful intervention program for patents with subacute low bnck pain. (Academic Thesis). Coteborg: Goteborg Umiversity, 1994.

18. Lindstrom 1, Ohund C, Eek C et al. The eflect of graded activity on patients with subacute low back pain: a randomized prospective chinical study with an operant. conditioning behavioral approach. Phys Ther 1992; $2: 279-93$.

19. Lindström 1, Ohlund C, Eek C, Wallin L, Peterson LE, and Nachenson A. Mobility. strength, and fitness after a graded activity program for patients with subaculow back pain. A randomized prospective clinical study with a behawional therapy approach. Spine $1992 ; 17: 641.52$

20. Lindström $I$, Öhlund $C$, and Nachemson A. Physical performance, pain, pain bellavior and subjective disability in patients with subacute low back pain. Scand $₫$ Rehab Med $1995 ; 27: 153-60$

21. Linton Su and Bradiey 1 A. An 18-month follow-up of a secondary prevention program for back pain: help and hindrance factors related to outcome maintenance. Clin I Pain $1992 ; 8: 227-36$

22. Linton Si, Bradley LA, Jensen I, Spangfort E, and Sundell L. "The secondary prevention of low back pain: a controlled study with follow-up. Pain 1989;36:197-207.

23. Linton Su and Hallden K. Can we screen for problematic back pain? A screening questionnatre for predicting outcome in acute and subacute back pain. Clin I Pain $1998 ; 14: 209-15$.

24. Linton SJ. Behavional remediation of chronic pain: A status teport. Pain 1986,24:12541 .

25. MoCauley JD, Thelen MH, Frank RG, Willard RR, and Caller KE. Hypnosis companed to relaxation in the outpatient management or chronic low back pain. Arch Phys Wed Rehabil 1983;64:548-52.

26. Mitchell RI and Carmen GM. The functional restoration approach to the treatment of chronic pan in patients with soft tissue and back injures. Spinc 1994;19:633-42.

27. Montey $S$, Eccleston $C$, and Willams A. Systematic review and meta-analysis of randomized controlled trials of cognitive behaviour therapy and behaviour therapy for chronic pain in aduits, excluding headache. Pain 1999;80:1-13.

28. Newton-John $\mathrm{TR}$, Spence $\mathrm{SH}$, and Schote D. Cognitive-behavioural therapy versus emg biofeedback in the treament of chronic low back pain. Behaviour Research so lincripy $1995,33: 691-7$.

29. Nicholas MK, Wilson PH, and Goyen J. Operant behavioural and cognitive-bohavionral weatment for chronic low back pain. Behav Res Ther 1991,29:225-38.

30. Nicholas $M K$, Wilson PH, and Goyen J. Comparison of cognitive behavioul group treatment and an alternative non-psychological treatment for chronic low back pain. Pain $1992 ; 48: 339447$

31. Nouwen A. Fing biofeedback used to reduce standing levels of paraspinal muscle tension in chronic low back pain. Pain 1983:17:353-60.

32. Roberts AH. The operant approach to the management of pan and excess disability lin: AD Holzmen \& Do Turk. Pan mangement: a handbook of psychologioal treatment approaches. New York, Pergamon Press, Inc, 1986.

33. Rose MJ, Reily JP, Pennie B, Bowen-Jones K, Stanley lM, and Slade PD. Chronic low back pain rehabilation programs: a study of the optinum duration of treatment and a comparison of group and individual therepy. Spine $1997,22: 2246-53$.

34. Rudy "TE and Turk DC. Cognitive-behavional treatment of the patient with chronic pain. In: AH White and JA Schoferman. Spine care: diagnosis and conservative treatment. Vol. One. St. Louis, Mosby Year Bowi, Inc., 1995.

35. Spizer WO, LeBlanc FE, and Dupuis ME. Scientific approach to the assessment and management of activity-tated spinal disorders. Spine 1987;7 (Suppl.) 1-59.

36. Strong J. Incorporating cognitive-behavioral therapy with occupational therapy: a comparative study with patients with low back pain. J Occup Rehabil 1998;8:61-71. 
37. Stuckey $\mathrm{SJ}$, Jacobs $A$, and Goldfarb J. Emg biofedback training relaxation trainings and placebo for the relief of chronic back pain. Percept Motor Skills 1986;63:1023-36.

38. Turk DC and Flor H. Eviological the ories and treatments for chronic back pain. II. Psychological models and interventions. Pain 1984; 19:209-33.

39. Turk DC, Okifuji A, Sinclair JD, and Starz TW. Differential repsonses by psychosociall subgroups of fibromyalgia syndrome. Arthritis Care Res 1998;11:397-404

40. Turk DC, Rudy TE, and Sorkin BA. Neglected topics in chronic pain treament outcome studies: determination of success. Pain $1993 ; 53: 3-16$.

41. Tumer JA. Educational and behavioral interventions for back pain in primary care. Spine 1996,21:2851-9.

42. Tumer JA and Chapman CR. Psychological interventions for chronic pain: a critical review. I. Relaxation training and biofeedback. Pain 1982;12:1-21.

43. Turner JA and Chapman CR. Psychological interventions for chronic pain: a critical review. II. Operant conditioning, bypnosis, and cognitive-behavioural therapy. Pain. $1982 ; 12: 23-46$.

44. Turner JA and Clancy S. Comparison of operant behavioral and cognitive-behavioral group treatment for claronic low back pain. I Consult Clin Psychol 1988;56:261-6.

45. Turner JA, Clancy $\mathrm{S}, \mathrm{McQuacle} \mathrm{KJ}$, and Candenas DD. Effectiveness of behavioral therapy for chronic low back pain: a component analysis. J Consult Clin Psychol $1990 ; 58: 573-9$

46. Turner JA and Jensen MP. Ericacy of cognitive therapy for chronic low back pain. Pain $1993 ; 52: 169-77$

47. Turner JA. Comparison of group progressive-relaxation training and cognitive-behavioral group therapy for chronic tow back pain. J Consult Clin Psychol 1982;50:757 65 .

48. van der Windt $D$, wan der Heijden $G$, van den Berg $S$, ter Riet $G$, de Winter $A$, and Bouter L. Ultrasound therapy for musculoskeletal disorders: a systematic review. Pain $1999: 81: 257-71$.

49. Tulder van MW, Assendelft WJ, Koes BW, and Bouter LM. Method guidelines for systematic reviews in the Cochrane Collaboration Back Review Group for Spinal Disorders. Spine 1997;22:2323-30.

50. Tulder van MW, Assendelft WJ, Koes BW, and Bouter LM. Spinal radiographic findings and nonspecific low back pain. A systematic review of observationall studies. Spine $1997 ; 22: 427-34$

51. Tulder van MW, Koes BW, and Bouter LM. A cost-of-illness study of back pain in The Netherlands. Pain 1995;62:233-40.

52. Tulder van MW, Koes BW, and Bouter LM. Conservative treatment of acute and chronic nonspecific low back pain. A systematic review of randomized controlled trials of the most common interwentions. Spine $1997,22: 2128-56$.

53. Vlacyen JW, Haazen IW, Schuerman JA, Kole-Snijders AM, and wan Eck H. Behavioral rehabilitation of chronic low back pain: comparison of an operant treatment, an operantcognitive treatment and an operant-respondent treatment. Br J Clin Psychol $1995,34: 95-118$.

54. Waddell G. A new clinical model for the treatment of low back pain. Spine 1987;12:632 44.

55. Williams AC, Pither CE, and Richardson PH. The effects of cognitive-behavioural therapy in chronic pair. Pain 1996;65:282-4. 


\section{Behavioral-graded activity compared with usual care after first-time disk surgery: Considerations of the design of a randomized clinical trial}

Raymond W.J.G. Ostelow, Albere J.A. Koke" , Anna J.H.M. Beurskens", Henrica C. W. de Vet: Maria R. Kerckhoffsab, Johan W.S. Wlaeyen" Pieter M.J.C. Wolters', Willem M. Berfelo", Piet A. van den Brandt

Affiliations of authors.

a Department of Epidemiology, Maastricht University.

Department of Physiotherapy, University Hospital Maastricht.

- Institute for Rehabilitation Research, Hoensbroek.

a Hogeschool Limburg, Department of Physiotherapy, Hecrlen.

- Department of Neurosurgery, University Hospital Maastricht. 


\section{ABSTRACT}

Objective: To present the design of a trial on the effectiveness of a behavioral-graded activity model.

Design: Randomized clinical trial

Patients: Patients undergoing first-time lumbar disk surgery who still have low-back pain at the 6-week neurosurgical consultation.

Interventions: A patient-tailored behavioral-graded activity program that is based upon operant therapy. The key elements of this progtam are baseline measurements, goals setting, and time contingency. This program is compared with usual care in physiotherapy, which is pain-contingent.

Outcome measures: Primary measures are the patient's global impression of the effect and their functional status. Secondary measures are kinesiophobia, catastrophizing; pain, main complaint, range of motion, and relapses. The direct and indirect costs will also be assessed. The effect measures are rated before randomization and 3, 6, and 12 months later.

Discussion: Several trials have been conducted on the effectiveness on behavioral treatments. Subjects were always patients with chronic low back pain. In this trial, we apply such a treatment in patients after first-time disk surgery in a primary care setting.

Key Indexing Tems: Behavioral Treatment, Intervertebral Disk, Lumbar Vertebrae, Surgery, Physiotherapy, Randomized Clinical Trials. 


\section{INTRODUCTION}

\section{Why publish a design?}

Publishing the design of a study before the results are available has various advantages. First, it nay counteract possible publication bias: a study producing positive results seems more likely to be published than a study showng no difference between the study groups. 12. Therefore if the design is published but not the results the study can still be included in a systematic review becaldse data can be retrieved from the researcher. In addition, publishing the design of a study before the results are available provides the researcher (and the reader) an opportunity to reffect critically on the design of the study, irrespective of the results. When results are contrary to the expectations of the researcher, methodologic flaws are examined; however, if results are in line with the expectations of the researchers, methodologic flaws are more likely to be overlooked. ${ }^{2}$ Furthermore, this article can elaborate on the interventions and theoretic background more extensively than in the methods section of an article reporting the results of a study. This difference is of interest to caregivers, who can learn about the intervention in detail, which is especially useful if the intervention is complex or if caregivers are not or not yet familiar with the intervention. In this article, we describe the design of randomized clinical trial on the effect of a behavioral treatment applied by physiotherapists in patients with low-back pain after first-time lumbar disk surgery. This therapy is not or not yet widely used to treat these patients. We then discuss the background of the study and the methodologic choices.

\section{First-time lumbar disk surgery}

In the Netherlands 10,000 surgeries are performed each year because of lumbosacral radicular syndrome, which is based on a herniated lumbar disk. The success rate in the literature varies from $60 \%$ to $90 \%, 4-10$ meaning that despite surgery, in $10 \%$ to 40 $\%$ the results are unsatisfactory and symptoms persist. These persistent symptoms mainly consist of pain, motor deficits, and a decreased functional status. In $2 \%$ to $19 \%$ of all the patients who underwent surgery, a recurrent hemiated lumbar disk occurs, $74 \%$ of which within 6 months after their first surgery. ${ }^{11,12}$ If patients still have these symptoms despite the surgery, they are often referred to physiotherapy.

\section{Theoretic madells of pain}

The biomechanic model assumes a causal relationship between tissue damage and pain. However, the definition of pain given by the International Association for the Study of Pain 1.3 states that tissue damage is not a necessary condition for pain to occur. The biopsychosocial model, in a significant distinction, holds that when dealing with pain, the complex interaction between biologic, psychologic, and social entities of patients may be greatly important. Both models can be applied to explain the unsatisfactory results of lumbar disk surgery. 
The biomechanic model of disease

The biomechanic model of disease mainly focuses on somatic issues. The (traditional) biomechanic model is based on the idea that a physical pathologic condition leads to pain and disability. Clinical recognition and diagnosis of the underlying pathologic condition provide the basis for rational physical treatment of the illness. For example, Kahanovitu al " and Mayer et alls looked at the changes in back muscles caused by the surgery and found that these changes may contribute to problems after surgery. In particular, muscle strength and encurance are considered to prevent the occurrence of low-back pain ${ }^{16}$ is Furthermore, intraoperative complications le.g. dural tears, level errors or root damagel may indicate poor prognosis. However, even in research that focuses on these somatic issues, there are indications that psychologic, social and financial factors may be important in the maintenance of persistent symptoms. 19

\section{The biopsychosocial modet}

The more recently developed biopsychosocial model emphasizes the role of psychologic and social factors in the development and maintenance of symptoms. Since Fordyce 20 introduced the biopsychosocial model, this new framework has gained interest in the field of chronic low -back pain. The complex interaction among biologic, psychologic, and social entities of patients may also be import in how patients respond after their first-time disk surgery. ${ }^{20-22}$ The biopsychosocial approach is based on the behavioral equation Stimulus-Organism-Response-Consequences (SORC) (Fig. 1).22 "R" is the problematic behavior, such as pain. The other components represent controlling variables of which the response $(\mathbb{R})$ is a function. The immediate environmental. variables are represented as "S" (the internal or external stimuli that precede $R$ ) and "C" (the consequences that follow R). "O" represents the biomedical variables. Within such a biopsychosocial approach, the causes or maintaining factors of behavior in terms of explicit environmental events are objectively identified and manipulated. The equation represents not a static but a dynamic system in which consequences provide new stimuli for subsequent SORC chains. Currently, pain is defined as a sensory and an emotional experience. Emotions are typically subjective, never observable in themselves, and can only be inferred by their effects at some observable level, such as psychophysiological reactivity, cognitions (c.g. beliefs about pain and pain control), and overt pain behaviors. Pain behaviors are sensitive to social consequences. When expressed by the patients, desirable things can happen (positive reinforcement) and unpleasant situations can be avoided (avoidance learning). By means of these environmental influences, pain disability can be maintained long after healing has occurred.2124 


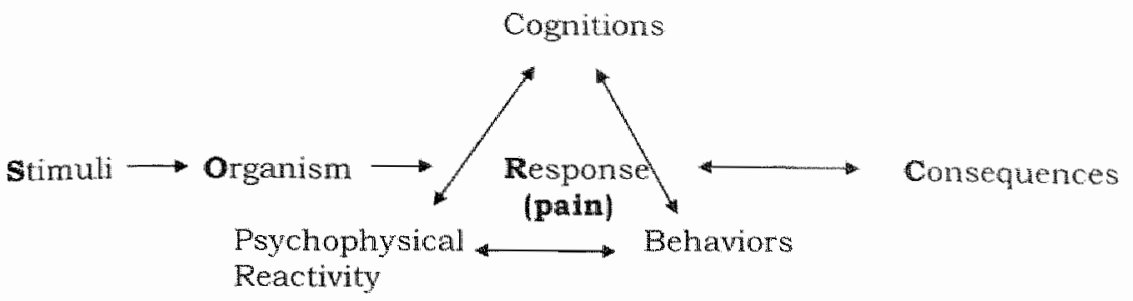

$\begin{array}{llll}\mathbf{S} & \mathbf{O} & \mathbf{R} & \mathbf{C}\end{array}$

Figure 1. The SORC Model applied to panz2.

\section{Treatment of first-time lumbar disk surgery patients}

Treatment of patients after lumbar disk surgery has been considered important for more than 3 decades. ${ }^{25}$ The content of the treatment ranges from advice, to normal physical training to total rehabilitation programs. ${ }^{7,25 \cdot 27}$

\section{Biomechanic model of disease}

In the Netherlands, physiotherapists are taught the biomechanic model of disease, which assumes a causal relationship between tissue damage and pain. Therefore pain. (or the reaction of patient on the previous treatment) is used as a guideline to determine the intensity of the exercises and the advice about activities in daily living (ADL). In general, usual care in physiotherapy has 3 main components: the reduction of pain, exercises that use pain as a guideline to determine the intensity of the exercises, and advice on ADL and work (again with pain as a guideline). A bionechanic approach like this might lead to pain behaviour. 2 s:

\section{Biopsychosocial model}

Treatments according to the principles of the biopsychosocial model often are referred to as cognitive-behavioral therapy. Based on this model, 3 treatment modalities have been proposed (Fig 1). First, cognitive treatment attempts to decrease distorted ways of thinking about pain and increase feelings of self-control with cognitiwe coping strategies. Second, the respondent treatment trains the patient to apply relaxation skills to reduce psychophysiologic reactivity to personal stressors. Third, operant therapy attempts to increase health behaviors with graded activity and positive reinforcement, thereby attempting to decrease pain behaviors and increase tolkrance levels, 20.24 From this perspective, chronic low back pain in general is approached differently. The guideline is not pain for the reaction on the previous treatment of the patient) but the functional abilities of the patient. The behavioral-graded actiwity program assessed in this study is an operant therapy in which principles developed for the treatment of chronic low-back pain are applied to patients after first -time disk surgery. 


\section{Discussion}

\section{Aim of this study}

In this study, we aim to assess the effectiveness of a behavioral-graded activity program compared with usual care, in patients who still have low-back pain 6 weeks after first-time disk surgery. Thus we assess the behavioral-graded activity not in patients with chronic low-back pain, but in patients with a new start in their low-back pain episode who had not yet recovered. These patients might be considered as being on the threshold of becoming patients with chronic low-back pain. 29

\section{Study design}

The effectiveness of the behavioral-graded activity in comparison with usual care in patients who underwent a first-time disk surgery will be assessed in a randomized clinical trial. The study protocol was approved by the Medical Ethics Committee of the University Hospital Maastricht. Fig 2 shows the outline of the study.

\section{Selection of patients and informed consent}

Patients with low-back pain and/or sciatica are referred to a neurosurgeon. If surgery is indicated, the status of the patient, including duration of symptoms, pain, motor or sensitivity deficits, reflexes and the findings on a magnetic resonance imaging or radiography, is documented before the surgery. The policy of participating hospitals in the south of the Netherlands requires that after surgery, the patient is typically hospitalized for 3 to 5 days. In this period, the hospital physiotherapist teaches the patient low-back exercises and how to resume functions of normal daily lining. The patient is advised to resume normal activities as soon as possible. Only patients with an antalgic posture, serious motor deficits, and/or the need for a prescription analgesics will be referred to a physiotherapist immediately after discharge from hospital. Each patient will then be seen by the neurosurgeon again after 6 weeks. Patients who still have symptoms that restrict their A.D.L. and/or work are referred to a physiotherapist. These patients are informed about our randomized clinical trial by the neurosurgeon. If they show interest, they are contacted by the research assistant. This experienced physiotherapist (MRK) explains the goal of the study and the implications of participating and checks the eligibility of the interested patient. Patients are inchuded if they are aged between 18 and 65 years; undergo first-time disk surgery at only one level; have symptoms (pain) that restrict their normal daily living and/or work; and are willing to acopt the consequences of participating. Patients are excluded if they experience complications during surgery, which is judged by the neurosurgeon based on preset criteria. These patients may have a worse prognosis than patients who undergo the surgery without complications. In addition, patients with confirmed and relevant underlying diseases that influence ADL fe.g. stenosis, malignancies) are excluded. Patients are also excluded if one of the treatments is contraindicated (e.g. respiratory complaints). If a patient meets the selection criteria and is willing to participate, the informed consent procedure is completed. 


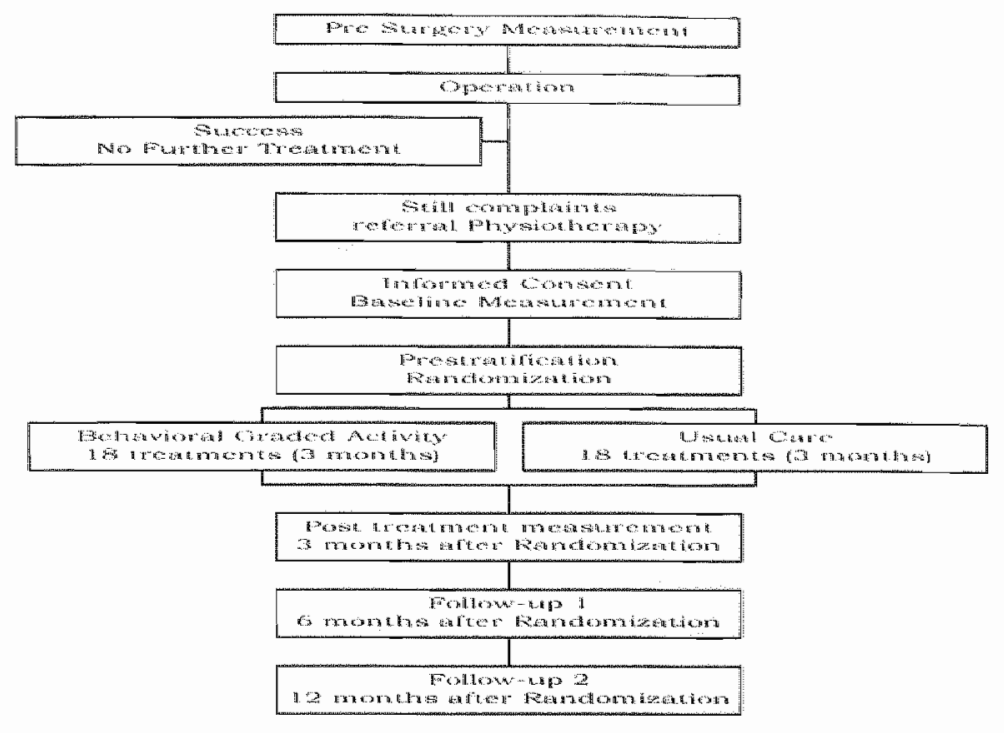

Figure 2. The study design.

\section{Sample size}

The study attempts to enroll 200 patients, with 100 patients per treatment arm. This sample size is sufficient to detect a $20 \%$ difference in recovery rate (Global Perceived Effect [GPE]) between the behavioral-graded activity program and the usual care. We think that a $20 \%$ difference is clinically relevant; this difference is statistically significant at $\alpha=0.05$ with a power (1-beta) of $80 \%$. To obtain this study size we are cooperating with 4 hospitals and 75 physiotherapists.

\section{Randomization}

An independent examiner prepared the envelopes by coding them according to a random computer-generated list. Although there is concealed randomization, an unequal distributions of prognostic factors over the two therapies may occur. To prevent this, we prestratified based on 2 important prognostic factors. The first prognostic factor was the duration of the symptoms before surgery (less than or longer than 3 months) as a measure of the chronicity of the low-back pain. The second prognostic factor was whether a patient has been referred to a physiotherapist immediately after surgery, which accounts for the severity of the symptoms. One method to prevent unequal treatment-group sizes is block randomization, 3 in in this study we chose blocks of four. After every 4th patient, the distribution per stratum of patients aljocated to both therapies is equal. If a patient meets alj criteria she/he will be handed an opaque, sealed and coded envelop prepared by an independent examiner. In this envelope, there is a list of the names of all physiotherapists who perform the allocated therapy. The principal investigator (ROI contancts the patient by telephone to determine which physiotherapist is most easily accessed by this patient and ensures that the patient starts therapy as soon as possible after randomization. 


\section{Blinding}

By using these opaque envelopes the research assistant who performs all measurements is blinded to the allocated treatment. The patients are blinded to a certain extent because they are unaware of the exact content of both treatments; these patients may also be termed naive to the content of the treatment not received. The physiotherapists are not blinded but are not inwolved in the effect measurements.

\section{Interventions}

\section{Behavioral-graded activity}

The behavioral-graded activity program in this study is an operant therapy based on the principles of the biopsychosocial model. Operant therapy attempts to increase health behaviors with graded activity and positive reinforcement, thereby decreasing pain behaviors, 20,24 The term "behavioral-graded activity" for this program emphasizes the behavioral component rather than merely the physical training principles. The treatments are given by physiotherapists in an outpatient setting, which is common in the Netherlands. Before the start of the study, therapists followed a practical training course in this approach and were updated on course of the research project.

Behavioral-graded activity is based on contingency management as described in more detail by Fordyce 20 and Fordyce et al.31 and applied by Lindstrom. ${ }^{32}$ The essence of this program is to develop an individually graded exercise program to teach the patient that it is safe to move while increasing the level of activity. What is important in the program is that the level of activity is based on the baseline measurements, which are performed at the start of the program.. The program starts with two main complaints as reported by the patient (see effect measurements). The main complaints of the patient are activities that are important to the patient and cannot be avoided. First, the patient is asked to perform these activities during the initial baseline measurements until the patient has to stop because of pain. After these baseline measurements, the patient sets his or her individual treatment goals for this activity. The therapist acts only as a coach in this goal-setting, because it is important that the goal is the patient"s internal goal. Starting from baseline and knowing the treatment goal, quotas can be set on time-contingent principles. Then quotas are systematically increased to enable the patient to reach his or her preset goal within 3 months (18 sessions of 30 minutes eachl of therapy. The quotas should always be exactly followed, neither overperformed nor underperformed. Thus there is a shift from the pain-contingency (baseline) to timecontingency (quotas) management. The first quotas are slightly lower than baseline level to ensure that the first experience of the patient while performing the exercises is successful. Successful completion of the quotas will enhance the patient"s motivation: positive reinforcement is a key principles in the operant conditioning theory. In total, the therapist strives to implement 5 activities or exercises in the program, depending on the patient's wishes and needs. In this way, a patient-tailored, individual behavioral-graded activity program is developed. During the program, a patient must practice at home. As a general rule, all activities or exercises must be practiced at least once a day. Every activity or exercise is documented by the patient on a performance chart. These performance charts are discussed with the physiotherapist, and the patient is reinforced for achievements, disregarding pain behaviors. To facilitate the generalization of change in behavior to the home situation, partners are invited to attend some therapy sessions with the patient to gain clear insight into the rationale behind the therapy. If a patient has difficulty performing the desired activity, the 
physiotherapist uses another strategy: shaping. Shaping is "developing a new behawior by reinforcing successive approximations toward the terminal response", sa This strategy is based on relearning well behariors. 34

An example of the behavioral-graded activity approach is shown in Fig 3. Suppose walking is one of the main complaints of the patient. The baseline measurements show an average at which the patient is forced to stop because of pain. After determining this baseline, the patient sets his or her goal for this particular activity. The quotas can then be increased for each session to reach the pre-set goal, starting below baseline level.

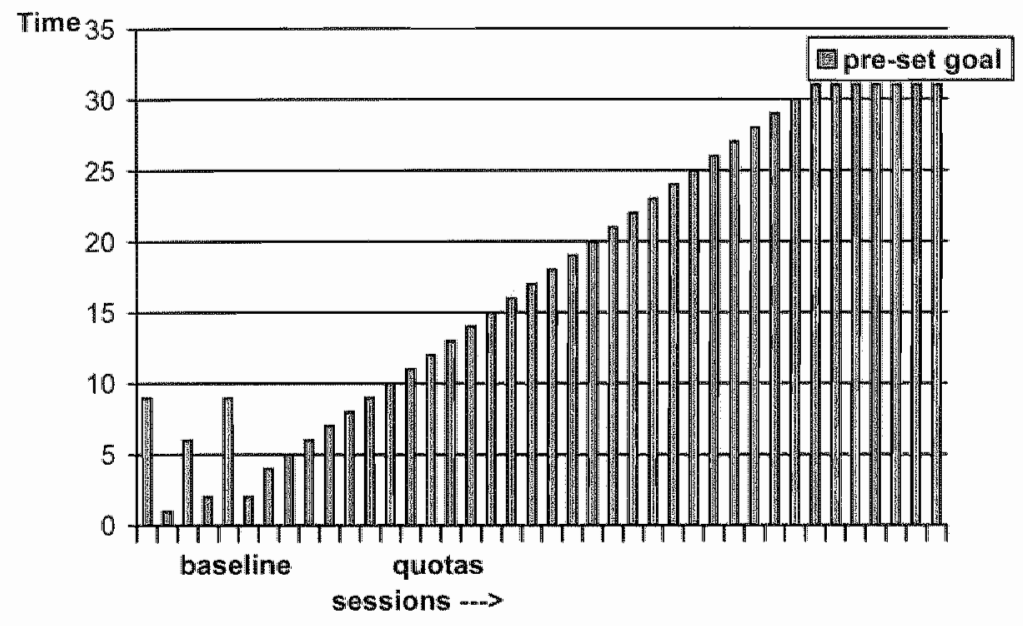

Figure 3. Walking in B Behavional-Graded Activity program. Time, Walking time, Dastine. baseline measurement; pre-set goal, patients goal for tme he wants to walk; guotas, time contingent, gradually increased quota"s towards the pre-set. goal.

\section{Usual care}

Usual care in this study is based on the biomechanic model. As a concept, usuall care within physiotherapy is difficult to grasp if examining the individual techniques being used in everyday practice. In usual care, pain is the guideline for therapy. The choice of application and/or exercises strongly depends on the level and severity of the pain. In a survey in the United Kingdom, the most commonly reported modalities were symptomatic treatments. 55 If a patient reports a strong reaction after the previous treatment (eg, pain), the intensity of therapy will be reduced until the patient is able to withstand a higher intensity again. This model is described in the Guidelines of the Dutch Association of Physiotherapy (KNGF).36 After extensive interviews and discussions with the physiotherapists in the usual care group, we reached consensus about the categories of treatment goals. The most frequently named goals ror the treatment of this particular population are listed in Table 1. The exact techniques used for each treatment goal differ tremendously within and among physiotherapists. Therefore operationalization to the extent of individual techniques is not possible and 
not desirable. We think that when inwestigating usuall care for a specific population the whole spectrum of treatments used by physiotherapists for this population should be included. On the other hand, techniques are limited to only "usual" techniques (in physiotherapy), with the exclusion of acupuncture, osteopathic techniques and other alternative techniques. The techniques allowed are also listed in Table 1 . Specific operant-behavioral components are not allowed. There are 18 sessions of 30 minutes duration within a period of 3 months. Contrary to behavioral-graded activity, usual care physiotherapists are allowed to stop treatment when a patient no longer has symptoms and the treatment goals have been reached. This fits the principles of usual care.

Table 1. Treatment gaals and used techniques/exercises in usual care.

Treatment Goals

MDL-thaining, optimize physical finess, optimize munc/jont mobility, optinize muscle strength, optimize muscle length, optimize muscte tonus, optimize stability trunk muscles, combat pair.
Techniques/exercises

Back Specific Instuction/education, ADL training program, manipulations, mobility and strength exercises, stability exercises, massage, wamm (packages de ultra short wave) and other rodalities

ADL. Activites of daily living.

\section{Contrast between interventions}

The contrast between both interventions is an important issue in this study because both interventions are performed by a physiotherapist. However, there are some important features that are responsible for the contrast. First, behavioral-gradled activity is based on systematically performed baseline measurements. Usual care is based on anamnesis and physical examination of the patient. In addition, in behavioral-graded activity the management is time-contingent once quotas have been set. Usual care evaluates the reaction of a patient to the previous treatment and possibly adapts the therapy based on this evaluation, which is pain-contingent. Furthermore, in behavional-graded activity, specific behavioral components are used, including a performance chart, systematic reinforcement of health behaviors and extinction of pain behaviors, and specific goal setting by the patient. Thus what is done in both interventions can be the same (ie, exercises) depending on the patient, but how it is done makes the difference between behavioral-graded activity and usual care.

\section{Integrity check}

On a random basis, a whole treatment program of both interventions will be recorded on audiotapes. The first author (RO) and an independent, blinded expert will examine a sample of these recordings to determine if the treatments have been performed as described. In addition, quality assessment will be conducted based on the characteristics of the treatments (pain-contingent vs. time-contingent).

\section{Prognostic varlables and outcome measurements}

In a recent consensus meeting in the Netherlands on the lumbosactal radicular syndrome, the lack of reliable clinical measurements was made clear. ${ }^{19}$ The guidelines 
on sciatica recommend mainly range of motion and Lasegues sign ${ }^{37}$ for control measurement in normal practice, which will be scored in our baseline measurement. However, in our opinion these are not the most appropriate and sensitive methods for measuring improvement in clinical research. It is known that all kinds of clinical findings correlate poorly with the disability level of a patient, $2,3 s ;$ Therefore this study mainly focuses on patient-tailored disability measurements. The primary outcome measures are the most relevant for the patient and clinician. In addition, our measurements focus on some of the aspects that may be of great importance to the biopsychosocial model, the secondary outcome measures, which reflect on the complex interaction among biologic, psychologic, and social entities. Furthermore, we will assess the costs. Table 2 gives an overview of the data collection.

\section{Prognostic variables}

The status of the patient before surgery (Table 2, patient and lumbosacrall radicular syndrome characteristics) in terms of duration of symptoms, pain, motor or sensitivity deficits, reflexes and the findings on magnetic resonance imaging or radiography will be assessed.

Negative affectivity is measured by the Negative Emotionality (NEM) subscale, a. 25 item, 2 point subscale of the Multidimensional Personality Questionnaire, ${ }^{41,42}$ that quantifies positive (llow NEM scores) and negative affect (high NEM scores) of the patient. Bradbum is cited by Costa $\&$ McCrae 4 in reporting that positive affectivity is associated with social interest, sociability and activity, whereas megative affectivity correlates with psychosomatic symptoms, anxiety, worries and poor role adjustment. The NEM was preferred to other instruments because it does not contain items reflecting bodily or somatic symptoms, which might influence the score.

Expectancy is measured as described by Vlaeyen et alth and modified after Borkovec 8 Nau. 45 After 2 treatments, the patients will be contacted and asked to what extent they believe that this specific treatment is beneficial to them. After these 2 treatments, the patients had sufficient information to score expectancy based on their perception of the treatments and not simply their idea about them, which would be the case when expectancy would be measured before treatment. Expectancy will be scored on a 10 point scale, where 0 = the patient has no expectancy at all that he will benefit from this treatment and $10=$ the patient is absolutely convinced of the benefit. Besides its use as an assessment of the prognostic value, expectancy will be used to compare the level of credibility between the 2 groups at the start of therapy. "Thus we can check to what extent the patients were naive (see earlier discussion blinding)

\section{Outcome measurements}

\section{Primary outcome measures}

Global Perceived Effect (GPE) is measured by self-assessment on a 7 point scale (1 = completely recovered and $7=$ worse than ever). From the viewpoints of both patients and clinicians, asking patients to assess their perceived benefit is sensible.

Low-back specific functional status is measured by the Roland Disability Questionnaire (RDQ), which has shown to be useful $4 \%$.50 The Dutch translation has proved to be a valid instrument that is sensitive to change over time. 51,52 
Table 2. Overvisw of data collection o messurement.

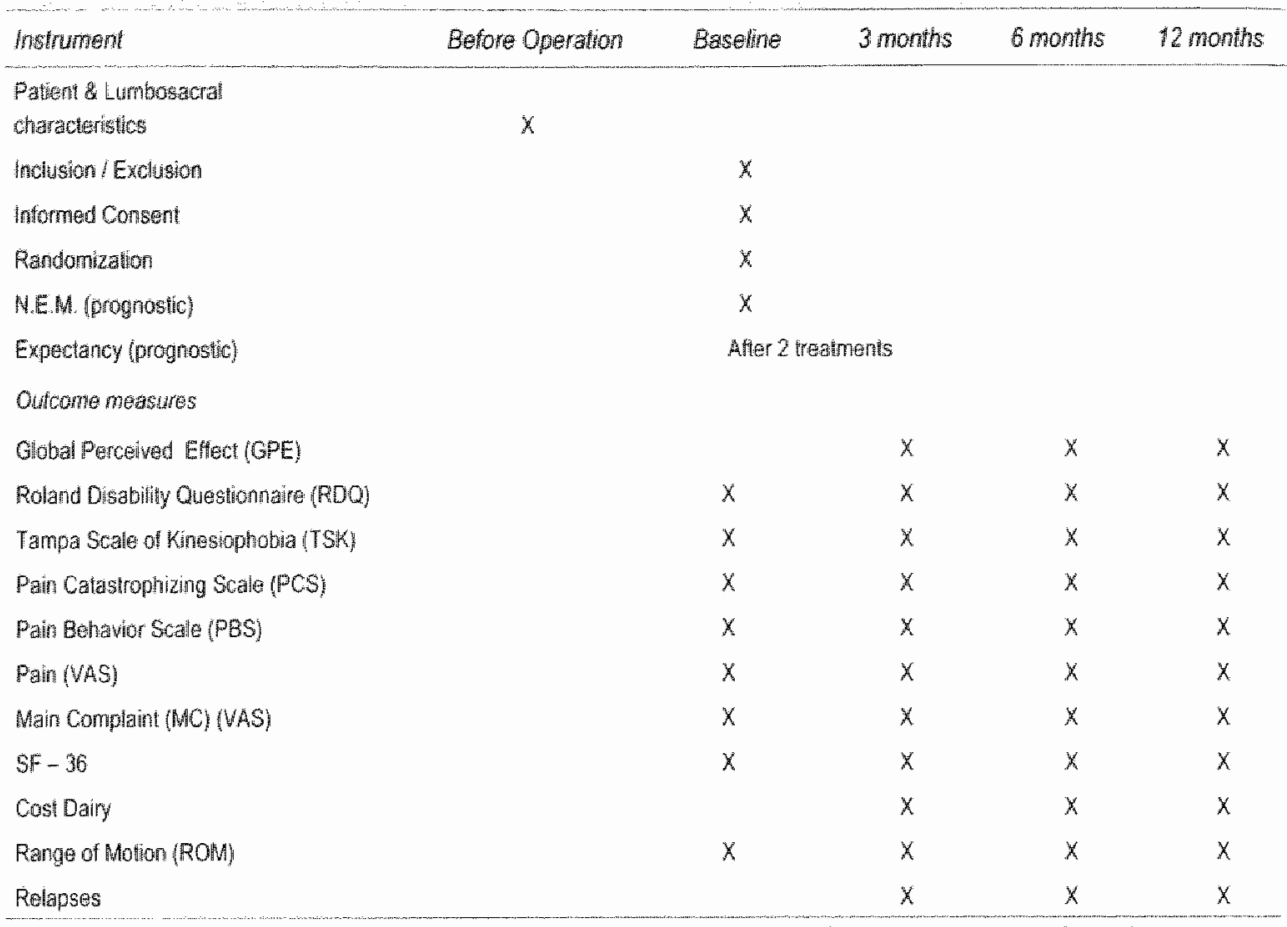

NEM, Negative Emotionality. VAS, Visival Analogue Scale; SF.36, Short Form 36 Questronnatre.

\section{Secondary outcome measures}

Fear of movement is measured by the Tampa Scale for Kinesiophobia (TSK). 53 Kori et al $^{54}$ introduced the term "kinesiophobia" to describe the condition in which a patient has an excessive, irrational and debilitating fear of physical movement and activity resulting from a feeling of vulnerability to painful injury or reinjury. The TSK consists of 17 items, each rated on a 4 -point Likert scale. The Dutch translation has fair and consistent internal validity, 55,56

Pain catastrophizing is measured by the Pain Catastrophizing Scale (PCS).57 A patient is said to catastrophize pain, when he or she views pain as extremely threatening ${ }^{4}$ Catastrophizing is considered a maladaptive belief that may intensify pain, depression, and fear. 38

Pain behavior is measured by the Pain Behavior Scalle (PBS). The PBS was originally an obserwation scale scoring 10 pain behaviours with 3 -point scales. 59 The ratings of 8 behaviours can be obtained after a relatively short observation time. For these items, excellent reliability coefficients are found. Rating of 2 other behaviors ("clown time" and "medication use") is only possible after at least 1 day of observation. These items showed poor reliability coefficients and were removed from the scale, resulting in improved internal consistency. Validity of both, the 8-item PBS and the Dutch version proved to be sufficient. 
Pain intensity of the low-back or the leg will be scored on a Visual Analogue Scale (VAS). The relevance, wallidity and reliability of the VAS are commonly accepted for lowback pain. 61.63

The Main Complaint (MC) ${ }^{64}$ will be selected by the patient at baselne in a standardized way. The patient selects 2 frequently performed activities that are important in his or her daily life but which are difficult because of low-back pain. The severity will be scored on a VAS. 51

Health status will be evaluated by the short-form 36 (SF-36). 65 The Dutch translation by van der Zee et al ${ }^{66}$ showed satisfactory validity and reproducibility.

Costs will be evaluated with cost dairies. 67 These are kept up to date by the patients. In this way, costs can be calculated and include additional therapies, drug use, visit to health care providers, out-of-pocket expenses, and paid help. In addition, costs that refer to the value of production lost to society because of low-back pain-related absence from work or days of inactivity at home can be calculated.

The range of motion in flexion and extension of the lumbar spine is measured by the Cybex Electronic Digital Inclinometer-320 (EDI-320). The reproducibility of this instrument proved to be satisfactory especially for flexion. 6870

Relapses of low-back pain and reoperations are evaluated during the 12 -month followup period.

\section{Analysis}

Baseline comparability will be performed by descriptive statistics to examine if randomization was successful. If necessary, adjustments for prognostic inequalities will be performed. Before these analyses are done, all decisions about which deviations are considered as serious protocol deviations will be made. Differences between baseline measurement and follow-up will be calculated for every individual and will be compared between the 2 treatment groups. Group differences and $95 \%$ confidence intervals will be calculated for all outcome measures. Then statistical analyses will be performed according to the intention-to-treat principle, meaning that patients will be analyzed in the treatment group to which they were randomly allocated. In addition, a per-protocol analysis will be performed. This means analyzing only those patients with no serious protocol deviations. Comparing the results of the intention-to-treat and the per-protocol analysis will indicate to what extent protocol deviations might have biased the results. Regression analyses will be conducted both to adjust for baseline differences and to study the influence of the prognostic variables and patient characteristics on the outcome.

\section{CONCLUSION}

This article describes the design of a randomized clinical trial. In addition to the method, the interventions were highlighted because a behavioral approach is not or not yet widespread, certainly not for patients after surgery. However, many trials have been conducted concerning behawioral treatment in low-back pain. ${ }^{71}$ Most subjects were patients with chronic low-back pain symptoms lasting 6 months or longer. This is justified by the working mechanism of behavioral therapy, which is focused on issues 
that are prevalent in chronic pain patients. In this study, we are interested in whether a behavioral approach is also effective when applied to patients undergoing frrstume disk surgery, who still have symptoms at their 6 weeks neurologic consultation.

There are some concluding remarks concerning the method. We did not choose a waiting list control group because the medical ethics committee considered it not appropriate to withhold treatment from patients who had been waiting for recovery for 6 weeks. Patient blinding is a validity criterion in most reviews, which is not possible in this trial. The best avallable alternative is to check whether both interventions have the same credibility to patients. This will be compared by the expectancy that patients in both groups have about the therapy after 2 sessions. Equal distribution of expectancy between both intervention groups will be regarded as similar credibility for both interventions. Blinding of outcome measurement is another issue. Currenty, many people advocate the use of patient-specific measurement because they are considered the most appropriate and sensitive for measuring improvement in clinical research. 21,38 . $40,50,51$ The advantage is that these outcome measures are the most relevant for the patient and clinician. The disadvantage is that blinding is difficult because the patient must complete the questionnarres.

In this study, we choose to implement the behavioral-graded activity program for primary cate physiotherapists, where other studies often use in-patient programs or a hospital-based approach. The advantage to this approach is that if the behavioralgradled activity program proves more effective than the usual care, it can be implemented in the daily practice of the physiotherapist because this is context of the research project. A prerequisite, however, is that the physiotherapists receive sufficient: training in the behavioral techniques. However, if the program does not prove to be better than usual care the question remains whether the program will have been conducted in an adequate manner. To investigate this question we will analyze the audiotapes.

\section{REFERENCES}

1. Wastbrook PJ, Berlin JA, Gopalan R, Matthews DR. Publication bias in clinical research. Lancet 1991;337:867-872.

2. Dickersin $K$. The existence of publication bias and risk factors for its occurrence. JAMA $1990,263: 1385-1389$.

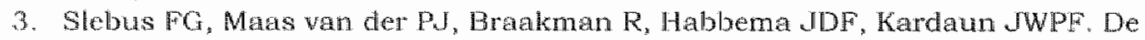
electiviteit van beeldvormende diagnostiek en chirurgie bij de lumbale hernia nuclei pulposi. Rotterdam: Rapport aan het Ministerie van WVC; 1989 april 1989.

4. Kortes DS, Loupassis $\mathrm{G}$, Stamas $\mathrm{K}$. Results of lumbar discectomy: a study using 15 diferent evaluation methods. European Spine Journal 1992;1:20-24.

5. Barrios C, Ahmed M, Arrotegui JI, Bjornsson A. Clinical factors predicting outcome after surgery for herniated lumbar disc: an epidemiological multivariate analysis. II Spinal Disord 1990;3:205-9.

6. Pappas CTE, Harrington T, Sonntag VKH. Outcome analysis in 654 surgically treated tumbar disc herniations. Neurosurgery 1992;30:862-66.

7. Smulders WLM, Loon wan G. Nabehandeling na lumbale discectomie of chemonucleolyse. Een 'out-patient' enquete. Fysiopraxis 1993:4-6.

8. Hurme M. Alaranta H. Factors predicting the result of surgery for lumbar intervertebral disc herniation. Spine $1987 ; 12: 933 \sim 8$. 
9. Manniche $\mathrm{C}$, Asmussen $\mathrm{KH}$, Winterberg $\mathrm{H}$, Rose Hansen $\mathrm{EB}$, Kramhoft J. Jordan $\mathrm{A}$. Back pain, sciatica and disability following firstime conventonal haemilaminectomy for lumbar disc herniation. Use of "Low Back Pain Rating Scale" as a postal questionnaire. Dan Med Bull 1994;41:103-6.

1.0. Manniche C. Asmussen KH, Vinterberg H, Rose Hansen EB. Kramoft J, Jordan A. Analysis of preoperative prognostic factors in first time surgery for lumbar dise herniation, including Finneson's and modified Spengler's score systems. Dan Med Bull $1994 ; 41: 110-5$.

11. Connolly ES. Management of persistent or recurrent symptoms and signs in the postoperative lumbar disc patient. Neurosurg Chn N Am 1993:4:161-6.

12. van Burken MMG, Senders EACM. Goede resultaten van heroperatie wegens terugkerend radiculair syndroom na een HNP operatie. Ned Tijdschr Geneeskd $1992 ; 136: 692-95$.

13. Intemational Association for the Study of Pain SoT. Classification of chronic pain syndromes and defintions of pain terms. Pain 1986; supplement 3:s1-5225.

14. Kahanovitz N, Viola K, Gallagher M. Long-term strength assessment of post-operative discectomy patients. Spine 1989;14:402-3.

15. Mayer TG, Mooney $\mathrm{V}$, Gatchel RJ. Quantifying postoperative deficits of physical functioning following spinal surgery. Clin Orthop $1989 ; 244: 147-57$.

16. Biering Sörensen F. Physical measurements as risk indicators for low-back trouble over a one-year period. Spine $1984 ; 9: 106-19$.

17. Cassisi JE, Robinson ME, O'Conner P, MacMillan M. Trunk strength and lumbar paraspinal muscle activity during isometric exercise in chronic low back pain. Spine $1993 ; 18: 245-251$.

18. Roy SH, DeLuca DL, Casavant DA. Lumbar muscle fatigue and chronic lower back pain. Spine 1989;14:992-1001.

19. CBO. Consensus: Het lumbosacrale radiculare syndroom. consensusbijenkomst. Utrecht: CBO 1995.

20. Fordyce WE. Behavioral methods for chronic pain and illnesis. St. Louis: Mosby; 1976.

21. Waddell $G, 1987$ Volvo award in chinical sciences. A new clinical model for the treatment of low-back pairn. Spine 1987;12:632-44.

22. Vlaeyen JWS. Chronic low back pain: assessment and treatment from a behavioral rehabilitation perspective. Lisse: Swets \& Zeitlinger; 1991.

23. Philips HC. The effects of behavioral treatment on chronic pain. Behav Res Ther $1987 ; 25: 365-77$.

24. Vlaeyen JW, Haazen IW, Schuerman JA, Kole Snijders AM, Eek van H. Behavioral rehabilitation of chronic low back pain: comparison of an operant treatment, atn operant-cognitwe treatment and an operant-respondent treatment. Br al Clin Psychol $1995 ; 34: 95-118$

25. Hansen JW. Postoperative management in lumbar dise protrusions. Acta Orto Scan 1964;71 (suppli) 1-47.

26. Oerlemans HM. Fysiotherapie na een lumbale laminectomie. Ned Tijdschr Fysioth $1988 ; 98: 245-251$.

27. Noordzij CM, Dolder van R. Fysiotherapeutische begeleiding van geopereerde HNP. patienten. Ned Tijdschr Fysioth 1991;101:160-2.

28. Linton S.J. Hellsing AL, Andersson D. A controlled study of the effects of an early intervention on acute musculoskeletal pain problems. Pain 1993;54:353-9.

29. Sicientific approach to the assessment and management of activity-related spinal. disorders. A monograph for clinicians. Report of the Quebec Task Force on Spinal Disorders. Spine 1987:s1-59.

30. Roberts C. Torgerson D. Understanding Controlled Trials. Randomisation methods in controlled trials. BMU 1998;317:1301. 
31. Fordyce WE, Fowler RS, Lehmann JP, Delateur BJ, Sand PL, Trieschmann RB. Operant. conditioning in the treatment of chronic pain. Arch Phys Med Rehabil 1973;54:399. 408.

32. Lindström I, Ohlund C, Eek C, Wallin L, Peterson LE, Fordyce WE, et al The effect of graded activity on patients with subacute low back pain. Phys Ther 1992,72:279-93.

33. Kazdan AE. Behavior modification in applied settings. Dorsey Press 1980.

34. Vlaeyen JWS, Groenman NH, Thomassen J, Scheurman JA, Eek wan H, Snijders AMJ, et al. A Behavioral Treatment for Sitting and Standing Intolerance in a Patient with Chronic Low Back Pain. Clin I Pain 1989;5:233-7.

35. Peat GM, Sweet CA. Does prewious physical therapy contribute to self-reported disability in chronic low back pain? J Back Musculosk Rehabil 1997;9:29-33.

36. Wees van der PJ, editor. Beroepsprofiel Fysiotherapeut. Kon Ned Genootschap Fysioth. Amersfoort Houten: Bohn Stafleu Van Loghum; 1998.

37. Smeele lJM, Hoogen van den JMM, Mens JMA, Chavannes AW, Faas A, Koes BW, et al NHG-Standaard Lumbosacraal Radiculair Syndroom. Huisarts en Wetenschap $1996 ; 39: 78-89$.

38. Johanssen F, Remvig L, Kryger $\mathrm{P}$, Beck P, Warming $S$, Lybeck $K$, et al. Exercises for chronic low back pain: a clinical trial. Joumal of orthopaedics and sports physical therapy 1995:22:52-9.

39. Mellin $\mathrm{G}$. Correlations of spinal mobility with degree of chronic low back pain after correction for age and anthropometric factors spine 1987;12:464-8.

40. Mellin $G$. Physical therapy for chronic low back paini correlations between spinal mobility and treatment outcome. Scand J Rehabil Med 1985; 17:163-6.

41. Tellegen A. Brief Manual for the Multidimensional Personality Questionnaire. Unpublished Manual. University of Minnesota 1982.

42. Stegen $K$, Neujens $A$, Crombez $G$, Hermans $D$, Woestijne van de KP, Bergh van den $O$. Negatiwe affect, respiratory reactivity, and somatic complaints in a $\mathrm{CO} 2$ enriched air inhalation paradigm. Biol Psychol 1998;49:109-22.

43. Bradburn NM. The structure of psychological well being. Chicago, IL: Aldine 1969.

44. Costa PT, McCrea RR. Influence of extraversion and neuroticism on subjective wellbeing: happy and unhappy people. I Personality Social Psychology 1.980;36:668-78.

45. Borkovec TD, Nau SD. Credibility of analgue therapy rationalles. J behav ther exp psychology $1972 ; 3: 257 \cdots 60$.

46. Vlaeyen JW, Teeken Gruben NJ, Goossens ME, Rutten van Molken MP, Pelt RA, Eek wan $\mathrm{H}$, et al. Cognitive-educational treatment of fibromyalgia: a randomized clinical trial. I. Clinical effects, V Rheumatol 1996;23:1237-45.

47. Roland M, Morris R. A study of the natural history of back pain. Part 1: development of a reliable and sensitive measure of disability in low-back pain. Spine 1983;8:141-4.

48. Deyo RA. Comparative validity of the sickness impact profile and shorter scales for functional assessment iit low-back pain. Spine 1986;11:951-4.

49. Deyo RA. Measuring the functional status of patients with low back pain. Arch Phys Med Rehabil 1988;69:1044-53.

50. Beurskens AJ, Vet de $\mathrm{HC}$, Köke AJ, van der Heijden GJ, Knipschild PG. Measuring the lunctional status of patients with low back pain. Assessment of the quality of four disease-specific questionnaires. Spine 1995;20:1017-28

51. Beurskens AJ, Vet de $\mathrm{HC}$. Köke AJ. Responsiveness of functional status in low back pain: a comparison of different instruments. Pain 1996;65:71-6.

52. Gommans IHB, Koes BW. Tulder van MW. Validiteit en responsivteit van de Nederlandstalige Roland Disability Questionnaire. Ned Thidschr Fysioth 1997;107:28-33

53. Miller RP, Kori SH, Todd DD. The Tampa Scale. Unpublished Report. Tarmpa, FL 1991.

54. Kori SH, Miller RP, Todd DD, Kinisophobia: A New view of Chronic Pain Behavior. Pain Management 1990:35-43. 
55. Vaeyen JW, Kole Snijders AM, Boeren RG, Eek van H. Fear of movement/(relinjury in chronic low back pain and its relation to behavioral pertormance pain 1995;62:363-72.

56. Kole-Snijders AMJ. Validity of the Tampa Scale for Kinisifobia-Duth Version (TSK DV) for chronic low back pain patients. In: 7 th Worid Congress on Pan; 1993 August 22-27; Paris; 1993.

57. Sullivan MJL, Bishop SR, Pivik J. The Pain catastrophizing Scale: Development and Validation. Psychol Assess 1995;7:524-32.

58. Rosenstiel AK, Keefe FJ. The use of coping strategies in chronic low back pain patients: relationship to patient characteristics and current adjustment. Pain 1983;17:33-44.

59. Richards JS, Nepomuceno $\mathrm{C}$, Riles $\mathrm{M}$, Suer $Z$. Assessing pain behavior the UAB Pain Behavior Scale. Pain $1982 ; 14: 393-8$.

60. Vlaeyen JWS, Pernot DFM, A.M.J. K-S, Schuerman JA, Eek van H, Groenman NH. Betrouwbaarheid en validiteit wan een Nederlandse versie van de Pain Behavior Scale. Ned Tijdschr Psychol 1990;45:184-9.

61. Carisson AM. Assessment of chronic pain.. I. Aspects of the reliability and valiclity of the visual analogue scale. Pain 1983;16:87-101.

62. Revill sI, Robinson JO, Rosen M, Hogg MI. The reliability of a linear analogule for evaluating pain. Anaesthesia 1976;31:1191-8.

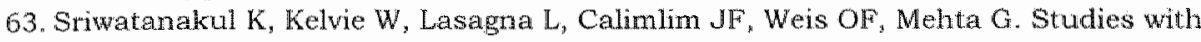
different types of visual analog scales font measurement of pain. Clin Pharmacol "Ther $1983 ; 34: 234-9$.

64. Beurskens AJHM, Vet de HCW, Köke AJ, Lindeman E, Heijden van der GJ, Regtop W, et al. A patient-specific approach for measuring functional status in low back pain. $J$ Manipulative Physiol Ther 1999;22:144-148.

65. Ware JE, Sherbourne CD. The MOS 36-item short-form health survey (SF -36). I. Conceptual framework and item selection. Med Care 1992;30:473-83.

66. Zee van der $K$, Sanderman $R$, Heyink J. De psychornetrische kwaliteiten van de MOS 36-item Short Form Health Survey $(\mathrm{SF}-36)$ in een Nederlandse populatie. T Soc Gerzondheidsz. 1993;71:183-91.

67. Goossens MEJB, Rutten MPMH, Vaeyen JWS, Linden van der SJ. The cost diary: a method to measure direct and indirect costs in cost effectiveness research. Journal of Clinical Epidemiology 1999;Accepted.

68. Chiarello CM, Savidge R. Interrater reliability of the cybex EDI-320 and fluid groniometer in normals and patients with low back pain. Archives. Physical Medical Rehabilitation $1993 ; 74: 32-37$.

69. Koes BW, Mameren van H, Bouter LM, et al. De reproducecrbaarheid van mettingen aan de wervelkolom met de hoekmeter EDl 320. Ned Tijdschr Fysioth 1989;99:207-11.

70. $\mathrm{B} 0 \mathrm{~K}$, Hilde $\mathrm{G}$, Storheim $\mathrm{K}$. Intra- and interobserver reproducibility of Cybex EDI-320 measuring spinal mobility. Scand J Med Sci Sports 1997;7:140-3.

71. Tulder van MW, Koes BW, Bouter LM. Conservative treatment of acute and chromic nonspecific low back pain. Spine 1997;22:2128-56. 



\section{Effectiveness of behavioral-graded activity after first-time lumbar disc surgery}

Raymond W.J.G. Ostelow, Henrica C.W. de Vet, Willem M. Berfelos, Maria R. Kerckhoffsac, Johan W.S. Vlaeyen', Pieter M.J.C. Wolters", Piet A. van den Brandta

Affiliations of authors

a Department of Epidemiology, Maastricht University.

b EMGO Institute, Vrije Universiteit Medical Center Amsterdam.

c Department of Neurosurgery, University Hospital Maastricht.

a Department of Physiotherapy, University Hospital Maastricht.

* Hogeschool Zuyd, Department of Physiotherapy, Heerlen.

- Department of Clinical \& Experimental Psychology, Maastricht University.

Submitted 


\section{ABstract}

Objective: To assess the effectiveness of a behavioral graded activity (BCA) program compared to usual care (UC) in physiotherapy after first-time lumbar disc surgery. The BGA program was a patient-talored intervention based upon operant treatment principles. The essence of the BGA is to teach patients that it is safe to increase activity levels.

Method: A randomized controlled trial. Assessments were carried out before and after treatment by an observer blinded to treatment allocation. Patients that still had symptoms that restrict their ADL and/or work at the 6 weeks post-surgery consultation by the neurosurgeon were included.

Exclusion criteria were: complications during surgery, relevant underlying pathology or if physiotherapy or BGA-program were contraindicated. Primary outcome measures are the patient's global perceived effect and the functional status. Secondary measures are: fear of movement, viewing pain as extremely threatening, pain, severity of the main complaint, range of motion, general health, social functioning, and re-operations. Physiotherapists in the BGA group received proper training.

Results: Between November 1997 and December 1999, 105 patients were randomized; 53 into UC and 52 into BGA. Usual Care shows a statistically significant better improvement on global perceived effect as compared to BGA. For all other outcome measures no statistically significant, or clinically relevant differences were found between both intervention groups. In general the physiotherapists' compliance to the BGA program was satisfactory, although not all treatments, both in BGA and UC, were exactly delivered as planned, resulting in less contrast between both interventions as a-priori planned. In both groups one reoperation accurred.

Conclusion: A BGA program is not more effective than UC in patients after firsttime disc surgery. In usual care statistically significant more patients considered themselves as recovered. On functional status and all other outcome measures there were no relevant differences between interventions. The number of reoperations was negligible.

Key Indexing Terms: Lumbar Disc Surgery, Rehabilitation, Randomized Controlled Trial, Physiotherapy, Behavioral Treatment. 


\section{INTRODUCTION}

In the Netherlands 10,000 operations are performed each year because of the lumbosacrall radicular syndrome, which is based on a hembated lumbar disct.2. An intemational comparison of back surgery rates showed quite some differences between countries. "The success rate in the literature varies from $60 \%$ to $90 \%$, 10 meaning that despite surgery, in $10 \%$ to $40 \%$ of patients results are unsatisfactory and symptoms persist. These persistent symptoms mainly consist of pain, motor deficits, and a decreased functional status. In $2 \%$ to $19 \%$ of patients who undergo surgery, a recurrent herniated lumbar disc occurs, $74 \%$ of which occur within 6 months after the first surgery. 11,12 If patients still have these symptoms despite surgery, they are often referred to physiotherapy. The content of post-surgery treatment ranges from advice, through normal physical training, up to total rehabilitation programs, $3,13-15$ Sometimes all patients are treated immediately after surgery, but often treatment is reserved for patients who still have symptoms after some time.

In the Netherlands physiotherapists traditionally work according to a biomechanical model of disease, thereby assuming a causal relationship between tissue damage and pain. From this perspective, pain for the reaction of patients on the previous treatment) is used as guidance to determine intensity of exercises and advices concerning activities in dally living (ADL). In general, physiotherapists usual care consists of three main components: reduction of pain, exercises with pain as a guidance to determine the intensity of exercises, and advice on ADL and work (again with pain as guidance). A biomechanical approach like this might lead to pain behavior. More recently, treatments are guided by principles of the biopsychosocial model, generally referred to as cognitive-behavioral therapy. $17,1 \%$

A recent study highlighted the effectiveness of cognitive-behavioral interventions, as compared to no treatment, for chronic low back patients. 19 In gemeral, three behavioral treatment approaches can be distinguished: operant, cognitive and respondent therapies. Each of these focuses on the modification of one of the three response systems that characterize emotional experiences that is belavior, cognitions, and physiological reactiwity. Within the cognitive-behavioral field, operant therapy is the most relevant therapy to be applied by physiotherapists and it aims to increase health behaviors and tolerance levels using graded activity and positive reinforcement. ${ }^{18,20}$ Instead of pain for the reaction on the previous treatment of the patient\} a time contingent increase in functional activitics of patients is used as guidance. The behavioral graded activity (BGA) program assessed in this study is an operant therapy in which these principles, developed in the treatment of chronic low back pain, are applied to patients after first-time disc surgery. Based on recent studies ${ }^{19,21}$ we hypothesize that BGA alters fear of movement and other mediators, which will subsequently lead to improved functional status and a higher rate in recovery. So the aim of this study is to assess whether a BGA program is more effective than usual care (UC) in first-time lumbar disc surgery patients in a primary care setting. 


\section{Patients and methods}

Study Design and Randomization

The effectiveness of behavioral graded activity (BGA) in comparison to usual care (UC) after first-time disc surgery was assessed in a single blind randomized controlled trial. By using opaque, sealed and coded randomization envelopes (prepared by an independent person according to computer generated random tables) the outcome assessor (MRK) was blinded. To prevent unequal distributions of prognostic factors we prestratified according to duration of the complaints before surgery (cut-off: 3 months) and according to whether patients have been referred to physiotherapy immediately after surgery (yes/no), accounting for severity of symptoms. Use of permuted blocks of four patients ensured almost equal number of patients within each stratum. To assess the success of randomization several important prognostic factors (table 1) were measured at baseline as well as scores for all outcome measures. At the end of treatment ( 3 months after randomization) outcome measures were compared to detect treatment effects in terms of recovery rate and functional status. Furthermore, it is important to assess whether there is a change in kinisiophobia and other mediators that might lead to better long-term results. To assess these long-term effects we included a 6 and 12 months follow-up. This paper focuses on the post-treatment results. The Medical Ethics Committee of the University Hospital Maastricht approved the study protocol. An extensive description of the design, background of the intervention and outcome measures is published elsewhere. 22

\section{Selection of patients and informed consent}

Patients were scheduled for a routine post-surgery visit with the neurosurgeon six weeks after surgery and in case of persisting symptoms (severe leg or back pain, motor deficits, or restriction of their $\mathrm{ADL}$ and/or work) they were referred to physiotherapy. Patients received oral and written information. Then, the research assistant (MRK, an experienced physiotherapist) contacted patients by phone explaining the goal and implications of participating in the study. Inclusion criteria were: age between 18 and 65; first-tume disc surgery (one level only); complaints (e.g. pain) that restrict their normal daily living and/or work. Patients were excluded if there were complications during surgery, to be judged by the neurosurgeon based on pre-set criteria lloss of cerebrospinal fluid, nerve root leasions, and more that $600 \mathrm{ml}$ blood loss); in case of confirmed and relevant underlying diseases that influenced ADL (e.g. stenosis, malignancies, M. Bechterew, $M$. Scheuermary or if one of the treatments was contraindicated (e.g. because of respiratory complaints). If patients were eligible and willing to participate, informed consent was signed. After baseline measurement patients received an opaque envelope containing a list of physiotherapists applying the allocated treatment.

\section{Interventions}

\section{Behavioral Graded Activity}

Behavioral graded activity (BGA) is an operant behavioral treatment using graded activity and positive reinforcement in order to increase health behaviors and decrease pain behaviors. ${ }^{18,20}$ It was based upon time-contingency management as 
described in more detail by Fordyce 20.23 and applied by Lindstrom ${ }^{24}$ The term "Behavioral Graded Activity" for this program emphasizes the behavioral component, rather than merely physical training principles and is described extensively elsewhere.22 Primary care physiotherapists provided the treatments. Prior to the start of the study, BGA therapists followed a 2 -day practical training course in this approach and received "up-date" neetings in course of the study. The training course consisted of theoretical background and practice-simulations. In the follow-up meetings feedback was provided on the own performance. For that reason videos were installed in practices of participating physiotherapists. The essence of BGA was to establish individually graded exercise training, based on baseline measurements performed at intake, to teach patients that it is safe to increase activity levels. During initial baseline measurements patients were asked to perform activities (selected by patients themselves) or exercises until (pain) tolerance upon which patients set their own, individual, treatment goals. The next step was to set quotas (time contingent), which were systematically increased towards the pre-set goal. Quotas were not to be over-performed nor under-performed. First quotas were slightly under baseline level, to assure that patients' initial experiences, whille performing exercises, were successful which enhances motivation: positive reinforcement is one of the key principles in the operant conditioning theory. In this way, a patient-tailored, individual BGA-program was developed. Patients had to practice at home. Activities or exercises were to be documented on performance charts that were discussed with the physiotherapist.

\section{Usual Care}

The content of usual care (UC) was determined after extensive interviews and discussions with the participating physiotherapists. In general the whole spectrum of techniques used by physiotherapists within these patients were included which, in our opinion, is sensible when investigating usual care. There were only a few restrictions. Specific BGA components were not allowed and some other therapies performed by only a small number of physiotherapists were excluded such as acupuncture, osteopathic techniques and all kind of other "alternative" tecluniques.

Physiotherapists in both treatment conditions documented every session on treatment registration forms. Both treatment conditions consisted of 18 sessions (30 minutes each) within a period of 3 months. Contrary to the BGA, UC physiotherapists were allowed to stop treatment if patients had no longer complaints and treatment goals had been achieved. This corresponds with usual care principles.

\section{Contrast between both interventions}

A priori we identified important features for determining the contrast. First, BGA Is based on systematically performed baseline measurements, whereas UC is based on anamnesis and physical examination. Second, BGA management is time contingent once quotas have been set, whereas UC evaluates reactions of patients on previous treatments and possibly adapts treatment intensity based on this evaluation, which is pain contingent. Third, in BGA specific behavioral components were used; goal 
setting by patients, performance chart, systematic positive reinforcement for health behaviors and extinction of pain behaviors.

In order to assess the contrast, three blinded experts scored a random sample of audiotapes recorded in a selection of patients from both treatment groups. All treament sessions were recorded but only the $1^{\text {st }}, 2^{\text {nd }}$, the $10^{\text {in }}$ and the last session were used because we thought those sessions were most informative. After selecting suitable sound samples (by MRK on basis of preset criteria) they were placed in a random order on a master tape. All assessments were scored on a visual analogue scale (VAS) and for purpose of clarity these scores were afterwards categorized in 3-

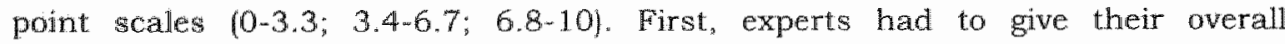
impression for every sound sample with regard to UC characteristics: 1 denotes "no usual care characteristics", 2 "some usual care characteristics" and 3 "mainly usual care characteristics" (meaning that BGA sound samples ideally should score "1" and UC "3"). Secondly, for every sound sample there was a quality assessment of BGA characteristics in general. First, experts had to identify BGA characteristics and if present (in their opinion) they rated the quality from the BGA perspective: 1 denotes "poor quality", 2 "moderate quality" and 3 "good quality". Finally, there was a quality assessment of three typical BGA characteristics (if present in the sound sample): extinction of pain behavior, reinforcement of health behaviors and providing information about prognosis and symptoms from a biopsychosocial perspective (meaning that BGA sound samples ideally should score " 3 " and UC "1"). Also we included three sound samples of a typical BGA treatment that were recorded beforehand and which, in our opinion, represented the "golden standard".

\section{Progmostic factors and outcome measurements}

Demographics and clinical information were recorded from patients' records. At baseline the duration of complaints, medication, previous treatments and kind of job were documented. To assess to what extent patients believed in recovery from their symptoms and in therapy we used three methods. 1) Confidence of patients, 2) expectancy, and 3 ) negative affectivity.

1) How confident patients were in general (regardless of therapy) about their recovery (much, moderate, not, don't know) was asked at baseline.

2) Expectancy was measured according to Vlaeyen et al.2s After 2 treatment sessions, patients were asked to what extent they believed that allocated treatment could be beneficial. (10-point Likert-scale: 0 =expects no benefit at all, $10=$ absolutely convinced of benefit .

3) Negative affectivity was measured by the Negative Emotionality (NEM) subscalle (14 items, 2 point scale) of the Multidimensional Personality Questionnaire26.27 that quantifies negative affect (high NEM scores) of patients.

\section{Outcome measurements}

Primary outcome measures were: Global perceived effect (GPE) rated on a 7-point scale $\|=$ completely recovered, $7=$ worse than ever $)$. These ratings were dichotomized as improved ("completely recovered" and "much improved"), versus not improved ("slightly improved", "not changed", "slightly worsened", "much worsened", "worse 
than ever). The Roland Disability Questionatre (RDQJ measured low back specific functional status. The Dutch translation proved to be valid, 20 ,

Secondary outcome measures were fear of moxement (Tampa Scale for kinesiophobia (TSK), The Dutch translation has fair and consistent internal validity. ${ }^{32}$ The term "kinesiophobia" is used for the condition in which a patient experiences an excessive, irrational and debilitating fear of physical movement and activity resulting from a feeling of vulnerability to painful injury or re-injury. The Pain Catastrophizing Scale (PCS) 33 measured catastrophizing (viewing pain as extremely threatening. Catastrophizing is considered to be a maladaptive belief that may intensify the experience of pain, depression and fear. Intensity of low back pain or sciatica was scored on a visual analogue scale (VAS). Relevance, validity and reliability of the VAS are commonly accepted in the area of low back pain.34.36 At baseline, patients selected two important ADL activities that were severely hampered by their symptoms, in a standardized way. These were called Main Complaints $(\mathrm{MC})^{37}$ and severity was scored on a VAS. General health and social functioning were evaluated by using the corresponding subscales of the SF-36. 38 The Dutch translation by van der Zee et al. showed satisfactory validity and reproducibility. ${ }^{39}$ Range of motion ( $R O M$ ) (flexion, extension) of the lumbar spine is measured by the EDI-320 that proved to have a satisfactory reproducibility, especially for flexion. ${ }^{40-42}$ Occurrences of re-operations were recorded.

\section{Analysis}

Treatment registration forms were examined for protocol deviations, using a consensus meeting with the project team. In the BGA program protocol deviations were defined as: use of passive treatment modalities, more than twice not fulfilling quotas, co-interventions by other health care providers (e.g., neurosurgeon, general physician, or treatment by other physiotherapist). In usual care only significant cointerwentions such as stopping treatment because of a neurosurgeons' advice after a MRI, were recorded as protocol deviations.

Statistical analyses were carried out according to the intention to treat principle: all patients, including withdrawals from treatment and patients with poor compliance, remained in the group to which they were assigned by randomization. If patients dropped-out, the reason for this determined the replacement proceduie: 1) patients were deleted from analysis if there was no association with allocated treatment (e.g. patients moves out of catchment's area, or drop outs before first treatment, 2) patients received a negatiwe score if they had more pain, or when the neurosurgeon advised to stop treatment because of strong indications for a (new) herniated disc, 3) patients received a positive score if they had returned to work completely or other indications that justify a positive score. For substitution of negative or positive scores we used the $10^{\text {th }}$ or $90^{\text {th }}$ percentile score of the total group. An expert panel assigned replacement values indeperdently and blinded for treatment allocation. If 2 out of 3 attributed similar substitution values, this value was used. In addition a per-protocol analysis was performed that was restricted to those patients that were compliant to the treatment protocol. For all analyses SPSS 9.0 for Windows (SPSS Inc. North Michigan Avenue, Chicago, IL, 60611) was used. For outcome measures collected at baseline the difference with post treatment values was calculated for 
each individual and these change-scores were compared for the two treatment groups using student's t-test for statistical significance. For outcome measures whout baseline measurement (e.g. GPE) difference between groups at the posttreatment group were analyzed. Group differences and two-talled $95 \%$ confidence intervals $(95 \% \mathrm{Cl})$ were calculated for all outcome measures. In order to adjust for possible baseline differences a multiple linear regression analysis for continuous outcome measures was performed with the change scores as dependent variable, treatment as independent variable, and baseline scores of the prognostic variables (and the main outcome measure, if appropriate) as co-variables. With regard to the audiotapes for assessing the contrast, first agreement between the three experts was calculated on the original VAS score by means of Pearson's $\mathbb{r}$. Then, for each characteristic, the percentages on the various 3 -point scales, separately for each treatment condition were calculated.

\section{Results}

From November 1997 until December 1999 a total of 671 patients were checked for eligibility by 9 neurosurgeons in the 4 participating hospitals in the South of the Netherlands. Most patients were more or less recovered and had no further symptoms $(57 \%), 141$ patients $(21 \%)$ were excluded because of warious reasons: patients, although operated in one of the participating hospitals, were not living in the catchment's area $(n=40)$, not motivated to participate $(n=32)$, too old $(n=30)$, comorbidities $(n=22)$, language problems $(n=8)$ earlier lumbar surgeries $(n=7)$, and because of insurances $(n=2)$. We failed to trace 43 patients. In total 105 patients were eligible and signed informed consent. Figure 1 summarizes the patient flow through the study.

In both groups the majority underwent standard discectomy. None of the included patients had a root block or bracing. In BGA 1 patient had laminectomy and 1 foraminectomy, while 1 patient in UC had a facetectomy. In BGA there was 1 patient with complications during surgery in UC (nerve root leasion) and i in BGA (loss of cerebrospinal fluid). In both groups post-surgery treatment was equal while thospitalized (UC mean of 7.7 days (SD: 2.7 ), versus BGA mean of 7.0 days (SD:

1.3)). The first 2 to 3 days patients stayed in bed in order to recover from surgery. Then, patients were instructed by a physiotherapist with regard to low-back exercises and how to resume functions of normal daily living for 3 to 4 days. This is standard procedure in the participating hospitals. Analgesics were prescribed on a pro re nata (PRN) basis. In UC $34 \%$ of the patients used pain medication versus $38 \%$ in BGA. Distributions of baseline characteristics of both groups are presented in Table 1. In BGA there were slightly more women and the number with paid jobs was higher. However, both groups had similar demographics and clinical baseline characteristics. Furthermore, expectancy was similar for both treatment groups and for all outcome measures both groups showed quite similar scores. 


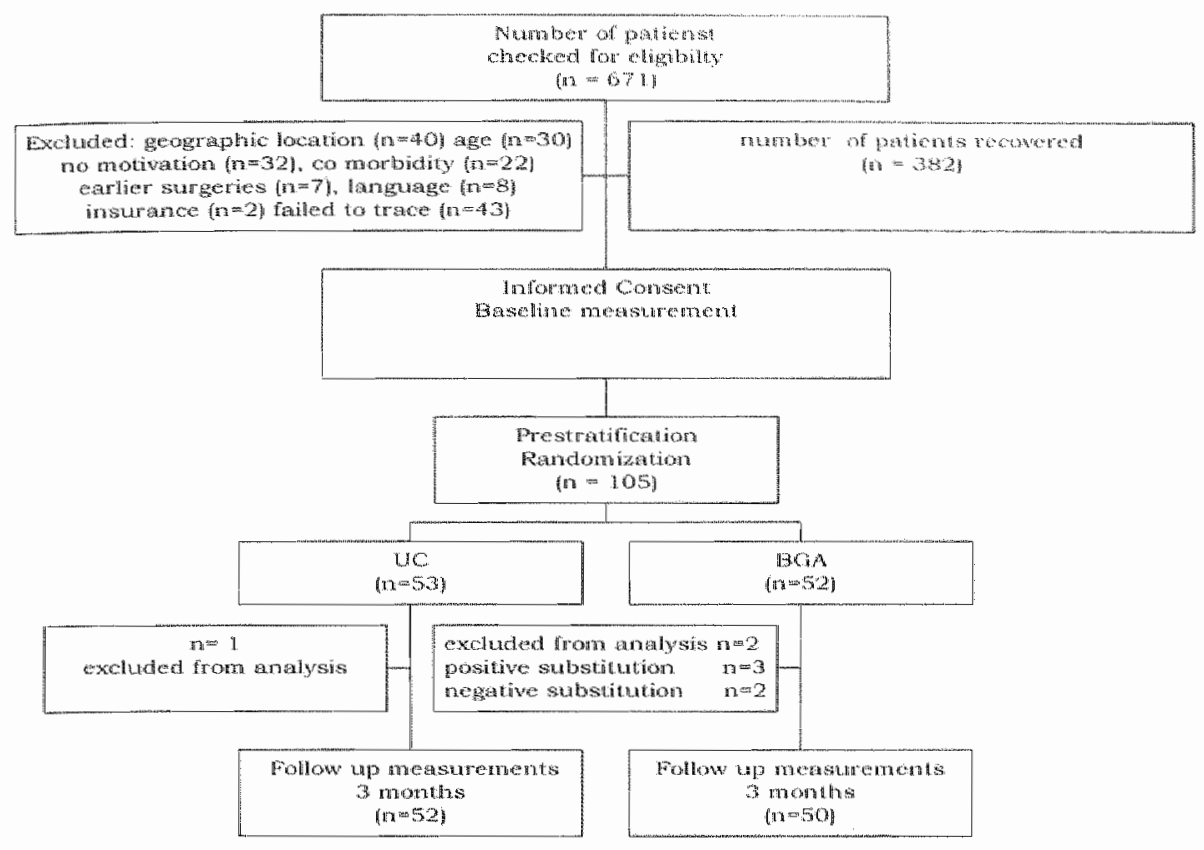

Figure 1. Patient flow trough study.

In UC there were on average 15.5 treatments versus 14.8 in BGA.

In total 8 patients dropped out: 1 in $U C$ and 7 in BGA. The patient in UC disappeared after 2 treatments without stating any reason and was therefore excluded from the analysis. Two patients in BGA withdrew from the study because of aggravated symptoms. Negative scores therefore substituted their values. One patient had exacerbation of symptoms before the first treatment and another patient suffered from rheumatic symptoms, a disease he had not reported before randomization. As we considered these drop outs independent of treatment they were excluded from further analysis. One patient reported to be completely pain free after 2 treatment sessions and therefore was no longer motivated to participate in the study and one patient reported, because of complete resumption of work land no more symptoms), to withdraw because of lack of time and motivation. One patient withdrew because of personal circumstances but was largely recovered after 5 treatment sessions. The values of these three patients were substituted by positive values.

Table 2 presents the results on effectiveness of treatment. In UC $67 \%$ of the patients rated themselves as "recovered" on dichotomized global perceived effect. versus $48 \%$ of the patients in $\mathrm{BGA}$. This $19 \%$ difference is statistically significant $(p=0.048)$. In UC 3 patients $(5.8 \%)$ scored "much worsened" or "worse than ever" versus 6 patients $(12 \%$ ) in BGA. The disability score /Roland Disability 
Table 1. Baseline characteristics of both treatment groups.

\begin{tabular}{|c|c|c|}
\hline Characteristics & Usual Care $(n=53)$ & $B G A(n=52)$ \\
\hline Age (yearig) & $43.7(8.8)$ & $42.8(8.8)$ \\
\hline Ho (\%) of women & $19 \quad(35.8)$ & $26 \quad(50.0)$ \\
\hline Type of surgery: standard discectomy (\%) & 70 & 78 \\
\hline \multicolumn{3}{|l|}{ Level of surgery } \\
\hline - $\quad L 4 L 5(\%)$ & 43.1 & 49.0 \\
\hline - $\quad L 5-\$ 1(\%)$ & 529 & 44.9 \\
\hline \multicolumn{3}{|l|}{ Surgical tindings } \\
\hline - Sequester $(\%)$ & 38.5 & 38.8 \\
\hline - Prolussion $(\%)$ & 51.9 & 49.0 \\
\hline Duration hospitalization (days) & $7.7(2.7)$ & $7.0(1.3)$ \\
\hline \multicolumn{3}{|l|}{ Duration of symptoms before surgery } \\
\hline - $\leq 3$ moriths: (No $(\%))$ & $9 \quad(17)$ & $7 \quad(13)$ \\
\hline - $\quad \geq 3$ months: (No $\left.\left(X_{0}\right)\right)$ & $44 \quad(83)$ & $45 \quad(87)$ \\
\hline Physiotherapy immediately atter surgery $(\%)$ & 33 & 42 \\
\hline Taking pain medication (No ("\%) & $18 \quad(34)$ & $20 \quad(38)$ \\
\hline Physiotherapy before sufgery (No $(\%)$ ) & $30 \quad(56.6)$ & $32 \quad(60,4)$ \\
\hline Other treatment before surgery (No $(\%)$ ) & $16 \quad(30.2)$ & $13 \quad(23.9)$ \\
\hline Paid employment $($ ho $(\%))$ & $37 \quad(698)$ & $47 \quad(90.4)$ \\
\hline \multicolumn{3}{|l|}{ Confidence with regard to recovery in general (No $(\%)$ ) } \\
\hline - Great deal & $22 \quad(41.5)$ & $2 \sharp \quad(40.4)$ \\
\hline - Moderate amount & $18 \quad(34.0)$ & $24 \quad(46.2)$ \\
\hline - No & $3 \quad(5.7)$ & $3 \quad(5.8)$ \\
\hline - Don't know & $10 \quad(18.9)$ & $4 \quad(7.7)$ \\
\hline Expectancy of allocated treatment $(0-10 \text { points })^{*}$ & $6.9(1.6)$ & $6.9(1.1)$ \\
\hline Negative affectivity (0-14 points) & $3.7(4.0)$ & $4.2(4.1)$ \\
\hline \multicolumn{3}{|l|}{ Outcome measures } \\
\hline Roland Disability Questionnaire (0-24 points) & $13.5(4.5)$ & $14.5(3.7)$ \\
\hline Tampa Scale (17-68 points) & $36.9(6.8)$ & $35.9(6.3)$ \\
\hline Pain-Catastrophizing Scale (0-52 points) & $16.9(11.7)$ & $17.1(10.2)$ \\
\hline Main Complaint $(0-100)$ & $67.4(15.4)$ & $71.1(16.5)$ \\
\hline Pain in back (No $(\%))$ & $45 \quad(85)$ & $48 \quad(92)$ \\
\hline Severity of pain in back $(0-400)$ & $46.7(27.3)$ & $43.4(30.0)$ \\
\hline Sciatica $(\mathrm{No}(\%))$ & $52 \quad(98)$ & $50 \quad(96)$ \\
\hline Severity of scialica $(0-100)$ & $41.3(30.8)$ & $39.0(28.2)$ \\
\hline Range of Motion & $81.2(22.7)$ & $78.1(22.6)$ \\
\hline General Health (Subscale SF.36) & $65.6(200)$ & $68.2(18.4)$ \\
\hline Social Furictioning (Subscale SF.36) & $59.4(25.3)$ & $56.7(26.6)$ \\
\hline
\end{tabular}

* Administered after 2 reatments.

Values are means with standard deviations between brackets unless stated otherwise. 
Table 2. Results at post-treatment.

\begin{tabular}{|c|c|c|c|c|c|c|}
\hline \multirow{2}{*}{ 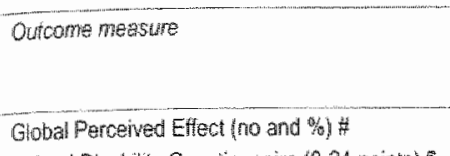 } & \multicolumn{2}{|c|}{$\begin{array}{c}\text { UO } \\
\text { downenent } \\
(n=52)\end{array}$} & \multicolumn{2}{|c|}{$\begin{array}{c}\text { BGA } \\
\text { Improvenant } \\
(n=50\end{array}$} & \multirow{2}{*}{ 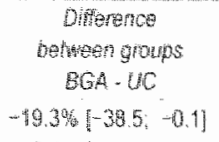 } & \multirow{2}{*}{ 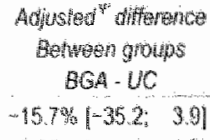 } \\
\hline & 35 & $(67 \%)$ & 24 & $(48 \%)$ & & \\
\hline Roland Disabilfy Questionnaire (o-24 points) & -5.6 & $(53)$ & -5.2 & $(5.9)$ & $0.4-13,26$ & $0.95 \quad \mathbb{4}-1.4,3.3]$ \\
\hline Pain Catastrophizing Sale (10-52 points) & -1.9 & $(9.5)$ & -29 & $(8.0)$ & $-1.0|-4.4: 25|$ & $-0.9 \quad\left[\begin{array}{lll}4.2 & 27\end{array}\right]$ \\
\hline Tampa Scale (17-68 points) s & -0.7 & 68 & -0.7 & $(6.7)$ & $00 \quad-27,0,09$ & $-6.8 \quad-35 ; \quad 1.9$ \\
\hline Main Compleint $(0-100) \$$ & -30.3 & 25.2 & -32.3 & $(27.7)$ & $-2, \quad[-125 ; 03]$ & $-0.2^{3}[-1,1: 1: 40,6]$ \\
\hline Severity of pain in back (0-100) $\$$ & -16.0 & $(25.3)$ & -9.3 & $27.8)$ & $60 \quad[-3.8 ; 71]$ & $50 \quad[-4.9,449]$ \\
\hline Severty of sciatica $(0-100)$ s & -142 & 223.9 & -11.6 & $(313)$ & $26 \quad[-8.3 ; 13.5]$ & $1.8 \quad[8.2 * 11.9]$ \\
\hline Range of Motion & 127 & $(220)^{2}$ & 127 & $(19.6)^{* *}$ & $0.1[-8.5,8.7]$ & $36[-107 ; 3.4]$ \\
\hline General Health (Subscale SF.36) & 29 & $(14.2)$ & 0.7 & $(125)$ & $22 \quad \mid-7,5,31\}$ & 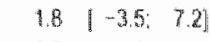 \\
\hline Sociar Functioning (Substatle SF-36) & 18,3 & 120.2 & 19.5 & $(27.5)$ & $12 \quad[-10 \% ; 8,2]$ & $0.7 \quad-7.2 \quad 8.8$ \\
\hline
\end{tabular}

All outcome measures are presented in means and standard deviation, unloss otherwise stated.

"\#" Rating of global perceived effect on a seven-point scale wete dichotomized (see method section)

"Negative values denote positive results for patients

* 9 missing due lo lecthnical problems

* I missing due to techmical problems

4. Adjusted for following baseline variables: RDQ, duration of complaints, confidence, TSK, NEM, PEM, Pain Back and PCS

A Aso adjusted for Main Complaint To

Questionnaire) improved significantly in both groups (5.6 points in UC, versus 5.2 in BGA) but the difference between BGA and UC was negligible. Post treatment the UC group scored 7.9 points on the RDQ, versus 9.3 for BGA. This pattern was identical for the scores on the main complaint, pain (leg and back), range of motion and social functioning: statistically significant improvement within groups but differences between groups were neither substantial nor statistical significant. On the pain catastrophizing scale, the Tampa scale as well as on General Health Subscale of the SF-36 no substantial improvenents were recorded. Adjustments for a priori identified co-variables (baseline scores of RDQ, TSK, NEM, Low Back Pain intensity on VAS, PCS, duration of complaints, and confidencel did not alter the results substantially. In both groups one patient underwent re-operation, both at the same level as initially.

The per-protocol analysis was restricted to 78 patients: 45 in UC versus 33 in $B \mathrm{BA}$. The prognostic comparability between intervention groups that qualified for perprotocal analysis was quite similar to the results in table 1. In general the perprotocol analysis resulted in slightly larger improvements within groups, but between group differences did not change in any substantial way.

\section{Integrity check}

The finall master tape consisted of 24 sound samples (13 BGA samples and 1. U. UC samples! plus the three "golden standard" samples. The Pearson's $r$ for the assessments was on average 0.65 with a range from 0.55 to 0.82 on the various characteristics. Overall the agreement was satisfactory. Furthermore, the 3 golden standard samples were scored in all instances as expected, thus supporting the validity of our scoring system. Calculating the percentages of the scores on the 3 point scales for both treatment conditions separately showed that, on average, $70 \%$ 
to $80 \%$ of the sound samples were scored in expected categories on the various quality assesments and $20 \%$ to $30 \%$ were not classified in the expected direction (e.g. UC samples were scored as "no usual care characteristics" or, identified BGA characteristics were rated as "poor quality" while UC samples were rated as "good quality with regard to BGA characteristics).

\section{Discussion}

In a single blind randomized controlled trial the effectiveness of a behavioral graded activity (BGA) program compared to usual care (UC) was assessed. Overall the comparability at baseline between both treatments was good. On global perceived effect the BGA program performed statistically significant worse than UC $(19 \%$ difference). All other outcome measures did not reveal any differences between both groups. Although there were more dropouts in $B G A$, per protocol analysis produced results similar to the intention to treat analysis. Adjustment for baseline characteristics did not alter the results substantially, although the difference between both groups on GPE was slightly smaller and the statistical significance became borderline. In both groups only one re-operation occurred. Analysis of the audiotapes showed that experts classified $70 \%$ to $80 \%$ of the samples in the right categories.

The difference on global perceived effect between both groups was consistent with the "patients' satisfaction with the result of treatment" scored on a VAS inot presented). But when patients were asked how satisfied they were with the therapist (10 point scale) both groups had similar scores (UC: 8.8 and BGA 8.2) indicating that satisfaction with therapist is probably not an important factor for explaining the differences between groups. Although there were no differences between both groups for $\mathrm{RDQ}$ scores, the within-group improvement was considerably (5.2 wersus 5.6). Because we lacked a no treatment control group we are not able to attribute this improvement to either treatment (BGA or UC) or simply to the time factor. The reason for not having included a no-treatment control group was that a-priori it was considered inappropriate to withhold treatment to patients if they still had complaints six weeks after surgery. A standard prescription for physiotherapy in this category of patients is considered usual care and the aim of this study was to investigate whether BGA was more effective than UC. Therefore, all patients who still suffered complaints were treated in this study. Although there was a considerable improvement in both groups post-treatment, RDQ scores are still high indicating that despite considerable improvenent patients still have difficulies in their $\mathrm{ADL}$, indicated by scores of 7.9 in UC and 9.3 in BCA. Also patients" Main Complaint improved in both groups with approximately $50 \%$ but patients still report to have complaints post-treatiment. Again, the factor time might have been important.

Dropouts were unevenly distributed between both groups: only 1 patient dropped out from UC while 7 patients in the BGA group. Because these numbers themselves 
are remarkable a blinded panel assessed diferent reasons for dropout in order to determine the substitution values. On basis of this we concluded that only 2 patients in BGA suffered exacerbation and missing values were substituted by negative values. On the other hand 3 patients clearly showed improvements and received positive scores. Although it can be argued that the information about reasons for drop-out is subjective, it is more sensible replace missing values according to reasons of drop out than to assign mean values. In our opinion, bias because of drop-out is better anticipated in this way.

In the per-protocol analysis 78 patients were included $(45$ in UC and $33 \mathrm{in} B G A)$. In the BGA more patients were excluded because treatment protocol was more restrictive, as compared to usual care. But comparability between both groups that were included in per protocol analysis was comparable with baseline characteristics for all patients. In general, the per-protocol analysis resulted in slightly more improvement within groups. This can be attributed to the fact that especially patients that do not really show any improwement during treatment are more likely to deviate from the protocol or that the treatment, if complied well, does induce larger improvements. But the between group differences did not change in any substantial way and therefore we concluded that our findings are not influenced by protocol deviations.

A priori we hypothesized that BGA would reduce catastrophizing and fear avoidance (mediators), which would lead to an improvement of patients' overall rating of recovery and an improvement in their ADL. However, the stability of both catastrophizing and fear awoidance is remarkably because nor in $U C$, neither in BGA these mediators were significantly altered. Several reasons for these unexpected findings can be brought up. Firstly, interventions are not delivered ass expected. Secondly, existing literature has been too optimistically interpreted. Thirdly, this specific population might not benefit from behavioral approaches.

Whether interventions were delivered as planned was a critical issue because both interventions were supervised by (different) physiotherapists. Despite the 2 -day training course and follow-up meetings during the trial, BGA still might not have been delivered as planned. Changing behavior of caregivers might be as difficult as changing behaviors of patients. Therefore we recorded treatment sessions in both treatment conditions. Overall, $70 \%$ to $80 \%$ of the audio samples were classified in the right categories. Therefore, we concluded that although experts were able to distinguish between both approaches in the majority of the cases, there was an overlap of $20 \%$ to $30 \%$, resulting in less contrast as we a priori thought land hoped for). Furthermore, these results indicate that UC incorporates specific characteristics of BGA (e.g. reinforcement of health behaviors, extinction of pain behavior and more functional trainingl and that BGA-therapists, although specifically trained in this approach, still use some of UC characteristics in treatment or communication to patients. This is in concordance with a survey that showed that even if physiotherapists are trained in biopsychosocial approaches, attitudes and beliefs conceming details about specific treatment issues differ 
widely ${ }^{4}$. However, as $70 \%$ to $80 \%$ was classified correctly and BGA did not show the slightest sign of being more effective that $\mathrm{UC}$ we do not think that the misclassification of $20 \%-30 \%$ concealed any possible effect of BGA. Therefore, we come to the conclusion that based on the results of this study there are no reasons to implement BGA in primary care for first-time lumbar disc surgery patients.

In a recent study, Danielsen ${ }^{4 *}$ concluded that vigorous medial exercise therapy, started 4 weeks after surgery for lumbar disc hemiation reduced disability and pain after surgery and that there was hardly any danger associated with early and vigorous training. This was in line with a previous study that concluded that high intensity training started 5 weeks after" surgery had favourable effects ${ }^{45}$. This was mainly based on the fact that the high intensity group had no more exacerbations or re-operations as compared to the mild exercise group and both groups had a comparable improvement with regard to disability. Dolan ${ }^{46}$ concluded that exercise therapy improved outcome within the exercise group, although between group results were not presented. Our results regarding outcome on physical measures and disability also showed improvement over time. However there are differences between our study and the others. First, the results of two of these studies ${ }^{44,40}$ include the outcome of surgery because the follow-up measures of these studies are compared with the pre-surgery levels of these outcome measures. Furthermore; these studies 445,46 assessed different kind of exercise regimes but none of these interventions incorporated specific behavioural components. Moreover, fear avoidance or catastrophizing were no outcome measures in these studies so the stability we found in our mediators cannot be compared. Another difference is that in our trial only patients who still had symptoms at 6 weeks were included instead of including all patients after surgery. Therefore, it can be argued that the more severe cases entered our trial. These differences make a direct comparison of the results of these studies with our trial difficult. Considering the stability in fearavoidance it might be the hypothesized that BGA is not specifically enough addressing fear-avoidance. A recent study showed that exposure of chronic lowback patients to specific activities or exercises improved fear-avoidance substantially as opposed to general exercises. ${ }^{7}$ Whether exposure also results in reduction of fear-avoidance in post-surgery patients is a challenge for future research.

In line with these other studies we also conclude that activity after first-time lumbar disc surgery is safe as the re-operation rate was very low and therefore it is not necessary for patient to stay passive after surgery.

In summary, the results of this RCT do not support the use of a specific BGA program for patients after first-time lumbar disc surgery. Furthermore, we concluded that some specific BGA features are incorporated in UC in primary care setting. Whether more specific behavioral approaches should be used for post surgery patients is a challenge for future research, but based on these results we conclude that there is no basis for applying behavioral graded activity in patients after first-time lumbar disc surgery. 


\section{ACKNOWLEDGEMENTS}

The authors would like to thank the "Profileringsfonds" of the University Hospital Maastricht and the "Stichting Annatonds" for their financial support. Also we are grateful to the neurosurgeons from the participating hospitals: University Hospital Maastricht, Atrium Hospital Heerlen, Maasland Hospital Sittard and Laurentius Hospital Roermond for referring patients to our study. Thanks to Rob Pelt and Jan Thomassen for training and monitoring the physiotherapists. We appreciate the assistance of Cobie Martens on logistic and data management.

\section{REFERENCES}

1. Slebus FG, Maas van der PJ, Braakman $\mathbb{R}$, Habbema JDF, Karclaun JWPF. De effectiviteit van beeldvormende diagnostiek en chirurgie bij de lumbale hernia nuclei pulposi. Rotterdam: Rapport aan het Ministerie van WVC, 1989.

2. Health Council of the Netherlands. Management of the lumbosacral radicular syndrome (sciatica). The Hague: Health Councill of the Netherlands, 1999

3. Cherkin DC, Deyo RA, Loesser JD, Bush T, Waddell G. An international comparison of back surgery rates. Spine 1994;19:1201-6.

4. Korres DS, Loupassis G, Stamos K. Results of lumbar discectorny" a study using 15 different evaluation methods. Eur Spine J 1992;1:20-4.

5. Barrios $\mathrm{C}$, Ahmed M, Arrotegui JI, Bjornsson A. Clinical factors predicting outcome after surgery for therniated lumbar disc: epidemiological multiwariate analysis. J Spinal Disord $1990 ; 3: 205-9$.

6. Pappas CTE, Harrington T, Sonntag VKH. Outcome analysis in 654 surgically treated lumbar disc herniations. Neurosurgery 1992;30:862-6.

7. Smulders WLM, Loon van G. Nabehandeling na lumbale discectomie of chemonucleolyse. Een 'out-patient' enquete. Fysiopraxis 1993;2:4-6.

8. Hurme M, Alaranta $\mathbb{H}$. Factors predicting the result of surgery for lumbar interwertebral disc herniation. Spine 1987;12:933-8.

9. Mamniche $\mathrm{C}_{2}$ Asmussen $\mathrm{KH}$, Vinterberg $\mathrm{H}$, Rose Hansen EB, Kramholt $J$, Jordan A. Back pain, sciatica and disability following first-time conventional haemilaminectomy for lumbar disc herniation. Use of "Low Back Pain Rating Scale" as a postal questionnaire. Dan Med Bull 1994;41:103-6.

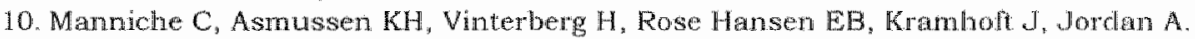
Analysis of preoperative prognostic factors in firstutime surgery for lumbar disc. herniation, including Finneson's \& modified Spengler's score systems. Dan Med Bull $1994,4: 110-5$.

11. Connolly ES. Management of persistent or recurrent symptoms and signs in the postoperative lumbar disc patient. Neurosurg Clin N Am 1993:4:161-6.

12. Burken van MMG, Sanders EACM. Goede resultaten van heroperatie wegens terugkerend radiculair syndroom na een HNP operatie. Ned Tijdschr Geneesk $1992 ; 136: 692-5$

13. Hansen JW. Postoperative management in lumbar disc protrusions. Acta Orto Scan $1964 ; 71$ (suppl): $1-47$.

14. Oerlemans HM. Fysiotherapie na en lumbale laminectomie. Ned Tijdschr Fysiother $1988: 98: 245-51$.

15. Noordzij CM, Dolder van R. Fysiotherapeutische begeleiding wan geopereerde HNP. patiënten. Ned Tijdschr Fysiother 1991;101:160-2.

16. Linton SJ, Hellsing AL, Andersson D. A controlled study of the effects of an early intervention on acute musculloskeletal pain problems. Pain 1993;54:353-9.

17. Turk DCFH. Etiological theories and treatments for chronic back pain II. Psychologicall models and interventions. Pain 1984;19: 209-33 
18. Waeyen JW, Haazen IW, Schuerman JA, Kolle Snjders AM, Eek van H. Behavioural rehabilitation of chronic low back pain: comparison of an operant treatment, an operantcognitive treatment and an operant-respondent treatment. Br J Clin Psychol $1995,34: 95 \cdot 118$.

19. Tuluer van MW, Ostelo RWJG, Vlaeyen JWS, Linton SU, Morley SJ, Assendelft WJ. Behavioral treatment for chronic low back pain: a systematic review within the framework of the Cochrane Back Review Group. Spine 2001:26:270-81.

20. Fordyce WE. Behavioral methods for chromic pain and illness. St. Louis: Mosby, 1976.

21. Vlacyen JW, Linton SJ. Fear avoidance and its consequences in chronic musculoskeletal prin: a state of the art. Pain $2000 ; 85: 31,7-32$

22. Ostelo RWJG, Koke AJA, Beurskens AJHM, et al. Behawioral-Graded activity compared with usual care after first-time disk surgery: Considerations of the design of a randomized clinical trial. J Manipulative Physiol Ther 2000;23:312-19.

23. Fordyce WE, Fowlex RS, Lehmann JF, Delateur BJ, Sand PL, Trieschmann RB. Operant conditioning in the treatment of chronic pain. Arch Phys Med Rehabil 1973:54:399-4:08.

24. Lindström 1 , Ohlund $C$. Eek $C$, et al. The effect of graded activity on patients with subacute low back pain: a randomized prospective clinical study an operantconditioning behavioral approach. Phys Ther $1992 ; 72: 279-293$.

25. Vlaeyen JWS, Kole-Snijders AMJ, Eek van H. Chronische pin en revalidatie. Houten: Bohn Stalleu Van Loghum, 1996.

26. Tellegen A. Brief Manual for the Multidimensional Personality Questionnaire. Unpublished Manual. Uniwersity of Minnesota. 1982.

27. Stegen $K$, Neujens $A$, Crombez $G$, Hermans $D$, Woestijne van de KP, Bergh wan den $O$. Negative affect, respiratory reactivity, and somatic complaints in a $\mathrm{CO} 2$ enriched air inhalation paradigm. Biol Psychol 1998;49:109-22.

28. Roland M. Morris R. A study of the natural history of back pain. Part I: development of a reliable and sensitive measure of disability in low-back pain. Spine. 1983;8:141-4.

29. Beurskens AJ, Vet de HC, Köke AJ. Responsiveness of functional status in low back pain: a comparison of different instruments. Pain 1996;65:71-6.

30. Gommans IHB, Koes BW, Tulder van MW. Validiteit en responsiviteit van de Nederlandstalige Roland Disability Questionnaire. Ned Tijdsch Fysiother 1997;107:28-33

31. Miller RP, Kori SH, Todd DD. The Tampa Scale (Unpublished Report). Tampa, FL 1991.

32. Vlaeyen JW, Kole Snijders AM, Boeren $\mathbb{R G}$, Eek van $H$. Fear of movement/(re)injury in chronic low back pain and its relation to behavioral performance. Pain 1995;62:363-72.

33.Sullivan MJL, Bishop SR, Pivik J. The Pain catastrophizing Scale: Development and Validation. Psychol Assess 1995;7:524-32.

34. Carlsson AM. Assessment of chronic pain 1. Aspects of the reliability and validity of the

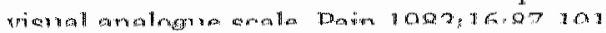

35. Revili SI, Robinson JO, Rosen M, Hogg MI. The reliability of a linear analogue for evaluating pain. Anaesthesia 1976;31:1191-8.

36. Sriwatmakul $K$, Kelvie W, Lasagne L, Cetimlim JF, Weis OF, Mehta G. Studies with different types of visual analog scales for measurement of pain. Clin Pharmacol Ther $1983 ; 34: 234-9$.

37. Beurskens $\mathrm{Al}_{\mathrm{J}}$, Vet de $\mathrm{HC}$, Köke AJ, et al. A patient-specific approach for measuring functional status in low back pain. J Manipulative Physiol Ther 1999;22:144-8.

38. Ware JE, Sherbourne CD. The MOS 36-item short-form health survey (SF-36) I. Conceptual framework and item selection. Med Care 1992;30:473-83.

39. Zee wan der $K$, Sanderman $R$, Heyink $J$. De psychometrische kwaliteiten van de MOS 36 . item Short Form Health Survey $(\mathrm{SF} \sim 36)$ in een Nederlandse populatie. Tijdschr Soc Gezondheidsz 1993;71:183*1911

40. Chiarello CM, Savidge R. Interrater reliability of the cybex EDI-320 and fluid goniometer in normals and patients with low back pain. Arch Phys Med Rehabill 1993;74:32-7.

41. Koes BW, Mameren van H, Bouter LM, et al. De reproduceerbaarheid van metingen aan de wervelkolom met de hoekmeter EDI-320. Ned Tijdschr Fysiother 1989;99:207-11

42. Bo $\mathbb{K}$, Hilde $\mathrm{G}$, Storheim $\mathrm{K}$. Intra- and interobserver reproducibility of Cybex $\mathbb{E D I}-320$ measuring spinal mobility. Scand J Med Sci Sports 1997;7:140-3.

43. Ostelo RW, Stomp-van den Berg SG, Vlaveyen JW, Wolters PM, Vet de HC. Health care provider's Attitudes and Belieis regarding chronic low back pain. Submitted. 
44. Danielsen JM, Johnsen R, Kibsgaand SK, Hellewk E. Early aggressive exercise for postoperative rehabilitation after discectomy. Spine 2000;25:1015,20.

45. Manmiche $\mathrm{C}_{n}$ skall HF, Braendholt $\mathrm{L}$, et al. Clinical tral of postoperative dynamic back exercises after first lumbar discectomy. Spine 1993:18:92.7.

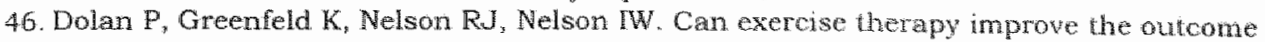
of microdiscectomy? Spine $2000 ; 25: 1523-32$.

47. Vhaeyen JW, Jong de J, Geilen $M$, Heuts PH, Breukelen wan G. Greded exposure in wivo in the treatment of pain-related fear: a replicated single-case expermental design in four patients with chronic low back pain. Behav Res Ther 2001;39:151-66. 



\section{Behavioral-graded activity after first-time lumbar disc surgery: One-year results of a randomized controlled trial}

Raymond W.J.G. Osteloab, Henrica C.W. de Vetc, Johan W.S. Vlaeyen, Maria R. Kerckhoffsabe, Willem M. Berfelo!, Pieter M.J.C. Wolters", Piet A. van den Brandta

Affiliations of authors

Department of Epidemiology, Maastricht University.

"Hogeschool Zuyd, Department of Physiotherapy, Heerlen.

EMGO institute, Vrije Universiteit Medical Center Amsterdan.

a Department of Clinical \& Experimental Psychology, Maastricht University.

"Department of Physiotherapy, University Hospital Mastricht.

Department of Neurosurgery, University Hospital Maastricht. 


\section{ABSTRACT}

Study Design and Objectives: In a randomized controlled trial (RCT) the effectiveness of behavioral graded activity (BGA) was assessed as compared to usual care (UC) in plyysiotherapy for patients after lumbar disc surgery ( $\mathrm{n}=105$ ).

Summary of Background Data: Little is krown about the effectiveness of rehabilitation programs after lumbar disc surgery. Most programs focus on biomechanical aspects, whereas psychosocial factors are hardly addressed. The aim of behavioral treatment is to alter these psychosocial factors, which might subsequently improve functional status. Behavioral treatments for patients following lumbar disc surgery have not yet been assessed in an RCT.

Methods: Inclusion criteria: age between 18 and 65 years; furst-time disc surgery; restrictions in normal daily activities (ADL). Exclusion criteria: surgical complications, confirmed and relevant underlying diseases. Outcome assessment took place 6 and 12 months after randomization.

Results: Six months after randomization, $62 \%$ of the patients had recovered following UC versus $65 \%$ of the patients following BGA. After 12 months, $73 \%$ and $75 \%$, respectively, had recovered. Differences between interventions, $3 \%$ and $2 \%$ respectively, after 6 and 12 months are not statistically significant. Furthermore, there were no differences between the two groups. Pain catastrophizing and fear of movement showed no relevant improvements. After one year, 4 of the BGA cases had undergone another operation versus 2 of UC cases.

Conclusion: The two treatment conditions administered in the current study to patients following lumbar disc surgery were equally effective. Both fear of movement and pain catastrophizing, seem to be unaffected by either treatment in these patients. It is concluded that treatment principles derived from theories within the field of chronic low back pain might not apply to these patients and therefore there is no reason to implement behavioral graded activity for these patients.

Key words: Rehabilitation, Lumbar Disc Surgery, Behavioral Treatment, Graded Activity, and Randomized Controlled Trial. 


\section{INTRODUCTION}

Only a few good-quality studies exist which address the nature and frequency of persisting or recurrent symptoms following lumbar disc surgery. The published figures, however, vary widely, ranging from $22 \%$ to $45 \%$ of patients reporting residual sciatica after lumbar disc surgery and $30 \%$ to $70 \%$ of patients reporting residual low back pain. ${ }^{1-10}$ Persisting symptoms mainly consist of pain, motor deficits, and a decreased functional status. Rehabilitation after lumbar disc surgery is an important tool in order to minimize these complaints. Although many different treatments have been suggested, little is known about the effectiveness of postsurgery rehabilitation. In a systematic review, 13 studies were identified that addressed the effectiveness of active rehabilitation after lumbar disc surgery." These studies were highly heterogeneous with regard to the start of the rehabilitation program ranging from two days up to more than 12 months postsurgery. Also, duration and intensity of the interventions differed widely, from a one-week post-surgery simple straight leg-raising regimelz to a 3 -month rehabilitation program. 13 We found no strong evidence for the effectiveness of any treatment. Based on two high-quality randomized controlled trials (RCTs), ${ }^{14,15}$ wre found some evidence for short-term effectiveness of intensive exercise programs that start 4 to 6 weeks post-surgery as compared to mild exercise programs. No relevant differences could, however, be demonstrated on long-term follow-up. It has been suggested that high intensity exercise programs confront patients with their fears and insecurities and that they may learn that symptoms related to training are not necessarily dangerous. 15

All interventions in the included studies are locused on biomechanical aspects such as range of motion or muscle strength, whereas psychosocial factors le.g. fear of movement) are hardly addressed. This is remarkable because most of the patients studied can be considered as chronic pain patients suffering from symptoms for a period of several months prior to surgery. In these patients psychosocial aspects such as fear of movement may be wery important. Directing interventions towards psychosocial aspects might, therefore, be ptomising in terms of patient outcome.

Based on recent studies 16.7 we hypothesized that behavioral graded activity (BGA), which is an operant treatment, may alter fear of movement and pain catastrophizing, and thus may subsequently lead to improved functional status and higher rates of recovery. So far, however, this has onlly been studied in patients with non-specific chronic low back pain. As far as we know, there is no randonized controlled trial that evaluates a behavioral program for patients following lumbar disc surgery. Therefore, the aim of this randomized controlled study is to evaluate whether a behavioral graded activity program is more effective than usual care as provided by physiotherapists when applied to patients after first-time lumbar disc surgery. Primary outcome measures ate recovery and functional status. 


\section{Materials and Methods}

\section{Study design and randomization}

In al randomized controlled trial we compared the effect of behavioral graded activity (BGA) and usual care (UC) in physiotherapy on the functional status and the recovery rate in patients after first-time lumbar disc surgery. The Medical Ethics Committee of the University Hospital Maastricht approved the study protocol. An extensive description of the design, background to the intervention and outcome measures thas been published elsewhere. ${ }^{\text {is }}$

By using opaque, sealed and coded randomization envelopes, which were based on computer-generated randomization lists, the research assistant who also performed the outcome assessments (MRK) was blinded. To assess the success of randomization several important prognostic factors (Table 1 ) were measured at baseline including scores for all outcome measures. Outcome measurements took place post-treatment ( 3 months after randomization) to detect short-term effects, and 6 and 12 months after randomization to detect long-term effects. In this paper we present the results of the 6 and 12 months follow-up. The short-term results have been reported elsewhere. ${ }^{19}$

\section{Selection of patients and informed consent}

Patients were scheduled for a routine post-surgery visit to the neurosurgeon six weeks after surgery. In the case of persisting symptoms (severe leg or back pain, motor deficits, or restriction of activities of daily life (ADL) and/or work) they were referred for physiotherapy, the neurosurgeon checked the eligibility criteria and patients received oral and written information about the study. The research assistant then provided further details about the study and reevaluated their eligibility. Inclusion criteria were: age between 18 and 65 years; first-time disc surgery (one level only); complaints (e.g. painj restricting their ADL and/or work. Patients were excluded in the case of surgical complications, to be judged by the neurosurgeon and based on preset criteria (merve root lesion, loss of cerebrospinal lluid, Loss of more than $600 \mathrm{ml}$ blood), in case of confirmed and relevant underlying diseases that influenced ADL (e.g., stenosis, malignancies, M. Bechterew, M. Scheuerman), or if one of the treatments was contraindicated (e.g. due to respiratory complaints). If patients were eligible and willing to participate, informed consent was signed.

\section{Interventions}

Behavioral Graded Activity (BGA) is based on operant treatment principles, using graded activity and positive reinforcement in order to increase healthy behavior and to decrease pain behavior. ${ }^{20,21}$ It is based upon time-contingency management as described in more detail by Fordyce 20,22 and applied by Lindstrom. 23 The term "Behavioral Graded Activity" for this program emphasizes the behavioral component, rather than merely physical training principles and has been described extensively elsewhere. ${ }^{18}$ Physiotherapists who attended a 2-day practical training course and two refreshment meetings during the study provided the treatment. The essence of BGA was to establish individually graded exercise trainings, based on 
baseline measurements performed at intake, and let patients experience that it is safe to increase activity levels. During initial basehne measurements patients were asked to perform activities (selected by patients themselves) or exercises until reaching (pain) tolerance. Then, patients set their own, individual, treatment goals for these activities or exercises. The next step was to set quotas (time contingent). which were systematically increased towards the pre-set goal. Quotas were not to be over performed nor under-performed. First quotas were slightly under baseline level, to assure that patients" initial experiences, while performing exercises, were successful. This enhances motivation and enables positive remforcement, which is one of the key principles in the operant conditioning theory. In this way, a patienttailored, indiwidual BGA-program was developed. Patients had to practice at home and document activities or exercises on performance charts that were discussed at each treatment session.

The content of UC was determined after extensive interviews with the participating physiotherapists. In general, the whole spectrum of techniques used by the physiotherapists was included which, in our opinion, is sensible when studying usual care. The main topics of usual care could be outlined from the treatment registration forms: all physiotherapists instructed their patients to exercise trunk muscles to increase strength and stability. The exercises aimed, furthermore, at increasing the levels of ADL. Sixty-five percent of the physiotherapists explicitly instructed patients how to lift, sit, and stand and how to perform other kinds of ADL. Forty five percent of the physiotherapists used some kind of electrotherapy in at least 3 (or more) sessions to decrease pain and muscle tone. Thirty percent of the physiotherapists used some kind of hands-on technique (massage or manipulations) in some of the treatment sessions (ranging from 2 up to 13 sessions) to decrease pain and muscle tonus.

The physiotherapists documented every session on treatment registration forms in both treatment conditions. These treatment conditions consisted of a maximum of 18 sessions ( 30 minutes each) within a period of 3 months. Contrary to the BGA, UC physiotherapists were allowed to stop treatment as soon as the complaints had disappeared and the treatment goals had been achieved, thus complying with usual care principles.

\section{Integrity check of the interventions}

The following features were used to define the difference between BGA and UC. First of all, BGA is based on systematic baseline measurements, while UC relies on anamnesis and physical examination. Secondly, $\mathrm{BGA}$ management is time contingent once quotas have been set, while UC evaluates reactions on previous treatments and eventually adapts treatment intensity based on this pain contingent evaluation. Thirdly, BGA relies on specific behavioral components: goal-setting by patients, performance charts, systematic appraisal and reinforcement of health behaviors and extinction of pain behavior.

To assess the difference, audiotapes were recorded in a selection of patients from both treatment groups. All treatment sessions were recorded but only the 1 "s , 2 nd 
the $10^{\text {th }}$ and the last session were used for evaluation because these sessions were believed to be the most informative. Informative sound samples were copied to a master tape in random order. Three blinded experts scored the audiotapes of randomly selected treatment sessions. All samples were scored on a visual analogue scale (VAS). These continuous VAS scales were subsequently categorized into 3 point scales $(0 \mathrm{~mm}$ through $3.3 \mathrm{~mm}$ into " $1 " ; 3.4 \mathrm{~mm}$ through $6.7 \mathrm{~mm}$ into " 2 "; 6.8 mm through $10 \mathrm{~mm}$ into $\left.{ }^{\prime \prime}\right)$. As a first step, experts scored their overall impression of every sound sample with regard to UC characteristics. On this scale " 1 " denotes. "no usual care characteristics", "2" denotes "some usual care characteristics" and "3" denotes "mainly usual care characteristics", meaning that BGA sound samples. ideally should score " 1 " and UC " 3 ". As a second step, the overall quality of BGA characteristics in each sound sample was assessed. On this scale "1" denotes "poor quality", "2" denotes "moderate quality" and " 3 " denotes "good quality". Finally, the quality of three typical $\mathrm{BGA}$ characteristics (if present in the sound sample) was assessed: extinction of pain behavior, reinforcement of healthy behavior and whether information about prognosis and symptoms was provided from a biopsychosocial perspective. On these scales "1" denotes "poor quality", "2 "denotes "moderate quality" and " 3 " denotes "good quality". (BGA sound samples should ideally score " 3 " and UC " 1 "). Three pre-recorded sound samples, in our opinion containing the optimal quality for the BGA characteristics, were also included, in order to evaluate the scoring system.

\section{Prognostic factors and outcome measurements}

Demographic and clinical information was retrieved from the patient files. At baseline, the duration of complaints, medication, previous treatments and professional occupation were documented. At baseline, patients were also asked to rank their level of confidence with respect to recovery (great deal, moderate amount, no, clon't know). After 2 treatment sessions, patients were asked to what extent they expected the allocated treatment to be beneficial to them 110 -point Likert-scale: $0=$ expects no benefit at all, $10=$ absolutely convinced of benefit). ${ }^{24}$ Negative affectivity was assessed with the Negative Emotionality (NEM) subscale (14 items, 2 point scale) of the Multidimensional Personality Questionnaire. ${ }^{25,26}$ Negative affectivity correlates with psychosomatic symptoms, anxiety, worries, and poor role adjustment. High NeM scores denote high levels of negative affect.

\section{Outcome measurements}

Primary outcome measures were: (i) Global perceived effect (GPE) rated on a 7-point scalle ( 1 completely recovered, 7 =worse than ever) to assess recovery. These ratings were dichotomized into "improved" ("completely recovered" and "much improved"), versus "not improved" ("slightly improved", "not changed", "slightly worsened", "much worsened", "worse than ever"); (ii) The Roland Disability Questionnaire (RDQ) ${ }^{27}$ This measures low back specific functional status and the Dutch translation was validated.28.29 Secondary outcome measures were: (i) Fear of movement (Tampa Scale for Kinesiophobia (TSK)). ${ }^{30}$ The Dutch translation has a fair and consistent internal validity "31 (ii) The Pain Catastrophizing Scale (PCS) ${ }^{32}$ that measures catastrophizing (viewing pain as extremely threatening). Intensity of low 
back pain or sciatica was scored on a VAS. Relevance, validity and relability of the VAS are commonly accepted in the area of low back pain, 335 At baseline, patients selected two important ADL activities that were severely hampered by their symptoms, in a standardized fashion. These were called Main Complaints (MC).370 The severity was scored on a VAS. General health and social functioning were evaluated by using the corresponding subscales of the $S F-36 .{ }^{37}$ The Dutch translation by van der Zee et al. ${ }^{38}$ showed satisfactory validity and reproducibility. Range of motion (ROM) (flexion, extension) of the lumbar spine is measured by the EDI-320 that proved to be acceptably reproducible, especially for nexion. 394 occurrences of re-operations, use of medication and health care utilization were recorded at one-year follow-up.

\section{Analysis}

Treatment registration forms were screened, to identify protocol violations, during a consensus meeting with the project team. In the BGA program protocol violations were defined as: use of passive treatment modalities, not fulfilling quotas more often than twice, co-interventions by other health care providers le.g., neurosurgeons, general physicians, or treatments by other physiotherapist). In usual care, only major interventions such as ceasing treatment according to the advice of the neurosurgeon were recorded as protocol violations.

Statistical analyses were carried out according to the intention to treat principle: all patients, including withdrawals from treatment and patients with poor compliance remained in the group to which they were assigned by randomization. The cause of dropping out determined the replacement procedure: 1) patients were assigned the mean value of their group if there was no association with allocated treatment (c.g., patients moved out of the catchment area, or dropped out before first treatment), 2) patients received negative scores if they had more pain, or when the neurosurgeon advised stopping treatment because of the suspicion of a (new) herniated disc, 3) patients received positive scores if they had returned to work full-time or if there were other indications that justified a positive score (e.g. physiotherapists" report). For substitution of negative or positive scores we used the $10^{\text {th }}$ or $90^{m}$ percentile scores of the total group. Three experts assigned replacement values independently and blinded for treatment allocation. If 2 out of the 3 experts attributed the same substitution value, then this value was used. In addition, a per-protocol analysis was performed which was restricted to those patients who complied with the treatment protocol. For all analyses, SPSS 9.0 for Windows (SPSS Inc. North Michigan Avenue, Chicago, IL, 60611) was used. For outcome measures collected at baseline the difference with post-treatment values was calculated for each individual; these change-scores were used to compare both treatment groups using Student's twtest for statistical significance. For outcome measures without baseline measurement (e.g. GPw) difference between groups at the follow-up were analyzed. Group differences and two-lailed $95 \%$ Confidence Intervals $(95 \% \mathrm{Cl})$ were calculated for all outcome measures. In order to adjust for possible baseline differences a multiple linear regression analysis for continuous outcome measures was performed with the change scores as dependent variable, treatment as inclependent 
wariable, and baseline scores of the prognostic variables fand the particular outcome measure, if appropriatel as co-variables.

Subgroup analyses were carried out to determine whether particular categories of subgroups showed different outcomes than the treatment groups as a total. Dichotomized subgroups were formed according to negative affectivity (cut-off on NEM: 7), fear of movement (cuit off on TSK: 40) and confidence of patients about their recovery ("great deal" versus "moderate amount", "no", and "don"t know"). With respect to the audiotapes for assessing the treatment integrity of both interventions, first agreement between the three experts was calculated on the original VAS scores by means of Pearson"s $r$. Then, for each characteristic, the percentage correctly classified was calculated.

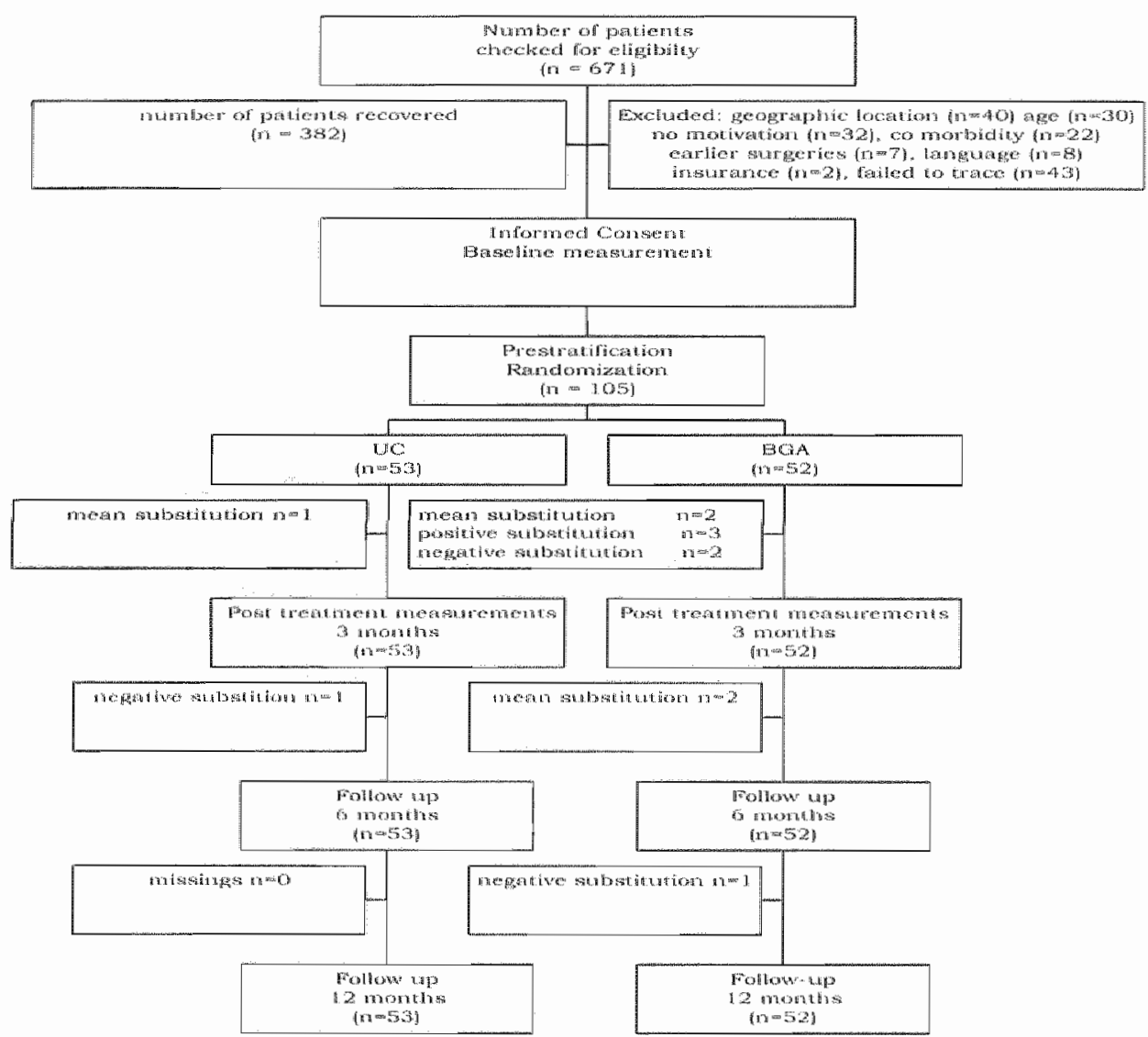

Figure 1: Patient tlow through study. 


\section{RESULTS}

From November 1997 until December 1999, 671 patients were screened for eligibility in the 4 participating hospitals in the South of the Netherlands. More than half of the patients recovered after first-time lumbar disc surgery and suffered no further substantial symptoms $157 \%$ ) 141 patients (21\%) were excluded because of various reasons: patients, although operated in a participating hospital, were not living in the catchment area $(n=40)$, not motivated to participate $(n=32)$, too old $(n=30)$, presented with co-morbidities $(n=22)$, language problems $(n=8)$, previous lumbar surgeries $(n=7)$, and due to insurance problems $(n=2)$. We failed to trace 43 patients $(6 \%)$. In total $105(16 \%)$ patients were eligible and signed informed consent. Figure 1 summarizes the patient flow through the study.

On average, 15.5 treatment sessions were realized in UC versus 14.8 in $B G A$. On the post-treatment measurement 8 patients dropped out: 1 from the UC group and 7 from BGA. The UC patient disappeared after 2 treatments without stating any reason and was therefore assigned the mean values of the usual care group. "Two BGA patients withdrew from the study due to aggravated symptoms: negative scores therefore substituted their values. One BGA patient showed an exacerbation of symptoms prior to treatment and another BGA patient suffered from rheumatic symptoms, a disease he had not mentioned before randomization. We considered the reasons for these drop outs not to be related to the postoperative treatment: therefore, they were assigned mean values. One BGA patient reported to be completely pain-free after 2 treatment sessions and was no longer motivated to participate in the study, and another BGA patient stepped out when resuming his professional occupation full time (without residual signs or symptoms), due to lack of time and motivation. One BGA patient withdrew because of personal circumstances and had actually recovered after 5 treatment sessions. The values of these three BGA patients were substituted by positive values. After 6 months followup 2 more patients dropped out from the BGA group: 1 patient underwent an operation for an intestinal disorder, another patient dropped out without obvious reasons and did not react to several "voice mail" requests. Both patients were assigned mean values. In the UC group one patient dropped ont because of aggravated symptoms; negative values were therefore used for substitution. After 12 months lollow-up another BGA patient dropped out due to aggravated symptoms; therefore negative vallues were used for substitution.

In both groups the majority of the patients underwent standard discectomy. In BGA one patient had a laminectomy and one patient a foraminotomy; in UC one patient. underwent a facetectomy. There was one patient with complications during surgery in UC (nerve root lesion) and one in BGA (loss of cerebraspinal nuid). The postsurgery regime was standardized and identical for both groups: while hospitalized IUC mean of 7.7 days (SD: 2.7), versus BGA mean of 7.0 days (SD: 1.3 ). physiotherapists instructed patients with respect to low-back exercises and how to resume ADL. Analgesics were prescribed on a pro re nata (PRN) basis: In UC $34 \%$ 
Table 1. Basche characteristics of both treatment groups.

\begin{tabular}{|c|c|c|c|c|}
\hline \multirow{2}{*}{$\begin{array}{l}\text { Characteristics } \\
\text { Age (years) }\end{array}$} & \multicolumn{2}{|c|}{ Usual Care $(\mathrm{n}=53)$} & \multicolumn{2}{|c|}{$B G A(n=52)$} \\
\hline & 43.7 & $(8.8)$ & 42.8 & $(8.8)$ \\
\hline No (\%) of women & 19 & $(35,8)$ & 26 & $(50.0)$ \\
\hline Type of surgery: standard discectony (\%) & 70 & & 78 & \\
\hline $\begin{array}{l}\text { Level of surgery } \\
\cdot \quad \text { L4L5 (\%) } \\
\cdot \quad \text { L5-51(\%) }\end{array}$ & $\begin{array}{l}43.1 \\
52.9\end{array}$ & & $\begin{array}{l}49.0 \\
44.9\end{array}$ & \\
\hline $\begin{array}{l}\text { Surgical findings } \\
\text { - Sequester }(\%) \\
\text { - Protrusion }(\%)\end{array}$ & $\begin{array}{l}38.5 \\
51.9\end{array}$ & & $\begin{array}{l}38.8 \\
49.0\end{array}$ & \\
\hline Duration hospitalization (days) & & $(2.7)$ & 7.0 & (1.3) \\
\hline $\begin{array}{l}\text { Duration of symptoms before surgery } \\
\qquad \begin{array}{l}\quad 3 \text { months: (No } \% \% \text { ) } \\
-3 \text { months: (No } \% \%) \text { ) }\end{array}\end{array}$ & $\begin{array}{r}9 \\
44\end{array}$ & $\begin{array}{l}(17) \\
(B 3)\end{array}$ & $\begin{array}{r}7 \\
45\end{array}$ & $\begin{array}{l}\text { (13) } \\
(87)\end{array}$ \\
\hline Physiotherapy immediately after surgery $(\%)$ & 33 & & 42 & \\
\hline Taking pain medication (No $(\%)$ & 18 & (34) & 20 & (38) \\
\hline Physiotherapy before surgery (No $(\%)$ & 30 & $(56.6)$ & 32 & $(60,4)$ \\
\hline Other treatment before surgery ( $N$ No $(\%)$ ) & 16 & $(30.2)$ & 13 & (23.9) \\
\hline Paid employment (No ( & 37 & $(69.8)$ & 47 & $(90.4)$ \\
\hline $\begin{array}{l}\text { Confidence with regard to recovery in general (N } \\
\text { - Great deal } \\
\text { - Noderate amount } \\
\text { - Don't know }\end{array}$ & $\begin{array}{r}22 \\
18 \\
3 \\
10\end{array}$ & $\begin{array}{l}(41.5) \\
(34.0) \\
(5.7) \\
(18.9)\end{array}$ & $\begin{array}{r}21 \\
24 \\
3 \\
4\end{array}$ & $\begin{array}{l}(40.4) \\
(46.2) \\
(5.8) \\
(7.7)\end{array}$ \\
\hline Expectancy of allocated treatment $(0-10 \text { points })^{*}$ & 6.9 & $(1.6)$ & 6.9 & $(1,1)$ \\
\hline Megative affectivity (0-14 points) & 37 & $(4.0)$ & 4.2 & $(4.1)$ \\
\hline Outcome measures & & & & \\
\hline Roland Disability Questionnaire (0-24 points) & 13.5 & $(4.5)$ & 14.5 & $(3.7)$ \\
\hline Tampa Scale (17-68 points) & 36.9 & $(6.8)$ & 35.9 & $(6.3)$ \\
\hline Pain-Calastrophizing Scale (0-52 points) & 16.9 & $(11.7)$ & 17.1 & $(10.2)$ \\
\hline Main Complaint $(0-100)$ & 67.4 & $(15.4)$ & 71.1 & $(16.5)$ \\
\hline Pain in back (No $\%)$ & 45 & $(85)$ & 48 & $(92)$ \\
\hline Severily of pain in back (0-100) & 46.7 & $(27.3)$ & 43.4 & $(30.0)$ \\
\hline Sciatica $(N o[\%)\}$ & 52 & $(98)$ & 50 & $(96)$ \\
\hline Severity of sciatica $(0-100)$ & 41.3 & $(30.8)$ & 39.0 & $(28.2)$ \\
\hline Range of Moltion & 81.2 & $(22.7)$ & 78.1 & $(22.6)$ \\
\hline Geineral Heath (Subscale SF-36) & 65.6 & $(20.0)$ & 68.2 & $(18.4)$ \\
\hline Social Funclioning (Subscale SF-36) & 59.4 & $(25.3)$ & 56.7 & $(26.6)$ \\
\hline
\end{tabular}

* Administered after 2 treatments

Walles are means with standlard doviations between brackets uninss stated otherwise.

used analgesics versus $38 \%$ in BGA. Distributions of baseline characteristics of both groups are presented in Table 1. In BGA there were slightly more women and the number of patients with paid employment was higher. However, both groups 
showed similar demographics and clinical baselne characteristics. Furthermore, treatment expectancies proved to be similar in both treament groups. Both groups showed quite similar scores for all outcome measures.

At the post-treatment measurements it appeared that in each group in one case surgery was repeated at the same level as initially. After 6 months follow-up 2 more operations were repeated, again one in each group. After 12 months follow-up another two operations were repeated in the BGA group. The total number of repeated operations at 12 months follow-up was 4 in BCA and 2 in UC.

Table 2 presents the results of the effectiveness of the interventions. After 6 months' follow-up $62 \%$ of the patients had recovered in UC versus $65 \%$ in BGA. After 12 months follow-up these rates were $73 \%$ in UC and $75 \%$ in BGA. The differences between interventions, $3 \%$ and $2 \%$ respectively, after 6 and 12 months follow-up are statistically not significant. Although the improvenents on the disability scores, as measured by the RDQ, are statistically significantly different within the groups and clinically relewant, differences between groups are not. After 12 months followup a statistically significant difference occurs in favor of the BGA on pain catastrophizing, although the $3.3-$ point difference $(95 \% \mathrm{CI}:-6,4 ;-0,1)$ on this scale bears no clinical importance. 42 TSK-scores show minor improvements only within the groups and no differences between the groups. Furthermore, table 2 shows that there are no large differences between groups on any of the other outcome measures, although the within-group improvements are statistically significant and clinically relevant. Adjustments for a priori identified co-variables (baseline scores of RDQ, TSK, NEM, pain back, PCS, duration of complaints and level of confidence in recovery) did not alter the results substantially. Therefore, we present only the unadjusted results. The per-protocol analyses were restricted to 78 patients: 45 patients in UC and 33 patients in BGA. The prognostic comparability between the intervention groups that qualified for the per-protocol analyses was quite similar to the results as summarized in Table 1. In general, the per-protocol analyses resulted in slightly larger improvements within groups, but the between group differences did not change substantially.

Subgroup analyses revealed no differences after 6 or 12 months follow-up in outcomes for negative affectivity (cut-off on NEM: 7), fear of movement (cut-off on TSK: 40) or confidence of patients concerning their recovery ("great deal" wersus "moderate amount", "no", and "don"t know").

After one year of follow-up the number of patients using medication and health care utilization was recorded over the preceding 3 months. In UC $31 \%$ used analgesics versus $21 \%$ in BGA. Over this same period $33 \%$ in UC visited a general practitionen (GP) versus $30 \%$ in BGA. Also the number of patients visiting a specialist (neurosurgeon, neurologist or orthopedic surgeon) and physiotherapist were more or less equal: 13\% in UC versus 15\% in BGA for specialists and $12 \%$ in UC versus $10 \%$ in BGA for physiotherapists. None of the above-mentioned differences are statistically significantly different. 


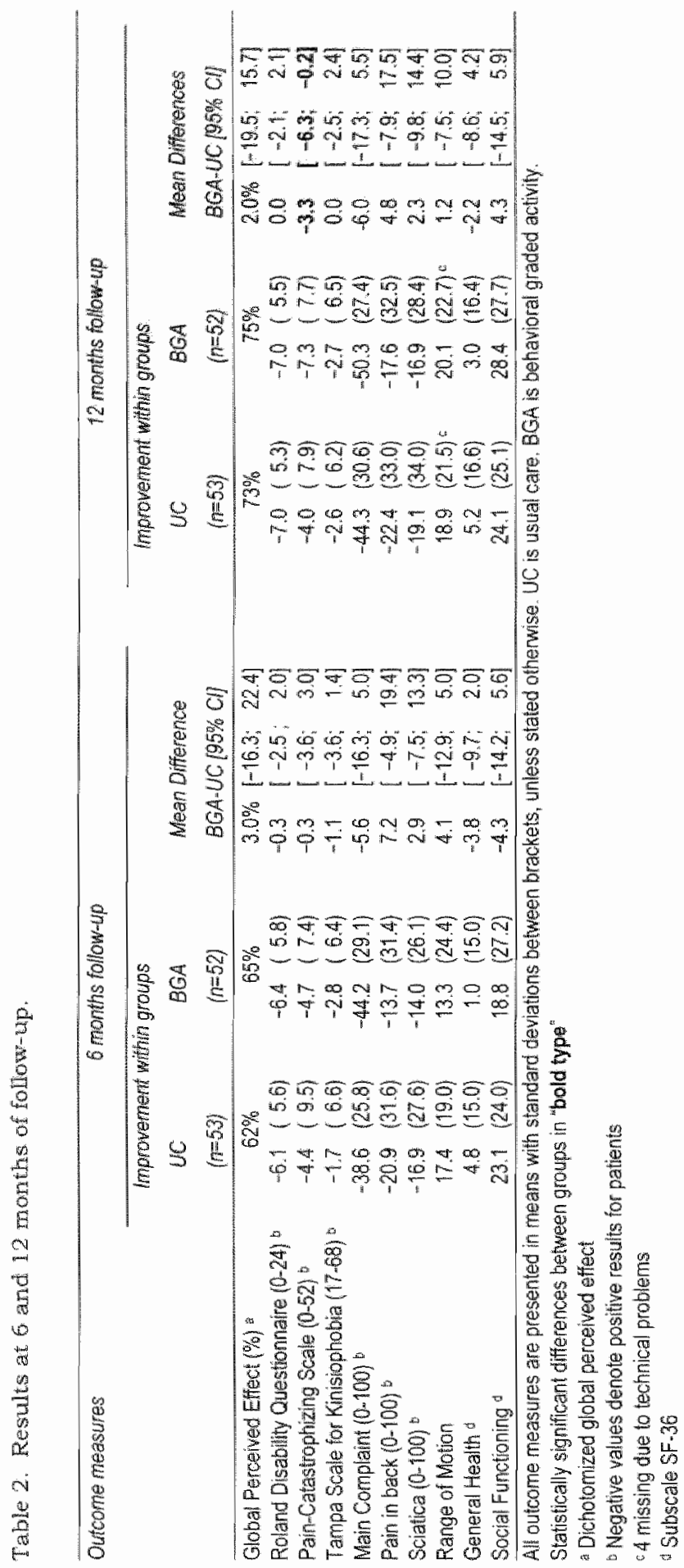




\section{Integrity check of the interventions.}

The final master tape contained 24 sound samples 13 BGA samples and 11 UC samples) plus the three prenecorded samples. The Pearson's $r$. for the agreement between experts, was on average 0.65 ranging from 0.55 up to 0.82 for the various characteristics. Therefore, we conclude that the overall agreement was acceptable. Furthermore, the 3 prerecorded samples were scored in all instances as expected, thus supporting the validity of our scoring system. Calculating the percentages of the scores on the 3-point scales for both treatment conditions separately showed that, on average, $70 \%$ to $80 \%$ of the sound samples were scored in expected categories on the various quality assessments and $20 \%$ to $30 \%$ were classified in one of the remaining categories le.g. UC samples were scored as "no usual care characteristics" or "Some usual care", or identified BGA characteristics were rated as "poor quality" or "moderate quality").

\section{Discussion}

\section{Main Findings}

The effectiveness of a behavioral graded activity (BGA) program compared to usual care (UC) was assessed in a single blinded randomized controlled trial. The posttreatment measurement, 3 months after randomization, revealed that on global perceived effect the BGA program performed statistically significantly worse than UC $(19.3 \%$ difference, $95 \% \mathrm{Cl}: 0.1 \%, 38.5 \%)$. For all other outcome measures there were no relevant differences between the groups, although the improvements within groups were, in general, statistically significant and clinically relevant. "These substantial improvements within groups on global perceived effect and RDQ in the short-term were to a lesser extent continued after 6 and 12 months but the differences between groups remained negligible. A same pattern could be observed for all other outcome measures. However, pain catastrophizing (PCS) and fear of movement (TSK) showed no relevant improvements at the post-treatment follow-up or after 6 and 12 months. In BGA 4 operations were repeated versus 2 in VC. There were no substantial differences with regard to medication use after one year of follow-up.

\section{Can post-surgery patients be considered as chronic pain patients?}

A priori we hypothesized that BGA would alter fear of movement and paincatastrophizing: which would subsequently lead to improved functional status and higher rates of recovery in patients after first time lumbar disc surgery. This assumption was primarily based on studies conceming fear of movement and paincatastrophizing in patients with chronic low back pain. ${ }^{16}$ However, the results of the current study do not support this hypothesis. Both fear of movement and paincatastrophizing, seem to be unaffected by either treatment in this population. One explanation might be that patients who underwent lumbar clisc surgery are different from patients with chronic low back pain. For example, RDQ scores at baseline in the current study are relatively high compared to recent studies that include patients with chronic low back pain ${ }^{43.45}$, indicating a more severe degree of 
disability. Furthermore, although patients in the current study had suffered symptoms for, on average, 12.8 months (SD: 47.1 months) and are, therefore, usually labeled as chronic, the period after the operation might be more important to classify these patients. It could be argued that patients who had a new start in their low back pain episode, because they had undergone an operation but had not yet recovered after 6 weeks, might be considered as balancing on the threshold of becoming patients with chronic low back pain ${ }^{4 s}$ and that treatment principles derived from theories with the field of chronic low back pain might therefore not apply to this group.

\section{Methodological issues concerning the current study}

Missing values are always a considerable nuisance when analyzing results." Unfortunately, no clear-cut solutions are available. In this study, 12 patients were lost to follow-up afiter one year. We decided to take into account the reasons for not attending the follow-up measurements because we think that this procedure best anticipates the information at our disposal. In BGA more protocol violations were recorded, as expected, because the definition of protocol violation in BGA was stricter compared to UC where only major interventions were considered to be protocol violations. In general, the per-protocol analyses resulted in slightly more improwements within groups, but the between-group differences did not change substantially. One explanation might be that especially patients who do not show any improvement during treatment are more prone to violate the treatment protocol. Another reason might be that the treatment induces larger improvements, if compliance is good. Anyhow, the between-group differences did not change substantially and therefore we concluded that our findings are not influenced by protocol viollations.

Treatment integrity of both interventions is an important issue in the current study. Despite the 2-day training course and refreshment meetings during the trial, BGA might still not have been delivered as planned. To change the behavior of carers might be as difficult as changing the behavior of patients. Therefore, we recorded treatment sessions in both treatment conditions on audiotapes. Overall, three blinded experts classified $70 \%$ to $80 \%$ of the sound samples in the correct categories resulting in the conclusion that although experts were able to distinguish between both approaches in the majority of the cases, there was an overlap of $20 \%$ to $30 \%$ resulting in less contrast than we thought (and hoped for) in advance. Furthermore, these results indicate that UC incorporated specific characteristics of BCA (e.g. reinforcement of health behaviors, extinction of pain behavior and more functional training) and BGA-therapists, albeit specifically trained, still used some UC characteristics in their treatment of or communication with patients. This is in accordance with a survey that showed that even if physiotherapists are trained in biopsychosocial approaches, attitudes and beliefs regarding details of specific treatment issues differ widely. 47 However, as $70 \%$ to $80 \%$ were classified correctly and BGA did not show the slightest sign of being more effective than UC, we do not believe that this overlap concealed any possible effect of BGA. 
We did not include a no-treatment control group because the aim of this study was to investigate whether BGA was more effective than UC as provided by physiotherapists, which is a standard prescription in the participating hospitals. Therefore, all patients who still suffered complaints at the six-tyeek routine postsurgery visit to the neurosurgeon were treated. Furthemore, it was considered inappropriate to withhold treatment from patients if they still had symptoms six weeks after surgery. But now, as both interventions show similar results, it is difficult to attribute improvements to either treatment. "These results may represent the natural course after first-time lumbar disc surgery.

\section{Comparison with other studies}

Comparing the results of the current study with the systematic review that assessed the effectiveness of active rehabilitation programs after lumbar disc surgery" is difficult because none of the included studies incorporated cognitivebehavioral treatment. However, in the current study, as well as in the systematic review, there are no relevant differences on long-term follow-up when comparing two active rehabilitation programs. Although active rehabilitation might be effective after lumbar disc surgery, it is not yet clear which components should be present in such a program. There is not much evidence with regard to the optimal starting point for rehabilitation after lumbar disc surgery. "Should all patients be treated. immediately after surgery or is it more efficient and effective to wait for 4 to 6 weeks. and then include only patients who have not yet recovered? In the current study patients were included if they still suffered from symptoms at the 6-weeks consultation. Therefore, based on this study, it is not possible to make recommendations with regard to the optimal starting point for post-surgery interventions.

\section{Future research}

Fear of movement did mot change in this study. If fear of movement could be diminished it might well result in better recovery rates and an improved functional status. It has been argued that a very essential step in decreasing fear of moverient is exposing patients to situations they have identified as "dangerous' or threatening'. Such a graded exposure is quite similar to BGA in that it gradually increases activity levels despite pain, but dissimilar in that it pays attention to the idiosyncratic aspects of the pain-related fear stimuli. In other words, patients should not perform activities or exercises in general but should explicitly be exposed to those elements that they fear. 16 Preliminary results show that exposure of patients with chronic low-back pain to specific exercises as opposed to general exercises reduced fear of movement substantially. 48 . Whether this holds true for patients after lumbar disc surgery is not yet studied.

Introducing interventions that include more specific behavioral dimensions raises an important issue concerning qualifications of therapists. It has been suggested that this qualification might be of great importance. Deliverimg behavioral treatments appropriately requires specific skills and experience that are not selfevident for all health care providers. Therefore we suggest that in future research, 
behavioral approaches should first be evaluated using well equipped and experienced pair-therapists. When reporting these studies, qualifications of therapists and content of training should be described. Using unqualilied and more or less inexperienced therapists to assess the effectiveness of behavioral approaches might mask possible effects. Other topics that need to be addressed concern the optimal starting point for rehabilitation programs and whether all post-surgery patients should be treated or whether treatment should be restricted to patients who still have symptoms $4-6$ weeks post-\$urgery.

\section{KEY POINTS}

- Little is known about the effectiveness of rehabilitation programs after lumbar disc surgery and no randomized controlled trials exist assessing behavioral treatment including patients following lumbar disc surgery.

- The two treatment conditions, behavioral graded activity and usual care as provided by physiotherapists, administered in the current randomized controlled trial, that included 105 patients after first-time lumbar disc surgery, were equally effective after one year of follow-up.

- Future research should focus on more specific treatments and use qualified and experienced health care providers for assessing the effectiveness of cognitive-behavioral programs.

\section{ACKNOWLEDGEMENTS}

The authors would like to thank the "Profileringsfonds" of the University Hospital Maastricht and the "Stichting Annafonds" for their financial support. Furthermore we would like to thank all participating neurosurgeons from the University Hospital Maastricht, Atrium Hospital Heerlen, Maasland Hospital Sittard and Laurentius Hospital Roermond for referring patients to our study. We are grateful to all physiotherapists and patients for participating in this study. We are indebted to Rob Pelt and Jan Thomassen for training and monitoring the physiotherapists. We appreciate the assistance of Cobie Martens with logistic and data management.

\section{REFERENCES}

1. Dvorak J, Valach $L$, Fuhrimanm P. Heim E. The outcome of surgery for lumbar disc herniation. II. A 4-17 year's' follow-up with emphasis on psychosocial aspects. Spine $1988 ; 13(12): 1423-7$.

2. Spangfort EV. The lumbar cisc hemiation. A computer aided analys sis of 2,504 operations. Acta Orthop Scand Suppl 1972,95: 1421-95.

3. Weber H. Lumbar disc herniation. A controlled, prospective study with ten years of observation. Spine 1983;8(2): 131-40.

4. Hurme $M$, Alaranta $\mathrm{H}$. Factors predicting the result of surgery for lumbar intervertebral disc herniation. Spine 1987;12(9):933-8. 
5. Barrios C, Ahmed M, Arrotegui JI, Bjornsson A. Clinical lachrs predicting outcome after surgery for hemiated lumbar disc: an epidemiolowical mulimariate andysis. I Spinal Disord $1990 ; 3(3): 205-9$.

6. Korres DS, Loupassis $G$, Stamos K. Results of Wmbar discectomy a sudy using 15 different evaluation methods. Eur Spine J 1992; 1:20 -4.

7. Pappas CTE, Harrington T, Sonntag VKH. Outcome analysis in 654 surgically treated lumbar disc hernatons. Neurosurgery 1992;30(6):862-866.

8. Smulders WLM, Loon van $G$. Nabehandeling na lumbale discectomit of chemonucleolyse. Een 'ont-patient' enquéte. Fystopraxis 1993,219$) \cdot 4-6$

9. Manniche $\mathrm{C}$, Asmussen KH, Vinterberg H, Rose Hansen EB, Kramhoh J, Jordan A. Back pain, sciatica and disability following first-tine conventional hatmilaminectony for lumbar disc herniation. Use of "Low Back Pain Rating Scale" as a postal questionnaire. Dan Med Bull 1994:41(1):103-6.

10. Manniche $\mathrm{C}$, Asmussen KH, Wuterberg H, Rose Hansen EB, Krambolt Jordan A. Analysis of preoperative prognostic factors in first time surgery for lumbar disc herniation, including Finneson's and modified Spengler's score systems. Dan Med Bull $1994 ; 41(1): 110-5$

11. Ostelo RWJG, Vet de HCW, Waddell G, Kerckhoffs MR, Leffers P, Tulder wan MW. Rehabilitation after first-time diso surgery. A systematic review within the Cochrane framework. The Cochrane library, Issue 2 2002. Oxford: Update Software

12. Kitteringham $\mathrm{C}$. The effect of straight leg raise exercises after lumbar decompression surgery - A pilot study. Physiotherapy 1996,82(2)" 115-23.

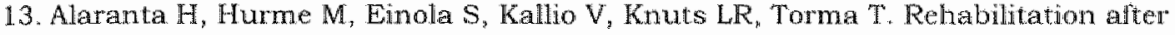
surgery for lumbar disc hemiation: results of a randomized dinical trial. Intet J Rehabil Res $1986 ; 9(3): 247-57$

14. Danielsen JM, Johnsen R, Kibsgaard SK, Hellevik E. Early aggressive exarcise fot postoperative rehabilitation after discectomy. Spine $2000,25(8): 1201-6$.

15. Manniche $\mathrm{C}$, Shall HF*, Braendmolt $\mathrm{L}_{\mathrm{v}}$ et al. Clinical trial of postoperative dymamic back exercises after first lumbar discectomy. Spine 1993; 18(1):92,7.

16. Vlaeyen JWS, Crombez G. Fear of movement/(re)injury, avoidance and pain disability in chronic low back pain patients. Man Ther 1999;4(4):187-195.

17. Tulder van MW, Ostelo RWJG, Vlaeyen JWS, Linton SJ, Molley SJ, Assendellt WJ. Behawioral treatment for chronic low back pain: a systematic revtew within the framework of the Cochrane Back Rewiew Group. Spine 2001;26(3):270-81

18. Ostelo RWJG, Köke AJA, Beurskens AJHM, et al. Behavioral-Graded activity conpared with usual cant after first-time disk surgety: Considerations of the design of a randomized clinical trial J Manipulative Phystol Ther 2000,23(5):312-9.

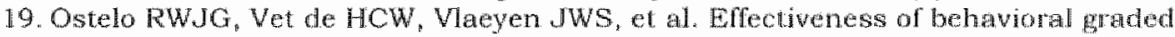
activity after first-time disc surgery. Submitted 2001 .

20. Fordyce WE. Behavioral methods for chromic pain and illiness. St. Louis: Mosby, 1976.

21. Waeyen JW, Haazen IW, Schueman JA, Kole Snijers AM. Eek van H. Behawoud rehabilitation of chronic low back pain: comparison of an opterant tieatment, an operant-cognitive treatment and an operant-respondent treatment. Br. J Clin Psychot $1995,34\left(P_{1}, 1\right): 95-118$.

22. Fordyce We, Fowler RS, Lehmann If Delateur BJ, Sand PL. Trieshmann RB. Operant conditioning in the treatment of chronic pain. Arch Phys Med Rehabil 1973:54(9):399. 408

23. Lindström 1, Ohlund C, Eek C, et al. The effect of graded actuity on patients witt subacute low back pain. a randomized prospective clinical study an operantconditioning behavioral approach. Plyys lhet 1992;72(4):279-93.

24. Vaeyen JWS, Kole-Srijders AMJ, Eek van H. Chronische pijn on revalidiatie Houten: Bohn Stakleu van Joghum, 1996

25. Tellegen A. Brief Manual for the Multidimensional Personality Questionnaire. Unpublished Manual. University of Minnesota 1982.

26. Stegen $K$, Neujens $A$, Crombez $G$, Hemans D, de Woestijne van de KP, Bergh wan der O. Negative affect, respiratory reactivty, and somatic complaints in a CO2 onriched air inhalation paradigm. Biol Psychol 1998;49(1-2):109-22. 
27. Roland M, Morris R. A study of the natural history of back pain. Part I: development of a reliable and sensitive measure of disability in low-back pain. Spine $1983 ; 8(21: 141 \sim 4$

28. Beurskens AJ, Vet de $H C$, Köke AJ. Responsiveness of functional status in low back pain: a comparison of different instruments. Pain 1996;65(1):71-6.

29. Gommans IHQ, Koes BW, Tulder van MW. Validiteit en responsivteit wan de Nederlandsetalige Roland Disability Questionnaire. Neder Tijdschr Fysioth $1997 ; 107(2): 28 \sim 33$

30. Miller RP, Kori SH, Todd DD. The Tampa Scale. Tampa, FL, 1991.

31. Vlaeyen JW, Kole Snijders AM, Boeren RG, Eek van H. Fear of movement/(rejinjury in chronic low back pain and its telation to behavioral performance. Pain 1995;62(3):36372 .

32. Sullivan MuL, Bishop SR, Pivik J. The Pain catastrophizing Scalle: Development and Validation. Psychological Assessment 1.995;7:524-32.

33. Carlsson AM. Assessment of chronjo pain. I. Aspects of the reliability and validity of the visual analogue scale. Pain $1983,16(1), 87-101$.

34. Revill SI, Robinson JO, Rosen M, Hogg MI. The reliability of a linear analogue for evaluating pain. Anaesthesia 1976,3199:1191-8.

35. Sriwatanakul K, Kelvie W, Lasagna L, Calimlim JF, Weis OF, Methta G. Studies with different types of visual analog scales for measurement of pain. Clin Pharmacol Ther $1983 ; 34(2): 234 ; 9$

36. Beurskens AJHM, Vet de HCW, Köke AJ, et al. A patient-specific approach for measuring functional status in low back pain. J Manipulative Physiol Ther $1999 ; 22: 1444-8$.

37. Ware JE, Sherbourne CD. The MOS 36-item short-form health survey (SF-36). I. Conceptual framework and item selection. Med Care 1992;30|6|:473-83.

38. Zee van der $\mathrm{K}$, Sanderman $\mathrm{R}$, Heyink $\mathrm{J}$. De psychometrische kwallteiten van de MoS 36-item short Form Health Survey (SF-36) in een Nederlandse populatie. T Soc Gezondheidsz. 1993; $7: 183-191$

39. Chiarello CM, Savidge R. Interrater reliability of the cybex EDI-320 and fluid goniometer in normals and patients with low back pain. Arch Phys Med Rehabil 1993;74:32-7.

40. Koes BW, Mameren van $H$, Bouter LM, et al. Reproduceetbaarheid van metingen aan de wervelkolom tnet de hoekmeter EDI-320. Neder Tijdschr Fysiother 1989;99(7/8):207-211

41. Bo K, Hilde $\mathrm{G}$, Storheim $\mathrm{K}$. Intra- and interobserver reproducibility of Cybex EDI-320 measuring spinal mobility. Scand J Med Sci Sports 1997;7(3):140-3.

42. Damme van $S$, Crombez $\mathrm{G}$, Vlaeyem JWS, Goubert L, Broeck van den A, Houdenhove vain B. The Pain Catastrophizing Scale: Psychometric characteristics and norms [Dutch] De Pain Catastrophizing Scale: Psycometrische karakteristieken en normeringen. Gedragstherapie $2000 ; 33(3): 211.222$.

43. Klaber Moffet J, Torgerson D, Bell-Seyer S, et al. Randomised controlled trial of exercise for low back pain: clinical outcome, costs, and preferences. BMJ 1999;319:279-83.

44. Mannion AF, Muntener M, Taimela $S$, Dvorak J. A randomized clinical trial of three active therapies for chronic low back pain. Spine 1999;24(23):2435-48.

45. Scientific approach to the assessment and management of activity-related spinal disorders. A monograph for clinicians. Report of the Quebec Task Force on Spinal Disorders. Spine $1987(12$ (supp 7)):s 1-59.

46. Pocock Su. Clinical Trials. A practical Approach. Chichester, New York, Brisbane, Toronto, Singapore: John Wiley \& Sons, 1991.

47. Ostelo RWJG, Stomp-van den Berg SGM, Vlaeyen JWS, Wolters PMJC, de Vet HCW. Health care provider"s Attitudes and Beliefs regarding chronic low back pain; A National Survey among. Dutch physiotherapists and the Development of the Pair Attitudes and Beliefs Scale for Physiotherapists. Submitted 2001.

48. Vhaeyen JW, Jong de $J$, Geilen $M$, Heuts PH, Breukelen van $G$. Graded exposure in vivo in the treatment of pain-related fear: a replicated single-case experimental desigra in four patients with chronic low back pain. Behav Res Ther 2001;39(2):151-66.

49. Williarns AC, Pither CE, Riachardson PH. The effects of cognitive-behavioral therapy in cronic pain. Pain 1996;65:282-4. 


\section{Economic evaluation of behavioral-graded activity following lumbar disc surgery}

Raymond W.J.G. Osteloa, Mariëlle E.J.B. Goossens ${ }^{\text {b }}$, Henrica C.W. de Vetc, Piet A. van den Brandta
Affiliations of authors
* Department of Epidemiology, Maastricht University
- Institute for Rehabilitation Research, Hoensbroek
c EMGO Institute, Vrije Universiteit Medical Center, Amsterdam 


\section{ABstract}

Introduction: Little is known about the effectiveness of cognitive-behavioral treatment options for patients following lumbar disc surgery. If the knowledge available was supported by an economic evaluation, the information could then be used to make recommendations for the implementation of cognitive-behavioral treatment in the routine of rehabilitation following lumbar clisc surgery.

Methods: In a randomized controlled trial the cost-effectiveness of a behavioral graded activity program is compared to usual care in patients following first-time lumbar disc surgery. For the economic evaluation a societal viewpoint was applied. A. total of 1.05 patients were included and they were followed for 12 months. Clinicall outcome measures included global perceived effect, the Roland Disability Questionnaire, severity of main complaint, severity of back pain, general health, and social functioning. To evaluate the economic consequences of the treatments, direct health care and non-health care costs were considered, as well as indirect costs.

Results: The clinical outcomes showed no relevant differences between the two treatment conditions. Treatment costs were almost identical in the two intervention groups. The difference in direct health care costs was, although not statistically significant, 264 EURO $[95 \% . \mathrm{CI}:-3 ; 525]$ higher in BGA than in UC per patient-year. It was mainly the excess cost for visiting the physiotherapist in the BGA group which accounted for this difference. The difference in direct non-health care costs, although not statistically significant, was 388 EURO $[95 \% \mathrm{CI}:-217$; 992] being lower in the UC group due to unpaid help by friends or family. Consequently, although again not statistically significant, the total direct costs in BGA are 638 EURO $\| 95 \%$ CI: $-91 ; 1368 \|$ higher than in UC. For the indirect costs there was a statistically significant difference, BGA being more expensive. The sensitivity analysis showed that these results are fairly robust.

Discussion: Possible explanations for these results may be that theories derived from the field of chronic low back pain might not apply for patients following lumbar disc surgery or that, because patients held different expectations with regard to the BGA program, physiotherapists might not have succeeded in dispelling the patients' fear and insecurities. Consequently, patients might have been more inclined to seek help from physiotherapists in the subsequent year. This study concludes that there are no differences between the two treatment conditions on any of the climical outcome measures but that BGA is associated with higher costs. Consequentlly, there is no reason for the implementation of BGA as the standard treatment for patients following lumbar disc surgery. 


\section{INTRODUCTION}

In the Netherlands 10,000 operations are performed each year because of the lumbosacral radicular syndrome, which is based on a herniated lumbar disc.?. An international comparison of back surgery rates showed considerable differences between countries. ${ }^{3}$ The occurrence of residual complaints after surgery show a wide variety, ranging from $22 \%$ to $45 \%$ of patients reporting residual sciatica after lumbar disc surgery and $30 \%$ to $70 \%$ of patients reporting residual low back pain. ${ }^{4}$ 14 Residual complaints mainly consist of pain, motor deficits, and a decreased functional status. Rehabilitation following lumbar dise surgery is an important tool. in order to minimize these complaints. Although many different treatments have been suggested little is known about the (cost)effectiveness of post-surgery rehabilitation. A recently performed systematic review found evidence for short-term effectiveness of intensive exercise programs starting four to six weeks post surgery as compared to mild exercise programs. However, on long-term follow-up, there was no treatment that proved more effective than reference treatments. 15

Recently, the focus of attention within rehabilitation following lumbar disc surgery has been shifted towards a more biopsychosocial perspective, including cognitivebehavioral interventions. Cognitive-behavioral theory is based on the biopsychosocial model, and following the International Association for the Study of Pain (IASP) definition of pain ${ }^{66}$, considers pain to be an emotionall experience that can be modulated by cognitive and contextual factors. Based on this model three cognitive-behavioral treatment modalities have been proposed: operant, cognitive, and respondent. 17,18 Each of these treatment modalities focuses on the modification of one of the three response systems that characterize emotional experiences: behavior, cognitions, and physiological reactivity. So far, these cognitive-behavioral treatments have mainly been described and evaluated within the field of chronic low back pain and not in the rehabilitation following back surgery. A recent systematic review highlighted the effectiveness of cognitive-behavioral interventions. as compared to no treatment, for patients with chronic low back. Despite moderate evidence that cognitive-behavioral treatment is effective, the studies rarely report on economic evaluations undertaken for cognitive-behavioral interventions. 20.21 Large differences between interventions and studies made it difficult to draw conclusions about the cost-effectiveness of most cognitive-behavioral interventions. Nevertheless, it seems that operant and cognitiwe treatment modalities are more cost-effective compared to prowiding no treatment.22,23 However, it remains unclear whether cognitive-behavioral interventions will also be (cost)effective for patients following lumbar disc surgery. This paper reports on a randomized controlled trial to assess the cost-effectiveness of an operant treatment compared to usual care as provided by physiotherapists in patients following first-time lumbar disc surgery. 15,24.25 Using the results of this study, one will be able to make recommendations for the implementation of operant treatment in the routine of rehabilitation following lumbar disc surgery. 


\section{METHODS}

\section{Study population}

From November 1997 until December 1999 patients were recruited by 9 neurosurgeons in 4 participating hospitals in the south of the Netherlands. Inclusion criteria were: age between 18 and 65; first-time lumbar disc surgery fone level. only); complaints (e.g. pain) restricting their activities of daily living (ADL) and/or work. Patients were excluded if there were complications during surgery, to be judged by the neurosurgeon based on pre-set criteria (loss of cerebrospinal lluid, nerve root lesions, and a blood loss exceeding $600 \mathrm{ml}$; in case of confirmed and relevant underlying diseases that influenced $\mathrm{ADL}$ (e.g., stenosis, malignancies, $M$. Bechterew, M. Scheuermany or if one of the treatments was contraindicated le.g. because of respiratory complaints). If patients were eligible and willing to participate, informed consent was signed and patients were handed an opaque, sealled and coded envelop - prepared by an independent person - that contained the allocated treatment. We used block randomization, block size of 4 , which was based on a random computer-generated list. The Medical Ethics Committee of the University Hospital Maastricht approved the study protocol.

\section{Treatment}

Both treatments were provided by primary care physiotherapists and consisted of 18 sessions of 30 minutes each within a period of three months. Physiotherapists who provided BGA underwent a two-day training session and they received followup training during the course of the trial. Contrary to BGA, UC-physiotherapists were allowed to cease treatment when a patient no longer had symptoms and treatment goals had been accomplished, thus complying with usual care principles.

\section{Behavioral Graded Activity (BGA)}

Behavioral graded activity (BGA) is an operant treatment using graded activity and positive reinforcement in order to increase health behaviors and decrease pain behaviors. $1 \% 26$ It is based on time contingency management as described in more deteil by Fordyce 26,27 and applied by Lindström. "2s. The term "Behavional Graded Activity" for this program emphasizes the behavioral component, rather than merely physical training principles and has been described extensively elsewhere. ${ }^{24}$ The essence of BGA was to establish an individually tailored exercise program of increasing intensity, based on baseline measurements performed at intake, to teach patients that it is safe to increase activity levels. Using these baseline measurements, quotas were set (time contingent) which were systematically increased towards the pre-set goal. In addition, patients had to practice at home. Activities or exercises were to be documented on performance charts and were discussed with the physiotherapist.

\section{Usual Care (UC)}

The content of UC was determined after extensive interviews with the participating physiotherapists. In general, the whole spectrum of techniques used by the physiotherapists in primary care was included which, in our opinion, is sensible 
when studying usual care. The main topics of usual care could be outined from the treatment registration forms: all physiotherapists instructed their patients to exercise trunk muscles to increase strength and stability. The exercises were ained at increasing the levels of ADL. Sixty-five percent of the physiotherapists explicitly instructed patients how to lift, sit, and stand and how to perform other kinds of ADL. Forty-five percent of the physiotherapists used some kind of electrotherapy in at least 3 (or more) sessions to decrease pain and muscle tone. Thirty percent of the physiotherapists used some kind of hands-on technique (massage or manipulations) in some of the treatment sessions (ranging from 2 up to 13 sessions) to decrease pain and muscle tonus.

\section{Clinical outcome assessment}

Patients visited one of the 4 participating hospitals where measurements took place. At baseline several prognostic factors were recorded. In addition to gender, type of surgery, duration of hospitalization, and use of analgesics were also recorded. Clinical outcome measures included global perceived effect (GPE), the Roland Disability Questionnaire (RDQ) ${ }^{29}$, severity of main complaint ${ }^{30}$, and severity of back pain. The latter two were scored on a visual analog scale (VAS). Gioball perceived effect was rated on a 7 -point scale $(1=$ completely recovered, $7=$ worse than ever $)$ that was dichotomized as improved ("completely recovered" and "much improved"), versus not improved ("slightly improved", "not changed", "slightly worse", "much. worse", "worse than ever"). For general health and social functioning the SF-36" was used. Clinical outcomes were assessed by means of self-reported questionnaires at baseline, post-treatment ( 3 months after randomization), and 6 and 12 months after randomization.

\section{Costs}

The economic evaluation was performed from a societal viewpoint. To evaluate the economic consequences of the treatments, the direct health care and non-health care costs were considered, as well as the indirect costs. Firstly, relevant categories of resource utilization were identified. Secondly, the volume of each category was measured. These volumes were measured over a period of 24 weeks (two periods of 12 weeks) and were extrapolated to anmul volumes per patient. Finally, these annual volumes were multiplied by the resource costs in order to calculate the costs per patient-year. 32

Identification of cast categories. The direct health care costs included the costs of: the allocated treatment, lumbar disc surgery, days of hospitalization, the number of visits to a general practitioner, physiotherapist or allied health professional, specialist, or alternative therapist, and prescribed medication. Direct non-health care costs included out-of-pocket expenses (i.e. equipment, over-the counter medicationy, costs of paid help and help from family or friends and travel expenses to health care providers. Indirect costs refer to the value of the production lost due to illness-related absence from work or hours of inactivity. 
Meastrement of resource utilization. The participating physiotherapists registered the number of treatment sessions attended for BGA and UC. The size of the other drect costs was obtained from the patent-cost diary ${ }^{33}$ in which the patients recorded alli medical consumption related to their residual back and/or leg complaints. The calculation of the indirect costs associated with production losses was based on recordings of the number of hours absent from work and the hours lost from activities (unpaid work) at home as listed by the patient in the cost diary. The patients in both groups completed this cost diary prospectively during two periods of three months within one year. For the first period the cost diary was handed out at the post-treatment measurement ( 3 months after randomization) and patients were instructed to keep a record of all costs, associated with their residual leg or back complaints, for the next three months. This cost diary was returned at the 6-month follow-up measurement. At the start of the second period 19 months after randomization) all patients received another cost diary for the following three months and were again instructed to keep a record of all costs. This cost diary was returned at the 12-month follow-up measurement. The research assistant checked both cost diaries with regard to completeness, for the 6 and 12 -months follow-up, respectively.

Resource costs. The direct health care and non-health care costs were, whenever possible, based on the Dutck guidelines for cost analysis in health care. ${ }^{\text {at }}$. The costs were collected during 1997 using Dutch guilders and have been converted into EURO at the rate of 2.2037 guilders to 1 EURO. The costs of various allied health professionals and specialists were based on the tariffs of the Dutch Central Organization for Health Care Charges (COTG) ${ }^{35}$. The professional organizations concerned were asked for tariffs for the various alternative health care therapists. The costs of lumbar disc surgery and of hospitalization were retrieved from the financial department of the participating hospitals. The costs of medication were based on the prices charged by the Royal Dutch Society for Pharmacy. ${ }^{36}$ The prices of over-the-counter medication and the costs of equipment (matresses, clothing et cetera) were based on the real amounts as reported by the patients in their cost diary. The costs of paid housekeeping were based on the price of professional help. ${ }^{34}$ Unpaid help by family or friends was allocated a value using the shadow price of informal help. ${ }^{34}$ In the analyses for both paid and unpaid labor the mean income of the Dutch population was used as presented by Statistics Netherlands, ${ }^{37}$ To calculate these costs of paid labor, the Human Capital Approach was used, which estimates the value of the potential production lost during the entire period of absenteeism in 1 patient-year. Table 1 presents the unit prices of the important cost components. 
Table 1. Prics used in the economic cwaluation fin EUPO.

\begin{tabular}{|c|c|}
\hline Casts & EURO \\
\hline \multicolumn{2}{|l|}{ Direct Heath care costs } \\
\hline Genera practitioner (per contact) $)^{34}$ & 16.62 \\
\hline Physiotherapist (per cantact) ${ }^{34}$ & 18.18 \\
\hline Manual Therapist (per contact) ${ }^{34}$ & 24.55 \\
\hline Cesart Mensendieck Exercise therapist (per contact) & 17.73 \\
\hline Hospitalization (per day) ${ }^{3}$ & 236.36 \\
\hline Lumbar disc surgery: & 4.24 .55 \\
\hline Specialist (per contact $)^{35}$ & Varable \\
\hline Alternative Health Care (per contact) it & Variable \\
\hline \multicolumn{2}{|l|}{ Direct non-health care costs } \\
\hline Paid housekeeping help (per hour) ${ }^{34}$ & 8.55 \\
\hline Unpaid help from family/ friends (per hour) ${ }^{34}$ & 7.95 \\
\hline Travel expenses (per $\mathrm{km})^{34}$ & 0.11 \\
\hline Expenses for Health Activities: & Variable \\
\hline Cosis for equipment: & Variable \\
\hline \multicolumn{2}{|l|}{ Indirect Costs } \\
\hline Absenteeism paid labor (per hour) $)^{37}$ & 15.12 \\
\hline Absenteeism unpaid labor (per hour) 3 $^{37}$ & 15.12 \\
\hline
\end{tabular}

a retrieved from the financial department of the participating hospitals

- suggested tariffs retrieved from the professional organizations concerned

costs directly retrieved from cost diary

\section{Analysis}

Chinical outcome. For this economic evaluation the clinical outcomes of the 12 . month follow-up were used. The analysis was carried out according to the intention-to-treat principle, which means that patients are anallysed in the group to which they were allocated. For the RDQ, the Main Complaint, the severity of back pain, general health, and social functioning the difference with 12 month follow-up values was calculated for each individual; these change-scores were used to compare the two treatment groups using Student"s $t$-test for statistical significance. For GPE the difference between groups at the 12 -month follow-up was analyzed. Group differences and two-tailed $95 \%$ Confidence Intervals $[95 \% \mathrm{Cl}]$ were calculated for all outcome measures. To adjust for possible baseline differences a multiple linear regression analysis for continuous outcome measures was used, with the change scores as dependent variable, treatment as independent variable, and baseline scores of the prognostic variables land the particular outcome measure, if appropriatel as co-variables. The adjusted results hardly changed the outcome, and therefore we present only the unadjusted results.

Costs. In case of missing data. (due to loss to follow-upl, the mean costs of the allocated treatment group was used to substitute the missing values. If patients forgot to bring their cost diary with them they had to fill one out, retrospectively, during the follow-up measurement. The differences between the two groups for health care utilization and use of other health care services were compared using 
the Mann-Whitney test. For comparing the costs between the two groups the standard approach of the Student's twest was used because for this comparison the arithmetic mean costs are considered to be most informative. ${ }^{38}$ Furthermore $95 \%$ conficlence intervals $(95 \%$ Cl) were calculated.

Sensitivity analyses.

The analysis of the costs is based on several assumptions. The impact on the results of changing these assumptions can be assessed in sensitivity analyses. If changes in the results due to different assumptions are minor, the results can be treated with greater confidence. If the sensitivity analysis produces substantial changes in the results, then greater caution is necessary when interpreting the data. Three altemative costs analyses will be performed.

The cost anallysis is based on the assumption that for comparing the treatment groups with regard to the costs the arithmetic mean is most informative, despite the fact that data are skewed and therefore we used the standard approach of the Student's t-test. ${ }^{3}$ In a sensitivity analysis we used the Mann-Whitney test in order to account for the skewness of the data.

Reporting the volume of unpaid help from friends or fiamily can be imprecise because patients might hold different views with regard to what exactly is understood by this type of help. Furthermore the exact number of hours may be difficult to estimate because this help often consists of a series of small tasks, sometimes incorporated in a social visit. Therefore, we analysed the influence of this cost category by excluding it.

Finally, the measurement of indirect cost was based on the Human Capitall Approach, which estimates the value of the potential production lost during the entire period of absenteeism in 1 patient-year. This method is likely to overestimate the actual loss, because in reality others may replace missing workers, or the absentee may make up the lost production once he or she returns to work. To approximate the actual production loss, it is more realistic to assume that losses occur only during the time needed to replace the sick worker, or to reorganize the production process. This is called the friction time. In another sensitivity analysis we estimated the value of the production loss assuming that no production is lost after this friction time. Koopmanschap ${ }^{3}$ who developed the Friction Costs Approach estimated the approximate friction time to be three months. 


\section{RESULTS}

\section{Patients}

From November 1997 until December 1999, 671 patients were screened for eligibility in 4 participating hospitals in the South of the Netherlands. More than half of the patients recovered after first-time lumbar disc surgery and suffered no further substantial symptoms $(57 \%) ; 141$ patients were excluded because of various reasons: patients, although operated in a participating hospital, were not living in the catchment area $(n=40)$, not motivated to participate $(n=32)$, 100 old $(n=30)$, presented with co-morbidities $(n=22)$, language problems $(n=8)$, previous lumbar surgeries $(n=7)$, and due to insurance problems $(n=2)$. We failed to trace 43 patients. In total 105 patients were eligible and signed informed consent.

\section{Baseline}

At baseline the patients in the two conditions did not differ with regard to prognostic characteristics concerning the lumbar disc surgery; in both groups the majority underwent standard discectomy. Also the duration of hospitalization was equal for both groups (UC mean of 7.7 days (SD: 2.7 ), versus BGA mean of 7.0 days (SD: 1.3)). Analgesics were prescribed on a pro re nata (PIRN) basis. At baseline 34\% of the UC-patients used pain medication versus $38 \%$ in BGA. Furthermore, there were slightly more women in BGA: $50 \%$ versus $36 \%$ in $\mathrm{UC}$. For the clinical outcome measures estimated at baseline there were no relevant differences. Table 2 presents the baseline values for the clinical outcome measures used in this cost-effectiveness analysis. Overall there were no relevant differences between groups at baseline. A more detailed description of the baseline comparison has been described in a separate paper. 40

Table 2. Baseline comparison of clinical outcome measures.

\begin{tabular}{|c|c|c|}
\hline Chical Outcome measure & UC & $B G A$ \\
\hline Foland Disability Questionnaire (0-24 points) & $43.5(4.5)$ & $14.5(3.7)$ \\
\hline Main Complaint $(0-100)$ & $67.4 \quad(15.4)$ & $7.1 \quad 16.5\}$ \\
\hline Severity of pain in back $(0-100)$ & $46.7(27.3)$ & $43.4(30.0)$ \\
\hline General Health (Subscale SF-36) & $65.6 \quad(20.0)$ & $68.2(18.4)$ \\
\hline Social Functioning (Subscale SF 36 ) & $59.4(25.3)$ & $56.7(26.6)$ \\
\hline
\end{tabular}

Numbers are means wilth standand deviations between brackets.

\section{Clinical outcomes}

After 12 months, the proportion of patients who recovered (GPE) in the BCA and UC groups was $75 \%$ and $73 \%$, respectively. The difference of $2 \% 195 \% \mathrm{Cl}:-19.5 ; 15.71$ was not statistically significant, nor clinically relevant. For the $\mathrm{RDQ}$, the severity of back pain, and the Main Complaint no differences could be obseryed. For general health and social functionirg again no differences were observed between the two groups. Table 3 presents the effects of the clinical outcome measures. 
Table 3. Improwernent in clinical outcome measures and differences in improwement between the treatment groups after 12 months.

\begin{tabular}{|c|c|c|c|c|}
\hline \multirow{2}{*}{$\begin{array}{l}\text { Ouflome measuress } \\
\text { Recovered (\%) }\end{array}$} & \multirow{2}{*}{$\begin{array}{l}\text { Behaviordi-graded aciwity a } \\
\qquad(n=52) \\
75\end{array}$} & \multirow{2}{*}{$\begin{array}{l}\begin{array}{c}\text { Usidaf care } \\
(n=53)\end{array} \\
73\end{array}$} & \multicolumn{2}{|c|}{ Difference } \\
\hline & & & $2.0-19.5$ & $15.1]$ \\
\hline Roland Disability Ouestionnaire (ROO) & $7.0(5.5)$ & $7.0(5.3)$ & $0.0-2.1$ & 2.11 \\
\hline Main Complaint $(0-100)$ & $50.3(27.4)$ & $44.3(30.6)$ & $6.0 !-5.5$ & 17.3! \\
\hline Sewerity of back pain $(0-100)$ & $17.6(32.5)$ & $22.4(33.6)$ & $-4.8[-17.5$ & 7.91 \\
\hline General Health : & $3.0(16.4)$ & $5.2(16.6)$ & $-2.2[-8.6$ & 4.2] \\
\hline Soctal Functioning ${ }^{2}$ & $28.4(27.7)$ & $24.1 \quad 25.1)$ & $4.3-14.5$ & $5.9]$ \\
\hline \multicolumn{5}{|c|}{ Presented ane the improvements from baseline, either percentage or mean (sd) } \\
\hline \multicolumn{5}{|c|}{$\begin{array}{l}\text { - Presented are the differences (behavioral-graded acivity minus usuall care) in recovery differences of mean improvement } \\
\text { from baseline [95\% confidence interval] } \\
\text { Sulbscale. SF-36 }\end{array}$} \\
\hline
\end{tabular}

\section{Costs}

Response of cost dainies. In the BGA group, $63.5 \%$ completed the cast diaries prospectively and turned them in at the follow-up measurements as compared to $86.8 \%$ in the UC group. In BGA and UC, 9 patients and 5 patients respectively, did not keep track of the costs prospectively and had to complete the cost diaries in retrospect, during the follow-up measurements. In BGA and UC, 10 patients and 2 patients, respectively, were lost to follow-up 12 months after randomisation and mean values of their treatment groups were used for substitution.

Direct health care costs. Table 4 shows the volumes per patientwyear for the various categories of health care utilization and other services. The number of treatment sessions attended is comparable for both groups. Patients in both groups hardly visited the general practitioner or medical speciallist and the difference is not statistically significant. In the BGA group 20 patients $(38.5 \%)$ visited an allied health professional, in 18 cases this was a physiotherapist. In UC 13 patients visited allied health professionals, all of whom were physiotherapists. The rumber of visits to allied health professionals is statistically significant higher in BGA. There were also statistically significantly more visits to altemative therapists by BGA patients. Furthermore there was one repeated surgery in BGA but no repeated surgeries in UC. There is a statistically significant difference between the two groups with regard to unpaid help. On average the BGA group used 58.4 (127.3) hours per patient-year versus only 16.6 (54.7) hours in the UC group. Finally, BCA also used statistically significantly more hours for paid housekeeping than $\mathrm{UC}$. 
Table 4. Mean (SD) utilization of health care and other services per patient-year by cost category and treatment group.

\begin{tabular}{|c|c|c|c|c|}
\hline \multirow{2}{*}{$\begin{array}{l}\text { Type of utilization } \\
\text { Type of measurement] }\end{array}$} & $\begin{array}{c}\text { Behavional graded actuily } \\
\text { Mean }(5 D) \\
(n=52)\end{array}$ & \multicolumn{2}{|c|}{$\begin{array}{l}\text { Usual Cara } \\
\text { Morn }(50) \\
m=53)\end{array}$} & \multirow{2}{*}{$\frac{0.00100}{0.088}$} \\
\hline & $15.3(3.8)$ & 160 & $(3.3)$ & \\
\hline General practice [no of visits] & $2.9(3.6)$ & 16 & $(30)$ & 0.246 \\
\hline Allied Health professions [no of treatment sessions] ${ }^{\mathrm{a}}$ & $15.7 \quad(22.1)$ & 6.7 & $(13.9)$ & 0.005 \\
\hline Medical specialist care [no of visits] & $2.8(4.5)$ & 3.0 & $(7.4)$ & 0.153 \\
\hline Allemative Health care [no of visits] & $0.5(1.7)$ & 0.1 & $(0.6)$ & 0.001 \\
\hline Surgery [no.] & $0.1 \quad(0.3)$ & 0.0 & & 0.003 \\
\hline Unipaid help from friends/family [no. of hours] & $58.4 \quad(127.3)$ & 16.6 & $(54.7)$ & 0.007 \\
\hline Paid housekeeping [no. of hours] & $23.8 \quad(58.5)$ & 16.1 & $(54.0)$ & 0.046 \\
\hline
\end{tabular}

a Alfed Health professions are physical therapy, manual therapy and Cesar/Mensendieck exercise therapy

SMann- Whitney lest.

bold type indicates is statistical significant at alpha $=0.05$

Converting these annual volumes of health care use and other serwices into costs, it appeared that there was only a small difference in treatment costs of 13 EURO 195\% CI: $-37 ; 11$ in favour of BGA (Table $5 \%$. The difference in direct health care costs, although not statistically significant, was 264. EURO [95\% Cl: $-3 ; 525]$ higher per patient-year in BGA than in UC. It was mainly the excess cost of visiting the physiotherapist in the BGA group which accounted for this difference. The direct non-health care costs, although not statistically significant, were 388 EURO [95\% CI: -217 ; 992] higher in BGA. Mainly the costs for unpaid help from friends or family accounted for this difference. Consequently, although again not statistically significant, the total direct costs in BGA are 638 EURO $195 \%$ C]: $-91 ; 1368]$ higher in BGA than in UC. Table 5 presents the differences in mean total costs during the complete follow-up period.

Table 5. Difference in mean total costs (SD) per patient-year during the complete followup period of 12 months (in EURO).

\begin{tabular}{|c|c|c|c|c|}
\hline \multirow{2}{*}{$\begin{array}{l}\text { Costs } \\
\text { Treaiment costs }\end{array}$} & $\begin{array}{l}\text { Behavioral graded activity (BGA) } \\
\qquad \begin{array}{c}\text { Mean (SD) } \\
(n=52)\end{array}\end{array}$ & $\begin{array}{c}\text { Usual Care }(U C) \\
\text { Meam }(S D) \\
(n=53)\end{array}$ & \multicolumn{2}{|c|}{$\begin{array}{c}\text { BGA - LC } \\
\text { Mean Difference }[95 \% \mathrm{Cl}\end{array}$} \\
\hline & $278(63)$ & $291(60)$ & -13 & {$[-37 ;$} \\
\hline Direct health care cosits & $565(822)$ & $301>489)$ & 264 & $|-3 ; 525|$ \\
\hline Direct non-health care costs & $1135(1486)$ & $747(1633)$ & 388 & {$[-217 ; 992]$} \\
\hline Tolal Direct costs & $1978(1894)$ & $1339(1873)^{\prime}$ & 638 & {$[-9: ; 1368]$} \\
\hline
\end{tabular}

Mean $=$ mean difference in total costs between treatment groups

$\mathrm{SO}=$ stand ard deviation

$95 \% \mathrm{Cl}=95 \%$ confidence interval 


\section{Indirect costs}

During the 12-month followm the average duration of absence from work because of complaints was 381.3 hours per patient-year (or 0.92 days per week) for BGA and 155.0 hours for UC (0.37 days per week). The associated costs amounted to 5774 EURO (SD: 8880 ) for BGA and 2347 EURO (SD: 6064) for UC. The 3427 EURO [95\% Cl: 489; 6365] difference between the two groups is statistically significant. Also the mean duration of absenteeism from unpaid labor per patientyear was higher in BGA. The associated costs for unpaid labor amounted to 1421 EURO (SD: 2804) for BGA and 407 EURO (SD: 1386 ) for UC. The 1014 EURO [95\% CI: $160 ; 1868$ difference between the two groups per patient-year is statistically significant.

\section{Sensitivity analysis}

Parametric versus non-parametric testing. Using the Mann-Whitney test in order to account for the skewness of the data, the difference between treatment cost was still not statistically significantly different. But the differences in direct and nondirect health care costs now reached statistical significance; meaning that $B G A$ generates more costs that UC. Also the difference in total dinect costs, to the disadvantage of $B G A$, is statistically significant. The differences in costs of absenteeism from paid and unpaid labor, to the disadvantage of $B G A$, are statistically significant, using the Mann-Whitney test.

Excluding unpaid help from friends or family. The difference between BGA and UC, on excluding unpaid help from friends or family, was reduced to 28 EURO $195 \% \mathrm{CI}$ : $-501 ; 445]$ but the cost was still higher for BGA. The difference in total direct costs was reduced to 280 EURO $[95 \% \mathrm{CI} \cdots 868 ; 310]$. But again, this difference, although not statistically significant, was to the disadvantage of BGA.

Human Capital Approach versus Friction Cost Approach. Using the main assumptions of the Friction Cost Approach, instead of the Human Capital Approach, reduced the indirect costs in both groups. During the 12 months followup 3 BGA patients and only 1 UC-patient were absent from paid labor for more than three months. Consequently, the costs of absenteeism from paid labor was reduced more in BGA than in UC, yielding a difference of 2555 EURO $195 \%$ CI: 395; 4713 ] as compared to a difference of 3427 EURO [95\% Cl: 489; 6365], using the Human Capital Approach. However, the costs in BGA associated with absenteeism from paid labor were still statistically significantly higher.

In general, no matter what changes in cost assumptions were made, the changes in the results were minor, thereby strongly supporting the conclusion that BGA is associated with higher costs. 


\section{Discussion}

In a randomized controlled trial the cost-effectiveness of the behavional graded activity program was compared to usual care in patents following first-time lumbar disc surgery. The contrast between the two interventions was based on how the intervention was delivered rather than on the content itsel, because BGA used specific operant features. After 12 months, there were no statistically significant or climically relevant differences on GPE, the RDQ, the severity of the Main Complaint, or the severity of back pain. Nor were differences observed for general health or social functioning. The treatment costs were comparable for both groups. However, comparing the total direct costs it appeared that there was a difference, although not statistically significant, of 638 EURO $[95 \% \mathrm{Cl}:-91$; 1368$]$ to the disadvantage of BGA. The indirect costs were also higher in BGA as compared to UC per patientyear. This difference was statistically significant.

The utilization of heallth care and other services (table 4) reveal that, although not all categories show statistically significant differences, there was a clear patterm in the direction of the differences. All categories reflect a higher health care utilization in the BGA group as compared to the UC group. Especially the number of visits to physiotherapists shows a distinct difference, as well as costs for unpaid help from friends or family. This observation was not in line with the expectations at the beginning of this trial. The overall goal of the operant treatment is to teach the patient that it is safe to increase activity level and to provide them with tools in order to improve their ability to be self-supporting. Furthermore, it was hypothesised that BGA would alter two important psychological mediators: fear of movement and catastrophizing. Because these mediators would be altered in a positive direction and the selfwsupportiveness would be increased, visits to physiotherapists were expected to be lower rather than higher in the BGA group. One possible explanation might be that these theories derived from the field of chronic low back pain might not apply to patients following lumbar disc surgery. This explanation is supported by the results for the psychological mediators. Fear of movement and catastrophizing seem to be unaffected, on average, by either treatment. 40

Another explanation might be that patients held different expectations with regard. to the BGA treatment, such that they expected more passive modalities for reduction of pain, and more pain-guided management in general. Therefore, physiotherapists might not have succeeded in dispelling fear and insecurities. Consequently, patients being still more insecure with regard to their own abilities might have been more inclined to seek help from another physiotherapist in the subsequent year.

Considering the costs of absence from paid labor, it appeared that BGA generated more costs than UC, in both the Human Capital as well as the Friction Cost Approach. However, some remarks have to be made. Firstly, return to work is possibly also an outcome that results from the surgery that patients underwent 6 weeks before inclusion in our trial. The natural course of recovery after surgery has 
probably influenced return to work to a great extent. Siecondly, return to work was not a specific treatment goal for either BGA or UC. The main goal of these types of treatments is to improve functional status. If patients are absent from work following lumbar disc surgery and if return to work is of paramount importance to them, more specific reintegration approaches focussing primarily on early resumption of professional activities are probably needed in order to improve the chance of return to work ${ }^{41}$ In summary, despite the consistent findings in the analysis, the results with regard to absence from paid labor have to be interpreted cautiously.

The costs of absenteeism from unpaid labor and days of mactivity at home were included merely to get an impression of how high they were; patients who do not participate in paid labor were included (e.g. housewives, persons who have retired (possibly early)). In retrospect the definition of this variable was too imprecise and therefore patients used different criteria to determine the number of hours for this variable. For future research it is important to describe this variable more precisely.

With regard to assumptions made in this economic evaluation some comments are worth mentioning. Because in our study we adopted the societal perspective, we did not restrict the cost analysis to treatment costs and health care utilization. We also included other relevant categories, including costs borne by the patient and family, such as over the counter medication, equipment, paid and unpaid help from friends and family, and indirect costs. Because of the patients' decisive role in reporting, the identification and measurement of these non-medical costs is somewhat arbitrary since they cannot be checked elsewhere. However, the sensitivity analysis showed that in general, the various assumptions did not alter the results substantially.

In our study, patients had to keep a diary for two periods of 3 months. The main reason for shortening the period during which cost diaries were kept was that this minimized the burden for patients. In addition, the procedure was also lless time consuming for researchers and less expensive. Keeping the diary for a whole year would probably have resulted in more precise estimates of the costs. However, a study by Croossens et al ${ }^{3,3}$ on fibromyalgia and chronic low back pain, showed that keeping the diary for a period of three months was representative of keeping the diary for the whole year. Therefore we assume that the costs recorded in our trial are representative of the costs for the whole year and furthermore, we even used two periods of 3 months. In our trial surgery was recorded not only in the cost diary by patients but also via hospital administration. Therefore, we had the opportunity to assess the difference between keeping the cost diary for abbreviated periods of time as compared to a whole year. From the cost diaries it was concluded that in BCA 1 operation was repeated versus no re-operation in UC. From the hospital data it was concluded that during the whole period of follow-up there were 4 repeated surgeries in BGA and 2 in UC. The differences between the two treatment groups with regard to repeated operations are more or less similar in both sources of 
information. We felt, therefore, that we could rely on the data as obtaned from the cost diary.

In this economic evaluation, we performed the analysis on the raw costs as advocated by Thompson, 35 despite the usual skewness in their distribution. There is still no consensus about the most valid and relable statistical method for comparing costs in pragmatic trials. Thompson ${ }^{38}$ argues that the arithmetic mean is needed for health care policy decisions and that using standard non-parametric methods may provide misleading conclusions. However, using a non-parametric method (Manm. Whitney U) did not change our results substantially.

In summary, we found no differences in any of the clinical outcome measures. The costs associated with BGA were, however, higher as compared to UC. Therefore, we conclude that, based on this economic evaluation, there is no need to implement the behavioral graded activity program as delivered in the current study, as the standard treatment for patients following lumbar disc surgery.

\section{ACKNOWLEDGEMENTS}

The authors would like to thank the "Profileringsfonds" of the University Hospital Maastricht (azM) and the Foundation "Annatonds" Leiden for their financial support. We gratefully acknowledge Cobie Martens for her work on data management.

\section{REFERENCES}

1. Slebus $F G$, Maas van der PJ, Braakman R, Habbema aDF, Kardaun JWPJF. De effectiviteit van beeldvormende diagnostiek en chirurgie bij de lumbale hernia nuclei pulposi. Rotterdam: Rapport aan het Ministerie van WVC, 1989.

2. Netherlands HC. Management of the lumbosacral radicular syndrome (sciatica). The Hague: Health Council of the Netherlands, 1999.

3. Cherkin DC, Deyo RA, Loeser JD, Bush $T$, Waddeli $G$. An international comparison of back surgery rates. Spine 1994; 19(11):1201-6.

4. Yorimitsu E, Chiba $K$, Toyama $Y$, Hirabayashi $K$. Long-term outcones of standard discectomy for lumbar disc herniation: a follow-up study of more than 10 years. Spine $2001 ; 26(6): 652-7$

5. Dvorak J, Valach $\mathbb{L}$, Fuhrimann $P$, Heim E. The outcome of surgery for lumbar disc herniation. II. A 4-17 years follow-up with emphasis on psychosocial aspects. Spine $1988 ; 13(12): 1423-7$.

6. Spangfort EV. The lumbar disc herniation. A computer aided analysis of 2,504 operations. Acta Orthop Scand Suppl 1972;95:1421-95.

7. Weber $H$. Lumbar disc hemiation. A controlled, prospective study with ten years of observation. Spine 1983;8(2):131 40.

8. Hurme M, Alaranta H. Factors predicting the result of surgery for lumbar intervertebral dise herniation. Spine 1987;12(9):933-8.

9. Barrios C, Ahmed M, Arrotegui JI, Bjornsson A. Clinical factors predicting outcome after surgery for herniated lumbar disc: an epidemiological multivariate analysis. J Spinal Disord 1990;3(3):205-9. 
10. Korrea DS, Loupassis $\mathrm{G}$, Stamos K. Resuls of Jumbar discectomy: a study using 15 different evaluation methods. European Spine Journal 1992;1:20-4.

11. Pappas CTE, Harrington $T$, Sonntag VKH. Outcome analysis in 654 surgically treated lumbat disc hemiations. Neurosurgery 1992;30(6):862-6.

12. Smulders WLM, Loon van G. Nabehandeling na lumbale discectomie of chemonucleolyse. Een 'out patient' enquête. Fysiopraxis 1993;2(9):4-6.

13. Manniche C, Asmussen KH, Vinterberg H, Rose Hansen EB, Kramhoft J, Jordan A. Back. pain, sciatica and disability following first-time conventional haemilaminectomy for lumbar disce hemiation. Use of "Low Back Pain Rating Scale" as a postal questionnaire. Dan Med Bull 1994:41(1):103-6.

14. Manniche $\mathrm{C}$, Asmussen $\mathrm{KH}$, Vinterberg $\mathrm{H}$, Rose Hansen $\mathrm{EB}$, Kramhoft J, Jordan $\mathrm{A}$. Analysis of preoperative prognostic factors in first-time surgery for lumbar disc herniation, including Finneson's and modified Spengler's score systems. Dan Med Bull $1994 ; 41(1): 110-5$

15. Ostelo RWJG, Vet de HCW, Waddell $G$, Kenckhoffs MR. Leffers P, Tulder van MW. Rehabilitation after first-time lumbar disk surgery. A systematic review within the Cochrane framework. The Cochrane library, Issue 2 2002. Oford: Update Software.

16. International Association for the Study of Pain SoT. Classification of chronic pain syndromes and definitions of pain terms. Pain 1986;supplement 3:\$1-\$225.

17. Turk DCFH. Etiological theories and treatments for chronic back pain. II. Psychological models and interventions. Pain 1984 19(3): 209-33.

18. Vlacyen JW, Haazen IW, Schuerman JA, Kole Snijders AM, Eek van H. Behavioral. rehabilitation of chronic low back pain: comparison of an operant treatment, an operant.. cognitive treatment and an operant-respondent treatment. Br J Clin Psychol. $1995 ; 34: 95-118$

19. Tulder van MW, Ostelo RW, Vlaeyen JW, Linton SJ, Morley SJ, Assendelft WJ. Behavioral treatment for chronic low back pain: a systematic review within the framework of the Cochrane Back Review Group. Spine 2001;26(3):270-81.

20. Goossens ME, Evers SM. Cost-effectiveness of treatment of back pain. In: Nachemson A, Jonsson E, eds. Evidence based treatment for back pain. Stocholm and Philidelphia: Lippincot, Williams \& Wilkins, 2000.

21. Goossens MEJB, Evers SMAA. Economic evaluation in back pain interventions. J Occup Relhabil 1997;7(1):15-32.

22. Goossens ME, Rutten van Molken MP, Leid RM, Bos SG, Vlaeyen JW, Teeken Gruben NJ. Cognitive-educational treatment of fibromyalgia: a randomized clinical trial. $\mathbb{I I}$. Economic evaluation. J Rheumatol 1996;23(7):1246-54.

23. Goossens MEJB, Rutten-van Mulken MPMH, Kole-Snijders AMJ. Health economic assessment of behavioural rehabilitation in chronic low back pain: a randomised clinical trial. Health Economics 1998;7:39-51

24. Ostclo RW, Koke AJ, Beurskens AJ, el al. Behavioral-Graded activity compared with usual care after" first-time disk surgery: Considerations of the design of a randomized clinical trial. J Manipulative Physiol Ther 2000;23(5):312-9.

25. Ostelo RWJG, Vet de HCW, Vaeyen JWS, et al. Effectiveness of behavioral graded activity after first-time dise surgery. Submitted 2001

26. Fordyce WE. Behavional methods for chronic pain and illness. St. Louis: Mosby , 1976.

27. Fordyce WE, Fowler RS, Lehmann JF, Delateur BJ, Sand PJ, Trieschmann RB. Operant conditioning in the treatment of chronic pain. Arch Phys Med Rehabil 1973;54(9):399408.

28. Lindstrom 1 , Ohlund $\mathrm{C}$, Eek $\mathrm{C}$, et al. The effect of graded activity on patients with subacute low back pain: a randomized prospective clinical study an operant conditioning behavioral approach. Physical Therapy 1992;72(4):279-293.

29. Roland M, Morris R. A study of the natural history of back pain. Part I: development of a reliable and sensitive measure of disability in low back pain. Spine 1983;8(2):14 1-4.

30. Beurskens $A J$, Vet de $H C$, Köke $A J$, et al. A patient-specific approach for measuring functional status in low back pain. J Manipulative Physiol Ther 1999;22:144-8.

31. Ware JE, Sherbourne CD. The MOS 36-item short form health survey (SF-36). I. Conceptual framework and item selection. Med Care 1992;30(6):473-83. 
32. Rutten van Mölken MPMH, Doorslaer wan ERA, Vhet wan RCJA. Statistical analysis of cost outcomes in a randomized controlled rrial. Fealth Economics 1994;3:333-45.

33. Goossens ME, Rutten van Molken MP, Vlaeyen JW, Linden van der Si. The cost diary: a method to measure direct and incirect costs in cost-effectiveness research. If chn Epidemiol 2000;53(7):688-95.

34. Oostenbrink JB, Koopmanschap MA, Rutten FFH. Handbook for cost studies, methods and guidelines for economic evaluation in health care [in Dutch]. Amstelveen: Health Care Insurance Councill, 2000.

35. Gezondheidszorg CoTG. Tarieven voor medisch speciallisten, exclusief psychiaters. Utrecht: Centraal orgaan Tarieven Gezondheidszorg, 1996.

36. Report. T. Z-index. The Hague, 2000.

37. Centraal Bureau Statistiek. Werkgelegenheid, arbeidsduur en lonen van werknemers, vanaf 1995. Heerlen Voorburg: Statistics Netherlands.

38. Thompson SG, Barber JA. How should cost data in pragmatic randomised trials be analysed? BMU 2000;320(7243): 1197-200.

39. Koopmanschap MA, Rutten FF. Indirect costs in economic studies: confronting the confusion. PharmacoEconomics 1993;4(6):446-54.

40. Ostelo RW, Vet de HC, Vlaeyen JW, et al. Behavioral Graded Activity After First-time Lumbar Disc Surgery. One Year Results of a Randomized Controlled Trial. Submitted 2002.

41. Donceel P, Du Bois M, Lahaye D. Return to work after surgery for lumbar disc herniation. A rehabilitation-oriented approach in insurance medicine. Spine $1999 ; 24(9): 872-6$. 



\section{Health care provider's attitudes and beliefs regarding chronic low back pain}

Raymond W.J.G. Ostelond, Suzanne G.M. Stomp-van den Berglb, Johan W.S. Vlaeyen' ${ }^{\circ}$ Pieter M.J.C. Wollters', Henrica C.W. de Vete

Affiliations of authors

a Department of Epidemiology, Maastricht University.

- Netherlands Institute for Health Services Research, Utrecht.

c Department of Clinical \& Experimental Psychology, Maastricht.

d Hogeschool Zuyd, Department of Physiotherapy, Heerlen.

- EMGO Institute, Vrije Universiteit Medical Centre, Amsterdam 


\section{Abstract}

Attitudes and belliefs of health care providers appear to be important in the management of chronic low back pain. In this study attitudes and beliefs of Dutch physiotherapists are surveyed, and the underlying dimensions are investigated in order to develop the Pain Attitudes and Beliefs Scale for Physiotherapists (PABS_PT). In total, 421 physiotherapists (response rate $62.3 \%$ ) participated in this study. Results of the survey suggest that there is a reasonable consensus among physiotherapists with regard to the management of chronic low back pain: reassure about the hamluess nature of the complaints and reactivate patients. Items were submitted to a principal factor analysis (PAF) with oblimin rotation that yielded an interpretable 2-factor model. Based on highest loading items, factor 1 was labelled "biomedical orientation", whereas factor 2 was labelled "behavioural orientation". The internal consistency ICronbach's Alpha) of factor 1 was 0.84 and for factor $2,0.54$ explaining $25.2 \%$ and $8.2 \%$. respectively, of the total variance. Assessment of the effect of characteristics of physiotherapists on scores on the different scales was encouraging as results pointed in the directions one would expect. Physiotherapists who attended biopsychosocial education courses had higher scores on the "behavioural orientation" factor and vice versa. Biomedical specialists had statistically significantly higher scores on the "biomedical orientation" factor. Furthermore, the findings suggest that the PABS_PT discriminates between physiotherapists with a "behavioural orientation" versus those with a "biomedical orientation". To examine the influence of these different orientations with regard to chronic low back pain on patient outcome is a challenge for the near future.

Keywords: chronic low back pain - attitudes and bellefs of health care providers. 


\section{INTRODUCTION}

Non-specific chronic low back pain is widely recognized as a major medical, social and economic problem and represents a major challenge to health care. "Important factors that determine how patients deal with chronic low back pain (CLBP) are often not related to physical pathology or pain severity. Attrudes and beliefs about the relationship between pain and function appear to explain partially the vartation in disability reported by individuals with chronic pain. ${ }^{2}$ Attitudes and beliefs of patients with CLBP are influenced by many factors, including past pain experience, ${ }^{3}$ culture, ${ }^{4}$ and social and economic factors, 5,6 The pain attitudes and beliefs of patients might be strengthened if patients find that they share the same attitudes and beliefs with health care providers. In a study by Rainville et al.? the attitudes and beliefs of physicians correlated with their rating of severity of patients' symptoms irrespective of their expertise in CLBP. Furthermore, physicians' attitudes and beliefs appear to infuence their recommendations regarding activities and work for patients with chronic low back pain. ${ }^{7}$ In another study, the physiotherapist's opinion about the importance of exercise in prevention appeared to be an important predictor of the total number of instructions given to a patient, indicating that a greater belief in the importance of exercise was reflected in more instructions. ${ }^{8}$ It appears that, in general, attitudes and beliefs of health care providers are important in the management of chronic low back pain.

Various disciplines, with possibly differing attitudes and beliefs concerning the management of CBLP, are involved in its management. In the Netherlands, patients with CLBP often consult physiotherapists: $27 \%$ of all patients consulting physiotherapists suffer from CLBP. 9 This study, therefore, specifically focuses on physiotherapists.

The aims of the current study are two-fold: First of all, the attitudes and beliefs of physiotherapists are surveyed. Secondly, the dimensions of these attitudes and beliefs are investigated in order to develop the Pain Attitudes and Beliefs Scale for Physiotherapists (PABS PT). This scale facilitates the examination of the role attitudes and beliefs on the development and persistence of chronic pain.

\section{METHODS}

\section{Item collection and expert reviewing}

We reviewed existing questionnaires concerning attitudes and beliefs of patients with chronic pain and rephrased items to a therapist's point of view. The following questionnaires were screened: 1 . Tampa Scale for Kinesiophobia (TSK), "10 measure of excessive, irrational and debilitating fear of physical movement and activity. The Dutch version (TSK-DV) has a fair and consistent internal validity, 1.12 2. Pain Catastrophizing Scale $(\text { PCS })^{13}$ that measures an exaggerated negative orientation toward pain. 3. The Back Beliefs Questionnaire $(\mathrm{BBQ})^{14}$ measures the attitudes and beliefs of patients regarding the inevitability of his/her back pain. 4. The Fear Awoidance Beliefs Questionnaire (FABQ) focuses on patients' beliefs about how physical activity and work 
affected their low back pain. ${ }^{3}$ In addition we added items that we thought might be relevant for the management of CLBP. Then an expert review procedure was performed: several experienced physiotherapists who are also involved in educating physiotherapists in cognitive behavioural approaches and researchers in the field of chronic pain were consulted. Two important criteria for this expert-validity procedure were: 1) items should be unambiguous; 2) items should be able to discriminate between different attitudes and beliefs. Examples are: Item number 1 of the TSK (I'm afraid that I might injure myself if l exercise) was rephrased as "If patients complain of pain during exercise, I worry that damage is being caused". Items can be scored on a six-point Likert scalle: "totally disagree" (score: 11, "largely disagree" (score:2), "disagree to some extent" (score:3), "agree to some extent" (score: 4), "largely agree" (score:5) and "totally agree" (score:6). "Extreme" was defined as score 1 or 2 for "disagreement" and score 5 or 6 for "agrement".

Initially the questionnaire consisted of 37 items, 6 of which were excluded after the expert procedure. The 31-item questionnaire and a pre-paid return envelope were mailed to a random sample of physiotherapists $(n=540)$ belonging to the Royal Dutch Association of Physiotherapy (KNGF). In addition, we specifically included all therapists $(n=137)$ who had attended specific education courses (over the last three years) in the management of chronic pain provided by The Knowledge Centre (NPi) for allied health professionals. After one month non-responders received a reminder.

\section{Statistical Analysis}

For demographic variables of participants, distribution frequencies were calculated. To assess the results of the survey, the mean score on each item, standard deviations, mode and range (10tm and $90^{\mathrm{t}}$ percentile) were calculated. To explore underlying dimensions a principal factor analysis (PAF) with an oblimin rotation was performed; a statistical approach aimed at clustering of items and item reduction. Prior to this procedure, each item was individually analysed because factor analysis can be biased if items are skewed. 16 Items were excluded if skewness was not between -1 and +1 or if less than $10 \%$ of responders scored in each of the "extreme" categories. On the remaining items the principal factor analysis (PAF) was performed. For the extraction of the number of factors, the eigenvalue $>1$ rule and the scree test were used. Also the content of the factors was taken into account. Items with loadings $\leq 0.25$ on any factor were excluded. If loading on one factor exceeded 0.25 but differences between loadings was less then 0.1 , items were also excluded. Cronbach's alpha was calculated as a measure of internal consistency. For all analyses SPSS10.0 for Windows (SPSS Inc. North Michigan Avenue, Chicago, 14,60611 ) was used.

\section{Characteristics of physiotherapists.}

Various characteristics of physiotherapists might have an effect on the attitudes and beliefs with regard to CLBP. We assessed how gender, age and whether physiotherapists themselves had an experience of low back pain had an effect on the scores of the different dimensions of the questionnaire. Also we assessed the effect of the following variables: 
Differences in education courses attended. Education courses might affect the scores on the questionnaire. Education courses were coded either as "biomedical" (w. g. manual therapy, McKenzie) or "biopsychosocial" (e.g. cognitive behavioural management such as graded activity, operant treatment approaches or respondent techniques). Subjects reporting education courses in both fields were excluded from these analyses, in order to establish maximal contrast on this variable.

Specialism. It is quite possible that education courses do mot necessarily overlap with self-reported specialism. One might have attended education courses as an introduction without being fully committed to such an approach, whereas self-reported specialism probably better reflects the true approach to which subjects feel committed. Therefore, we asked respondents to indicate their primary specialism. Subjects reporting "Manual Therapist" or "McKenzie therapist" were coded as a "biomedical" specialist; subjects reporting "Chronic Pain Therapist" or similar expressions ("Chronic Recurrent Conditions" or "Pain Rehabilitation"| were coded as "biopsychosocial".

Work setting. We hypothesized that in rehabilitation centres, physiotherapists are used to working in a more multidisciplinary setting as opposed to physiotherapists in private clinics and may, therefore, hold a more biopsychosocial orientation. Furthermore, in the Netherlands pain clinics are typically situated within rehabilitation centres for specialized hospitals) and therefore physiotherapists are more exposed to severe, chronic pain patients, which might be associated with a more biopsychosocial orientation.

\section{RESULTS}

Six hundred and seventy-seven questionnaires were mailed. After one reminder, 421 questionnaires were returned (response rate 62.3\%). The demographics of the respondents are presented in Table 1.

Table 1. Demographics of responders.

\begin{tabular}{|c|c|c|}
\hline \multicolumn{3}{|c|}{ Characteristics } \\
\hline \multicolumn{2}{|c|}{ Gender ( $\%$ women) } & $37 \%$ \\
\hline \multicolumn{2}{|l|}{ Work setting } & $\begin{array}{l}86 \% \text { private clinic } \\
4 \% \text { hospital } \\
3 \% \text { rehabilitation centre } \\
7 \% \text { combination / other }\end{array}$ \\
\hline Experience & $\begin{array}{l}\text { Private clinic, mean (sd) in years } \\
\text { Hospital; mean (sd) in years }\end{array}$ & $\begin{array}{l}17(7) \\
13(9)\end{array}$ \\
\hline \multicolumn{2}{|c|}{ Age; mean (sd) in years } & $41(7)$ \\
\hline
\end{tabular}




\section{Missing vilue}

Three hundred and seventy-three responders $(88.6 \%)$ completed all items of the questionnaire. One responder returned a blank questionnaire (no reason stated) and was, therefore, excluded. Furthermore, the sample included three responders with 6,5 and 4 missing values, respectively. Two responders reported 3 missing values, 3 responders showed 2 missing values and 39 responders were identified with 1 missing value. Missing items were excluded from analysis but other items of those responders were taken into account because there was no pattern in the missing items. For the analysis of the survey, all 31 items presented in tables 2 and 3 were used. For clarity of presentation, items that were excluded for factor analysis are presented in table 2 . The items on which factor analysis was performed are presented in table 3.

\section{Survey of attitudes and beliefs}

Tables 2 and 3 display the source of the items. Furthermore, mean scores, standard deviations, mode, and $10^{\mathrm{h}}$ and $90^{\mathrm{in}}$ percentile are presented. Table 2 shows three items producing mean scores smaller than 2 (item 15: $1.6(0.8)$, item $21: 1.8(0.9)$, and item $1: 1.8(1.0))$. The range $\left(10^{\text {th }}-90^{\text {th }}\right.$ percentile $)$ of these items was narrow: item 15 : 1-2, item 21: 1 3, and item 1: 1 3 , indicating that the majority disagreed with these items to a great extent. On the other hand three items showed consistently high mean scores: Jtem $16: 5.3(0.7)$, item $17: 4.7(1.1)$ and item 18:4.7 (1.2), with narrow 10th$90^{\text {th }}$ percentile score: Item 16:4-6, item 17:4-6, and item 18: 3-6, indicating that the majority agreed largely with these items. (All these six items were skewed such that they were deleted for the factor analysis) All other items revealed mean scores that can be considered in the middle range of a possible score (minimum 1, maximum 6) with broad $10^{\mathrm{m}} .90^{\mathrm{m}}$ percentile score, indicating that for these items neither strong agreements nor strong disagreements existed and that there is a wide range of attitudes and beliefs regarding these items.

\section{Exploring underlying dimensions.}

A principal factor analysis (PAF) with an oblimin rotation was performed on the questionnaire that consisted of 25 items (the initial 31 items minus 6 excluded items) in order to cluster the different items into factors and to reduce items of the total questionnaire. The Kaiser-Meyer-Olkin Measure appeared to be .869. Barlett's Test of Sphericity with an approx. Chi-square of 2089.7 , which was highly significant. Both measures justify the continuation of analysis. The eigenvalue $>1$ criterion initially yielded "7 factors. According to the "scree test" 2 factors remained. The subsequent factor analysis also yielded 2 factors. Analysing the results of the loadings led to the exclusion of 3 more items. Item 8 had a loading $\leq 0.250$. Item 19 and item 29 had loadings on both factors with a difference not exceeding the preset threshold of 0.1 . A high score on factor 1 (16 items) could be interpreted as "Biomedical Orientation". Examples of items loading high on this factor are: "Increased pain indicates new tissue damage or the spread of existing damage" (item 25); "Pain reduction is a precondition for the restoration of normal functioning" (item 24); "The severity of tissue damage determines the level of pain." (item 26). 


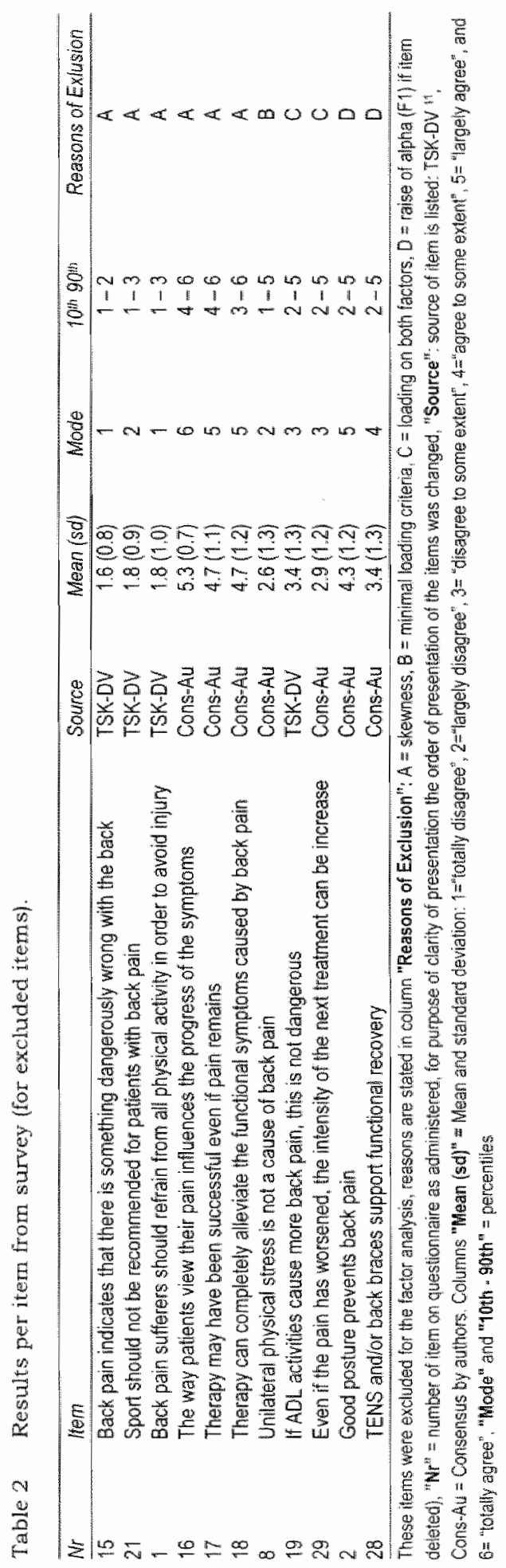


Based on the highest loading items, factor 2 (6 items) could be labelled as "Behavioural Orientation". Examples of items loading high on this factor are: "The cause of low back pain is unknown" (item 7), "Psychosocial factors are associated with functional limitations" (item 12), and "Mental stress can cause back pain even in the absence of tissue damage* (item 6 ). The results of the factor analysis are giwen in table 3 . The correlation between the "Biomedical Orientation" factor and the "Behaviourall Orientation" factor is -0.37 .

\section{Internal consistency}

To determine the internal consistency of both factors we conducted a reliability analysis on each factor by calculating Cronbach's alpha. The "Biomedical Orientation" factor (16 items) appeared to have an Alpha of 0.83 . After deleting 2 items that were indicated as giving a raise of Alpha (item 2 and item 28), Alpha increased somewhat to 0.84. This resulted in a 14 -item lactor. The "Behavioural Orientation" factor (6 items) appeared to have an Alpha of 0.54 . Total variance explained by factor $1=25.2 \%$ and $8.2 \%$ by factor 2 .

\section{Relation physiotherapists" characteristics and scores on the questionnaire}

To explore the effect of age (cut-off point $42=$ median), gender (male, female), and whether subjects had experienced an episode of low back pain themselves (present or past) on the scores on both factors, mean scores and standard deviations were computed for the different categories of each variable. These mean scores of both categories were compared using independent sample t-tests for every factor. Table 4 summarizes the results, the theoretical range of scores and the mean scores with the standard deviations, and the range of the entire sample. Women tend to score higher compared to men on both the "biomedical" factor (not statistically significant) and the "behavioural" factor (statistically significant $\mathrm{p}=.007$ ). The variable age revealed a difference on factor 1 : age $\geq 42$ statistically significantly higher scores. Low back pain experience did not show any difference.

The results on the variable "Education Courses" pointed in the direction expected: scores on the biomedical factor, though not statistically significant, are higher for physiotherapists who followed biomedical education courses. On the "behavioural" factor, physiotherapists who took biopsychosocial education courses had statistically significantly higher scores $(p=.002)$. Moreover, biomedical specialists score statistically significantly higher on the "biomedical" factor as opposed to the biopsychosocial specialist $(\mathrm{p}=.002)$, whereas biopsychosocial specialists score higher (although not statistically significant) on the "behavioural" factor. Although scores for the variable "Work Sekting" pointed in the direction expected (physiotherapists working in a private clinic score higher on the "biomedical" factor and physiotherapists working in a rehabilitation centre score higher on the behavioural factor) no statistically significant differences were found. 


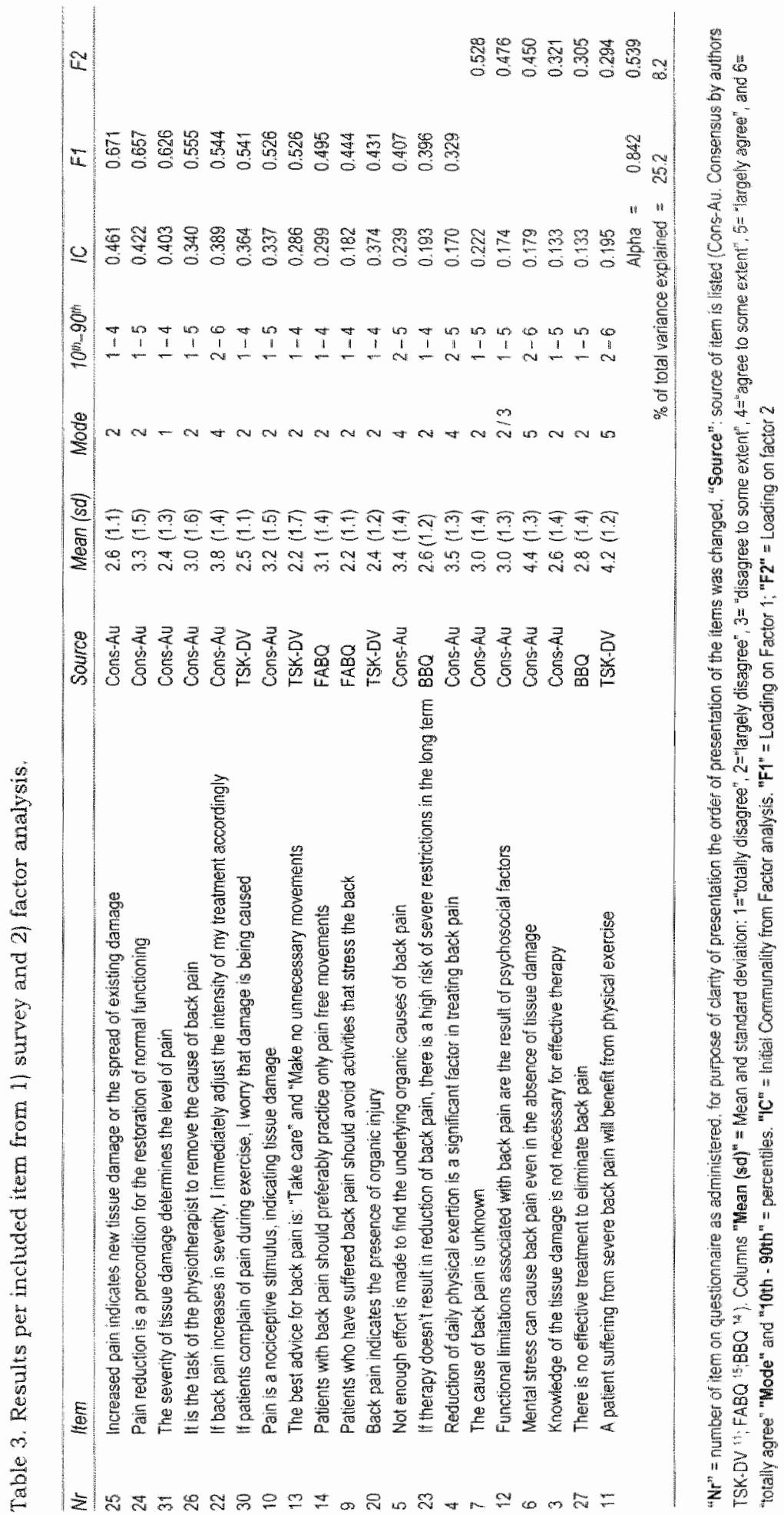


Table 4. Characteristics of physiotherapists in relation to scores on Factor 1 and Factor 2.

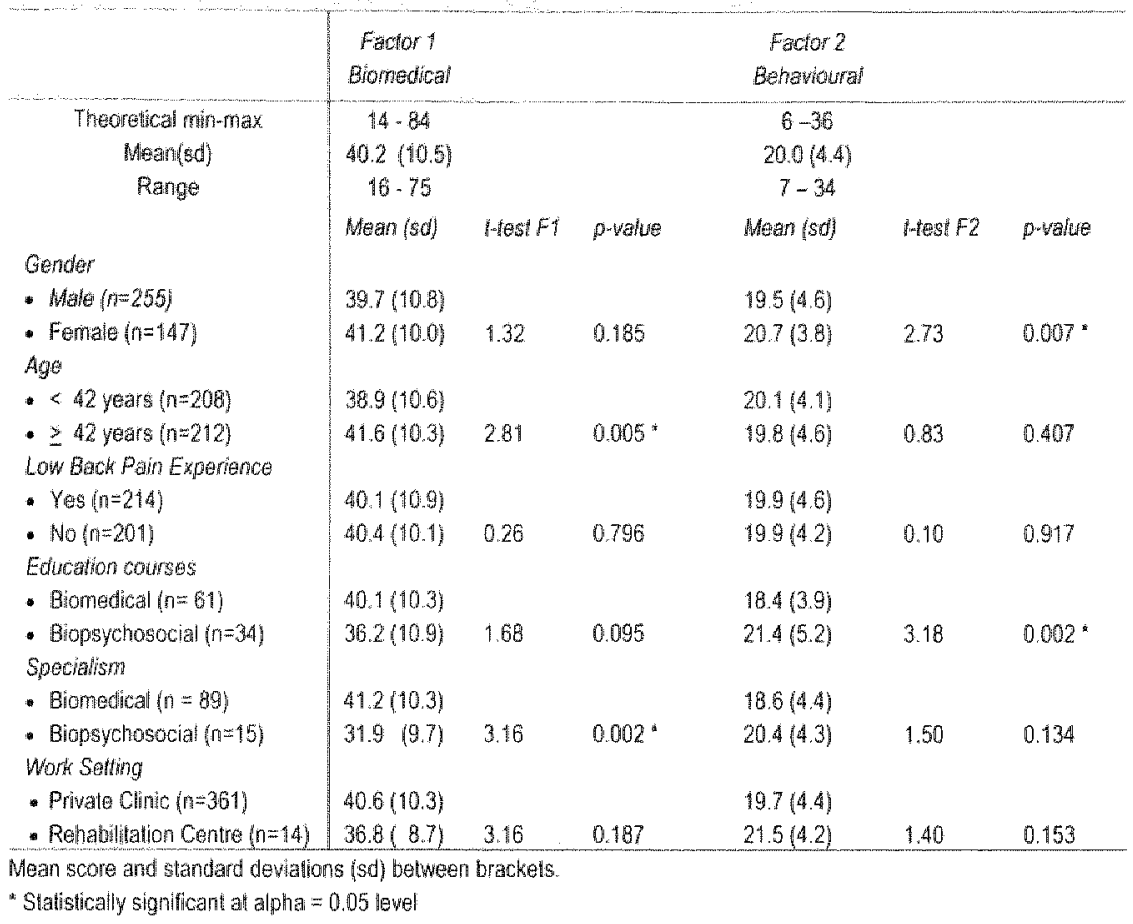

\section{Discusision}

A national survey among Dutch physiotherapists regarding their attitudes and beliefs towards chronic low back pain (CLBP) suggests that there is a reasonable consensus among physiotherapists with regard to the management of CLBP: reassure and reactivate patients. Factor analysis yielded an interpretable 2 -factor model. The procured questionnaire was named: Pain Attitude and Beliefs Sicale for Physiotherapists (PABS_PT). High scores on factor 1 were labelled "Biomedical Orientation", whereas high scores on factor 2 were labelled "Behavioural Orientation". Cronbachs" alpha of factor 1 was satisfactory whereas factor 2 had a poor internal consistency. "The variables "Education Courses" "Specialism" and "Work Sietting" affected the scores on the factors as anticipated. In terms of usefulness the PBAS_PT could be used to assess the orientation of pain-therapists, e.g. a physiotherapist.

\section{Survey}

The survey yielded 6 items on which the vast majority agreed or disagreed. Typically, these items are addressed in Dutch guidelines (general practitioners ${ }^{17}$, as well as physiotherapists' "is) for CLBP. Dutch physiotherapists seem to acknowledge the pivotal role of patients" ideas regarding the development and maintaining of CLBP. Furthermore, the results suggest that physiotherapists focus their treatment on functional limitations rather than on pain. This is in concordance with the strong 
disagnement that back pain indicates that there is something dangerously wrong with the back, and that patients with CLBP should refrain from physical activity, which might reflect the knowledge of the Dutch guidelines (as woll as other international guidelines). The guidelines stress the importance of reassuring patients with CLBP that nothing is dangerously wrong and advising patients to stay active. In general we conclude, that physiotherapists underscore these recommendations.

However, most other items that reflect on diagnosis or treatment in more detail (e.g. "Knowledge of tissue damage is not necessary for effective treatment" (item 3) or, "Not enough effort is made to find underlying organic causes of CLBP" (item 5), or "Patients suffering from severe back pain will benefit from physical exercise" (item 11), showed scores that were neither in strong agreement nor strong disagreement, and there was a wide variety. A reason for this might be that on the one hand from their training, physiotherapists are more biomedically oriented, whereas on the other hand, the biopsychosocial model is advocated, 17,18 thereby probably shifting the orientation towards a behavioural orientation. The wide variety indicates lack of consistency with regard to exact details in the management of CLBP.

\section{Analyses}

The communalities as presented in table 3 are low, which makes the factor analytical approach somewhat problematic with regard to interpretation of the factor solution. Because of these low communalities, the values of the loadings are not particularly high. Furthermore the internal consistency and explained variance of factor 1 was acceptable, but both were disappointing for factor 2 . However, as we considered this as an initial impetus to developing a questionnaire and to cluster items in order to be able to assess the orientation of physiotherapists, we continued this analysis. Because of these critical motes, the 2 -factor model should be interpreted with caution, but we still think that because 2 factors emerged, these data suggest that both factors have to be taken into account. Furthermore, because of the correlation between the 2 factors, the results show that a biomedical orientation (factor 1) is not diametrically opposed to behavioural orientation (factor 2). Despite the somewhat disappointing psychometric results, we considered it encouraging that the variables "Education Courses", "Specialism" and "Work Setting" affected scores on both factors as anticipated. Women scored slightly higher on both factors, but although there is a statistically significant difference on factor 2, we consider this small difference to be marginal. Previous low back pain experience revealled no differences in sum scores on the two factors. Physiotherapists over 42 years of age scored statistically significantly higher on the "Biomedical Orientation". This might possibly reflect the fact that the biopsychosocial orientation is of relatively recent date. Older physiotherapists may have had less opportunity to get acquainted with this approach. 


\section{Comparison with other questionnaire}

To our knowledge, there is one other questionnaire concerning health care providers" beliefs and attitudes. This "Health Care Providers' Pain and Impairment Relationship Scale (HC-PARS)" was developed by Rainville.2 In both studies by Rainville.7 in which attitudes and beliefs of health care providers were assessed the HC_PAIRS was used. This scale was validated for community health care and rehabilitation providers. Compared to the HC-PAIRS ${ }^{2}$ this study focuses more on diagnostic issues and issues that specifically address circumstances regarding treatment or advice given to patients with CLBP by physiotherapists. Furthermore, the PABS PT has two subscales whereas the HC PAIRS contains one scale only. Therefore, in our opinion, the PABS_PT is more informative because it gives more information on how sum scores on the two subscales are achieved. In case of one scale only, more combinations of items might lead to a similar sum score, thereby discarding how this score was achieved.

\section{Limitations}

The current study might have missed some important items because we screened patient questionnaires and attitudes and beliefs of patients are not necessarily the same as physiotherapists' attitudes and beliefs. But as experienced physiotherapists in the field of the management of chronic pain, who are also involved in training physiotherapists in cognitive behavioural approaches, were involved in the development of the PABS_PT, the possibility of missing important items has been reduced. Moreover, Houben ${ }^{19}$ showed that HC-PAIRS and PABS_PT correlated highly, suggesting that there were no substantial omissions in the PABS_PT as compared to the HC-PAIRS. In the current study, selection bias might have occurred because physiotherapists interested in cognitive behavioural approaches are more likely to return this kind of questionnaire. Another limitation might be the country in which this survey was performed. Transferring these results to other countries should be carried out with caution because definitions of specialism and education courses might differ greatly between countries. Before studying orientations of physiotherapists in other countries by means of the PABS_PT the characteristics of physiotherapists as used in the current study should be adapted.

\section{Future}

Although factor 1 showed satisfactory psychometric results, there certainly is room for improvement, especially for factor 2 . Items that were initially formulated from the biopsychosocial perspective were excluded from the factor analysis because most physiotherapists (dis)agreed to a great extent. To improve factor 2 in terms of internal consistency we suggest that future research focuses on items that address biopsychosocial issues.

To develop the PABS_PT further we suggest that a variety of disciplines including e.g. chiropractors, orthopaedic surgeons or therapists highly specialized in treatment of chronic pain are incorporated, as they are more likely to achieve extreme scores. Among physiotherapists, the biopsychosocial model recently gained much attention that could have modified attitudes and beliefs. Probably there were no subjects holding extreme attitudes and beliefs. By including the above mentioned disciplines one can 
assess whether the PABS_PT can discriminate between different (more extreme) orientations. For further investigation with regard to validity we suggest the use of external criteria. A possible external criterion could be the Photograph series of Daily Activities (PHODA), 20 This instrument is developed in order to create a hierarchy of back-stressing activities reflecting the full range of situations that patients avoid, starting with those that provoke only mild discomfort, and ending with activities or situations well beyond that patient's present abilities. Furthermore the impact of these different orientations on the management of CLBP should be investigated by, for example, by assessing recommendations regarding treatment options for hypothetical patients, as described in patient vignettes. To examine the infuence of these different orientations with regard to chronic low back pain on patient outcome is also a challenge for the near future.

\section{ACKNOWLEDGEMENT}

The authors would like to thank Cobie Martens for her assistance with regard to data management. Furthermore we would like to thank Michael Schermer from The Knowledge Centre (NPi) for allied health professionals for his efforts with regard to the survey.

\section{REFERENCES}

1. Waddell G. The Back Pain Revolution. Edinburgh London New York: Churchill Livingstone, 1998.

2. Rainville J, Bagnall D, Phalen L. Health care providers" attitudes and betiefs about functional impairments and chronic back pain. Clin J Pain 1995, 11(4):287-95.

3. Fordyce WE, Fowler RS, Lehmann, JF, Delateur BJ, Sand PL, Trieschmann RB. Operant conditioning in the treatment of chronic pain. Arch. Phys Med Rehabil 1973;54(9):399408.

4. Sanders SH, Brena SF, Spier CJ, Beltrutti D, McConnell H, Quintero O. Chronic low back pain patients around the world: cross-cultural similarities and differences. Clin $J$ Pain 1992;8(4):317-23.

5. Lee PW, Chow SP, Lieh Mak F, Chan $\mathrm{KC}$, Wong S. Psychosocial factors influencing outcome in patients with low back pain. Spine 1989; 14(8):838-43.

6. Volinn IJ. Issues of definitions and their implications: ADD and Jeprosy. Soc Science and Med 1989;29(10):1157-62.

7. Rainville J, Carlson $N$, Polatin P, Gatchel RJ, Indahl A. Exploration of physicians' recommendations for activities in chromic low back pain. Spine 2000;25(17):2210-20.

8. Kerssens JJ, Sluijs EM, Verhaak PF, Knibbe HJ, Hermans IM. Back care instructions in physical therapy: a trend analysis of individualized back care programs. Phys Ther 1999;79(3):286-95.

9. Ravensberg van CD, Klaveren van AJJ, Wams HWA, Elvers JHW, Oostendorp RAB, Hendriks HJM. Variabelen in samenhang met het aantal behandelingen fysiotherapie. Amersfoort: NPi, 1995.

10. Miller RP, Kori SH, Todd DD. The Tampa Scale. Unpublished Report. Tampa, FL, 1991.

11. Kole-Snijders AMJ. Validity of the Tampa Scale for Kinisifobia - Dutch Version (TSK DV for chronic low back pain patients. 7 th World Congress on Pain 1993, Paris.

12. Vaeyen JW, Kole Snijders AM, Boeren RG, Eek van $H$. Fear of movement/(re)injury in chronic low back pain and its relation to behavioral performance. Pain 1995;62(3):36372 . 
13. Sullivan MJL, Bishop SR, Pivik J. The Pain catastrophizing Scale: Development and Validation. Psychol Assess 1995:7:524-32.

14. Symonds TL, Burton AK, Tillotson KM, Main CJ. Do attitudes and beliefs infuence work loss due to low back trouble? Occup Med 1996;46(1):25-32.

15. Waddell $G$, Newton M, Henderson I, Somerville D, Main CJ. A Fear-Avoidance Beliefs Questionnaire (FABQ) and the role of fear-avoidance beliefs in chronic low back pain and disability. Pain 1993;52(2):157 68.

16. Bernstein IH, Teng G. Factoring items and factoring scalles are different: spurious evidence for multidimensionality due to item categerization. Psychal Bull 1989;105:476477.

17. Faas A, Chawannes: AW, Koues BW, et al. NHG-Standaard Lage-Rugpijn. Huisarts en wetenschap 1996;3911:18-31.

18. Bekkering GF, Hendriks HJM, Koes BW, et al. KNGF-richtlijn Lage-rugpijn. Supplement bij Neder Tijdschr Fysiother 2001;111(3):1-24.

19. Houben RMA, Ostelo RWJG, Vlaeyen JWS, Wolters PMJC, Peters M, Stomp van den Berg SGM. Internal Report, 2001.

20. Kugler $K$, Wijn J, Geilen M, Jong de J, Vlaeyer JWS. The photograph series of claily activities (PHODA). Heerlen, The Netherlands: Institute for Rehabilitation research and Academy for Physiotherapy, 1999. 
Epilogue 
Rehabilitation after lumbar disc surgery has gained far less attention than the operation itself. Possibly this could mean that after lumbar diso surgery no further problems exist. However, surgery to remove the lumbar dise protrusion does not solve all back problems. A substantial part of the patients still suffer residuall complaints after surgery. Rehabilitation might be an important tool in order to minimize these remaining complaints. Especially active treatment options could be important to assist patients in improving functional status. The main focus of the current thesis was to assess the effectiveness of rehabilitation programs after lumbar disc surgery. For this purpose a systematic review has been conducted on this topic. Furthermore we performed a randomized controlled trial to compare a behavioral graded activity (BGA) program to usual care (UC), as provided by physiotherapists, in patients following a lumbar disc surgery. The BGA program is based on operant treatment principles and is one of the three treatment modalities that are based on the biopsychosocial model. Other treatment modalities that are based on the biopsychosocial model are cognitive and respondent treatment modalities. These three treatment options are generally referred to as cognitivebehavioral approaches.

However, cognitive-behavioral approaches, so far, have only been investigated for patients with chronic low back pain and not for patients following lumbar disc surgery. But even for chronic low back pain the evidence is not clear. Therefore, a systematic review was undertaken to assess systematically the effectiveness of cognitive-behavioral approaches for patients with chronic low back pain. Systematic reviews include a comprehensive search strategy and a predetermined and explicit method to appraise and synthesize the information from individual studies 1,2 and have become a common good in the last decennium to investigate effectiveness of interventions. But there are some disadvantages associated with this method. These will be discussed in the first part of this chapter. Well conducted randomized controlled trials (RCTs) provicle the best evidence on the effectiveness of interventions. However, when conducting randomized controlled trials researchers should be aware of some distinct disadvantages. These will be discussed in the second part of this chapter. In addition the implications for future research as well as for clinical practice will be discussed. This chapter concludes with a personal wiew on recent trends with regard to cognitive-behavioral treatments.

\section{SYSTEMATIC REVIEWS}

\section{Methodologic criteria}

The criteria list recommended in the method guidelines for systematic reviews in the Cochrane Back Review Group was used in both systematic reviews " For assessing the quality of the included studies only items reflecting on the internal validity were used. One point was scored for each item satisfied. Unfortunately, as in many systematic reviews on musculuskeletal disorders, the conclusion in both systematic reviews was that the majority of the included studies were of poor methodologic quality. In the systematic review on rehabilitation after lumbar disc 
surgery, only 6 out of 13 studies (46\%) were considered as high-quality studies. In this review, studies were considered as high quality when fulfilling 5 out of the 12 internal validity criteria. In the systematic review on cognitive-behavioral treatment for chronic low back pain only 5 out of 21 included studies (24\%) were considered as high-quality studies. However, the interpretation of these methodological scores can be problematic. Using sum scores means items receiving a positive score can compensate items that are scored negative. This may result in the conclusion that a given study was of high quality although it was fatally llawed on one item. Numbers are bewitching and have a sense of objectivity although they remain products of human judgment. In both systematic reviews many studies had no adequate concealment of treatment allocation, or lacked a clear description of the procedure, and received, therefore, a negative score on this criterion. Despite this negative score for concealment of treatment allocation two studies in the cognitive-behavioral review and one study in the rehabilitation review were classified as high quality. Several authors have found that inadequate concealment of treatment allocation is associated with larger effect sizes. 45 Therefore it could be possible that there are even less studies of high quality, that is with unbiased results, in the systematic reviews. This illustrates the problem of using checklists in systematic reviews for the quality assessment of randomized controlled trials. Other methods to account for methodological quality of the included RCT's are available, such as a visual plot of the effect size against an overall score. Furthermore, it has been suggested that quality scores could be used as a "threshold score" for inclusion, or as a "weighting factor" in the statistical analysis., However, hardly any empirical evidence with regard to the preferential choice of these various methods is available and these methods were not applicable in our situation because of the small number of trials on the same topic.

Of course we are aware of the fact that there might be a difference in how a study is actually conducted and the quality of its publication. We hope with other reviewers ${ }^{\text {A }}$ that many medical journals will comply with the CONSORT statementio following the policy of the British Medical Journal (BMJ), Lancet and the Journal of the American Medical Association. Thereby, the quality of the publications of the RCits will be improved.

\section{Summarizing the avallable evidence}

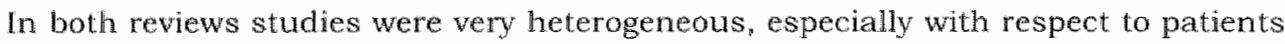
included and the interventions. Only for the comparisons between cognitivebehaviorall treatment and "no treatment, wating-list control, or placebo", in the cognitivembehavioral review, there was a sufficient number of studies which made pooling sensible. For all other comparisons there were in general only one or two studies, which makes pooling impossible or at least questionable. In the rehabilitation review, for none of the comparisons an adequate number of studies were available. Therefore we performed a qualitative analysis of the studies. Consequently, as for each intervention there were only one or two RCTs, drawing firm conclusions was impossible. The value of such systematic reviews lays primarily on identifying blank spots with regard to the evidence. Another issue that 
is debatable when summarizing the evidence concerns the use of a rating system for determining the level of evidence. In the definition of these levels of evidence the quality of studies is taken into account but the cut-of point for high quality is often arbitrary. Also the number of high-quality studies needed for establishing "strong evidence" is unclear. In some reviews a cut off point of two high quality studies is used. But there is no consensus, yet, with respect to these levels of evidence and further development of methods of evidence-based medicine is clearly needed."

Despite these shortcomings there are two major advantages of using the methods as recommended by the Cochrane Back Review Group. ${ }^{3}$ First of all, it makes the procedures of how reviewers reach their conclusion transparent. Secondly. using the same methodology in a certain field makes it possible to compare the results of various systematic reviews more easily. Comparing results of systematic reviews will be hampered if reviewers all use their own methods that also will contain arbitrary choices. Recently it appeared that even two or more high-quality systematic reviews on the same topic may arrive at a different conclusion. 12 A possible explanation could be that different methods of systematic reviews introduce bias and therefore should be interpreted with caution. On the other hand, it can be argued, that if two different methods of systematic reviews reach different conclusions, evidence is obviously not beyond doubt. This means that consumers of systematic reviews (e.g. physicians or guideline committees) should be careful and critical when interpreting the results of various systematic reviews.

\section{What is Homogeneity?}

The concept of homogeneity of patients deserves more attention. In our systematic review that assessed the effectiveness of cognitive-behavioral treatment we included only RCT's that studied patients with chronic low back pain. This means that in addition to a chronic pain problem the site of the pain (and diagnosis) was used as inclusion criteria. However, another recently published systematic review 13 on the effectiveness of cognitive-behavioral therapy included all studies in which patients reported chronic pain. In this review chronic pain was accepted as a label for a heterogeneous group of pain problems in which neither diagnosis, nor site of pain are an apparent major source of variance in any of the targets of treatment. "Ihis implies that these reviewers consider patients with rheumatoid arthritis imore or less comparable with patients whom suffer low back pain or knee pain because the target of the intervention is not primarily focused on medical outcome measures but on psychosocial outcome measures such as decreasing pain behavior", or improving cognitive coping styles. However, in our opinion the diagnosis could be a source of variance even when targets of interventions are primarily focused at these psychosocial outcome measures. Moreover, Carragee ${ }^{14}$ argues that it seems that psychological issues do not equally influence the various low back pain syndromes due to different etiologies. Obviously, whether a certain population of patients is considered homogenous depends on the perspective of the reviewers. A multidisciplinary team of reviewers could overcome these differences by clearly 
defining the concept of homogeneity of patients, or characteristics of patients, at the start of a systematic review and translating this into clearly defned eligibility criteria. Needless to say that this issue conceming the homogeneity of patients is similar when planning a randomized controlled trial.

The majority of patients in our trial had complaints for more than 3 months before they were indicated for surgery. Therefore they might be considered as patients with chronic low back pain with a specific cause, and in that respect they were fmore or less) homogeneous. During surgery the disc or the extruded portion of the disc is removed. Patients were included in our trial if they still suffered residual complaints 6 weeks after the surgery. The question is whether these patients following surgery, still have a specific cause for their back pain, or whether they resemble patients with non-specific low back pain. If the latter holds, that does imply that they have a similar prognosis and respond similarly to the treatments. In other words, they belong to a homogeneous population of patients with chronic low back pain. If so, results on effectiveness of treatments for chronic non-specific low back pain patients can be generalized to a population of patients following first-time lumbar disc surgery. Whether this holds true is discussed further under the heading: Results of the randomized controlled trial.

\section{RANDOMIZED CONTROLLED TRIAL AFTER LUMBAR DISC SURGERY}

\section{Participation of patients, neurosurgeons and physiotherapists}

As already mentioned before, well-conducted randomized controlled trials (RCTs) provide the best evidence on the effectiveness of interventions. "Well conducted" refers to the practical performance of the trial. Unfortunately, this seems to be one of the most underestimated issues, ${ }^{15,6}$ An efficient and experienced trial team is called for. Researchers should be aware of the time-consuming business of mantaining the enthusiasm in centers, to visit centers throughout the trial, to monitor recruitment of patients, and to identify methods to improve recruitment. Furthermore, it should be clear that a well-run trial of reasonable size also involves considerable data handling, including the chasing, checking, and monitoring of trial data to improve their quality and completeness. Every study protocol needs to address these issues and prowide detailed specifications of the trial procedures. meaning that patient entry, treatment and evaluation plus data collection procedures need to be clearly stated so that each member of the investigation team knows what is expected of them for each patient in the triall. 17 Unfortunately, these aspects of conducting research are often underestimated, resulting in a time schedule too tight and lacking financial resources for adequate measures to enhance motivation and to encourage recruitment staff, patients and care providers to comply with the protocol, because too often these are considered to be superfiuous. 
In the current trial the following strategies were used to enhance motivation and to encourage everybody involved: user-friendly flow charts for the neurosurgeons as a reminder for the inclusion of patients, regular short presentations during weekly meetings of the neurasurgeons, a regular newsletter with a recognizable logo ("The Backpacker $)$, and refreshment meetings for physiotherapists, separate for both treatment conditions to avoid contamination of the treatments between both groups. The aim of the newsletter was to provide feedback on the progress of the trial on a regular bases for everybody involved, including figures of inclusion, reminders of important issues of the trial (e.g. inclusion and exclusion criteria) and in one edition there was a quiz with two tickets to a theater show for the one who predicted the right number of included patients at a certain time. From October 1997 through March 2001 fourteen newsletters were sent to all participants.

The monitoring of the trial proceedings showed that, as always, the inclusion lagged behind the still too optimistic planning. Therefore, after 5 months of inclusion we decided to include two extra hospitals in other cities, both in the South of the Netherlands, where the same team of neurosurgeons operated for herniated lumbar discs. Before the start of the trial this was not considered necessary. But reality proved to be more unmanageable as anticipated. Including the two extra hospitals meant an expansion of the catchment area. Therefore it was necessary to recruit new physiotherapists in both treatment conditions. In total 6 new BGA therapists were recruited. For these therapists training sessions had to be organized similar to the training of the BGA therapists that already participated. In the recruitment of UC therapist we encountered a problem. Many physiotherapists that we approached refused to get involved because they felt uneasy performing a treatment in which they were not involved from the beginning, although - in our opinion - it was care as usually provided by physiotherapists. This emphasizes two important issues. Firstly, that there is a wide variety in the treatment options applied by physiotherapists in patients after first time lumbar disc surgery. Secondly, it stresses the importance of involving health care providers as early as possible in developing the treatment protocols, even if researchers expect a low threshold because in theory the treatment represents care as usual. In the end we were able to recruit 6 new UC therapists. This time and energy consuming expansion of our trial paid of well. The inclusion of the two hospitals yielded 25 extra patients $124 \%$ of the total number included) for our trial. Table 1 presents the number of included patients per hospital. 
Table 1. Numbers of included patients per hospital

\begin{tabular}{|c|c|c|}
\hline Hospital & Number of patients & Percent \\
\hline University Hospital Maastrich ${ }^{\text {th }}$ & 37 & 35.2 \\
\hline Atrium Hospital Heerten" & 43 & 41.0 \\
\hline Maasland Hospital Sittard** & 15 & 14.3 \\
\hline Laurentitus Hospital Roemonond & 10 & 9.5 \\
\hline Total & 105 & 100 \\
\hline
\end{tabular}

* Hospilats that participatad from the beginning

* Hospilas that participaled form the sol month

\section{No control group}

Assessing the effect of no treatment was not the alim of this trial. Moreover, we would have needed another 50 patients (so probably another $6-7$ more months to include these patients). In addition, it would have been very difficult to have a no treatment group because almost every patient who still has substantial complaints 6 weeks after surgery wants some kind of treatment. From an ethical point of view, it was not considered appropriate to withhold treatment to these patients, because by doing so we would hawe offered less than usual care.

\section{Contrast between interventions during the course of the trial}

During the analysis of our trial we had to conclude that the contrast between interventions was less than expected. In retrospect, it is tempting to think that, knowing what we know now, this could have been foreseen because physiotherapists delivered both interventions. Indeed, the contrast between both interventions was considered to be an essential issue, at the start (May 1997) of our trial. Our main concern was recruiting a sufficient number of physiotherapists that were willing to and capable of delivering the BGA program to patients following a lumbar disc surgery. At the start of our trial most physiotherapists were not familiar with the BGA program, which is an operant treatment in which the progress of the training is not guided by pain. Furthermore, the BGA program was doubted to be appropriate for these patients and, moreover, there were considerable doubts with regard to the feasibility of the BGA program. ${ }^{3}$ Only after correspondence with an international expert in this field ${ }^{\text {w }}$ who performed an RCT" to assess a high-intensity exercise program for patients following lumbar disc surgeryzo we were able to convince the Medical ethical Committee and the Advisory Board on Scientific Research of the University Hospital Maastricht that our program was not dangerous for patients after lumbar disc surgery.

However, in the course of our project, cognitive-behavioral treatments (in general) were gaining more interest of care providers, including physiotherapists, and a growing number of physiotherapists attended training sessions in cognitivebehavioral approaches. This phenomenon also occurred in the UC group and therefore UC physiotherapists sometimes incorporated some cognitive-behavioral characteristics in their treatment. On the other hand, as the results of the audiotapes show that, despite their training BGA therapists still used some typical UC characteristics in their treatment. Based on the analysis of the audio tapes, we 
had to conclude that there was an overlap of $20 \%$ to $30 \%$ between interventions resulting in less contrast than expected. Despite, this overlap, we do not think that this is an explanation for the fact that we found no difference between both groups, as $70 \%$ to $80 \%$ of the sound samples were classified correctly and BGA did not show any sign of being more effective that UC. The initial skepticism towards the BGA program at the beginning of our trial is in contrast with the (over? fenthustasm with which cognitive-behavioral treatments, in general, are adopted for musculoskeletal disorders recently.

\section{Different practices, same treatment, different results}

In our trial recovery rates per practice differed widely both in $\mathrm{BGA}$ as well as in UC. Unfortunately, numbers of patients per practice are too small. for proper analyses. This variance in success rates probably explains why in various participating practices there are different opinions with respect to the success of interwentions. Some authors claim that small (pilot) studies should not be used to evaluate effectiveness, 21 because they are likely to produce imprecise results. However, another interesting question is brought up by the variances in success rates: why have some practices such nice results? Is this only due to chance or random variation, or are there some real determinants of success? It would be worthwhille to assess this variety in success rates. We hypothesize that other variables, than those included in pilot studies or RCTs, possibly are of major importance. Attitudes and beliefs of health care providers might influence patients' attitudes and beliefs, which is an important factor that determines how patients deal with their disability. ${ }^{22}$ The influence of this interaction between health care providers and patients needs further investigation.

\section{Quality assessment}

After assessing the quality of all the included trials in both systematic reviews we considered it fair to subject our own randomized controlled trial (RCT) to the same quality assessment. Two rewiewers (M Dirx and MPA Zeegers) independently assessed the RCT using the criteria list recommended in the method guidelines for systematic reviews in the Cochrane Back Review Group. ${ }^{3}$

Out of the 12 items reflecting on the internal validity 8 criteria were scored positive (method and concealment of randomization, drop-out rate during the intervention period, withdrawals during follow-up, co-interventions avoided or equal, intention. to treat analysis, similarity of baseline chatacteristics, and adequate length of follow-upj. The 4 items that received a negative score will be discussed below.

Blinding of patients. This criterion was scored "unclear" by both reviewers. As it is difficult to blind patients for these kinds of treatment this criterion was redefined for our systematic review ${ }^{23}$ in terms of credibility of the treatment. If interventions were found to be equally credible to patients this criterion should receive a positive score. In our RCT the credibility of both interventions was assessed and the reviewers agreed that both interventions were credible. However, there remained discussion about whether "credibility of treatment" can replace the concept of "blinding of patients". Therefore this item was scored unclear. 
Blinding of outcome assessment. This criterion received a negative score, as both primary outcome measures are self-reported outcome measures. Unfortunately, there are no other outcome measures available apart from questionnaires for evaluating outcome measures such as perceived global effect or improvement in functional status experienced by the patient. Currently, in many studies patientspecific measurements are used because they are considered the most appropriate and sensitive for measuring improvement in clinical research. 24.27 The disadvantage is that in trials in which the patients cannot be blinded for treatment, blinding of outcome measurement is impossible, because the patient must complete the questionnaires. The advantage of patient-specific outcome measures is that these are the most relevant for the patient and clinician.

Blinding of care providers. Satisfying this criterion was impossible as the aim of this RCT was to assess the effectiveness of different treatment approaches by physiotherapists in primary care. The therapists had to be instructed and trained in order to be able to deliver this new treatment.

Compliance. This item was scored "unclear" by both reviewers. The reason for this was that they interpreted the concept of complance more broadly as it was defined in the criteria list. Compliance was defined as the number and frequency of session attend by the patients. Both rewiewers hold the view that there is more to compliance than just these two items. Apart from attending treatment sessions, compliance also implies really performing the exercises correctly and whether patients comply with instructions for their normal daily activities. This information could not be retrieved from the publication and is also difficult to record in pragmatic trials. In summary, there were four sources of potential bias in this trial, none of which we consider to be fatal.

\section{Results of the randomized controlled trial}

The results of our RCT reveal that on the post-treatment measurement, 3 months after randomization, the $B G A$ program performed statistically significantly worse than UC $(19,3 \%$ difference, $95 \% \mathrm{Cl} ; 0,1 \% ; 38,5 \%)$ on global perceived effect. But after 12 months follow-up the difference of $2 \%[95 \% \mathrm{Cl}-1.9 .5 ; 15.7]$, in advantage of BGA, was far from statistically significant. For outcomes on low back pain specific functional status, catastrophizing, fear of re-injury/movement, main complaint, pain, range of motion, general health and social functioning no statistically significant differences between both groups were observed at any of the follow-up measurements. Therefore, we argue that the two treatment conditions, $\mathrm{BGA}$ and $\mathrm{UC}$, administered in the current RCT including patients following first time lumbar disc surgery, are equally effective after one year of follow-up. A reason for this could be that theories, derived from the field of chronic low back pain, might not apply for patients following lumbar disc surgery. Furthermore, the cost effectiveness analysis reveals that BGA is associated with higher clirect and nondirect health care costs. The costs for visiting a physiotherapist accounted largely for the surplus costs in BGA. An explanation for this might be that patients held different expectations with regard to the BGA program, in such a way that they expected more passive modalities for reducing pain, and more pain-guided management in general. Therefore, physiotherapists might not have succeeded in 
dispelling the patients' fears and insecurities and therefore patients were more inclined to seek help from a physiotherapist in the following year. In summary. based on this study, we see no reason for implementing BGA as the standard treatment for these patients. If the present high-quality $\mathbb{R C}[$ would have been included in our systematic review that assessed the effectiveness of rehabilitation programs after lumbar disc surgery, it would primarily have contributed to the heterogeneity between the included RCT's because none of the imcluded studies incorporated operant treatment. Therefore this RCT cannot be pooled with other included RCTs.

\section{IMPLICATION FOR FUTURE RESEARCH}

Many interesting themes with regard to the rehabilitation for patients following lumbar disc surgery need further attention. Intensive exercise programs seen to be the most effective treatment for improvement of functional status and faster return to work on short-term follow-up. However, for long-term follow-up there was no convincing evidence that intensive treatments are more effective than mild exercise programs. ${ }^{23}$ Furthermore, the exact content of these intensive exercise programs is not yet clear. Future research should focus on this content. Should general exercise programs (e.g aerobics) be used for the rehabilitation or should these intensive exercises be more patient taillored? But also the context in which these programs should be delivered is not yet clear. In our systematic review2a one $\mathrm{RCT}^{\mathrm{T}}$ compared a supervised exercise program with patients performing exercises at home, and found that both approaches were equally effective.28 Unfortunately, this was a small lowquality study. Future RCTs should investigate the context in which these programs could most effectively be delivered. Questions to be answered are whether patients can practice at home or whether they need supervision. If supervision is needed, should that be on an individual basis or are exercise sessions in groups more effective? Other questions that need to be answered are: what is the optimal starting point for rehabilitation after lumbar disc surgery? Should all patients be treated immediately after surgery or is it more effective and efficient to wait for 4 to 6 weeks and then include only patients who have not yet recovered?

For improving the outcomes for long term follow up, it might be interesting to assess whether self-management programs are more effectiwe on the long term because these kinds of programs specifically address the self-effectiveness of patients, which might be of paramount importance for prolonging the effectiveness of treatments beyond the duration of the intervention itself. Whether these selfmanagement programs should coincide with intensive exercise programs needs further investigation.

Whether patients following lumbar disc surgery benefit fron other cognitivebehavioral approaches than BGA also needs further investigation. At the start of our RCT we hypothesized that if fear of movement could be diminished it might result in better recovery rates and an irmproved functional status. But, in general, 
fear of movernent turned out to be rather stable in these patients. It has been argued that a very essential step in decreasing fear of movement is exposing patients to situations they have identified as 'dangerous' or 'threatening'. In a socalled, graded exposure program, patients should not perform activities or exercises in general but should explicitly be exposed to those elements that they fear. ${ }^{29}$ It is interesting to see that in replicated single-case experimental design including patients with chronic low-back pain, who are exposed to specific exercises as opposed to general exercises, fear of movement is substantially altered in a positive direction. 30 But prudence is called for, because untill now only four patients were included in this replicated single-case experimental design. ${ }^{30}$ Whether these positive results also extend to the subgroup of patients following lumbar disc surgery requires further study.

Finally, as already mentioned earlter, the influence of attitudes and beliefs of health care providers should be further examined. These attitudes and beliefs might: influence the attitudes and beliefs of patients, but may also determine treatment. preferences of physiotherapists because the choice of specific methods of rehabilitation is mainly based on personal experience. To assess the influence of these attitudes and beliefs on various treatment orientations that physiotherapists might hold, the Pain attitude and Beliefs Scale for Physiotherapists (PABS_PT), which is described in this thesis (Chapter 8) should be further developed. Thereupon research should focus on the possible influence of these treatment orientations or patient outcome.

\section{IMPLICATION FOR CLINICAL PRACTICE}

The aim of the consensus guideline for rehabilitation following lumbar disc surgery, issued by the Royal Dutch Society for Physiotherapy ${ }^{31}$ was to standardize treatment after lumbar disc surgery. The recommended treatment goals immediately after surgery are: providing information with regard to post-surgery treatment and prognosis, pain reduction, and increasing mobility and strength through exercises. Pain should be used as a guideline to determine the intensity of the exercises and the advice about activities in daily living. After 4 to 6 weeks patients should be given further assistance to regain strength, mobility and stability of the spine and to restore normal functions of daily activities and/or work. In case of excessive pain and/or avoidance behaviors, cognitive-behavioral treatment options are to be considered, according to the guideline. Based on the results of the systematic reviewan this advice could be further accentuated because intensive exercise programs seem to be the most effective treatment option and they are not associated with repeated surgeries. Furthermore, based on the results of our trial ${ }^{2,23}$, we see no reason to implement BGA as the standard therapy for patients following lumbar disc surgery.

\section{PERsonal WIEW ON COGNITIVE-BeHAVIORAL INTERVENTIONS}

Many international guidelines on chronic low back pain (CLBP) ${ }^{3 *}$ advocate cognitive-behavioral approaches. In our systematic reviews we conclude that there is strong evidence that cognitive-behavioral treatments are more effective than no 
treatment for patients with chronic low back pain. In other words, for the treatments suggested in the guidelines there is some scientific eridence. But recently cognitive approaches are considered for many other musculoskeletal disorders. As an example, the consensus guideline for rehabilitation after lumbar disc surgery31 adwocates cognitive-behavioral approaches. In addition also for subacute low back pain, Repetitive Strain Injuries (RSI, whiplash and neck disorders cognitive-behavioral approaches are advocated.

The central idea for cognitive-behavioral interventions for musculoskeletal disorders is that CLBP is not only a physical problem, but may also depend on the patient's attitudes and beliefs, psychological distress, and illness behavior. Consequently, the treatment of CLBP should not primarily be focused on removing an underlying organic disease, but at the reduction of disability through the modification of environmental contingencies and cognitive processes. Because many musculoskeletal disorders, such as, Repetitive Strain Injuries (RSI) or whiplash seem to be equivalent to CLBP in that is not only a physical problem, but may also depend on the patient's attitudes and beliefs, psychological distress, and illness behavior these cognitive-behavioral approaches are considered, despite the fact that for many of these disorders hardly any evidence exist with regard to cognitivebehavioral interventions. Considering that therapists are beginning to perform some form of cognitive-behavioral treatment as part of usual care, from the viewpoint of evidence based medicine it is defendable to perform a pragmatic trial, like we did, and evaluate whether the care as provided by the physiotherapists is favorable to the patients. But to advocate these treatments in guidelines, while there is hardly any evidence is questionable. The care providers exposed to guidelines are encouraged to provide these various cognitive-behavioral treatment options in primary care but care providers should be trained and experienced before being capable of delivering cognitive-behavioral treatments. ${ }^{35,36}$ It could be argued that these required specific skills are not self-evident for all health care providers in primary care. Therefore it is questionable whether all health care providers can deliver these treatments properly. In my opinion, it is a logical first step to evaluate the effectiveness of cognitive-behavioral approaches, using well-equipped and experienced pain-therapists, for musculoskeletal disorders in which evidence with regard to cognitive-behavioral treatments has not yet been established. If these cognitive-behavioral approaches then appear to be effective, the difficult task of implementing these kinds of approaches in primary care should commence.

\section{REFERENCES}

1. Cook DJ, Sackett DL, Spitzer WO. Methodologic guidelines for systematic reviews of randomized control trials in health care from the Potsdam Consultation on Meta Analysis. J Clin Epidemiol 1995;48(1): 167-71.

2. Oxman AD, Guyatit GH. Validation of an index of the quality of review articles. J Clin Epidemiol 1991;44(1)1):1271-8.

3. van Tulder MW, Assendelft WJJ, Koes BW, Bouter LM. Method guidlines for systematic reviews in the Cochrane Collaboration. Back review group for spinal disorders. Spine $1997 ; 22(20): 2323-2330$. 
4. Schulz KF, Chalmers $I$, Hayes $R J$, Altman DG. Empirical evidence of bias. Dimensions of methodological quality associated with estimates of treatment effects in controlled trials. JAMA $1995 ; 273(5): 408-12$.

5. Chamers TC, Celano $\mathrm{P}$, Sacks HS, Smith H. Bias in treament assignment in controlled clinical trials. New England joumal of medicine 1983;309(22):1358-61.

6. Verhagen AP. Quality assessment of randomised clinical trials: (Thesis) Maastricht University, 1999.

7. Detsky AS, Naylor CD, O'Rourke $\mathrm{K}$, McGeer AJ, LAbbe KA. Incorporating variations in the quality of individual randomized trials into meta-analysis. $J$ Clin Epidemiol $1992 ; 45(3): 255 ; 65$

8. van Tulder MW, Ostelo RWJG, Vlaeyen JWS, Linton SJ, Morley SJ, Assendelf WJ. Behavioral treatment for chronic low back pain: a systematic review within the framework of the Cochrane Back Review Group. Spine 2001;26(3):270-281.

9. Smidt $\mathbb{N}$. Conservative treatments for tennis elbow in primary care (Thesis): Institute for Research in Extramural Medicine, VU Medical Center Amsterdam, 2001.

10. Moluer D, Schulz KF, Altman DG, Lepage L. The CONSORT statement: revised recommendations for improving the quality of reports of parallel-group randomised trials. Lancet 2001;357(9263):1191-4.

11. Wilson MC, Hayward RS, Tunis SR, Bass EB, Guyatt G. Users' guides to the Medical Literature. VIII. How to use clinical practice guidelines. B. what are the recommendations and will they help you in caring for your patients? The EvidenceBased Medicine Working Group. Jama 1.995;274(20): 1630-2.

12. Hopayian K. The need for caution in interpreting high quality systematic reviews. BMJ $2001 ; 323: 681-4$.

13. Morley S, Eccleston C, Williams A. Systematic review and meta-analysis of randomized controlled trials of cognitive behaviour therapy and behaviour therapy for chronic pain in adults, excluding headache. Pain 1999;80(1-2):1-13.

14. Carragee $\mathbb{E}$ J. Psychological screening in the surgical treatment of lumbar disc herniation. Clin J Pain 2001; 17(3):2 15-9.

15. Farrell B. Efficient management of randomised controlled trials: nature or nurture. BMJ 1998;317(7 167): 1236-9.

16. Stead M, Mason S, Shevlin T, Brown J. Employing staff on long term contracts is important for RCTs. BMJ 1999;318(7 190): 1075.

17. Pocack SJ. Clinical Trials. A practical Approach. Chichester, New York, Brisbane, Toronto, Singapore: John Wiley \& Sons, 1991.

18. AWO. Advisory board on scientific research academic hospital Maastricht (Letter) 94$214,1994$.

19. Manniche C. Personal Communication (Letter), 1996.

20. Manniche C, Asmussen K, Leuritsen B, et al. Intensive dynamic back exercises with or without hyperextension in chronic back pain after surgery for lumbar disc protrusion. A clinical trial. Spine 1993; 18(5):560 7

21. Beurskens $A J$, de Vet HC, Kant I. Dwalingen in de methodologie. VII. Pilotonderzoeken: zin en onzin. Neder Tijdschr Geneeskd 1998;142(39):2142 5 .

22. Rainville J, Ahern DK, Phalen L. Altering beliefs about pain and impairment in a functionally oriented treatment program for chronic low back pain. Clin J Pain $1993 ; 9(3): 196-201$.

23. Ostelo RWJG, Vet de HCW, Waddell G, Kerckhoffs MR, Leffers $P_{\text {, van }}$ Tulder MW. Rehabilitation after first time disk surgery. A systematic review within the Cochrane framework (In Press).

24. Deyo RA, Battie M, Beurskens AJ, et al. Outcome measures for low back pain research. A proposal for standardized use. Spine 1998;23(13):2003-13.

25. Beurskens AJ, the Vet HC, Koke AJ, van der Heijden GJ, Knipschild PG. Measuring the functional status of patients with low back pain. Assessment of the quality of four disease-specific questionnaires. Spine 1995;20(9):1017-28.

26. Beurskens AJ, de Vet HC. Koke AJ. Responsiveness of functional status in low back pain: a comparison of different instruments. Pain 1996;65(1):71-6.

27. Waddell G. 1987 Volvo award in clinical sciences. A new clinical model for the treatment of low-back pain. Spine 1987;12(7):632-44. 
28. Johannsen $F$, Remvig $L$, Kryger $P$, et al. Superpised endurance exercise training compared to home training after first hmbar diskectony: a clinical trial. chin Exper Rheumatol 1994;12(6):609-14.

29. Vaeyen JWS, Crombez G. Fear of movement/relnjury, avoidance and pain disability in chronic low back pain patients. Man Ther 1999,4/4)-187-195.

30. Vlaeyen JW, de Jong $J$, Geilen $M$, Heuts PH, wan Breukelen $G$. Graded exposure in vivo in the treatment of pain-related fear: a replicated single-case experimental design in four patients with chronic low back pain. Behav Res Ther 2001;39(2):151-66.

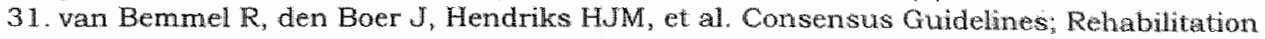
after lumbar disc surgery [Dutch] KNGf-ontwerprichtlijn; Postoper tief Lumbosacraal Radiculair Syndroom. Amersfoort: Royal Dutch Society for Physiotherapy (KNGF), 1998.

32. Ostelo RWJG, Vet de HCW, Vlaeyen JWS, et al. Effectiveness of behaworal graded activity after first-time disc surgery. Submitted 2001 .

33. Ostelo RWJG, Vet de HCW, Vlaeyen JW, et al. Behavioral Graded Activity After First-time Lumbar Disc Surgery. One Year Results of a Randomized Controlled Trial. Submitted 2002.

34. Koes BW, van Tulder MW, Ostelo RWJG, Km Burton A, Waddell G. Clinical guidelines for the management of low back pain in primary care: an international comparison. Spine 2001;26(22):2504-13.

35. Vlaeyen JWS, Kole-Snijders AMJ, Eek Hv, Chronische pijn en revalidatie Hoensbroek: Bohn Stafleu Van Loghum, 1996.

36. Williams AC, Pither CE, Riachardson PH. The effects of cognitive-behavioral therapy in cronic pain. Pain 1996;65:282-4. 


\section{SUMMARY}

The focus of this thesis is the effectiveness of interventions applied in rehabilitation following lumbar disc surgery. A substantial number of patients still suffer residual complaints after surgery. Rehabilitation might prove to be an important tool in minimizing these remaining symptoms. Although there are many plausible theories regarding the effectiveness of active, as well as passive, interventions following lumbar disc surgery, there is a lack of sound evidence. The choice of one specific method of rehabilitation is mainly based on the personal experience of care providers, or on studies of poor methodological quality. Active rehabilitation programs will in the long run enhance the patients" independence from health care services. Recently, the focus of attention within rehabilitation following humbar disc surgery has shifted towards a more biopsychosocial perspective. It has been suggested that high intensity exercise programs confront patients with their fears and insecurities and that they should learn that symptoms related to training are not necessarily dangerous.

Chapter 2 presents a systematic review of studies on the effectiveness of active treatment programs used in the rehabilitation of patients following lumbar disc surgery. Relevant papers were identified by searching the Medline, Embase and Psyclit databases up to April 2000 and the Cochrane Controlled Trials Register 2001 , Issue 3 , and by checking the references of relevant papers. Two reviewers independently performed the inclusion of both randomized and non-randomized controlled trials and made an independent assessment of methodological quality. A rating system consisting of four levels of scientific evidence summarizes the results. This systematic review includes 1.3 studies, six of which were of high quality. For treatments that start immediately after the surgery, there is no strong evidence of effectiveness, mainly due to a lack of good quality studies. Two high-quality RCTs compared intensive exercise programs to mild exercise programs, starting 4 to 6 weeks post-surgery. There is strong evidence that intensive exercise programs are more effective on functional status and faster return to work (short-term follow-up) compared to mild exercise programs, and there is strong evidence that on long-term follow-up there is no difference in overall improvement following an intensive or a mild exercise program. With regard to all other primary outcome measures (e.g. pain) there is conflicting evidence as far as long-term follow-up is concerned. Furthermone, there is no strong evidence for the effectiveness of supervised training compared to home exercises. There is also no strong evidence for the effectiveness of multidisciplinary rehabilitation compared to usual care. There is limited evidence that treatments in working populations aimed at return to work are more effective than usual care as measured by work resumption. Also, there is limited evidence that low-tech and high-tech exercises, initiated more than 12 months post-surgery are more effective in improving low back functional status compared to pliysical. agents, joint manipulations or no treatment. None of the treatments investigated seems to produce a risk of re-herniation or re-operation. 
Chapter 3 presents a systematic review of randomized controlled trials (RCTs) to determine whether behavioral therapy is more effective than reference treatments for chronic nonspecific low back pain, and which type of behavioral treatment is most effective. The authors searched the Medline and Psyclit databases and the Cochrane Controlled Trials Register up to April 1999, and Embase up to September 1999. References of identified relevant papers were also screened. Two reviewers performed methodological quality assessment and data extraction independently. The authors computed a pooled effect size, using the random effects model, to assers the magnitude of effect. For the qualitative analysis a rating system consisting of four levels of scientific evidence was used. Only 5 studies (25\%) were of high methodological quality. There is strong evidence that behavioral treatment has a moderate positive effect on pain intensity and small positive effects on generic functional status and behavioral outcomes of patients with chronic low back pain when compared to waiting-list controls or no treatment. There is moderate evidence that addition of a behavioral component to a usual treatment program for chronic low back pain has no positive short-term effect on generic functional status, pain intensity or behavioral outcome. Furthermore, there is limited evidence that a graded activity program in an industrial setting is more effective than usual care, and that behavioral treatment and exercise are equally effective.

It was concluded that behavioral treatment seems to be effective in patients with chronic low back pain, but it is still not known which patients benefit most from which type of behavioral treatment.

Chapters 4 to 6 report on the design, the short-term and the long-term resiltts of a randomized controlled trial (RCT) in which patients were included from November 1997 until December 1999 in the South of The Netherlands. This RCT assessed the effectiveness of a behavioral graded activity (BGA) program, compared to usual care (UC) as provided by physiotherapists, for patients following lumbar disc surgery. One hundred and five $(n=105)$ patients were included. The BGA-program was based on operant treatment principles and was time-contingent (time-dependent). The content of UC was determined after two consensus meetings with the participating physilotherapists. In general, the whole spectrum of techniques used by the physiotherapists was included which, in our opinion, is sensible when studying usual care. Inclusion criteria were: age between 18 and 65 years; first-time disc surgery; restrictions in the activities of daily life (ADL). Exclusion criteria were: surgical complications, confirmed and relevant underlying diseases. Immediately after treatment $67 \%$ of the patients had recovered following UC, versus $48 \%$ of the patients following BGA. This $19 \%$ difference was statistically significant. Six months after randomization, $62 \%$ of the patients had recovered following UC versus $65 \%$ of the patients following BGA. After 12 months, $73 \%$ and $75 \%$, following UC and BGA respectively, had recovered. Differences between the two interventions after 6 and 12 months, $3 \%$ and $2 \%$ respectively, were not statistically significant. Furthermore, there were no relevant differences between the two groups in any of the follow-up measurements. Pain catastrophizing and fear of movement showed no relevant improvements. After one year, 4 of the BGA cases had undergone another operation versus 2 of the UC cases. It was concluded that the two treatment conditions 
administered in the current study to patients following humbar disc surgery were: equally effective. Both fear of movement and pain catastrophizing seem to be unaffected by either treatment in these patients. It is hypothesized that treatment principles derived from theories within the field of chronic low back pain might not apply to these patients and therefore there is no reason to implement behavioral graded activity in the care of these patients. When future research on the effectiveness of cognitive-behavioral programs is considered, the focus should be on more patient-tailored treatments, and qualified and experienced health care providers should be used.

Chapter 7 evaluates the cost-effectiveness of the two interventions included in the current study from a societal viewpoint. To evaluate the economic consequences of the treatments, direct health care and non-health care costs were considered, as well as indirect costs. The clinical outcomes showed no relevant differences between the two treatment conditions. Treatment costs were fairly similar in the two intervention groups. The difference in direct health care costs was, although not statistically significant, 264 EURO $[95 \% \mathrm{Cl}:-3 ; 525]$ higher in BGA than in UC per patient-year. It was mainly the excess of costs incurred for visits to a physiotherapist in BGA, which accounted for this difference. The direct non-health care costs were, although not statistically significant, 388 EURO $195 \% \mathrm{CI}:-217$; 992] higher in BGA. The costs for unpaid help from friends or family accounted for this difference. Consequently, although not statistically significant, the total direct costs are 638 EURO [95\% CI: $-91 ; 1368$ ] higher in BGA than in UC. For the indirect costs, there was a statistically significant difference to the disadvantage of BGA. The sensitivity analysis showed that these results are fairly robust, a possible explanation being that theories derived from the field of chronic low back pain might not apply to patients following lumbar disc surgery. Another explanation might be that patients had different expectations with regard to the BGA-program and therefore physiotherapists might not have succeeded in dispelling their fears and insecurities. Consequently, patients might have been more inclined to seek help from physiotherapists in the subsequent year. This study conchides that there are no differences between the two treatment conditions in any of the clinical outcome measures but that BGA is associated with higher costs. Consequently, there is no reason for the implementation of BGA as the standard treatment for patients following lumbar disc surgery.

Attitudes and beliefs of health care providers appear to be important in the management of chronic low back pain. Chapter 8 describes a study in which attitudes and beliefs of Dutch physiotherapists are surveyed, and the underlying dimensions are investigated in order to develop the Pain Atitudes and Beliefs Scale for Physiotherapists (PABS_PT). Attitudes and beliefs of health care prowiders appear to be important in the management of chronic low back pain. In total, 421 physiotherapists (response rate $62.3 \%$ ) participated in this study. Results of the survey suggest that there is a reasonable consensus among physiotherapists with regard to the management of chronic low back pain: reassure patients about the harmless nature of the complaints and reactivate patients. Items were submitted to 
a principal factor analysis (PAF) with oblimin rotation that yielded an interpretable 2-factor model. Based on the highest loading items, factor 1 was labelled "biomedical orientation", whereas factor 2 was labelled "behavioural orientation". The internal consistency (Cronbach's Alpha) of factor 1 was 0.84 , and of factor 2, 0.54 , explaining $25.2 \%$ and $8.2 \%$, respectively, of the total variance. Assessment of the effect of characteristics of physiotherapists on scores on the different scales was encouraging as results pointed in the direction one woulld expect. Physiotherapists who attended biopsychosocial education courses had statistically significantly higher scores on the "behaviloural orientation" factor and vice versa. Biomedical specialists had statistically significantly higher scores on the "biomedical orientation" factor. Furthermore, the findings of this explorative analysis suggest that the PABS_PT has the potential to discriminate between physiotherapists with a "behavioural orientation" versus those with a "biomedical orientation". To examine the influence of these different orientations with regard to chronic low back pain on patient outcome is a challenge for the near future.

Chapter 9 discusses the methodology and results of the systematic reviews and the randomized controlled trial. The use of checklists in systematic reviews for quality assessment of randomized controlled trials is critically examined. In addition, advantages and disadvantages of the guidelines of the Cochrane Back review group are discusised as well as the clinical effects and costs of the randomized controlled trials. Finally, the implications for future research and for clinical practice are considered. This chapter is concluded by a personal view on cognitive-behavioral interventions. 


\section{SAMENVATTING}

De belangrijkste doelstelling van dit proefschrift is om de effectiviteit van behandelingen die worden toegepast in de revalidatie van patienten na een lumbale hernia operatie te onderzoeken. Enen substantieel gedeelte van de geopeneerde patiënten heeft na de operatie restklachten. De behandelingen die tijdens de revalidatiefase worden toegepast kunnen wellicht van groot belang zijn om deze restklachten zo veel mogelijk weg te nemen. Ondanks veel plausibele verklaringen aangaande de effectiwiteit van zowel actieve als passieve vormen van behandeling in her kader van het revalideren na een lumballe herniaoperatie, ontbreekt het aan overtuigend bewijs. De keuze voor een bepaalde vorm van behandeling is voornamelijk gebaseerd op persoonlijke en klinische ervaring van de hulpverlener of op studies die in methodologisch opzicht tekort schieten. Actieve behandelingen tijdens de revalidatiefase zouden, op de lange termijn, de onafhankelijkheid van de patiënt ten opzicht van het medisch circuit vergroten. Recentelijk is er ook meer aandacht voor een biopsychosociaal perspectief binnen het revalideren na een lumbale herniaoperatie. Een hypothese, gebaseerd op de literatuur, luidt dat intensieve oefenprogramma's de patient zouden kunnen confronteren met zijn angst en onzekerheden ten aanzien van bewegen en dat patiënten moeten leren dat symptomen die samenhangen met het oefenen niet noodzakelijkerwijs gevaarlijk zijn.

Hoofdstuk 2 beschrift een systematisch literatuuronderzoek waarin de studies worden samengevat die de effectiviteit onderzocht hebben van actieve behandelingen in de revalidatie van patiênten na een lumbale herniapatiënten. Om de relevante literatuur op te sporen zijn de volgende bibliografische databestanclen tot en met april 2000 doorzocht: Medline, Embase en Psyclit. Verder is het Cochrane Controlled Trials Register 2001, Issue 3, nagekeken. Tot slot zijn ook de referentielijsten van de relevante onderzoeken gescreend. Twee onafhankelijke onderzoekers hebben de studies aan de hand van vooraf opstelde criteria ingesloten. De methodologische kwaliteit, of wel de interne validiteit, van alle geselecteerde artikelen is aan de hand wan een lijst met 12 criteria beoordeeld door twee onafhankelijke onderzoekers. De resultaten zijn samengevat met een scoringssysteem, dat uit 4 niveaus van bewijskracht bestaat. In dit systematisch literatuuronderzoek zijn in totaal 13 studies ingesloten. Zes van deze studies werden methodologisch als hoogkwalitatief beoordeeld. Er zijn weinig studies ingesloten die de effectiviteit van behandelingen die onmiddellijk postoperatief starten op een adequate wijze onderzachten. Vandaar dat wij helaas geen harde uitspraken kunnen doen over de effectiviteit van deze behandelingen. Er is wel sterk bewijs gevonden dat intensieve oefenprogramma's die 4 tot 6 weken postoperatief starten effectiever zijn op korte termijn dan mild intensieve oefenprogramma's. Dit. komt vooral tot uiting in scores op functionele status en in de snelheid waarmee patienten die een intensief oefenprogramma hebben gevolgd hun werk kunnen hervatten. Er bljikt echter dat indien naar algemeen ervaren herstel wordt gekeken 
op de lange termijn (meer dan 6 maanden na randomisatie) dat beide benaderingswijzen even effectief zijn. Voor de overige uitkomstmaten londer andere "pijn") is er tegenstrijdig bewijs met betrekking tot welke benadering het meest effectief is. Verder is er geen overtuigend bewijs woor de effectiviteit wan oefenen onder supervisie door een fysiotherapeut vergeleken met thuis oefenen. Evenmin is er overtuigend bewijs voor een multidisciplinaire benadering vergeleken met usual care. Er is beperkt bewijs dat een interventie die zich specifiek richt op werkherwatting bij werknemers na een lumbale herniaoperatie effectiever is dan de standaard zorg door bedrijfsartsen. Verder zijn er beperkte aanwijzingen dat actieve oefenprogramma's effectiever zijn dan het toedienen van fysische applicaties, of manipulaties, of geen behandeling indien deze meer dan 1. jaar postoperatief worden opgestart. In geen van de ingesloten studies werden aanwijzingen gevonden dat de onclerzochte interventies schadelijke gevolgen hadden in de zin van een klachten ten gevolge van een nieuwe lumbale hernia, of de noodzaak een hernieuwde lumbalie herniaoperatie.

In Hoofdstuk 3 wordt een tweede systematisch literatuuronderzoek beschreven. De doelstelling van dit literatuuronderzoek was om te onderzoeken of cognitiefgedragsmatige interventies effectiever zijn dan andere interventies die worden toegepast bij patiënten met chronische a-specifieke lage rugklachten. Tevens is onderzocht of een bepaalde type interventie binnen de cognitief-gedragsmatige het meest effectief is. De volgende bibliografische databestanden zijn doorzocht om de relevante gerandomiseerde, gecontroleerde studies (RCTs) te kunnen traceren: Medline, Psyclit en het Cochrane Controlled Trials Register tot april 1999, en Embase tot september 1999. Verder zijn ook de referentielijsten van de relevante RCTs gescreend. Twee onderzoekers hebben onafhankelijk van elkaar cle studies op hun methodologische kwaliteit beoordeeld. Daarnaast hebben deze onderzoekers ook onafhankelijk van elkaar de relevante gegevens uit de ingesloten studies geëxtraheerd. Vervolgens zijn er "gepoolde effect sizes" berekend met behulp van het zogenaamde "random effects" model. Op deze wijze werd een indruk verkregen van de grootte van het effect. Met behulp van een scoringssysteem, dat uit 4 niveaus van bewijskracht bestaat zijn de resultaten samengevat. Van de 20 studies die werden ingesloten blijken er slechts $5(25 \%)$ van hoge methodologische kwaliteit te zijn. Ej is sterk bewijs dat cognitief-gedragsmatige interventies effectiever zijn indien deze vergeleken worden met wachtlijstcontroles of geen behandeling. Dit effect, waarvan de grootte als matig gekenmerkt wordt, doet zich voor op de uitkomstmat pijnintensiteit. Bij de vergelijking van deze twee benaderingswijzen is tevens een klein positief effect is waar te nemen op de uitkomstmaten algemene functionele status en bij een aantal gedragsmatige georiënteerde uitkomstmaten. Er zijn ook aanwijzingen gevonden dat het toevoegen van gedragsmatige componenten aan een standaard behandeling niet effectiever is dan de standaard behandeling alleen. Daarnaast zijn er beperkte aanwijzingen dat een graded activity programma effectiever is dan een standaard behandeling in de bedrijfsgezondheidszorg indien naar werkhervatting wordt gekelken. Ook zijn et beperkte aanwijzingen dat een gedragsmatige benadering even effectief is als een oefenprogramma. De conclusie op basis van dit systematische literatuuronderzoek luidt dat er sterke aanwijzingen 
zijn dat cognitief-gedragsmatige interventies een effectieve behandeling vormen voor patiënten met chronisch a-specifieke lage rugklachten, maar dat het vooralsnog onduidelijk blijf welk type patient het meest batat heeft bij welke vorm van cognitief-gedragsmatige interventies.

In Hoofdstuk 4 tot en met 6 wordt verslag gedaan van het gerandomiseerde onderzoek dat de kern vormt van dit proefschrift. Achtereenvolgens komen het design. (het ontwerp van de studie), de korte en lange termijn resultaten aan bod. In dit gerandomiseend onderzoek (RCT) is de effectiviteit onderzocht van een gedragsgeoriënteerd graded activity programma (BGA) in vergelijking met de standaard behandeling door de fysiotherapeut (UC) bij patienten na een lumbale hemiaoperatie. Van november 1997 tot en met december 1999 zijn er in total 105 patiënten ingesloten voor deelname aan dit onderzoek. Het BGA programma is gebaseerd op operante behandelprincipes. Bij deze benadering is de opbouw niet afhankelijk van de pijn maar wordt de intensiteit stapsgewijs opgebouwd in de tijd. Dit wordt ook wel tijdscontigent genoemd. Met iedere individuele patient wordt op basis van een basislijn (de beginmetingen) afspraken gemaakt over het te bereiken doel. De invulling van de standaard behandeling door de fysiotherapeut is gebaseerd op een tweetal consensus bijeenkomsten met alle declnemende fysiotherapeuten. De meeste behandelopties die doot de fysiotherapeuten werden genoemd als standaard behandeling waren toegestaan in deze RCT. Ons inziens is dit redelijk indien men de gebruikelijke therapie als controle interventie kiest. Patiënten werden ingesloten indien zij tussen de 18 en 65 jaar oud waren, het de eerste lumbale herniaoperatie betrof en indien er beperkingen werden gerapporteerd in het algemene dagelijkse leven (ADL). Patiënten werden uitgesloten indien er complicaties waren tijdens de operatie, of indien er sprake was van bevestigde en relevante co-morbiditeiten. De effectmetingen vonden plaats onmiddellijk na de behandeling ( 3 maanden na randomisatie) en tijdens de 6 - en 12 maanden followup meting. Onmiddellijk na de behandelperiode bleek dat $67 \%$ van de patiënten uit de UC groep zichzelf als hersteld categoriseerde in vergelijking met $48 \%$ van de patienten uit de BGA groep. Dit verschil van $19 \%$ was statistisch significant. Tijdens de eerste follow-up meting, 6 maanden na de randomisatie, waren $62 \%$ van de patiënten in de UC groep en $65 \%$ van de patienten in de BGA groep hensteld. Na 12 maanden waren in totaal $73 \%$ patiënten in de UC groep hersteld versus $75 \%$ van de patiěnten in de BGA groep. De verschillen tussen beide groepen op 6 maanden $(3 \%)$ en op 12 maanden (2\%) zijn statistisch niet significant. Oolk op de overige uitkomstmaten waren geen statistisch significante, noch klinisch relevante, verschillen te ontdekken. De catastroferende ideeën die patienten kunnen hebben ten aanzien van hun pijn en de angst om te bewegen vertoonde geen relevante veranderingen na de behandeling of bij de follow-up metingen. Eèn jaar na de start wan het onderzoek waren er in de BGA groep 4 mensen die een hernieuwde lumbale herniaoperatie moesten ondergaan in vergelijking met 2 patiënten in de UC groep. Naar aanleiding van deze resultaten hebben wij geconcludeerd dat er geen relevante verschillen zijn te waarnemen tussen de beide behandelingen en dat beide dus even effectief zijn voor de revalidatie van patiënten na een lumbale herniaoperatie. De catastroferende ideeën ten aanzien van pijn en de angst om te bewegen wordt door 
geen van beide positief beinvloedt. Een mogelijke verklaring hiervoor is dat de theorieên die gebaseerd zijn op de behandeling van patiënten met chronische aspecifieke lage rugklachten niet zonder meer kunnen worden toegepast bij patiënten na een lumbale herniaoperatie. Daarom is er op basis van deze resultaten dit effectonderzok geen reden om het $\mathrm{BG}$ A programma te implementeren binnen de revalidatie fase voor deze categorie patienten. Voor het toekomstig onderzoek naar de effectiviteit van cognitief-gedragsmatige interventies wordt geadwiseerd gebruik te maken van adequaat geschoolde therapeuten die veel ervaring hebben met deze behandelstrategieen. Bovendien zou het toekomstig onderzoek zich moeten richten op behandelingen waarbij de specifieke klachten en beperkingen van de individuele patiënt centraal staat.

In Hoofdstuk 7 worden de kosten wan de twee behandelingen met elkaar vergeleken. Deze kosteneffectiviteitsanalyse werd uitgevoerd vanuit een maatschappelijk perspectief. Met behulp van kostendagboekjes zijn zowel de directe als indirecte kosten vastgelegd om zo de economische consequenties van de beide behandelingen te evalueren. Alle deelnemende patiënten werden gedurende 1 jaar gevolgd. De klinische uitkomstmaten lieten geen relevante verschillen zien tussen de beide behandelingen. De krosten voor de behandeling zelf waren voor beide groepen gelijk. De directe kosten in de gezondheidszorg waren, hoewel niet statistisch significant verschillend: 264 EURO $(95 \%$ BI: $-3,525)$ hoger per patiëntjaar in de BGA groep indien vergeleken, met de UC groep. Dit verschil werd vooral veroorzaakt doordat er meer gebruilk werd gemaakt van fysiotherapie gedurende de follow-up periode in de BGA groep. De directe kosten buiten de gezondheidszorg waren 388 EURO [95\% BI: $-217,992]$ hoger in de BGA groep. Dit statistisch niet significante verschill werd vooral veroorzaakt door de meerkosten voor de informele zorg in de BGA groep. Dit had tot gevolg dat de totale directe kosten, hoewel ook niet statistisch significant, 638 EURO (95\% BI: $-91,1368$ ) hoger zijn in de BGA groep. Voor de indirecte kosten was er wel een statistisch significant verschil ten nadele van de BGA. De sensitiviteitsanalyses toonden aan dat de resultaten robulust waren. Een mogelijke verklaring voor deze resultaten zou kunnen zijn dat de theorieèn die gebaseerd zijn op de behandeling van patiënten met chronische a-specifieke lage rugklachten niet zonder meer kunnen worden toegepast bij patiënten na een lumbale herniaoperatie. Een andere verklaring zou kunnen liggen in het feit dat patienten wellicht een ander verwachtingsbeeld hadden met betrekking tot het BGA programma. Daarom kan het mogelijk zijn dat de fysiotherapeuten er niet in geslaagd zijin om de angsten en onzekerheden bij de patiënten weg te nemen waardoor patiënten meer geneigd waren om tijdens het follow-up jaar een fysiotherapeut te raadplegen. Deze studie toont aan dat er op de 1 jaars follow-up meting geen verschillen zijin in klinische uitkomsten tussen de beide groepen, maar dat in de BGA groep wel meer kosten worden gemaakt. Daarom is er op basis van dit kosteneffectiviteitsonderzoek geen reden om een BGA programma te implementeren als standaard behandeling voor de revalidatie van patiënten na een lumbale herniaoperatie. 
De attitudes van fysiotherapeuten bliken een belangrijke rol te spelen in het beleid dat zij voeren ten aanzien van chronische a-specifieke lage rugklachten. In Hoofdstuk 8 wordt een onderzoek beschreven nar de attitudes van fysiotherapeuten in Nederland ten aanzien van de diagnostiek en behandeling van chronische a-specifieke lage rugklachten. De onderliggende dimensies van deze attitudes zijn onderzocht om zo een aanzet te geven voor de ontwikkeling van een 'Pain Attitudes and Beliefs Scale for Physiotherapists' (PABS PT). Aan dit onderzoek namen in totaal 421 fysiotherapeuten (respons van $62,3 \%$ ) deel. De resultaten laten zien dat er consensus lijkt te bestaan onder fysiotherapeuten over het belang van het geruststellen van de patient en hem in te lichten over het onschuldige karakter van de aandoening. Verder lijkt er ook consensus te bestaan ower het belang van het activeren van patiënt, ondanks het feit dat de patiënt rugklachten heeft. In een principale factoranalyse met oblimin rotatie, werd een interpreteerbaar 2 factoren. model geïdentificeerd. Gebaseerd op de items die het hoogst laadden op factor 1 werd deze als een "biomechanische benadering" gelabeld. Factor 2 werd als 'gedragsmatige benadering' gekenmerkt. De interne consistentie werd bepaald aan de hand van de Chronbach's Alpha. Voor factor 1 bedroeg deze 0,84, en woor factor 2, 0,54. De veriklaarde variantie bedroeg $25,2 \%$ woor factor 1 , en $8,2 \%$ voor factor 2 . De samenhang tussen enerzjids de scores op de 2 factoren van de PABS_PT en anderzijds de karakteristieken van de fysiotherapeuten kwam overeen met onze verwachtingen bij de start van deze studie. Fysiotherapeuten die cursussen hadden gevolgd waarin gedragsgeoriënteerde principes centraal stonden scoorden statistisch significant hoger op de factor voor 'gedragsmatige benadering'. Fysiotherapeuten die cursussen hadden gevolgd waarin biomechanische principes centraal stonden scoorden hoger op de factor voor biomechanische benadering: Fysiotherapeuten die zichzelf als 'biomedisch specialist' (bijwoorbeeld, manueel therapeut. McKenzie therapeut) classificeerde scoorden statistisch significant hoger op de factor voor biomechanische benadering. Verder zjn er op basis van de resultaten van deze exploratieve analyse aanwijzingen dat de PABS PT een onderscheid kan maken tussen therapeuten met een 'gedragsmatige benadering' en fysiotherapeuten met een biomechanische benadering. Wat de invloed is van deze verschillende benaderingswijzen op het beloop van klachten woor de patient met chronische a-specifieke lage rugklachten dient in de tokkomst verder te worden uitgediept.

In Hoofdstuk 9 wordt de gehanteende methodologie en de resultaten van de systematische literatuuronderzoeken bediscussieerd. Het gebruik van lijsten om de kwaliteit van gerandomiseerd onderzoek te meten wordt besproken. Daarnaast. worden tevens de voor -en nadelen van het gebruik wan de richtijnen van de Cochrane Back review group besproken. Vervolgens worden ook de resultaten van het gerandomiseercle onderzoek bediscussieerd. Hierbij komen zowel de praktische, de klinische als ook de economische aspecten aan bod. Tot slot worden de implicaties van de resultaten van dit proefschrift voor zowel toekomstig onderzoek als mede voor de dagelijkse praktijk besproken. Dit hoofdstuk shit af met een persoonlijke visie ten aanzien van cognitief-gedragsmatige interventies. 


\section{Dankwootd}

Een vreemde folklore, die wetenschap en dan vooral het fenomeen van het auteurschap. Bestudering van de kaft van dit proefschrift doet vermoeden dat het voorliggende werk de pennenwrucht is van ondergetekende. Dit benadert de werkelijkheid echter slechts ten dele. En hoe cliché een dankwoord dan ook mag overkomen voor buitenstaanders, aan het eind van de rit besef je als nowit tevoren clat je ai die mensen die direct en indirect een steun en toewerlaat zijn geweest bij de totstandkoming van dit proefschrift oprecht wil bedanken. Daarom ook in dit proefschrift een dankwoord.

De folklore will nu eenmaal niet al die namen op de kaft...

Namen die daar voor in aanmerking warem gekomen waren onder andere die van Albère Köke, Sandra Beurskens en Riekie de Vet. Hun oorspronkelike idee werd omgezet in een projectvoorstel dat uiteindeljk de basis was voor dit proefschrift. lk hoop dat jullie het nog enigszins herkennen. Riekie, jij hebt vervolgens dit hele traject verder begeleid, ook na je vertrek naar Amsterdam en ik zou alle promovendi zo'n een begeleiding toewensen: accuraat, wrijheid latend mar wel een vinger aan pols houdend en dat alles in een sfeer die ik als zeer prettig heb ervaren. Je commentaar op artikelen geeft iedere keer weer blijk van een schat aan kennis en ervaring. Ik ben blij dat ik daar de komende jaren weer van dichtbij gebruik van mag maken. Maria Kerckhoffs, je was reeds eerder begonnen aan dit project dan ik. Vakantie was, is en blijft namelijk een groot goed, maar dat hoef ik jou niet uit te leggen. Mede dankzij jou is dit hele project zo soepel verlopen. Natuurlijk waren er wel eens baaldagen (weer geen operaties vandaag, grr...., maar echte tegenslagen bleven uit. Vanwege jouw betrokkenheid en inhoudelijke kijk op de zaken ben ik er van overtuigd dat jij vandaag net zo goed het woord had kunnen voeren. Vandaar dat al heel vroeg (vroeger dan je waarschijnlijk beseft) vaststond dat jij paranimf MOEST zijn. Cobie Martens, samen met Maria vormde je het kloppend hart van het project. En eerlijk is eerlijk, je bezorgde mij ook wel eens hartkloppingen. Die gil: "OS-TE-LOO! HIERl" Heerlijk. IK zal hem missen, net zoals jouw onovertroffen wijze van werken. En ik ben het met je eens: dit is mijn mooiste proefschrift geworden. Johan Vlaeyen, op een zeer charmante wijze heb je een grote bijdrage geleverd aan de totstandkoming var dit proefschrift. Zo groot in mijn ogen dat ik blij ben dat je uiteindelijk ook een van de copromotoren bent geworden. Pieter Wolters, in de afgelopen jären finmiddels al meer dam een decennium! bleef ik je steeds maar weer tegenkomen. Eerst als docent fysiotherapie, daana als docent bij KBW te Matastricht, daarna als lid van de projectgroep, en tot slot ook nog eens als collega an de Hogeschool Zuyd. Bescheidenheid is zowel jouw handelsmerk als jouw kracht. Ik ben nu al nieuwsgierig naar de volgende hoedanigheid waarin ik je ongetwijfeld weer ga tegenkomen. Ook nog bedankt voor de 283 punten en Konmma's. Willem Berfelo, bedankt voor de neurochirurgische input en het warm houden van het HNP-vuurtje in het ziekenhuis. De uitspraak frapper, toujours frapper', heb ik zeker in mijn oren geknoopt. Piet van de Brandt, in je rol als promotor op afstand, zoals je dat zelf regelmatig benoemde, fungeerde je als een frisse wind. Een frisse wind kan zo nu en dan ook wel eens licht neigen naar een 
wat koel briesje maar stelt bovenal zaken aan de orde waar zo nu en dan toch net iets te gemakkelijk overheen wordt gestapt. Bedankt voor die kritische blik.

De leden van de begeleidingscommissie (Wim van Dijk, Joost Dekker, en Andre Knottnerus) wil ik bedanken voor het over de schouder meekijken. André, ik weet niet precies hoe je het woor elkaar kreeg, maar ondanks al je bezigheden wist je in grote lijnen altijd waar het project stond en je had juist oog voor de "achterkant van het borduurwerk". Zo "en passant" wist je mij ook vaak een hart onder de riem te steken.

De leden van de leescommissie, prof.dr. Sj. wan der Linden, prof.dr. E.A.M. Beuls, prof.dr. L.M. Bouter, prof.dr. M. A. van den Hout en prof.dr. M. Von Korff wil ik bedanken voor het lezen en beoordelen van mijn proefschrift. Dear Michael, I know you can easily read and understand this acknowledgment, but still, Engish is mone comfortable, isn't it? Thank you so much for the opportunity to spend some weeks at your Institute, The Center for Health Studies, Group Health Cooperative of Puget Sound, Seattle. It is difficult to point out exactly what it is, but I learned a lot and I had a wonderful time. Also thanks to you, Linda and Douglas for your great hospitality and I am honored that you made it all the way from Seatte to attend the defense of my thesis.

Na een lumbale herniaoperatie nog steeds niet hersteld zijn van de klachten is op zijn minst bijzonder vervelend en ongewenst, desondanks toch willen meedoen aan een onderzoek verdient respect. Vandaar een oprecht woord van dank aan alle 105 deelnemers. Dat deze patiënten aangemeld werden voor het onderzoek is met name te danken aan het team van het Academisch Neurochirurgisch Centrum Limburg en aan de neurologen van het Laurentius Ziekenhuis te Roermond en het Maasland Ziekenhuis te Sittard. Eien geheugensteuntje en reminders (frapper, toujours frappers") kunnen in zulke situaties geen kwaad en daar zorgde de mensen achter de balies en recepties voor. Naast de reeds genoemde ziekenhuizen gebeurde dat ook in het Academisch Ziekenhuis Maastricht en het Atrium Ziekenhuis te Heerten. Het is onmogelijk om iedereen bij naam te noemen, maar zij dic betrokken waren bij de werving van het HNP-traject weten wie ik bedoel. Na het insluiten van de patiënten kwam het behandelen van de patienten. Daarvoor waren 75 fysiotherapeuten verantwoordelijk in Zuid-en Midden-Limburg. Bedankt woor julie inzet en we beseffen maar al te goed dat een patient behandelen in het kader wan een wetenschappelijk onderzoek toch altijd meer tijd en energie kost. Rob Pelt en Jan Thomassen verzorgden (in zeer nauwe samenwerking met Johan er Marial de trainingen voor de therapeuten. Dankzij jullie ervaring op dit gebied zijn deze trainingen zeer goed verloper. En hoewel niet direct betrokken bij dit alles wil ik Mario 'Bonzo' Geilen wan harte bedanken voor zijn belangstelling en inzet. Dat laatste geldt met name voor de beoordeling van de tapes.

Daarnaast zijn er zo veel onzichtbare hulptroepen. Jos Slangen en Harrie van Montfort, bedankt voor jullie geduld met cen digibeet als ik. Sacha, jouw invoerprogramma's lin combinatie met Cobie natuurlikl zorgden voor een foutmarge bij de invoer die zo minimaal was dat de controles als overbodig voelde. 
Ook Loek Dohmen en Ger van Wunnik begrepen snel dat ik alleen maar geinteresseerd was in welk knopje ik eerst en welk knopje ik daama moest indrukken om al het geluid op CD te krijgen. De "Science and Vision" in deze kwam zeker van jullie. Linda Rieken heeft me laten zien dat je kan toveren met beelden. Bedankt voor het ontwerp van de kaft en ik ben blij dat we die afspraak van zo lang geleden zijn nagekomen. Brenda Vollers wil ik bedanken woor het corrigeren van het Engels.

Alle collega's van de capaciteitsgroep Epidemiologie van de Universiteit Maastricht wil bedanken voor de prettige samenwerking. Met het gevaar een enkeling te missen wil ik toch enige bij naam noemen. Maurice "Psion" Zeegers, ondanks dat je later begon was je me te snel af. Dat voelde ik reeds snel aankomen vandaar dat ik vertragingstactieken op je los liet o.a. in de persoon van Prof Dr Olle Thórgenson. Maar onverstoorbaar (hoewel je die vrijdag even uit het lood geslagen leek...) werkte je doelgericht naar jouw promotie toe. Succes in London en New York en vergeet niet dat chaos ook de toestand is waarin nog alles mogelijk is. Miranda Dirkx, je nuchtere kijk op zaken werkt relativerend. Erik van Rossum, hopelijk gaat al dat hoogpolig tapijt owerleg snel iets opleveren. Rob de Bie, bedankt voor de prettige samenwerking en $\mathrm{k}$ hoop nog steeds dat je begrijpt dat voòr het ene kiezen niet per definitie tégen het andere kiezen is. Patty Nelemans, ik moet toegeven (en dat doe ik niet graag, dat weet je) dat je scepsis ten aanzien van 'dat gedragsmatige gedoe' niet helemaal ten onrecht was. Maar we hebben het er nog wel eens over. Veron Schrijnenmakers voor het alvast oefenen en natuurlijk voor de Mestreechse Taol. Jan Schouten, de boeiende (en soms lange) discussies over het wel en wee in onderzoeksland kan ik hopelijk met je voortzetten op afstand. Pieter Leffers, met trillende knieën, maar ook nieuwsgierig, liet ik je wel eens stukjes lezen en ik was vergeten dat de rode pen zo onverbiddelijk kan zijn en 'Mind the Chicken'. Martin Prins, hoewel maar zeer kort, heb ilk het wel gewaardeerd dat je structureel en integer te werk bent gegaan in enigszins turbulente tijden. De collega's van de opleiding voor fysiotherapie van de Hogeschool Zuyd te Heerlen wil ik graag bedanken voor de prettige sfeer waarin wij konden samenwerken en jullie stimulerende belangstelling woor het traject waar ik in Maastricht mee bezig was.

Marielle Goossens, je leerde me rekenen met EURO's en zonder je hulp was Hoofdstuk 7 niet afgekomen. Ik hoop niet dat je dat kattenpension gaat beginnen. Dat ik je nog maar regelmatig mag tegenkomen omdat voor jou inhoud ook nog steeds op de eerste plaats staat. Suzanne Stomp, je bijdrage aan de PABS_PT heb ik enorm gewaardeerd. Toch spannend, zo'n factoranalyse, nietwaar? Daarnaast heb ik reeds in beperkte mate mogen samenwerken met mijn toekomstige collega's van het EMGO Instituut te Amsterdam. Voor dit proefschrift was dat met name met Maurits van Tulder. Maurits, bedankt voor het inwijden in het land van de reviews. En inderdaad, het is wel leuk, zeker als het van die 'appeltje-eitje' reviews zijn. Leuk dat we binnenkort weer meer kunnen samenwerken.

Naast het feit dat je gedurende en aantal jaren bezig bent met een promotieonderzoek, gebeuren er nog veel andere dingen, die maken dat je met een zeer goed gevoel terugkijkt op die periode. Arianne, Nijnke, Remco en Margreet eerst 
studiegenoten, later collega's, (hoevrel ...) maar bovenal mensen waarvan ik het leuk vind om ze ontmoeten. Naast werk werden gelukkig ook vele andere dingen besproken.

De Thembi club (en Andy natuurlijk) wil il bedanken voor al die vrijdagavonden. Ik hoop dat ik mijn erelidmaatschap waar kan maken. Marjan, als zeer wast onderdeel van de groep (en natuurlijk te erelid) hoop ik nog eensi vaker bij je te kunnen komen voor wijze raad en daad. Maakt me niet uit waarover. Uttie, bedankt dat ik via jou alwast een kijkje achter de coulissen kreeg. Ik ben benieuwd wat de toekomst allemaal voor je in petto heeft en hoop dat ook van dichtbij te mogen meenaken. IJmert, bedankt dat ik altijd bij je binmen kon vallen met vragen, opmerkingen of andere ongein. Nicole, Gert-Jan en Harrie, jullie will ik graag bedanken omdat we elkaar nu al zo lang kennen en naast eindeloze discussies over fysiotherapie en wetenschap gelukkig ook vele andere en belangrijke zaken hebben gedeeld. Graag wil ik een volgende keer weer (jaja, eerst Gert Jan natuurlijk) jullie arbiter zijn en ik beloof jullie dat het geen kaasfondue meer wordt! Marcus, ik ga niet eens een poging wagen om dingen onder woorden te brengen, maar je weet wat ik bedoel. Thanks Buddy and hang in there. Harry, mijn andere paranimf, na Kars, Teheran, Karachi, Kasghar, Calcutta, Auckland, Barcelona, Dublin en ga zo maar door, werd het weer eens tijd voor een gezamenlijke activiteit in het Maastrichtse. Nu is het de hoogste tijd voor nieuwe plannen, nietwaar? Maria en Hub, bedankt voor jullie blinde en onvoorwatardelijke steun. Het is geweldig om zo je gang te kumen gaan als ik heb mogen doen en te weten: "dich kins ummer truuk" . En tot slot, lieve Regina, bedankt voor het feit dat je zo vaak geloofde, tegen beter weten in, dat het nu echt de laatste dingetjes waren die gebeuren moesten. Maar nog veel meer voor alles wat ik niet ga toevertrouwen aan dit kille papier.

Einde! 



\section{List of Publications}

Ostelo RWJG, Koke AJA, Beurskens AJHM, Vet HCW do, Kerchohs MR, Vlaeyen JWS, Wolrers PMJ.

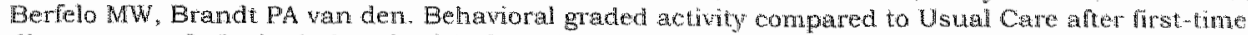
disc surgery. J Manipulative Physiol Ther 2000; 23.312-19

Thider MW van, Ostelo RWJG, Waeyen JWS, Limton SJ, Morley Su, Assendell WJ qan. Behavional treatment for chronic low back pain. The Cochrane Library, Issue 2, 2000. Oxford: Update Softwar:

Tulder MW wan, Ostelo RWJG, Vlaeyen JWS, Linton S. Morky SJ, Assendelft WJu wan.

Behavioral treatment for chronic low back pain. Spine 2001:26.270-8 I

Koes BW, Tulder MW van, Ostelo RWJG, Kim Burton A, Waddell G. Clnical guidelines tor the management of low back pain in primary care: un international comparison. Spime 2001:26:2504-13

Ostelo RWUG, Vet HCW de, Waddell G, Kenckhofs MR, Leflers P. Rulder MW van. Rehabilitaion following lumbar dise surgery. The Cochrane Library. Issue 2, 2002 Oxford: Update Softrence.

Ostelo RWJG, Bie RA de. Zwellingsmeting wan enkels. Validering wan de waterbakmethode. Ned Tijdschi Fystother $1997 ; 107: 1,16-20$

Verhagen AP, Ostelo RWYG. Wragenlijsten binnen de particulere praktijk? Fysiopraxis 1998; 7:28-9.

Beurshens AJHM, Ostelo RWJG, Wolters PMUC. Van patient nat wetenschappeligh ondenow Ned Tijoschr Fysionther 2000; $110: 16-18$

Ostelo RWJG, Beurstens. AJHM, Verbagen AP. Zicht op blinderen. Ned 'Tidsch Fysiother $2000 ; 110: 48-51$

Werhagen AP, Ostelo RWJG. A Rademaker. is de p-warde wel zo significant? Ned tijdschr Fysiothar $2000 ; 110: 92-5$

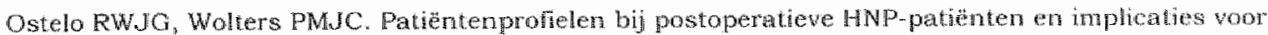
behandeling. Jaarboek Fysiotheraphe Kinesitherapie 200 1. Houten: Bohn Stantu, wan Loghum, 2000.

Ostelo RWJG, Vet HCW de. Ben HJM var. De arohtectur van wetenschappelijk onderzoek. Ned rijdschr Fysiother 2001; 111:23-26

Bekkering GE, Hendriks HJM, Koes BW, Oostendorp RAB, Ostelo RWJG, Thomassen wy The MW van. KNGF-richtlijn Lage rugpijn. Stipplement bij Ned Tijdschr Fysiother $2001 ; 11$ 1: $1-24$

Belkering GE, Tulder MW van, Hendriks HUM, Oostendorp RAB, BW Koes, Ostelo RW JC, Thomassen J. "E.widence-based" fystotherapie bij patienten met lage rugpin: wetenschappelijke onderbouwing wan de kNGF-richtijn. Ned Tijdschr Fysiother $2001 ; 11: 66-73$.

Ostelo RWJG, Vet HCW de, Bie RA de, Lefers P. Singe case design effectiviteitondergek bij

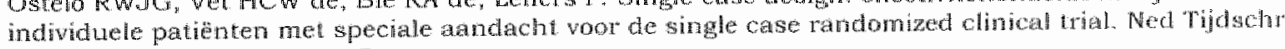
Fystother 2001 ; 11:131-135.

Pippolo E, Ostelo RWJG. Braces en Elastische bandages: ext systematische review nan de efrectivitent

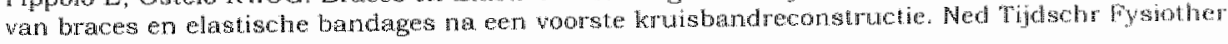
$2002 ; 112: 2-8$.

Korthals-de Bos ICB. Dieten Han, Tulder MN van, Busschbach J van, Hoving J1. Ostelo RWJO

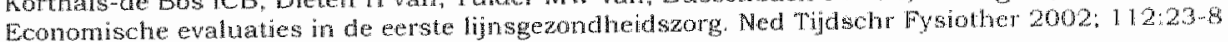

